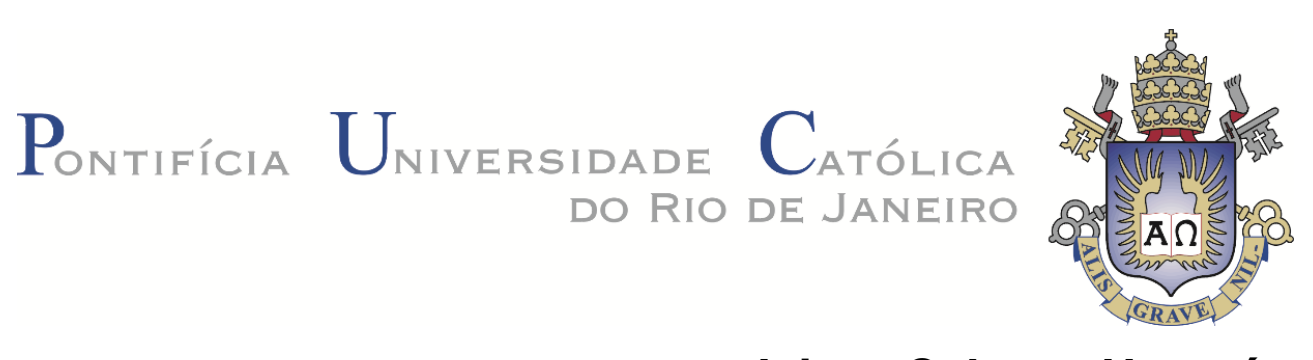

Jainor Cabrera Huamán

\title{
Previsão numérica do comportamento sísmico da barragem de rejeitos de Alpamarca no Peru
}

Dissertação de Mestrado

Dissertação apresentada ao Programa de PósGraduação em Engenharia Civil da PUC-Rio como requisito parcial para obtenção do grau de Mestre em Engenharia Civil.

Orientador: Prof. Celso Romanel

Rio de Janeiro

Maio de 2018 


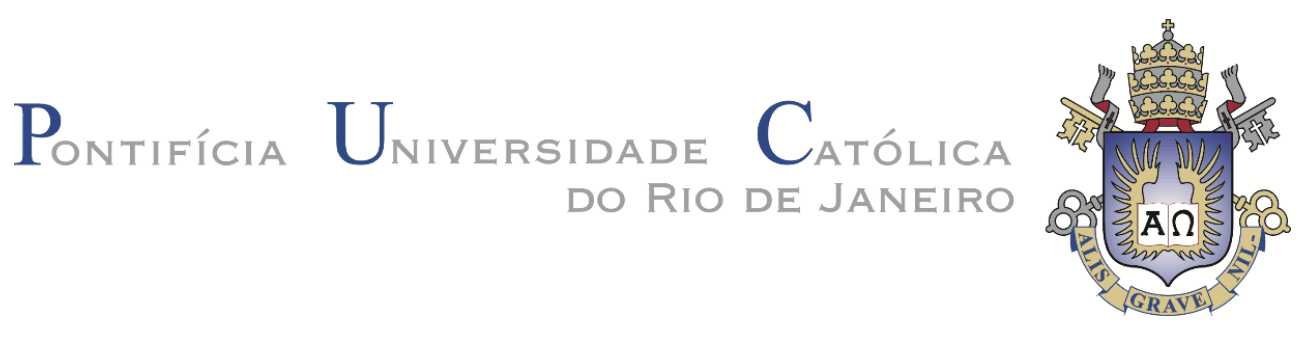

Jainor Cabrera Huamán

\section{Previsão numérica do comportamento sísmico da barragem de rejeitos de Alpamarca no Peru}

Dissertação apresentada como requisito parcial para obtenção do grau de Mestre pelo Programa de PósGraduação em Engenharia Civil da PUC-Rio. Aprovada pela Comissão Examinadora abaixo assinada.

Prof. Celso Romanel Orientador

Departamento de Engenharia Civil e Ambiental - PUC- Rio

Profa. Bernadete Ragoni Danziger Departamento de Engenharia Civil, UERJ

Prof. Zenon Aguilar Bardales Departamento de Engenharia Civil, UNI - Peru

Prof. Jackeline Rosemery C. Huertas Consultora independente

Prof. Márcio da Silveira Carvalho

Coordenador Setorial do Centro Técnico Cientifico - PUC-Rio

Rio de Janeiro, 24 de maio de 2018 
Todos os direitos reservados. É proibida a reprodução total ou parcial do trabalho sem autorização da universidade, do autor e do orientador.

\section{Jainor Cabrera Huamán}

Graduado em Engenharia Civil pela Universidade Nacional de Engenharia - UNI (Lima-Peru) em 2010. Principais áreas de interesse: Geotecnia computacional e barragens.

Ficha Catalográfica

Cabrera Huamán, Jainor

Previsão numérica do comportamento sísmico da barragem de rejeitos de Alpamarca no Peru / Jainor Cabrera Huamán; orientador: Celso Romanel. - 2018.

172 f. il. (color) ; $30 \mathrm{~cm}$

Dissertação (Mestrado em Engenharia Civil) Pontifícia Universidade Católica do Rio de Janeiro, Rio de Janeiro, 2018.

Inclui bibliografia

1. Engenharia civil - Teses. 2. Barragem de rejeitos. 3. Comportamento sísmico. 4. Ameaça sísmica. I. Romanel, Celso. II. Pontifícia Universidade Católica do Rio de Janeiro. Departamento de Engenharia Civil e Ambiental. III. Título.

CCD: 624 
A toda minha família, especialmente para meu pai. 


\section{Agradecimentos}

Ao meu pai Máximo, que desde o céu sempre me acompanha e cuida de mim. Sempre senti sua presença, dando-me as forças que eu precisava para alcançar meus objetivos. À minha mãe Lucia e meu irmão Roy, que são meu motor e motivo para seguir crescendo nesta vida.

À minha família, pelo amor e apoio incondicional em tudo o que me aventurei durante toda a minha vida.

À Ana Carolina, minha grande amiga. Através de você conheci a generosidade do povo brasileiro para com os estrangeiros, por sua amizade e ajuda incondicional durante todo o mestrado.

Aos meus amigos e colegas da PUC-Rio, que compartilharam comigo muitas experiências ao longo desta etapa: Judith, Raul, Paul, Erland, Andrés, Celso, Jhonatan, Carlo, Jorge, Kevin e Lizardo.

Aos meus queridos amigos brasileiros da PUC-Rio, Alan, Ana Luiza, Arthur, Bruno, Carol, Erica, Larissa, Mari, Raquel e Rodrigo, que compartiram comigo todo este tempo e se converteram em minha família aqui no Brasil.

As minhas queridas amigas Andrea Nascimento e Luana Raquel, pelo amor e pela grande amizade que me deram durante esse tempo.

Ao professor Celso Romanel, orientador da presente dissertação, que protagonizou seu papel direcionando e guiando minhas ideias, assim como auxiliando em momentos de necessidade intelectual durante todo o programa do mestrado.

Aos professionais que me apoiaram nesta pesquisa, Goyo Cisneros, Jorge Lopez, Miguel Roncal e Luis Vergaray pelos dados compartilhados. A Zenón Aguilar pelo apoio e sugestões nesta pesquisa.

O presente trabalho foi realizado com o apoio da coordenação de aperfeiçoamento de pessoal de nível superior - Brasil (CAPES) - código de financiamento 001 .

À Pontifícia Universidade Católica do Rio de Janeiro (PUC-Rio). 


\section{Resumo}

Cabrera Huamán, Jainor; Romanel, Celso (Orientador) Previsão numérica do comportamento sísmico da barragem de rejeitos de Alpamarca no Peru. Rio de Janeiro, 2018. 172 p. Dissertação de Mestrado - Departamento de Engenharia Civil e Ambiental, Pontifícia Universidade Católica do Rio de Janeiro.

A pesquisa apresenta uma análise do comportamento dinâmico da barragem de rejeitos Alpamarca localizada em região sismicamente ativa no centro do Peru. Estudos de ameaça sísmica constituem um aspecto fundamental no projeto de barragens de rejeito tendo em vista os grandes prejuízos ambientais, econômicos e sociais que a ruptura da estrutura, por carregamento dinâmico, possa produzir. Nesta pesquisa foram feitos estudos probabilísticos de ameaça sísmica utilizando o software de código aberto Openquake, que inclui leis de atenuação específicas para as condições geológicas do Peru. A simulação do comportamento dinâmico da barragem demandou a geração de terremotos de projeto com base no espectro de acelerações uniformemente provável determinado na investigação de ameaça sísmica e em função da classificação da barragem em relação a níveis de risco. No trabalho também são discutidas técnicas de tratamento dos acelerogramas, com o objetivo de diminuir o esforço computacional dos cálculos no domínio do tempo, porém sem perder precisão requerida para os resultados estimados.

\section{Palavras - chave}

Barragem de rejeitos; comportamento sísmico; ameaça sísmica 


\section{Abstract}

Cabrera Huamán, Jainor; Romanel, Celso (Advisor). Numerical prediction of the seismic behavior of Alpamarca tailings dam in Peru. Rio de Janeiro, 2018. 172 p. Dissertação de Mestrado - Departamento de Engenharia Civil e Ambiental, Pontifícia Universidade Católica do Rio de Janeiro.

The research presents an analysis of the dynamic behavior of the Alpamarca tailings dam located in Junín, central Peru, because of the catastrophic effects of earthquakes that frequently occur on the western coast of South America. Dam from the $4670 \mathrm{~m}$ elevation. Up to the elevation $4703 \mathrm{~m}$. Under the sea level, with the purpose of supplying the demand for tailings generation in the mining area. The tailings dams are important structures due to the storage of contaminant residues that would shave the environment in the event of a collapse or rupture, which is indispensable to carry out studies to characterize their seismic behavior. In this research, probabilistic seismic threat studies were performed using the OpenQuake software, working with the regional seismicity and soil attenuation law of Peru. Dynamic behavior analysis was performed using the FLAC 2D software, based on the finite difference method. The simulation of the seismic behavior of the dam is made by discussing several important aspects that should be considered for a correct analysis such as the selection of the project earthquake, the filtering of high frequencies to minimize the number of elements of the mesh, the introduction of Quiet conditions, the choice of constituent models including the incorporation of hysteretic damping, among other points.

\section{Keywords}

Tailings dam; seismic behavior; seismic hazard 


\section{Sumário}

1 Introdução 21

1.1. Motivação e objetivos $\quad 21$

1.2. Estrutura da dissertação 22

2 Conceitos de sismicidade 23

2.1. Conceitos gerais 23

2.1.1. Placas Tectônicas 23

2.1.2. Teoria da recuperação elástica (elastic rebound theory) 26

2.2. Tipos de ondas sísmicas 26

2.2.1. Ondas de corpo - P e S 27

2.2.2. Ondas de superfície 28

2.3. Localização de um sismo 31

2.4. Grandeza de um sismo 32

2.4.1. Magnitude 32

2.4.2. Intensidade 36

2.5. Ajustes no registro sísmico $\quad 37$

2.5.1. Correção da linha base 37

$\begin{array}{ll}\text { 2.5.2. Filtragem de frequências } & 38\end{array}$

3 Avaliação de Ameaça Sísmica $\quad 40$

3.1. Análise determinística 40

3.2. Análise probabilística 41

3.2.1. Catálogos sísmicos 42

3.2.2. Fontes sismogênicas 42

3.2.3. Determinação dos parâmetros das fontes sísmicas 44

3.2.4. Atenuação de ondas sísmicas 47

3.2.5. Estimativa probabilística da ameaça sísmica 47

3.2.6. Curva de ameaça sísmica 49

3.3. Openquake na avaliação de ameaça sísmica 52

3.3.1. Análise Probabilística Clássica de Ameaça Sísmica (cPSHA) 54 
3.3.3. Árvores lógicas $\quad 55$

3.3.4. Descrição de árvores lógicas 56

3.3.5. O processador da árvore lógica 58

3.3.6. Cálculo da ameaça sísmica 58

4 Ameaça sísmica para a barragem de rejeitos Alpamarca $\quad 60$

4.1. Introdução 60

4.2. Localização da barragem de rejeitos Alpamarca 60

4.3. Programa de ensaios de campo 61

4.4. Características gerais do projeto 62

4.5. Características tectônicas 63

4.6. Sismicidade da área de influência 66

$\begin{array}{ll}\text { 4.6.2 Fontes sismogênicas } & 67\end{array}$

4.6.3. Parâmetros de sismicidade local 68

4.6.4. Leis de atenuação (GMPE) 70

4.7. Incertezas e a árvore lógica 76

4.8. Estimativa probabilística da ameaça sísmica 78

5 Simulação numérica das respostas estática e sísmica de barragens 84

5.1. Características do programa FLAC 2D v. 8

5.2. Etapas de avaliação do comportamento estático 86

5.2.1. Distribuição dos recalques 86

5.2.2. Enchimento do reservatório de rejeitos 88

5.2.3. Fator de segurança estático $\quad 89$

5.3. Etapas de avaliação do comportamento dinâmico 91

5.3.1. Fator de segurança pseudo-estático 91

5.3.2. Modelos constitutivos para carregamentos cíclicos 92

5.4. Aspectos da modelagem numérica em análises sísmicas $\quad 96$

5.4.1. Convolução e deconvolução do registro sísmico 96

5.4.2. Base rígida / base flexível 97

5.4.3. Tamanho do elemento (zona) 98

5.4.4. Condições de contorno 99

5.4.5. Geração de registros sísmicos 103 
5.5. Soluções analíticas aproximadas para deslocamentos permanentes em taludes

5.5.1. Método de Bray e Travasarou (2007) 107

5.5.2. Método de Swaisgood (2013) 110

5.5.3. Critérios de deslocamentos permanentes permissíveis 111

6 Análises estática e pseudo-estática da barragem de rejeitos

Alpamarca $\quad 112$

6.1. Geometria e propriedades dos materiais 112

6.2. Simulação do processo construtivo 114

6.3. Fator de segurança estático 115

6.4. Fator de segurança pseudo-estático 117

7 Análise sísmica da barragem de rejeitos Alpamarca 119

7.1. Introdução 119

7.2. Geração de acelerograma artificial $\quad 120$

7.3. Correção da linha base e filtragem 122

7.4. Ajuste espectral 123

7.5. Frequência de corte e tamanho máximo de zona na discretização 125

7.6. Módulo de cisalhamento máximo Gmax 128

7.7. Amortecimento histerético e Railegh 130

7.8. Simulação elástica (não amortecida) 131

7.9. Modelo numérico para obtenção da resposta sísmica 133

7.9.1. Deslocamentos permanentes 134

7.9.2. Potencial de ruptura cíclica de poropressão 138

7.9.3. Acelerações horizontais 139

7.10. Efeitos da duração do registro sísmico 142

7.11. Modelo analítico para obtenção da resposta sísmica 146

8 Conclusões e Sugestões 147

9 Referências bibliográficas 149 


\section{Lista de figuras}

Figura 2.1 - Placas tectônicas principais. $\quad 24$

Figura 2.2 - Esquema da estrutura da Terra. $\quad 24$

Figura 2.3 - Tipos de movimento entre placas. 26

Figura 2.4 - Movimento das partículas do solo produzido pela propagação de ondas P (acima) e S (abaixo).

Figura 2.5 - Comportamento das partículas do solo produzido pela propagação de ondas Love e ondas Rayleigh.

Figura 2.6 - Ondas sísmicas registradas a $10.000 \mathrm{~km}$ do epicentro: A) sismo de foco profundo; B) sismo de foco superficial $\quad 30$

Figura 2.7 - Identificação das ondas sísmicas em um registro sísmico. 30

Figura 2.8 - Elementos para localização do epicentro de um sismo. 31

Figura 2.9 - Determinação da magnitude Richter (ML) de um sismo local. 33

Figura 2.10 - Saturação das escalas sísmicas mb e Ms. 35

Figura 2.11 - Escala de intensidades Mercalli Modificada. 37

Figura 2.12 - Erros introduzidos nas velocidades e deslocamentos pela falta da correção da linha base no acelerograma. 38

Figura 2.13 - À esquerda, efeito dos ruídos de alta frequência, à direita efeitos dos ruídos de baixa frequência.

Figura 3.1 - Geometria de fontes sismogênicas: (a) pontual; (b) linear; (c) tridimensional. 43

Figura 3.2 - Sismos de interface, intraplaca e corticais. 43

Figura 3.3 - Representação da lei de Gutenberg-Richter com processo de Poisson duplamente truncado.

Figura 3.4 - Ajuste pelo método da máxima verossimilhança (esquerda) e pelo método dos mínimos quadrados (direita). 45

Figura 3.5 - Exemplo de curva de probabilidade de excedência. 50

Figura 3.6 - Obtenção do espectro de resposta uniformemente provável a partir das $\begin{array}{lr}\text { curvas de probabilidades de excedência. } & 50\end{array}$

Figura 3.7 - Fluxo de cálculos na análise probabilística clássica de ameaça sísmica. $\quad 55$

Figura 3.8 - Variação do parâmetro "a" do gráfico de recorrência sísmica para o sul da Califórnia no período 1987-1996.

Figura 3.9 - Estrutura de uma árvore lógica - ramos individuais, conjuntos de 
ramificação e níveis de ramificação.

Figura 4.1 - Localização da barragem Alpamarca na região de Junin, província de Yauli, Peru.

Figura 4.2 - Geometria atual da barragem de rejeitos Alpamarca. 62

Figura 4.3 - Geometria final do alteamento da barragem de rejeitos Alpamarca. $\quad 63$

Figura 4.4 - Configuração da Placa de Nazca. 65

Figura 4.5 - Fontes sismogênicas de subducção e corticais no Peru. 67

Figura 4.6 - Fontes sismogênicas de subducção e corticais definidas por Aguilar

(2017). $\quad 68$

Figura 4.7 - Árvore lógica usada por Aguilar (2017). 78

Figura 4.8 - Fontes sísmicas de subducção do projeto SARA; à esquerda as fontes intraplaca e à direita as fontes de interface. 79

Figura 4.9 - Representação 3D da geometria do modelo de subducção no projeto SARA.

Figura 4.10 - Falhas consideradas no Openquake.

Figura 4.11 - Curvas de ameaça sísmica geradas do Openquake com fontes do projeto SARA.

Figura 4.12 - Espectros de resposta em rocha pelos programas CRISIS v.2015 e software OpenQuake e SENCICO, considerando período de retorno de 975 anos.

Figura 5.1 - Ciclo de cálculo do FLAC.

Figura 5.2 - Construção de aterro de grande extensão por camadas sucessivas-Law, 1975.

Figura 5.3 - Perfil de recalque em um aterro, com valor máximo na altura média H/2. 87

Figura 5.4 - Método construtivo à jusante. 88

Figura 5.5 - Métodos para a avaliação do fator de segurança em taludes de solo. $\quad 90$

Figura 5.6 - a) módulo de cisalhamento secante; b) degradação do módulo de cisalhamento normalizado G/Gmax e majoração da razão de amortecimento $\xi$ em função da deformação cisalhante cíclica. 93

Figura 5.7 - Processo iterativo do modelo linear equivalente. 93

Figura 5.8 - Curvas característica do primeiro ciclo de carregamento em modelo cíclico 95

Figura 5.9 - Processo de deconvolução e amplificação (convolução) de registros de aceleração. $\quad 96$

Figura 5.10 - Condição de contorno de campo livre. 100

Figura 5.11 - Variação da razão de amortecimento crítico normalizado em relação à 
frequência angular.

Figura 5.12 - Limite superior da curva de redução do módulo de cisalhamento para areias, proposta por Seed \& Idriss (1970). 102

Figura 5.13 - Espectros obtidos por meio do método do ajuste espectral. 106

Figura 5.14 -Analises acoplada e desacoplada para determinação dos deslocamentos horizontais permanentes produzidos por evento sísmico. 108

Figura 5.15 - Estimativa do período fundamental para potenciais massas de deslizamento. 108

Figura 5.16 - Seção na análise do deslocamento vertical permanente pelo método de $\begin{array}{ll}\text { Swaisgood (2013). } & 110\end{array}$

Figura 6.1 - Seção transversal da barragem de rejeitos Alpamarca no modelo numérico

Figura 6.2 - Distribuição das tensões horizontais após o alteamento da barragem de rejeitos.

Figura 6.3 - Distribuição das tensões verticais após o alteamento da barragem de rejeitos.

Figura 6.4 - Distribuição dos deslocamentos horizontais após o alteamento da barragem de rejeitos.

Figura 6.5 - Distribuição dos deslocamentos verticais após o alteamento da barragem de rejeitos.

Figura 6.6 - Fator de segurança estático $(\mathrm{FS}=1,57)$ após o término da construção e lançamento dos rejeitos determinado com o programa FLAC 2D.

Figura 6.7 - Fator de segurança estático $(\mathrm{FS}=1,64)$ após o término da construção e lançamento dos rejeitos determinado com o método das fatias de Spencer pelo programa SLIDE v.7.

Figura 6.8 - Fator de segurança pseudo-estático $(\mathrm{FS}=1,066)$ após o alteamento do dique e lançamento dos rejeitos determinado pelo método das fatias de Spencer com o programa SLIDE v.7.

Figura 7.1 - Procedimento geral para análise do comportamento sísmico de uma barragem.

Figura 7.2 - Acelerogramas originais dos sismos de Pisco, Lima e Costa Peru registrados pelas estações ÚNICA e Parque da Reserva. (Fonte: Web CISMID) 120

Figura 7.3 - Espectros de Fourier dos acelerogramas originais dos sismos de Pisco, Lima e Costa Peru registrados pelas estações ÚNICA e Parque da Reserva.

Figura 7.4 - Localizações dos epicentros dos sismos de Pisco, Lima, Costa Peru e do projeto da barragem Alpamarca. 
Figura 7.5 - Histórias de aceleração, velocidade e deslocamento originais e corrigidas pela linha base e filtragem para o sismo Pisco N-S.

Figura 7.6 - Histórias de aceleração corrigidas pela linha base e filtragem para os sismos Lima E-W e Costa Perú E-W.

Figura 7.7 - Registros sísmicos artificiais no domínio do tempo correspondentes aos ajustes espectrais dos sismos de Pisco, Lima e Costa Peru.

Figura 7.8 - Ajuste espectral no domínio do tempo dos registros de aceleração dos sismos de Pisco, Lima e Costa Peru.

Figura 7.9 - Espectros de potência das velocidades dos registros sísmicos na base do modelo e suas respectivas frequências de corte.

Figura 7.10 - Discretização da malha da seção transversal da barragem de rejeitos Alpamarca.

Figura 7.11 - Histórias de velocidades finais dos sismos de projeto

Figura 7.12 - Modelo para analises dinâmico, baseado nas mudanças do módulo de cisalhamento máximo em função da variação da tensão normal efetiva média nos rejeitos.

Figura 7.13 - Comparação entre as curvas de degradação do módulo de cisalhamento e do aumento da razão de amortecimento, experimentais e ajustadas, com a sigmoide Sig3.

Figura 7.14 - Ajuste da constante a para obter a concordância dos registros de velocidade prescrito e computado na base do modelo.

Figura 7.15 - Espectros de Fourier da história de velocidades determinados em análise elástica não amortecida para diferentes pontos da barragem de rejeitos

Figura 7.16 - Distribuição dos deslocamentos permanentes verticais (acima) e horizontais (abaixo) na barragem Alpamarca provocados pelo sismo de Pisco (2007).

Figura 7.17 - Distribuição dos deslocamentos permanentes verticais (acima) e horizontais (abaixo) na barragem Alpamarca provocados pelo sismo de Lima (1974).

Figura 7.18 - Distribuição dos deslocamentos permanentes verticais (acima) e horizontais (abaixo) na barragem Alpamarca provocados pelo sismo da Costa Peru (1970).

Figura 7.19 - Modelo da seção total para analises dinâmico da barragem

Figura 7.20 - Deslocamentos permanentes horizontais Pisco - Seção total

Figura 7.21 - Deslocamentos permanentes horizontais Lima - Seção total 
Figura 7.23 -Variação no tempo dos deslocamentos verticais causados pelo sismo de Pisco, Lima e Costa Peru em pontos da crista e corpo do dique.

Figura 7.24 -Variação no tempo dos deslocamentos horizontais causados pelo sismo de Pisco, Lima e Costa Peru na crista e corpo do dique.

Figura 7.25 - Distribuição do parâmetro de poropressão ru imediatamente após a ocorrência do terremoto.

Figura 7.26 - História das acelerações computadas na crista do dique para os sismos de Pisco, Lima e Costa Perú.

Figura 7.27 - Distribuição dos espectros de resposta de aceleração para o sismo de Pisco.

Figura 7.28 - Distribuição dos espectros de resposta de aceleração para o sismo de Lima.

Figura 7.29 - Distribuição dos espectros de resposta de aceleração para o sismo de Costa Peru.

Figura 7.30 - Duração significante SD595 e SD575 para o registro sísmico de Pisco (2007) no gráfico de Intensidade de Arias.

Figura 7.31 - Distribuição dos deslocamentos permanentes verticais (acima) e horizontais (abaixo) na barragem Alpamarca provocados pelo sismo de Pisco com duração significativa SD595.

Figura 7.32 - Distribuição dos deslocamentos permanentes verticais (acima) e horizontais (abaixo) na barragem Alpamarca provocados pelo sismo de Pisco com a duração significativa SD575. 


\section{Lista de tabelas}

Tabela 3.1 - Descrição dos módulos do software Openquake (Silva, 2012) 52

Tabela 4.1 - Anos de completude do catálogo sísmico. $\quad 69$

Tabela 4.2 - Parâmetros de sismicidade local $\quad 70$

Tabela 4.3 - Caracterização das fontes de subducção de intraplaca e de interface do projeto SARA $\quad 79$

Tabela 5.1- Modelos constitutivos no programa FLAC 85

Tabela 5.2- Fatores de segurança mínimos na condição estática 91

Tabela 6.1 - Propriedades dos materiais do dique, rejeitos e fundação. 113

Tabela 7.1 - Registros sísmicos usados para avaliação dinâmica. 120

Tabela 7.2 - Características do modelo numérico para o sismo de Costa Peru (1970). 127

Tabela 7.3 - Parâmetros de ajuste dos materiais com a função sigmoidal Sig3 130

Tabela 7.4 - Deslocamentos e acelerações na barragem de rejeitos Alpamarca 146 


\section{Lista de símbolos}

$\mathrm{A}_{\text {laço }}$ - área do laço de histerese

AP - amplitude do movimento do terreno

a - constante de atividade sísmica de Gutenberg-Richter

a,b,c,d - coeficientes das relações de atenuação

a',b',c' - parâmetros de ajuste da função Sig3

$\mathrm{a}(\mathrm{t}) \quad$ - acelerograma sem correção

$\alpha \quad$ - constante proporcional à massa

$\mathrm{B} \quad$ - constante de amortecimento proporcional à rigidez

$\beta$ - inclinação da curva da lei de recorrência

b - constante de proporção de terremotos de Gutenberg-Richter

$\mathrm{C}_{1}, \mathrm{C}_{2}, \mathrm{C}_{3}$ - coeficientes das relações de atenuação

$\mathrm{C}_{\mathrm{k}} \quad$ - fator dependente do tipo de solo

[C] - matriz de amortecimento viscoso

c $\quad$ - coesão

$c_{i}, \alpha_{i} \quad$ - coeficientes das relações de atenuação

$\mathrm{d}_{\mathrm{i}} \quad$ - espessura da camada $\mathrm{i}$

d - deslocamento médio observado da falha

$d_{e} \quad$ - distância epicentral

D - distância entre o epicentro e o foco

E - módulo de Young

e - índice de vazios

$\varepsilon \quad$ - variável aleatória de distribuição normal

$\xi \quad$ - razão de amortecimento

$\mathrm{F}_{\mathrm{i}} \quad$ - fonte sísmica $\mathrm{i}$

$F_{R} \quad$ - fator de falhas reversas

$\mathrm{F}_{\text {event }}$ - fator das relações de atenuação

$\mathrm{F}_{\mathrm{FABA}}$ - fator das relações de atenuação

$\mathrm{f}_{\mathrm{c}} \quad$ - frequência de corte

$f_{M}(m)$ - função de densidade de probabilidade da grandeza do sismo

$f_{R}(r)$ - função de densidade de probabilidade da localização do sismo

$\phi \quad$ - ângulo de atrito interno do solo 


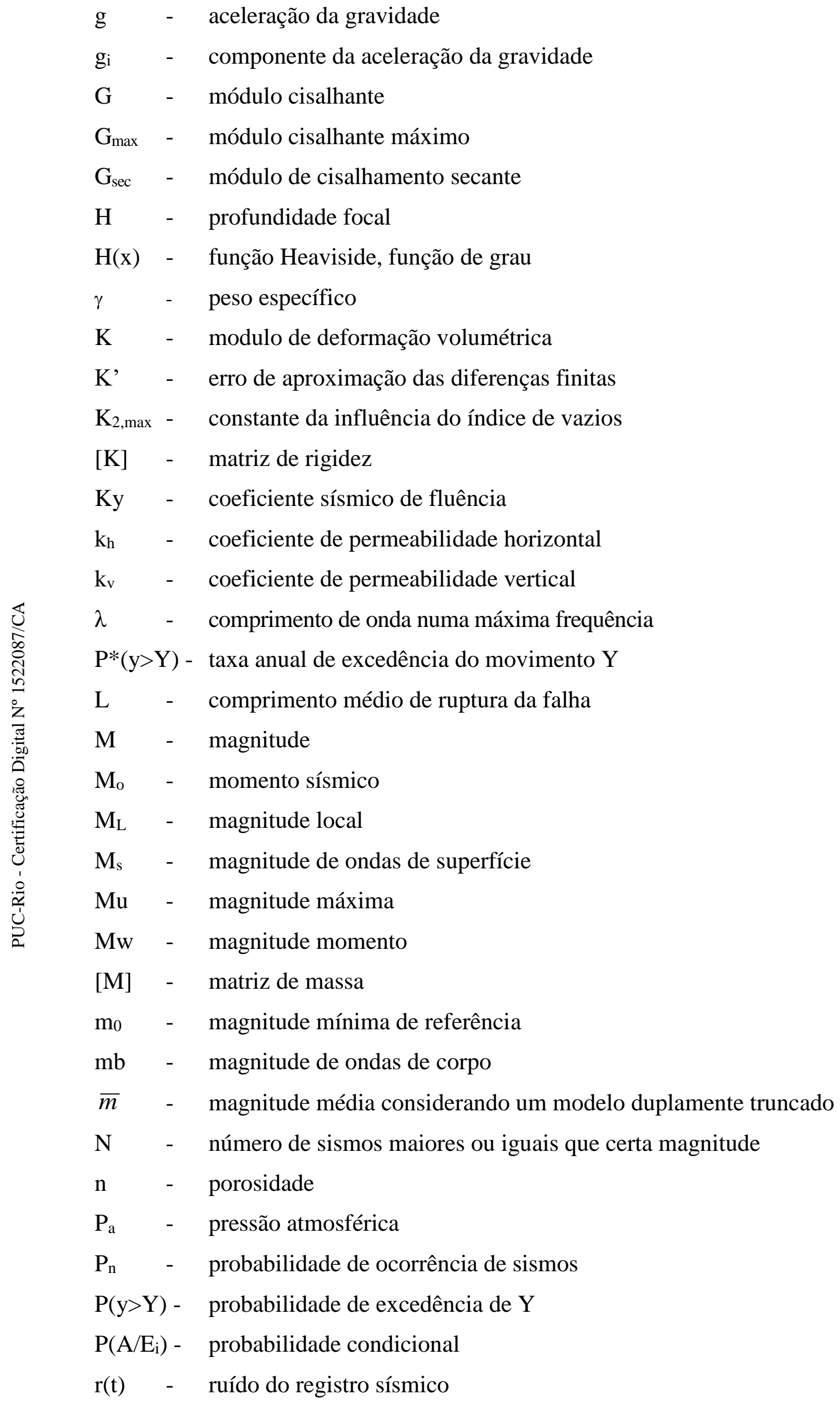


$\mathrm{r}_{\text {rup }}, \mathrm{D}_{\text {falha }}$ - distância mais próxima ao área de ruptura

$\rho \quad-\quad$ massa específica

$\mathrm{s}(\mathrm{t}) \quad$ - sinal do registro sísmico

$\mathrm{S} \quad$ - área da falha geológica

SD575 - tempo entre a chegada de 5\% da energia e $75 \%$ da energia do sismo

SD595 - tempo entre a chegada de 5\% da energia e 95\% da energia do sismo

Sa,Y,y - aceleração espectral

$\mathrm{S}_{\mathrm{i}} \quad$ - fator para sismos de interface

$\mathrm{S}_{\mathrm{S}} \quad$ - fator para sismos de intraplaca

$\mathrm{S}_{\mathrm{SL}} \quad$ - fator independente da magnitude dos terremotos

r $\quad$ - distância ao epicentro

$\mathrm{r}_{\text {rup }} \quad$ - distância mais próxima à ruptura

$\sigma_{\mathrm{ij}} \quad$ - componentes do tensor de tensões

$\sigma_{\mathrm{m}}^{\prime} \quad$ - tensão efetiva média

$\sigma_{\mathrm{n}} \quad-\quad$ tensão normal

$\sigma_{\mathrm{t}} \quad$ - tensão cisalhante

$\Delta \sigma_{\mathrm{zz}} \quad$ - incremento da tensão vertical

$\mathrm{T}$ - período estrutural

$\mathrm{T}(\mathrm{m})$ - taxa o número acumulativo de sismos que excedem uma magnitude

$\mathrm{T}_{\mathrm{r}} \quad$ - período de recorrência

$\mathrm{T}_{\mathrm{s}} \quad$ - período fundamental inicial da massa deslizante

t - tempo

$\Delta t_{p-s} \quad$ - tempo diferença entre os tempos de chegada

$V_{p} \quad$ - velocidades de propagação das ondas $P$

$V_{s} \quad$ - velocidades de propagação das ondas $S$

$\mathrm{Vs}_{30} \quad$ - velocidade cisalhante até $30 \mathrm{~m}$ de profundidade

$\mathrm{V}_{\mathrm{t}} \quad$ - velocidade tangencial

$\mathrm{W}_{\mathrm{d}} \quad$ - energia dissipada em um ciclo de histerese

$\mathrm{W}_{\mathrm{s}} \quad$ - energia de deformação máxima

$\mathrm{x} \quad$ - distância mais próxima à área de ruptura

$\mathrm{X}_{\mathrm{i}} \quad$ - componentes do vetor posição

$\mu \quad$ - resistência ao cisalhamento das rochas envolvidas no terremoto

$v \quad$ - coeficiente de Poisson

$\mathrm{Zh} \quad$ - representa a profundidade hipocentral

$\Phi$ - função de distribuição normal de probabilidade acumulada 


\section{Lista de abreviaturas}

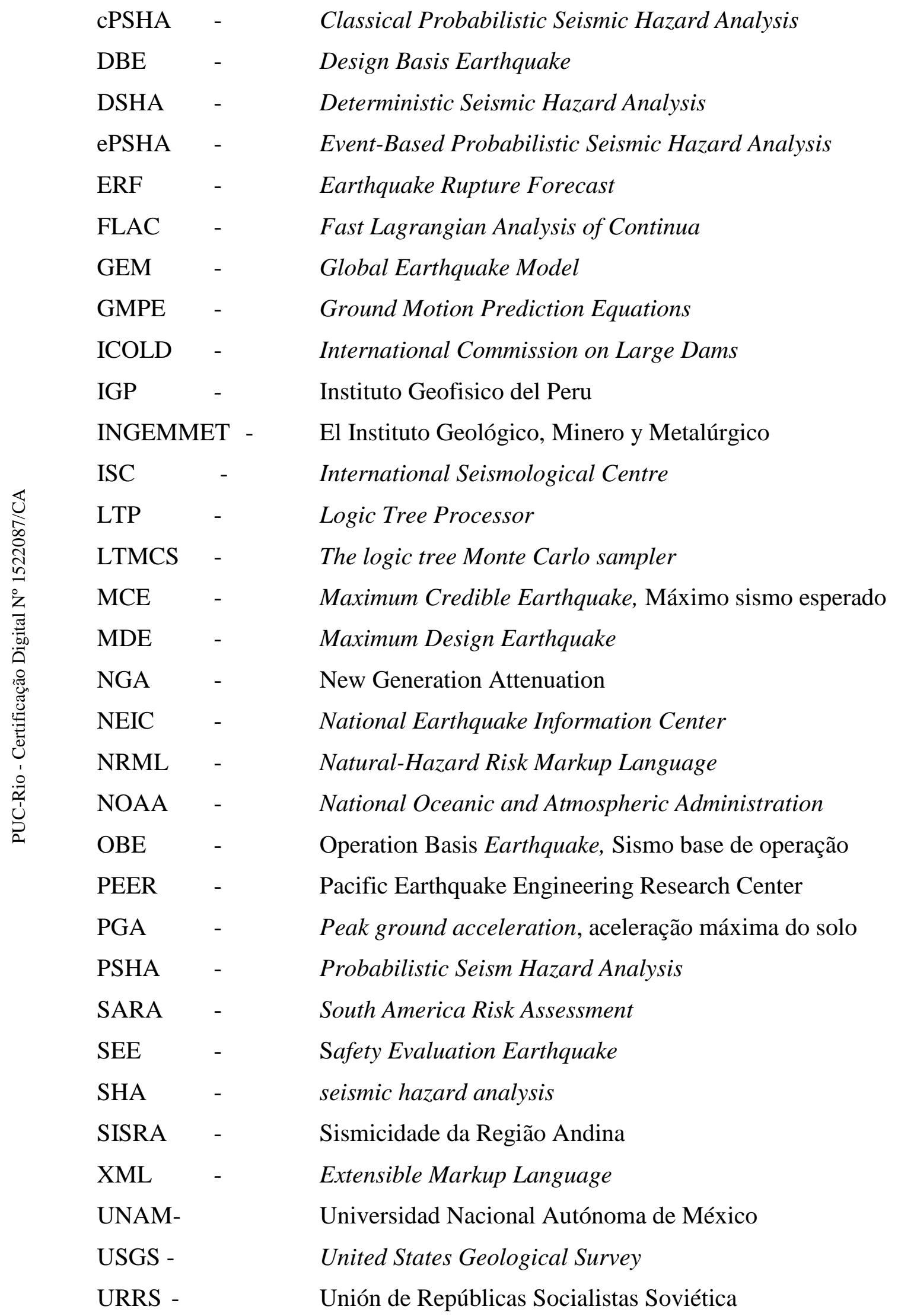




\section{Introdução}

\section{1. Motivação e objetivos}

Historicamente no Peru a indústria de extração mineral é responsável por grande parte da economia nacional. Um grande desafio enfrentado pelo setor mineral é a disposição de rejeitos, feita normalmente em estruturas conhecidas como barragens de rejeitos. Atualmente são discutidos vários problemas relacionados com o desempenho dessas barragens pois, em caso de ruptura, são potenciais causadoras de grandes prejuízos ambientais, econômicos e sociais. Os casos de acidentes em barragens de mineradoras no Peru reforçam os riscos associados a barragens de rejeitos, o que motivou este estudo.

No contexto histórico, a ruptura das barragens de terra San Fernando e Pacoima, na Califórnia em 1971, marcou um ponto de inflexão nas considerações do comportamento sísmico de barragens. Os métodos de análise pseudo-estáticos, empregados frequentemente até aquela ocasião, foram gradualmente substituídos por metodologias que simulam com maior verossimilhança os efeitos de eventos sísmicos no comportamento do solo e de elementos estruturais. Dentre estas metodologias, os estudos de ameaça sísmica constituem um aspecto fundamental em análises do comportamento sísmico de geo-estruturas. $\mathrm{O}$ desenvolvimento de métodos probabilísticos de ameaça sísmica, e o continuo aperfeiçoamento de leis de atenuação regionais, têm fornecido uma importante contribuição no projeto de estruturas mais resistentes e de maior confiabilidade quanto ao seu desempenho durante carregamentos sísmicos.

Outro aspecto a considerar, relacionado com o desenvolvimento de novas metodologias, é a crescente incorporação desses métodos em programas computacionais para utilização em microcomputadores, permitindo que engenheiros e analistas as utilizem como poderosas ferramentas para estimativa de respostas sísmicas de grandes estruturas mais precisas e confiáveis. 
O objetivo desta pesquisa é analisar através de modelagem numérica o comportamento estático (durante o alteamento do corpo da barragem) e dinâmico (carregamento sísmico) da barragem de rejeitos Alpamarca, situada no Peru, com auxílio do programa baseado no método das diferenças finitas FLAC-2D v.8. Trata-se de um dos simuladores computacionais mais completos, dentre os software comerciais atualmente disponíveis para análises de problemas geotécnicos sob ação de carregamentos dinâmicos.

\section{2.}

\section{Estrutura da dissertação}

Este trabalho está estruturado em sete capítulos, incluindo a presente introdução como capítulo 1, referências bibliográficas, anexos e apêndice.

O capítulo 2 aborda os conceitos básicos de sismicidade e de propagação de ondas, assim como os tratamentos dos registros sísmicos quando registrados em estações sismográficas.

O capitulo 3 contém os conceitos necessários para uma avaliação de ameaça sísmica, assim como a introdução do software Openquake e sua aplicação nos estudos de ameaça sísmica.

O capitulo 4 apresenta a avaliação da ameaça simica para a barragem de rejeitos Alpamarca, determinando os espectros de ameaça uniformemente provável usando os programas CRISIS e Openquake.

O capitulo 5 abrange a revisão dos aspectos teóricos na estimativa da resposta estática e dinâmica de barragens de terra e também brevemente descreve considerações para a modelagem numérica com o programa FLAC.

O capítulo 6 apresenta os resultados de análises estáticas e pseudo estáticas, enquanto que o capitulo 7 discute os resultados das análises sísmicas da barragem, submetida a três diferentes terremotos.

Finalmente, o capitulo 8 é reservado para conclusões e sugestões para trabalhos futuros em função dos resultados obtidos nesta pesquisa. 


\section{2 \\ Conceitos de sismicidade}

A investigação de problemas envolvendo carregamentos sísmicos requer do engenheiro geotécnico um conhecimento básico dos diferentes processos que influenciam a ocorrência de sismos e como eles geram movimentos do terreno. A sismologia é a ciência que investiga esses fenômenos, abrangendo o estudo da estrutura da Terra e sua relação com a ocorrência de sismos.

Nesse capítulo são introduzidos alguns conceitos gerais sobre a origem dos terremotos, bem como é feita uma breve descrição qualitativa dos principais parâmetros e termos técnicos utilizados para a sua caracterização. Adicionalmente comenta-se sobre alguns métodos para geração de sismos artificiais e apresenta-se metodologias para estimativa da ameaça sísmica, tanto através de métodos determinísticos quanto probabilísticos.

\section{1. \\ Conceitos gerais}

\subsection{1.}

\section{Placas Tectônicas}

São duas as teorias mais conhecidas que explicam a origem dos sismos: a teoria de tectônica de placas e a teoria da recuperação elástica. A teoria da tectônica de placas, ou teoria da deriva dos continentes, foi formulada pelo alemão Alfred Wagner no início do século XX, sendo atualmente bastante aceita pelos cientistas. Esta teoria considera que a litosfera é formada por placas tectônicas, separadas e distintas que flutuam sobre a astenosfera e se movimentam em trajetórias complexas muito lentamente (2 a $10 \mathrm{~cm} / \mathrm{ano}$ ). A litosfera está dividida em 16 placas tectônicas principais e várias secundárias (dentre as principais, Africana, da Antártida, Arábica, Australiana, Caribenha, Cocos, Euroasiática, Filipinas, Nazca, Norte-Americana, do Pacífico, Indiana, Scotia, Juan de Fuca e Sul-Americana (Figura 2.1). É nos primeiros $200 \mathrm{~km}$ da astenosfera (Figura 2.2), 
que são geradas as correntes de convecção, supostamente o mecanismo que proporciona a movimentação das placas tectônicas.

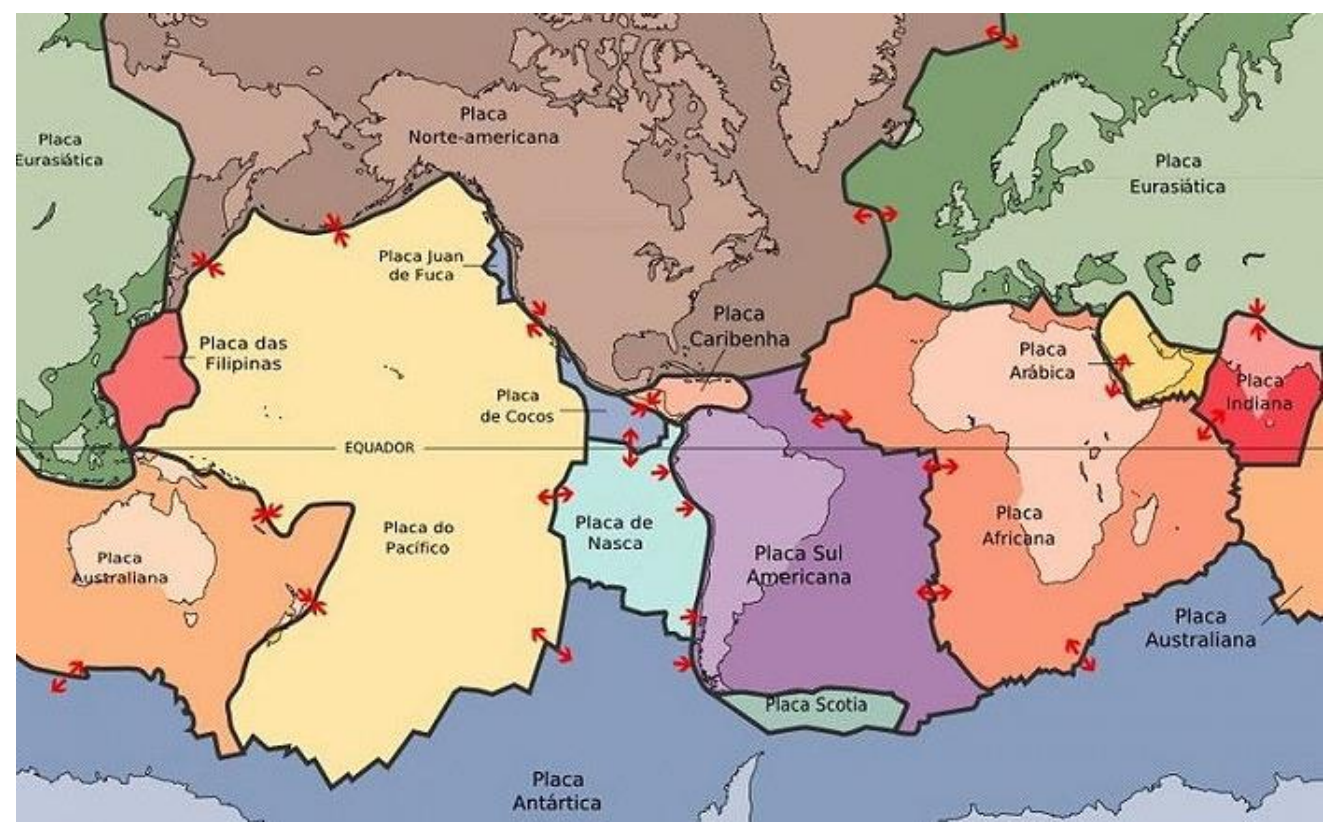

Figura 2.1 - Placas tectônicas principais.

(Fonte: http://pubs.usgs.gov/gip/dynamic/slabs.html)

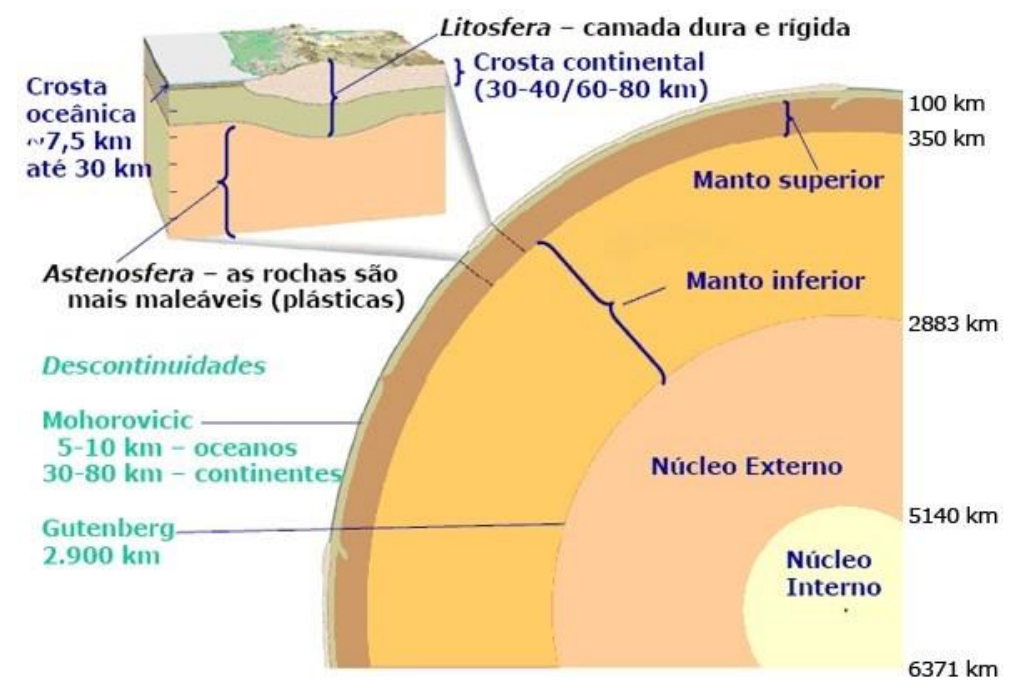

Figura 2.2 - Esquema da estrutura da Terra.

(Fonte: www.ige.unicamp.br/site/aulas/109/Terra-tempo_geo-aula1.pdf) 
Os sismos interplacas ocorrem nas zonas de fronteira entre placas tectônicas e dependem da forma com que as mesmas se movimentam entre si (Figura 2.3) e podem ser divergentes, convergentes ou laterais, como indicados na figura.

\section{- Movimento de deslizamento}

Placas deslizam umas em relação a outras, ao longo de fronteiras ditas transformantes ou conservativas. Devido à fricção, a tendência ao deslizamento é inicialmente inibida, acarretando o crescimento do estado de tensões e, consequentemente, da energia interna que, atingindo um valor elevado, é subitamente liberada sob forma de calor, geração de ondas sísmicas e movimento de deslizamento interplacas.

\section{- Movimento de separação (divergência)}

Placas se afastam umas em relação a outras, ao longo de fronteiras ditas divergentes ou construtivas. $\mathrm{O}$ espaço produzido pelo movimento de separação é preenchido com novo material da crosta terrestre, de origem magmática.

\section{- Movimento de colisão (convergência)}

Quando uma placa oceânica colide com uma placa continental, de menor densidade, a primeira tende a mergulhar sob a placa continental formando uma zona de subducção ao longo de fronteiras ditas convergentes ou destrutivas. Na superfície esse movimento interplacas produz o surgimento de fossas, na placa oceânica, e cadeias montanhosas, na placa continental. O movimento pode ocorrer também entre duas placas oceânicas ou entre duas placas continentais, podendo ser definidos os seguintes tipos adicionais de convergência:

- Convergência entre placas oceânicas

Uma das placas geralmente mergulha sobre a outra, formando um arco vulcânico.

- Convergência entre placas continentais

A densidade das rochas em ambas as placas é pequena em relação ao manto, sendo difícil o movimento de mergulho. Em face das tensões 
compressivas desenvolvidas nas fronteiras interplacas, pode, no entanto, ocorrer a formação de uma zona de subducção, gerada pelo movimento de sobreposição de uma placa em relação à outra.

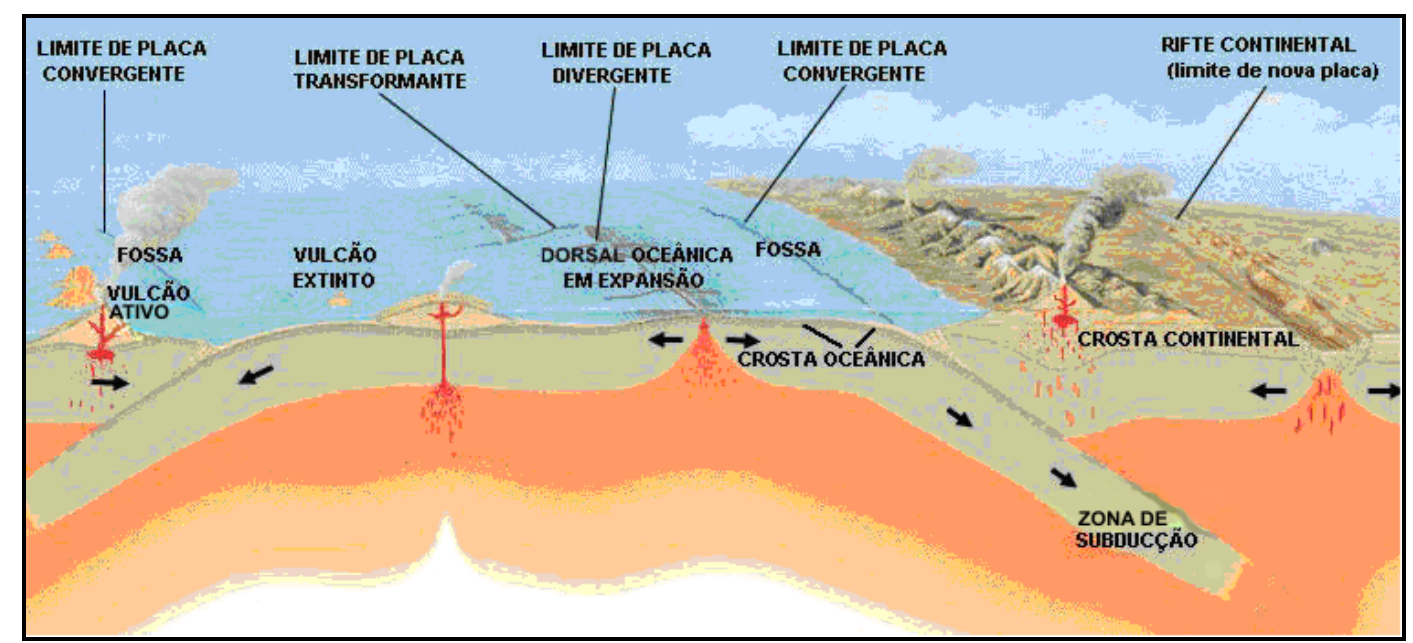

Figura 2.3 - Tipos de movimento entre placas.

\subsection{2.}

\section{Teoria da recuperação elástica (elastic rebound theory)}

A teoria da recuperação elástica descreve o processo de sucessivas acumulações e liberações de energia interna no maciço rochoso adjacente a falhas.

Quando materiais geológicos (rochas) estão sujeitos a níveis de tensão que ultrapassam seu limite de elasticidade, deformações permanentes podem ocorrer (dobramentos), se o comportamento do material for do tipo dútil. No caso de comportamento de material frágil, uma ruptura súbita pode acontecer (movimento de falhas) originando a propagação de ondas sísmicas.

\subsection{Tipos de ondas sísmicas}

Devido à liberação súbita de energia no hipocentro, ondas sísmicas são produzidas sob forma de ondas esféricas que se propagam através dos materiais geológicos. A curvatura da frente de ondas decresce com o aumento da distância ao hipocentro e, desta forma, a grandes distâncias a frente de ondas pode ser considerada como uma superfície plana e as ondas são tratadas como ondas planas. 
Outra hipótese assumida é que a propagação de ondas sísmicas ocorre em materiais elásticos, considerando-se que a partir de certa distância do foco sísmico a amplitude da perturbação se reduza para um limite que provoque apenas deformações elásticas do meio. Esta hipótese, importante para o desenvolvimento de estudos analíticos, pode ser removida na aplicação de métodos numéricos onde o comportamento de materiais geológicos pode ser descrito por relações constitutivas inelásticas. Ondas sísmicas podem ser classificadas como ondas de corpo ou ondas de superfície.

\subsection{1.}

\section{Ondas de corpo - P e S}

As ondas de corpo têm o interior da Terra como seu meio de propagação. São conhecidas como ondas longitudinais, compressivas, primárias ou simplesmente ondas $\mathrm{P}$ e ondas transversais, de cisalhamento, secundárias ou simplesmente ondas $\mathrm{S}$.

As ondas P são as de maior velocidade (por isto chamadas de primárias) e geram um movimento de compressão e extensão das partículas (movimento de vai e vem) na direção de sua propagação (Figura 2.4). As ondas $\mathrm{P}$ propagam em sólidos e fluidos, inclusive no ar (ondas sônicas).

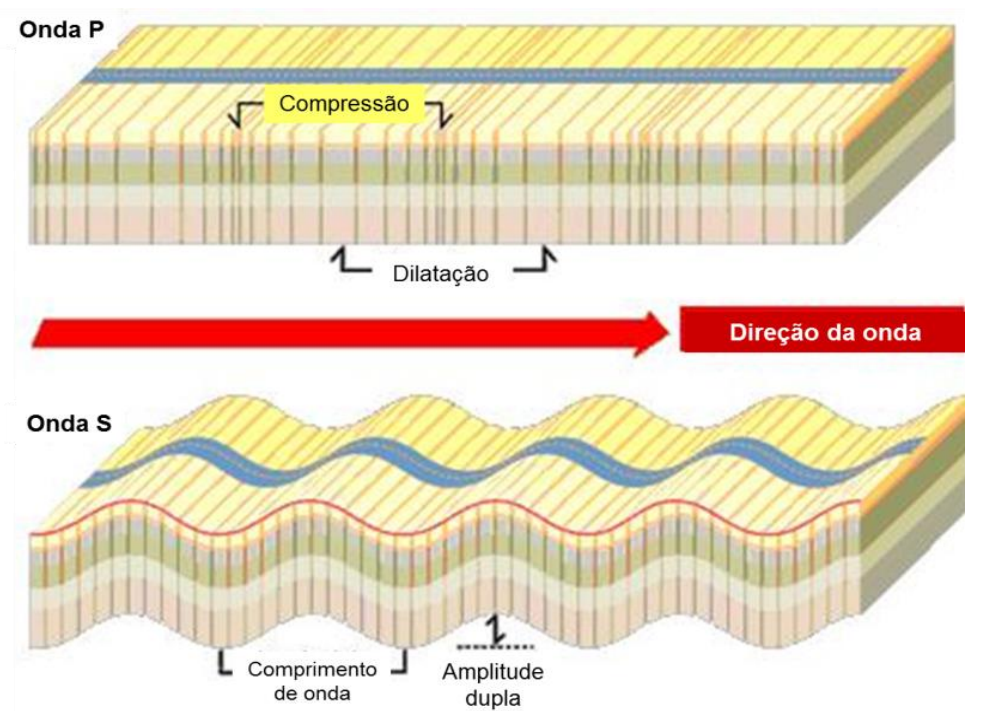

Figura 2.4 - Movimento das partículas do solo produzido pela propagação de ondas P (acima) e S (abaixo).

(Fonte: www.exo.net) 
O segundo tipo de ondas de corpo são as que produzem movimentos transversais, ou seja, perpendiculares à direção de propagação, mais lentas do que as ondas $\mathrm{P}$ e por esta razão também denominadas ondas secundárias. Por se propagarem por meio de tensões de cisalhamento não são registradas em fluidos. Dependendo do plano transversal de movimento das partículas são classificadas em ondas SV, quando o movimento das partículas está polarizado no plano vertical (Figura 2.4), e ondas SH, com polarização no plano horizontal.

\subsection{2.}

\section{Ondas de superfície}

Estas ondas têm origem na interferência construtiva e destrutiva de todas as ondas de corpo que se propagam em diferentes direções ao chegar à superfície da Terra (Kramer, 1996). Por serem ondas de longos períodos, apresentam uma maior probabilidade de entrar em ressonância com as estruturas e são consideradas, portanto, como responsáveis pela destruição de prédios e outras edificações na ocorrência de eventos sísmicos. Os dois principais tipos de ondas superficiais são as ondas Rayleigh e as ondas Love (Figura 2.5).
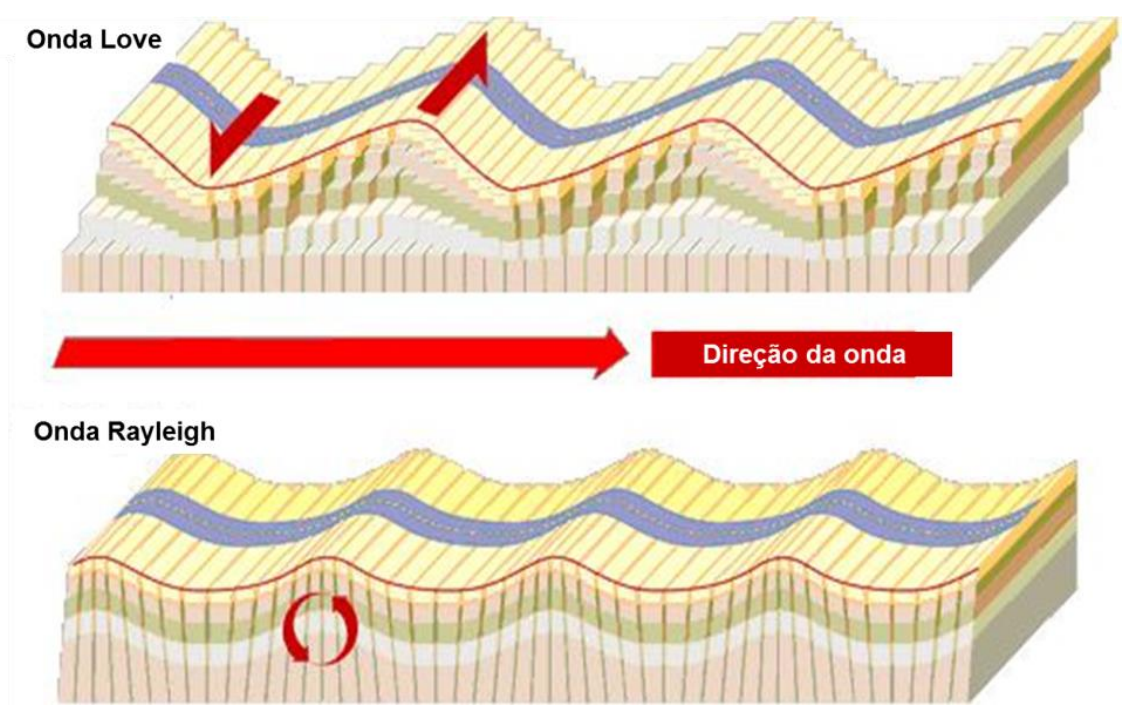

Figura 2.5 - Comportamento das partículas do solo produzido pela propagação de ondas Love e ondas Rayleigh.

(Fonte: www.exo.net)

As ondas Love (ou simplesmente ondas L) correspondem a iterações de ondas SH que ocorrem em uma camada de solo superficial com determinadas 
propriedades elásticas. Propagam-se com velocidade inferior às ondas de corpo $\mathrm{S}$ e produzem movimentos de partícula com polarização horizontal que se atenuam rapidamente com a profundidade.

As ondas Rayleigh ou simplesmente ondas $\mathrm{R}$ são produto da interação entre ondas P e SV na superfície terrestre, causando movimento de partícula que inclui as componentes longitudinal e transversal e cuja amplitude decresce exponencialmente com a profundidade. O movimento das partículas é elíptico, em plano normal à superfície do meio e paralelo à direção de propagação da onda. Em pequenas profundidades o movimento é retrógrado (como mostrado na Figura 2.5, contrário ao movimento dos ponteiros do relógio quando a onda se propaga da esquerda para a direita), invertendo o sentido em profundidades maiores.

Ondas $\mathrm{R}$ apresentam uma velocidade levemente inferior à velocidade de ondas S (Figura 2.5) e geralmente se situam entre $60 \mathrm{~m} / \mathrm{s}$ a $300 \mathrm{~m} / \mathrm{s}$. O decaimento geométrico é mais lento do que as ondas de corpo, proporcional a $1 / \sqrt{r}$ onde r é a distância ao epicentro. Terremotos de grande magnitude podem gerar ondas $\mathrm{R}$ que viajam ao redor da Terra várias vezes antes de se dissiparem. Pelo fato de se propagarem a grandes distâncias e afetarem as camadas superficiais de solo, onde se encontram as construções, a consideração dos efeitos de ondas R é de grande importância em projetos de engenharia, mesmo em regiões de baixa atividade sísmica, por serem ondas também geradas por explosões, movimentos decorrentes de tráfego pesado, funcionamento de máquinas, etc.

Em eventos de foco profundo prevalecem as ondas de corpo $\mathrm{P}$ e S, enquanto que em sismos de foco superficial predominam as ondas de superfície. A Figura 2.6 mostra os registros de dois sismos com origem no arquipélago de Tonga, no Pacífico, sendo o primeiro de foco profundo e o segundo de foco superficial, ambos detectados em Albuquerque, Novo México, a $10.000 \mathrm{~km}$ de distância. O sismo de foco profundo gerou ondas de corpo $\mathrm{P}$ e $\mathrm{S}$ de grande amplitude, mas relativamente pouca atividade produzida por ondas de superfície foi registrada. Por outro lado, no caso do sismo de foco superficial, observa-se claramente que a maior parte da energia foi liberada sob forma de ondas de superfície de grande amplitude.

Ondas superficiais são menos geradas por terremotos de grande profundidade porque as ondas de corpo $(\mathrm{P}$ e $\mathrm{SV})$ tendem a se tornarem verticais à 
medida que se propagam através de camadas menos densas, do substrato rochoso para o solo superficial, diminuindo a interação que origina as ondas $\mathrm{R}$.

Os registros sísmicos, sejam sismogramas ou acelerogramas, em certas condições permitem distinguir as diferentes ondas sísmicas com clareza. A Figura 2.7 apresenta um destes casos. Pode-se identificar a chegada das ondas P e S que posteriormente geram as ondas de superfície. Se os instantes de chegada das ondas $\mathrm{P}$ e $\mathrm{S}$ estiverem muito separados entre si, a indicação é que o sismo foi originado a uma grande profundidade.

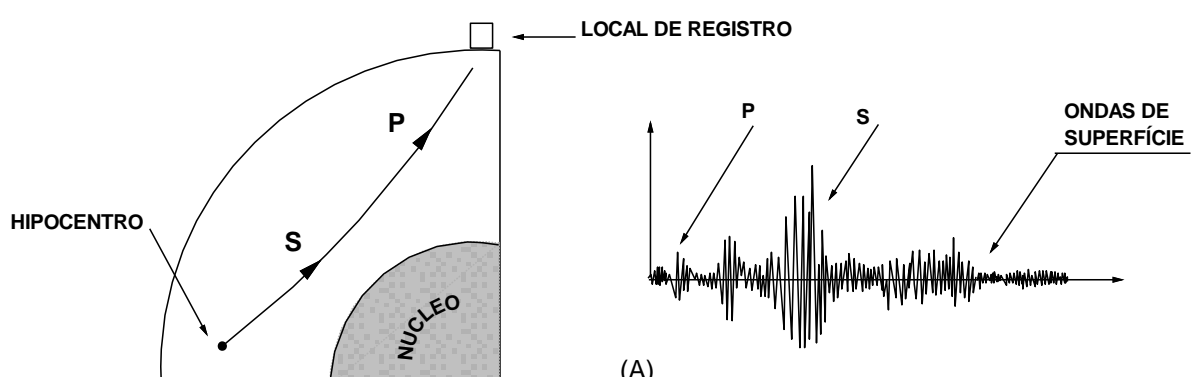

(A)

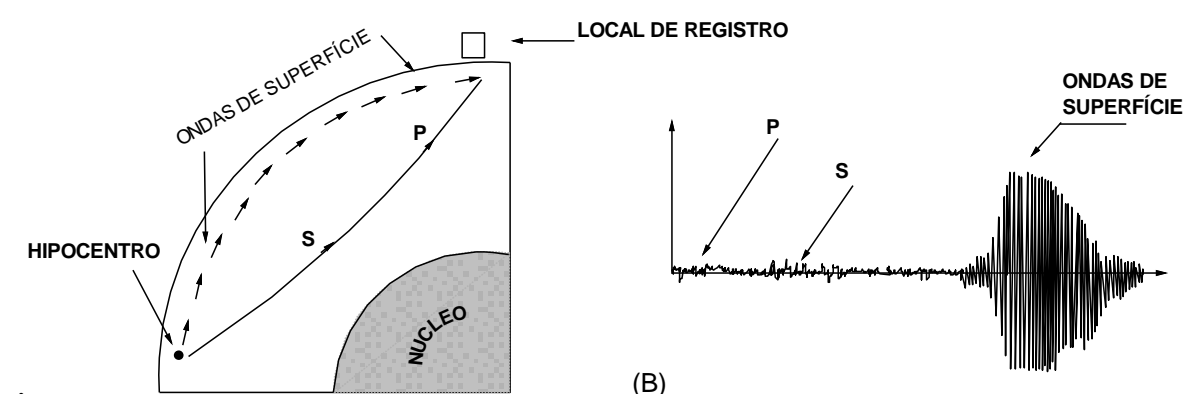

(B)

Figura 2.6 - Ondas sísmicas registradas a $10.000 \mathrm{~km}$ do epicentro: A) sismo de foco profundo; B) sismo de foco superficial (Fonte: Sauter, 1989).

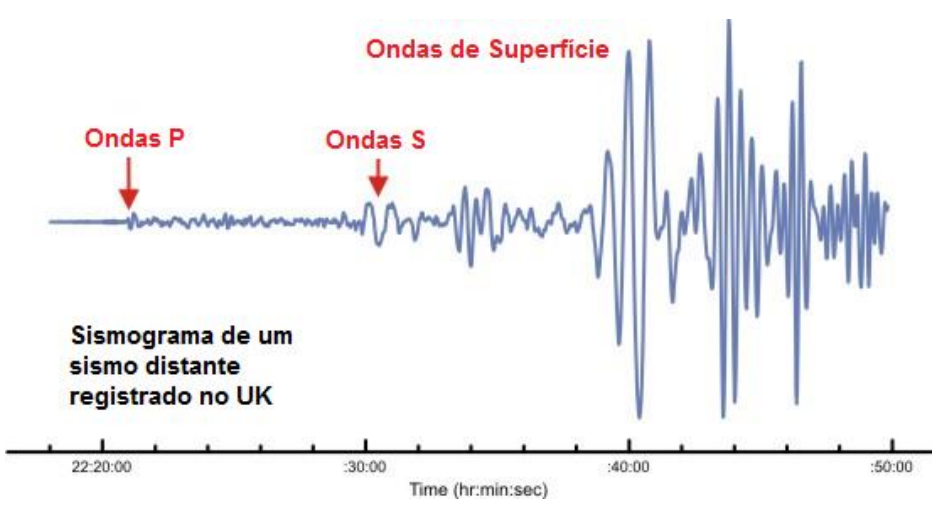

Figura 2.7 - Identificação das ondas sísmicas em um registro sísmico. (Fonte: mrborden.files.wordpress.com) 


\section{3.}

\section{Localização de um sismo}

Ainda que a ocorrência de um sismo envolva movimento de uma superfície de muitos quilômetros quadrados de área (no plano da falha), este parece ter sido provocado por uma fonte pontual quando observado a centenas ou milhares de quilômetros de distância. O ponto de onde as ondas sísmicas originam é chamado de hipocentro ou foco e a sua projeção na superfície da Terra designa-se por epicentro. A distância na superfície entre o epicentro e um observador, ou sítio, é conhecida como distância epicentral e a distância entre um observador e o foco é chamado de distância focal ou distância hipocentral (Figura 2.8).

A diferença entre os tempos de chegada de ondas $P$ e $S$ a uma estação sismográfica permite estimar a distância epicentral $d_{e}$ pela seguinte expressão:

$$
d_{e}=\frac{\Delta t_{P-S}}{1 / V_{P}-1 / V_{S}}
$$

onde $\Delta t_{p-s}$ é a diferença entre os tempos de chegada e $V_{p}$ e $V_{s} s \tilde{a} o$ as velocidades de propagação das ondas $P$ e $S$, respectivamente.

Conhecendo-se estes elementos obtidos em três diferentes estações sismográficas, basta traçar, com o auxílio de um compasso, três arcos de circunferência centrados nessas estações, com raios iguais às respectivas distâncias epicentrais, para determinar, na interseção, a localização do epicentro do terremoto.

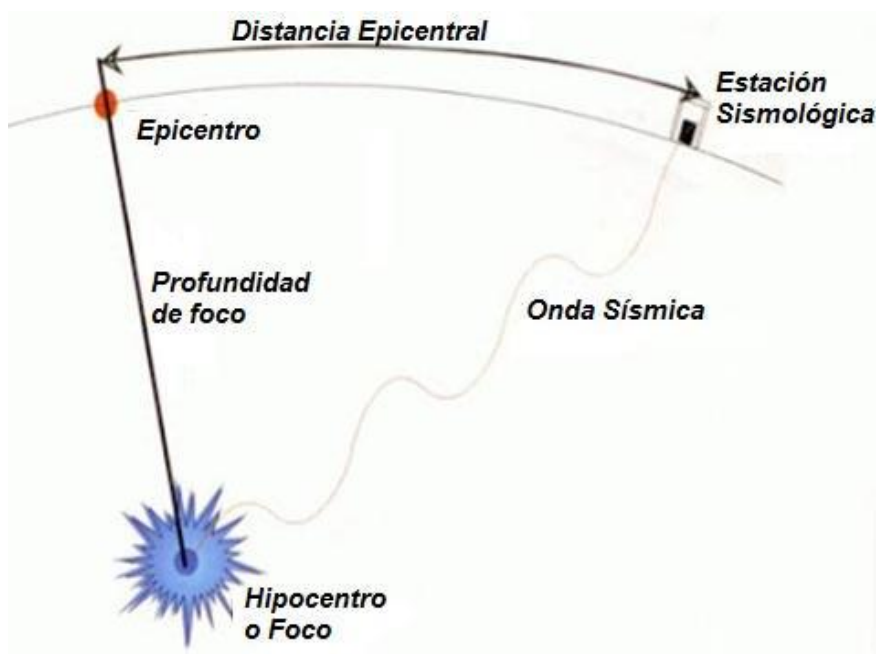

Figura 2.8 - Elementos para localização do epicentro de um sismo.

(Fonte: Roncal, 2017) 


\section{4. \\ Grandeza de um sismo}

\subsection{1.}

Magnitude

A magnitude é medida experimental obtida da amplitude das ondas sísmicas registradas em equipamentos sísmicos. Estes registros são chamados de sismogramas (registros de velocidades ou deslocamentos) ou acelerogramas (registro de acelerações). A magnitude está relacionada com a energia que é liberada no foco, sendo uma grandeza única, independentemente do local de observação.

Como medida de grandeza de terremotos, magnitudes apresentam duas grandes vantagens. Primeiro, são diretamente obtidas de sismogramas sem a necessidade de um processamento de sinal; segundo, as estimativas têm uma interpretação imediata: sismos de magnitude 5 são moderados, de magnitude 6 são fortes, etc. Terremotos com magnitude 2 ou inferior são detectados apenas por sismógrafos locais, porém eventos com magnitude 4,5 ou superior são severos o suficiente para serem registrados por sismógrafos em qualquer parte do planeta.

A primeira escala de magnitude foi desenvolvida por Charles Richter em 1935 na Califórnia, a qual é conhecida também como Magnitude Local $\left(\mathrm{M}_{\mathrm{L}}\right)$. Richter definiu a magnitude como o logaritmo na base 10 da amplitude máxima de uma onda sísmica registrada em um sismógrafo padrão WoodAnderson. Porém, a relação entre a magnitude de Richter e a quantidade de energia libertada não é linear, pois o acréscimo de um dígito no valor da magnitude corresponde uma quantidade de energia liberada 32 vezes maior (Kramer, 1996). A Figura 2.9 contém um exemplo de determinação da magnitude em função dos dados de um registro sísmico. Com base nos valores da amplitude máxima do movimento e da diferença entre os tempos de chegada das ondas $\mathrm{P}$ e $\mathrm{S}$ é possível estimar a magnitude do sismo mediante o segmento de reta que liga ambas as escalas indicando, no caso da figura, uma magnitude $\mathrm{M}_{\mathrm{L}}=5$. 
A escala Richter não é mais usada, tendo sido substituída por outras medidas de magnitude que registram com maior precisão a grandeza de um evento sísmico.

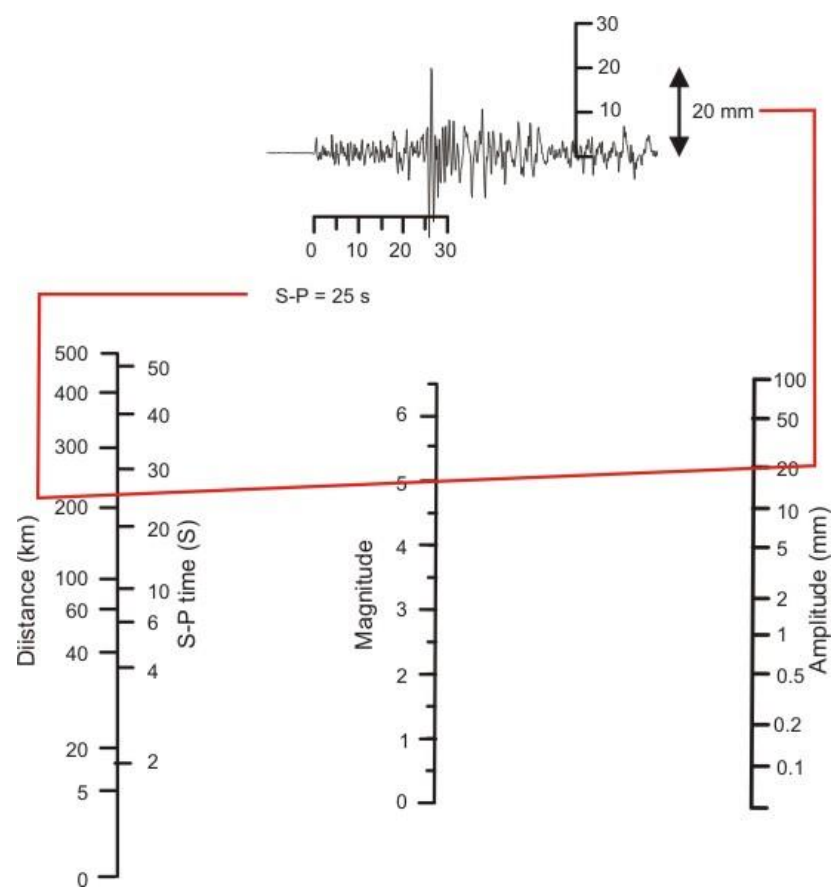

Figura 2.9 - Determinação da magnitude Richter (ML) de um sismo local.

(Fonte: csegrecorder.com)

Porque terremotos provocam ondas de corpo $(\mathrm{P}, \mathrm{S})$ e ondas de superfície $(\mathrm{R}, \mathrm{L})$ dois tipos de escalas de magnitude foram desenvolvidos: as escalas mb e Ms.

a) Magnitude das ondas de superfície Ms: baseada na amplitude máxima

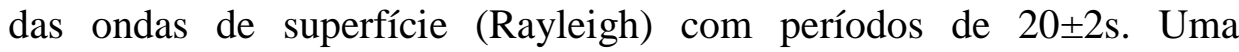
formulação padrão é dada por

$\mathrm{M}_{\mathrm{s}}=\log _{10}(\mathrm{~A} / \mathrm{T})+4.66 \log _{10}(\mathrm{D})+3.30$

onde A é a amplitude do movimento do terreno (em micras), $\mathrm{T}$ o período correspondente (em segundos) e D a distância entre o epicentro e o foco (em graus).

b) Magnitude das ondas de corpo mb: um sismo de foco profundo gera um tênue trem de ondas superficiais, mas as ondas de corpo não são afetadas pela profundidade. A magnitude mb é baseada na amplitude máxima das ondas P com período de 1s. Uma formulação padrão é dada por 


$$
\mathrm{m}_{\mathrm{b}}=\log _{10}\left(\mathrm{~A}_{\mathrm{p}} / \mathrm{T}\right)+\mathrm{Q}(\mathrm{D}, \mathrm{h})
$$

onde $A_{P}$ é a amplitude do movimento do terreno (micras), $\mathrm{T}$ o período correspondente, $(\mathrm{D}, \mathrm{h})$ um fator de correção dependente da distância epicentral $\mathrm{D}$ (em graus) e h a profundidade do terremoto $(\mathrm{km})$.

Estas escalas de magnitude também apresentam sérias limitações. Primeiro, são totalmente empíricas e não possuem uma conexão direta com os mecanismos físicos de um terremoto. As equações (2.2) e (2.3), por exemplo, não são matematicamente corretas porque a razão $\mathrm{A} / \mathrm{T}$ não é adimensional, mas mesmo assim o logaritmo desta quantidade é calculado.

Adicionalmente, as escalas $m_{b}$ e Ms não refletem corretamente a energia de grandes terremotos devido ao fenômeno chamado de saturação da escala. Para todos os terremotos com energia superior ao de San Fernando (1971, Califórnia, $\mathrm{m}_{\mathrm{b}}=6,2, \mathrm{M}_{\mathrm{s}}=6,6$ ) a escala $\mathrm{m}_{\mathrm{b}}$ indicará magnitude máxima de 6,2 (Loma Prieta, Califórnia, $\mathrm{m}_{\mathrm{b}}=6,2, \mathrm{M}_{\mathrm{s}}=7,1$ ) e para todos os terremotos com energia superior ao de São Francisco (1906, Califórnia) a escala $\mathrm{M}_{\mathrm{s}}$ registrará magnitude máxima 8,3. O maior terremoto já registrado mundialmente (Chile, 1960) foi classificado como magnitude $M_{s}=8,3$ enquanto que na escala de momento $\mathrm{Mw}$ atingiu um valor mais preciso de 9,5. A saturação da escala, associada à incapacidade de medir adequadamente a magnitude de grandes terremotos, acontece para $\mathrm{m}_{\mathrm{b}}>6,2$ e $\mathrm{M}_{\mathrm{s}}>8,3$ (Figura 2.10).

A magnitude de momento (Mw) foi proposta por Kanamori $(1977,1978)$, associada ao momento sísmico da fonte geradora do terremoto. Por ser decorrente de medidas de deslocamento da falha geológica, e não depender da medição de nenhuma onda, esta escala não apresenta problemas de saturação. Por este motivo, é a mais adotada na atualidade, sendo definida por

$$
M_{w}=\frac{2}{3} \log _{10}\left(M_{0}\right)-10.7
$$

onde $\mathrm{M}_{\mathrm{o}}$ é o momento sísmico em dina.cm ou $10^{-7}$ N.m. 


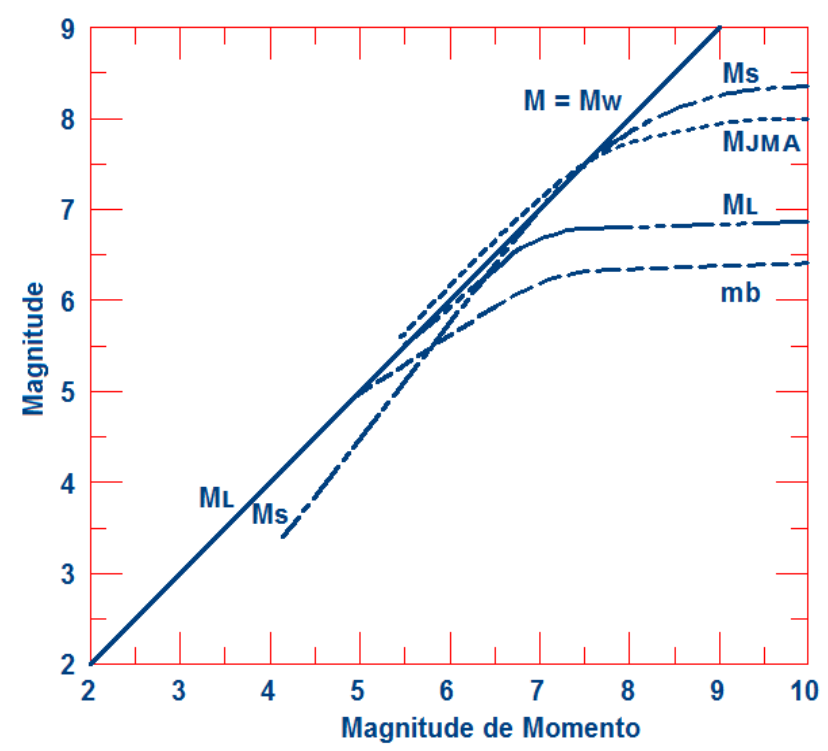

Figura 2.10 - Saturação das escalas sísmicas mb e Ms. (Fonte: Boore e Joyner, 1982.)

$$
M_{0}=\mu S d
$$

Com $\mu$ representando a resistência ao cisalhamento das rochas envolvidas no deslocamento da falha, $\mathrm{S}$ a área da falha geológica e d o deslocamento médio observado da falha.

O terremoto do Chile (1960) apresentou momento $\mathrm{M}_{0}=2.5 \times 10^{30}$ dina.cm (correspondente a $\mathrm{Mw}=9,5$ ) e o terremoto do Alaska (1964) $\mathrm{M}_{0}=7,5$ x $10^{29}$ dina.cm (correspondente a Mw $=9,1$ ). Da Figura 2.10 nota-se que Mw é comparável a Ms até que esta atinge a saturação na magnitude aproximada 8,2.

Diferentes correlações entre as escalas de magnitude foram propostas na literatura (Monroy e Bolaños, 2004; Scordilis, 2006) com o objetivo de uniformizar as medições em termos da magnitude Mw, embora essas correlações dependam de características regionais, pois as diferenças nas propriedades de atenuação na parte superior do manto podem causar imprecisões em algumas escalas.

A magnitude trabalhada nesta pesquisa é a magnitude de momento ( $\mathrm{Mw}$ ) se acordo como Roncal (2017), quem homogeneizou o catalogo sísmico de Peru para as magnitudes de momento. As relações empregadas foram: 
Para eventos com magnitudes $\mathrm{m}_{\mathrm{b}}$ (ondas de corpo) reportadas, Ms é calculado usando expressões dadas pela GSHAP (Global Seismic Hazard Assessment Program):

$$
\begin{array}{lll}
\mathrm{Ms}=1,644 \mathrm{mb}-3,753 & \mathrm{mb}<5,9 & 2.6 \\
\mathrm{Ms}=2,763 \mathrm{mb}-10,301 & \mathrm{mb} \geq 5,9 & 2.7
\end{array}
$$

Para eventos com magnitudes Ms (ondas superficiais) reportadas ou obtidas, Mw é calculado usando expressões dadas por ISC (International Seismological Center; Scordilis, 2006):

$$
\begin{array}{lll}
\mathrm{Mw}=0,67( \pm 0,005) \mathrm{Ms}+2,07( \pm 0,03) & 3,0 \leq \mathrm{mb} \leq 6,1 & 2.8 \\
\mathrm{Mw}=0,99( \pm 0,02) \mathrm{Ms}+0,08( \pm 0,13) & 6,2 \leq \mathrm{mb} \leq 8,2 & 2.9
\end{array}
$$

\subsection{2. \\ Intensidade}

Outra das grandezas de um sismo é a intensidade. Diferentemente da magnitude, a intensidade é uma escala descritiva e só é dependente das observações reais dos efeitos destrutivos do evento sísmico, que são comparadas com uma escala padrão. A escala mais usada foi criada por Giuseppe Mercalli, posteriormente modificada e adaptada, e por isso é normal referir-se que a intensidade de um sismo foi determinada na escala Mercalli Modificada (Wood e Neumann, 1931), mostrada na Figura 2.11. A escala é baseada em uma série de respostas tais como pessoas acordando, movimento de mobília, danos a chaminés e, finalmente, destruição total. Os 12 valores representam níveis crescentes de intensidade, que variam desde tremores imperceptíveis a uma destruição catastrófica. A escala não tem fundamento científico e se refere aos efeitos ocorridos no local do terremoto. Os baixos valores de intensidade estão associados a sensações de pessoas durante o terremoto, enquanto que os valores mais altos se relacionam com danos estruturais observados. 


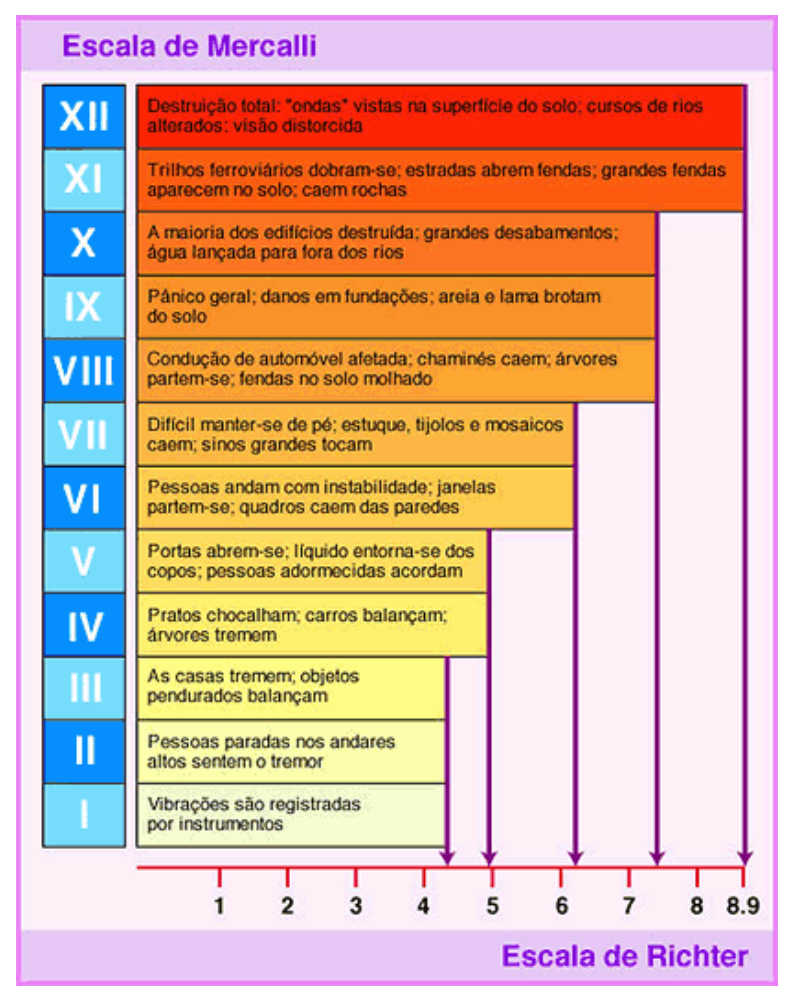

Figura 2.11 - Escala de intensidades Mercalli Modificada.

(Fonte: geomundo.com.br)

\section{5 .}

\section{Ajustes no registro sísmico}

\subsection{1.}

\section{Correção da linha base}

Um dos problemas que acontecem com acelerogramas registrados analógica ou digitalmente são os resíduos de velocidade em relação à linha de aceleração nula, também conhecida como linha base. Ainda que este erro possa ser pequeno em termos de aceleração, no final do registro sísmico, pode ser muito importante quando se calcula a velocidade por integração no tempo, geometricamente representada pela área contabilizada entre o acelerograma e a linha base.

Para ter uma ideia da importância deste erro, pode-se supor um desvio constante do acelerograma em relação à linha base de 0,001g, como ilustrado na Figura 2.12. Ao se integrar este erro, obtém-se um incremento linear da velocidade e um incremento parabólico do deslocamento, resultando em um valor de deslocamento de $196 \mathrm{~cm}$ após transcorridos 20s. Uma forma de compensar este erro é realizar um ajuste da linha base pelo acréscimo de uma onda de velocidade de baixa frequência, descrita por uma função polinomial ou periódica, de forma que a velocidade no final do registro torne-se nula. 
O procedimento mais adequado recomenda que o ajuste de linha base do registro sísmico seja feito após a filtragem (baseado na identificação da frequência de corte), já que após a filtragem o registro sísmico encontra-se com valores de aceleração, velocidade e deslocamentos finais diferentes de zero (Castaneda, 2013).

\subsection{2.}

\section{Filtragem de frequências}

Os movimentos previstos do terreno podem ser especificados de diferentes modos, dependendo de como serão usados no projeto. Muitas avaliações requerem uma história completa no tempo, outras somente precisam de um ou mais parâmetros do movimento do terreno.

Os registros sísmicos, particularmente os provenientes de equipamentos analógicos, invariavelmente contêm ruídos que podem distorcer os sinais em altas e baixas frequências. Acelerômetros digitais conseguem produzir registros mais fiéis do movimento do terreno, mas a grande parte dos registros sísmicos mundiais foi (e ainda é) feita através de equipamentos analógicos. Várias décadas passarão antes que os catálogos de acelerogramas analógicos tornem-se redundantes e, até lá, é importante compreender que a maioria dos registros disponíveis necessita de processos de filtragem para minimização dos efeitos de ruídos.

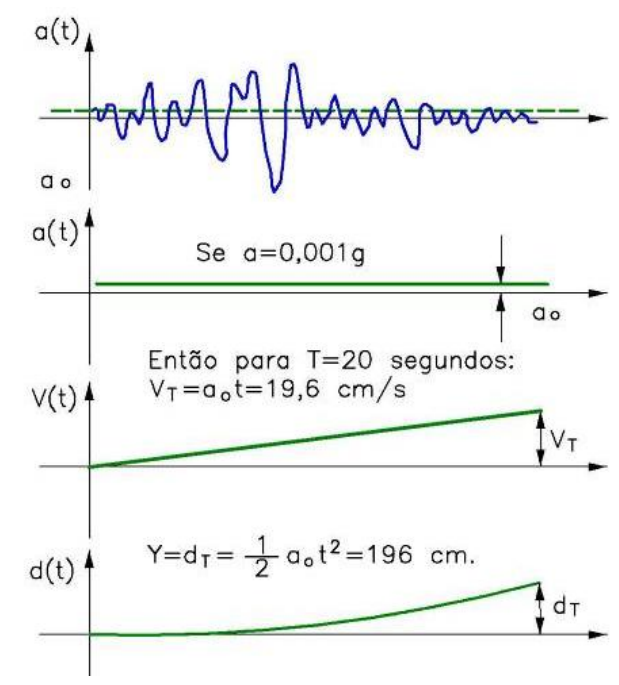

Figura 2.12 - Erros introduzidos nas velocidades e deslocamentos pela falta da correção da linha base no acelerograma.

(Fonte: modificado de Hudson, 1979) 
De modo geral pode-se considerar que o acelerograma é a soma do sinal do sismo e de ruídos,

$$
a(t)=s(t)+r(t)
$$

sendo $a(t)$ o acelerograma sem correção, $s(t)$ o sinal sísmico e $r(t)$ o ruído.

O ruído pode ser de alta ou de baixa frequência. $\mathrm{O}$ primeiro afeta fundamentalmente os picos de aceleração, ao passo que o segundo afeta basicamente o processo de integração (ondas cujos períodos são maiores do que a duração do terremoto e tendem a causar valores não nulos na história de velocidades e deslocamentos, afetando a posição da linha base). Estes erros podem ser eliminados limitando o registro sísmico a uma faixa de frequências desejada, empregando-se filtro de passa-baixa (remoção de altas frequências a partir de determinada frequência de corte), filtro de passa-alta (remoção de baixas frequências) ou filtro de passa-banda (remoção simultânea de altas e baixas frequências). A Figura 2.13 apresenta os efeitos de filtragem de ruídos de alta e baixa frequência no acelerograma. Existem vários programas computacionais disponíveis para filtragem de sinais como o SeismoSignal, utilizado neste trabalho ( SeismoSignal v.2016).
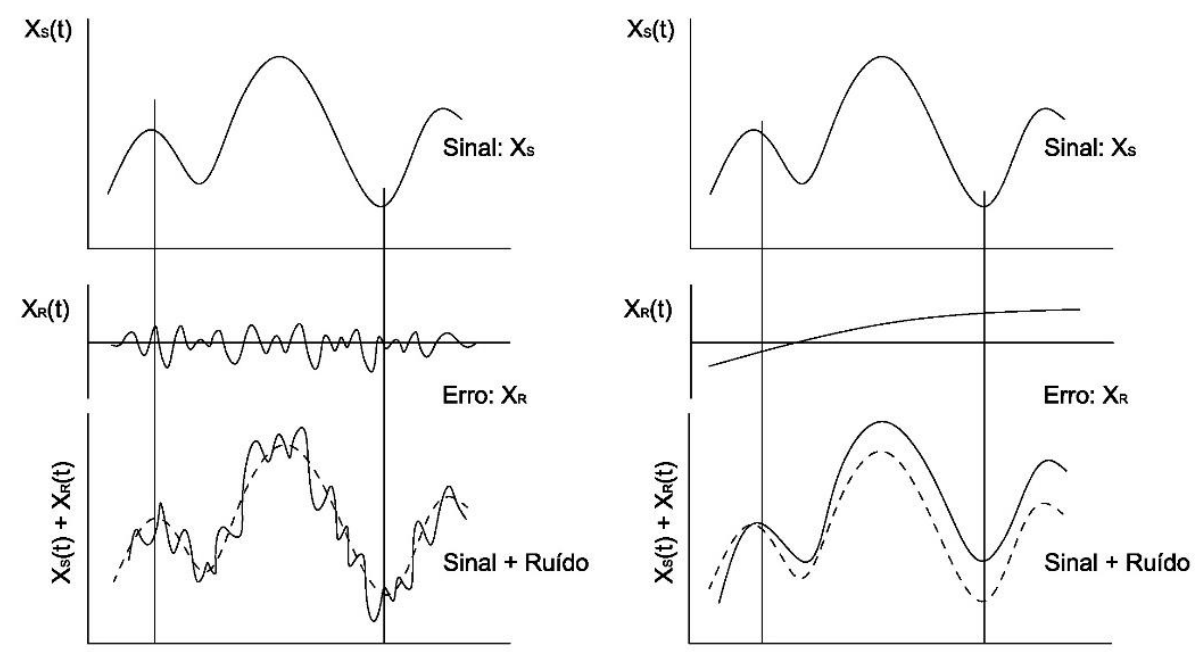

Figura 2.13 - À esquerda, efeito dos ruídos de alta frequência, à direita efeitos dos ruídos de baixa frequência.

(Fonte: modificado de Hudson, 1979) 


\section{3 Avaliação de Ameaça Sísmica}

Projetos de engenharia que envolvam análises sísmicas têm como meta construir estruturas que resistam a certos níveis de vibração do solo sem danos excessivos. O nível de vibração é geralmente descrito em termos de um único parâmetro do movimento do solo que, ao ser ultrapassado, caracteriza a ameaça sísmica. A análise de ameaça sísmica requer a quantificação deste parâmetro que pode ser feita de forma determinística, quando se assume um cenário para um terremoto particular, ou de forma probabilística, na qual incertezas na dimensão, na localização e no tempo de ocorrência são explicitamente consideradas (Almeida, 2002). A avaliação da ameaça e risco sísmico exige a identificação e a caracterização da origem da atividade sísmica que possa produzir movimentos do terreno significativos na região de interesse. A origem do sismo pode ser especificada com base em evidências geológicas, tectônicas, históricas e por instrumentação.

\section{1. \\ Análise determinística}

A análise da ameaça sísmica pelo método determinístico desenvolve-se considerando um cenário sísmico específico que permita estimar o movimento sísmico mais desfavorável para a área de estudo, com a desvantagem de não fornecer informações sobre a probabilidade de ocorrência do sismo de projeto. Além disso, este método tampouco produz resultados sobre o nível de vibração esperado durante certo intervalo de tempo ou sobre os efeitos das incertezas introduzidas nos vários passos necessários para calcular as características do movimento do terreno.

A análise determinística da ameaça sísmica é efetuada mediante as seguintes etapas: 
- Localizar as potenciais zonas sismogênicas que se relacionam geograficamente com o sítio de interesse, com base em estudos dos sismos históricos e das informações sismotectónicas disponíveis;

- Com base na magnitude selecionada, e na distância epicentral, avaliar os parâmetros máximos do movimento do solo, usando, na maior parte dos casos, a aceleração horizontal do solo como parâmetro de projeto;

- Efetuar os ajustes convenientes dos parâmetros estimados de forma a considerar efeitos de caráter local (Wang e Law, 1994).

Um resultado típico deste tipo de metodologia pode ser descrito pelo seguinte relatório: "a ameaça sísmica apresenta um valor de PGA de 0,35g como resultado de um terremoto de magnitude 6 na falha Balcones, a uma distância de 12 milhas do local” (Meneses, 2009).

\section{2.}

\section{Análise probabilística}

A ameaça sísmica probabilística é uma metodologia analítica que estima a probabilidade dos diferentes níveis de movimento do solo, causados pelo terremoto, sejam ultrapassados em um determinado sitio em certo período de tempo. Os resultados dessa análise são expressos como probabilidades estimadas por unidade de tempo (número esperado de eventos por ano). Apesar dos grandes avanços no conhecimento sísmico nos últimos anos, ainda existem lacunas na compreensão dos mecanismos que causam terremotos, e dos processos que controlam a forma como a energia de um terremoto propaga-se desde a sua origem. Logo, quando uma análise de ameaça sísmica probabilística é realizada, há inevitavelmente incertezas nos resultados obtidos; portanto, a probabilidade de ocorrência é fornecida como parte da resposta (NUREG-6372, 1997).

Um resultado típico deste tipo de metodologia pode ser descrito pelo seguinte relatório: "um valor de PGA de 0,28g correspondente a 2\% de probabilidade de ser excedido em 50 anos de exposição sísmica em determinado sitio" (Meneses, 2009). 


\subsection{1.}

\section{Catálogos sísmicos}

Todo estudo de ameaça sísmica deve ser precedido por uma detalhada investigação das características sismo-tectônicas da província sísmica onde se planeja o projeto de engenharia. Esta análise permitirá limitar a região de interesse e estabelecer critérios para a delimitação das fontes sismogênicos. É necessário fazer uma compilação de todos os registros de eventos sísmicos disponíveis que ocorreram nas proximidades do local do projeto. As informações sísmicas utilizadas na presente pesquisa foram obtidas dos seguintes catálogos sísmicos: Instituto Geofisico del Perú (IGP) e National Earthquake Information Center (NEIC) dos Estados Unidos. Destes catálogos foram removidos os sismos de baixa magnitude, que não apresentam importância significativa, bem como as réplicas (aftershocks). A padronização das magnitudes dos sismos remanescentes, que podem estar expressas em diferentes escalas, foi realizada em seguida.

\subsection{2. \\ Fontes sismogênicas}

Normalmente as fontes sismogênicas são definidas seguindo um modelo de zonas sismogênicas que apresentam características de sismicidade bem definidas (Gamarra, 2009). As fontes sismogênicas podem ser falhas geológicas ou áreas extensas onde se admite uma sismicidade difusa distribuída uniformemente. A Figura 3.1(a) representa uma atividade sísmica cujo comportamento pode ser modelado como uma fonte pontual, enquanto a Figura 3.1(b) considera uma falha geológica superficial modelada como uma fonte linear e a Figura 3.1(c) mostra a modelagem mais utilizada, considerando uma fonte tridimensional. Estabelecer as características de fontes pontuais ou lineares é mais complicado, devido à pouca instrumentação existente para representar as falhas adequadamente.

Para estudos localizados na costa peruana, objeto da presente pesquisa, as fontes sismogênicas são geralmente definidas em função do mecanismo de falha que acontece no processo de subducção de placas tectônicas, com a placa de Nazca penetrando abaixo da placa Sul-americana. 

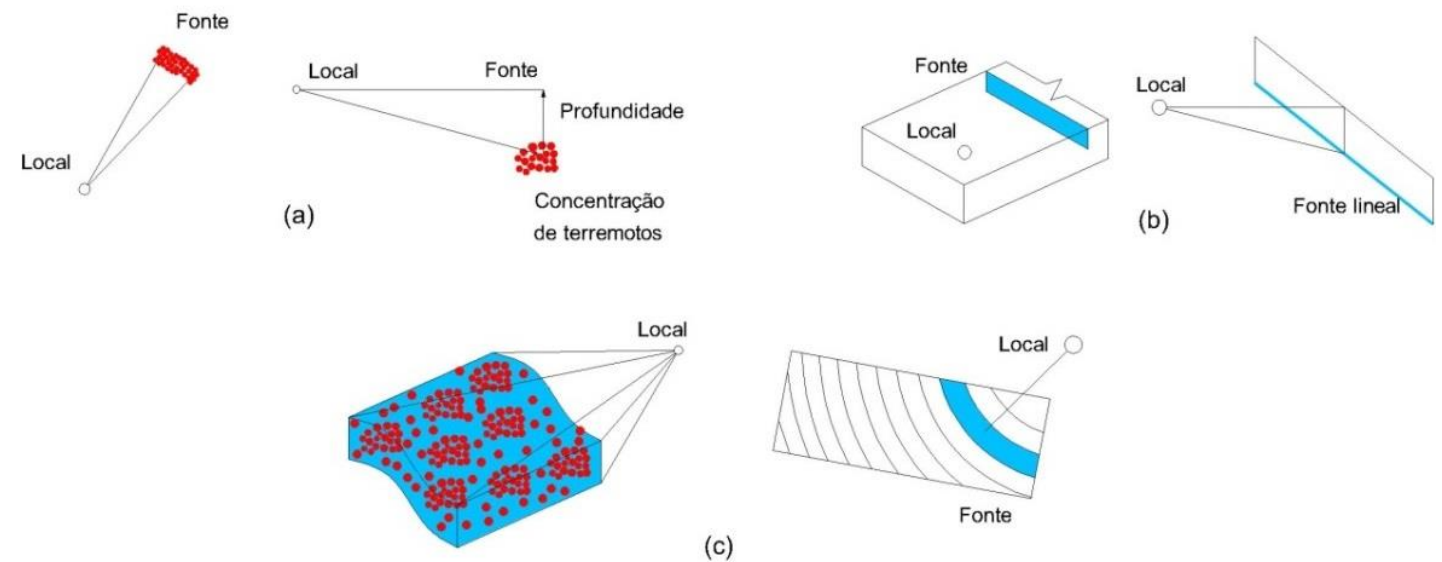

(c)

Figura 3.1 - Geometria de fontes sismogênicas: (a) pontual; (b) linear; (c) tridimensional. (Fontes: Kramer, 1996; Monroy e Bolaños, 2004)

Em função deste mecanismo de falha é possível definir três tipos de fonte sismogênicas, conforme Figura 3.2:

- Fontes corticais: agrupam os sismos que não são produto direto do mecanismo de subducção, como os sismos produzidos por falhas geológicas ou vulcanismo. Tem profundidades máximas de $20 \mathrm{~km}$.

- Fontes de subducção de interplaca ou interface: agrupam os sismos que ocorrem nas zonas de fronteira entre placas, em profundidades de até $75 \mathrm{~km}$.

- Fontes de subducção de intraplaca: agrupam os sismos que ocorrem no interior de placas tectônicas, em profundidades maiores do que $75 \mathrm{~km}$.

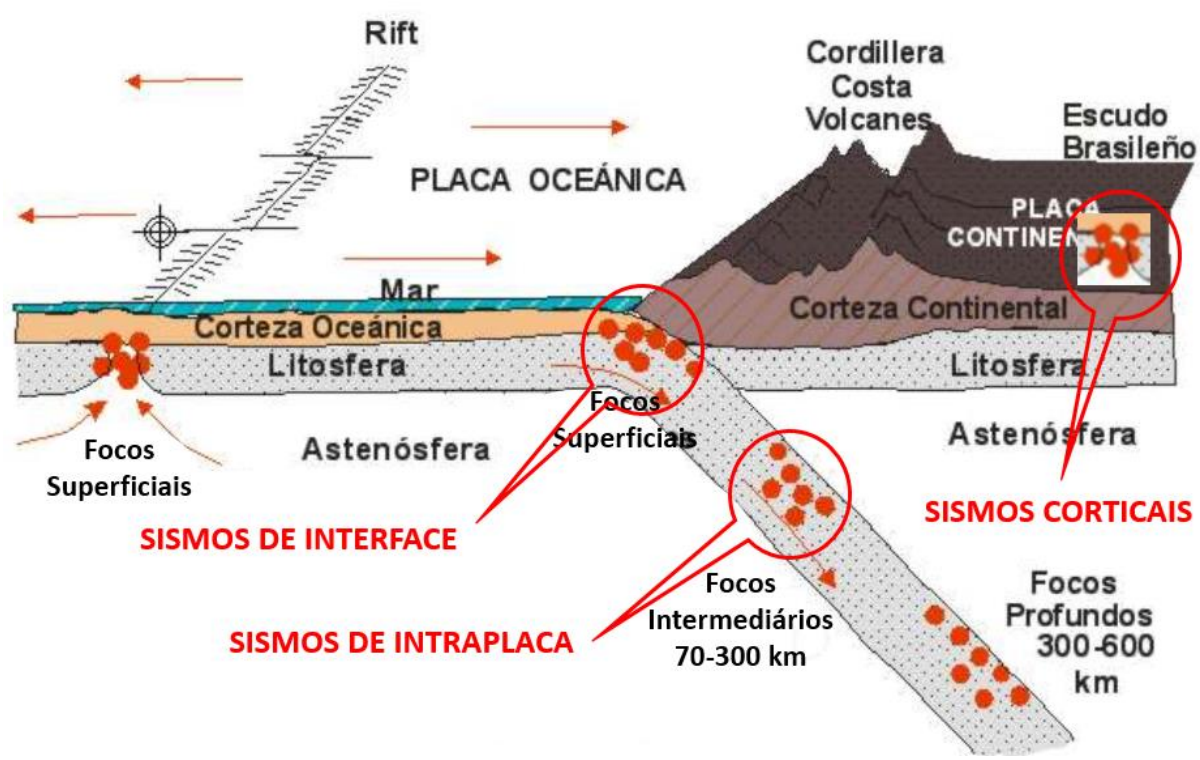

Figura 3.2 - Sismos de interface, intraplaca e corticais.

(Fonte: Gamarra, 2009) 


\subsection{3.}

\section{Determinação dos parâmetros das fontes sísmicas}

Uma vez que as fontes sismogênicas tenham sido definidas, as características de sismicidade de cada fonte devem ser estabelecidas em função de uma lei de recorrência, também chamada de distribuição temporal de magnitudes. Esta lei relaciona o tamanho dos sismos, em termos de magnitude ou intensidade, com sua frequência no tempo, tendo como hipótese de que sismos passados podem ser utilizados para extrapolar a sismicidade da fonte sismogênica no futuro. A lei de recorrência mais utilizada é a de Gutenberg-Richter (1944), representada na Figura 3.3, que estabelece uma relação linear entre magnitude e o número de sismos em determinada fonte sismogênica.

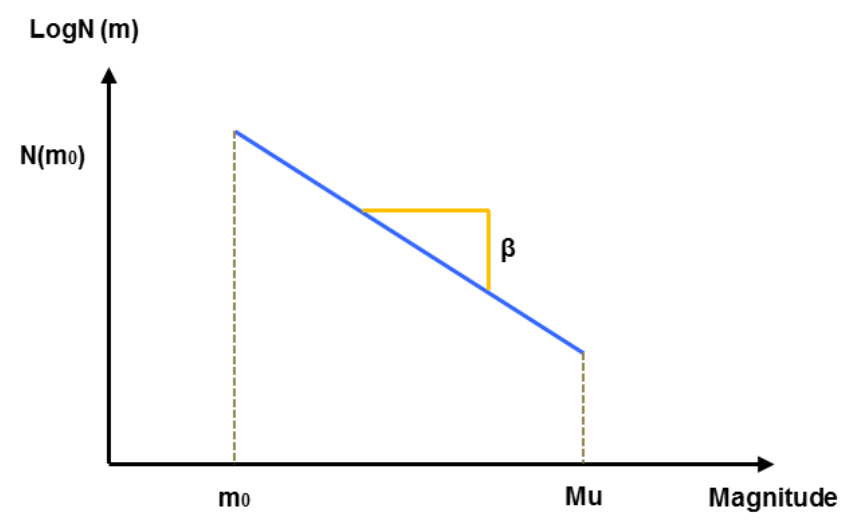

Figura 3.3 - Representação da lei de Gutenberg-Richter com processo de Poisson duplamente truncado.

A lei de recorrência de Gutenberg-Richter é expressa por

$$
\log N=a+b \cdot M
$$

onde $\mathrm{M}$ é a magnitude, $\mathrm{N}$ o número médio de sismos com magnitude maior ou igual a M, "a" reflete a atividade sísmica e "b" reflete a proporção de terremotos com pequenas e grandes magnitudes.

Ao considerar eventos sísmicos, a lei de recorrência é escrita sob forma exponencial, em um intervalo de magnitude delimitado pela magnitude mínima de referência moe a magnitude máxima $\mathrm{M}_{\mathrm{u}}$ (duplo truncamento).

$T(m)=N \frac{\left(e^{-\beta m}-e^{-\beta M_{u}}\right)}{\left(e^{-\beta m_{0}}-e^{-\beta M_{u}}\right)}$

onde $\beta=\ln (10) * b$ 
Embora a lei de Gutenberg-Richter seja amplamente utilizada, é também questionada quando aplicada na modelagem sísmica de falhas geológicas. Nesse caso, o modelo do sismo característico (Schwartz e Coppersmith, 1984) pode ser utilizado, o qual sugere que em uma fonte isolada, com boa quantidade de dados, há um intervalo de magnitudes próximo à magnitude máxima $(\mathrm{Mu})$ com maior probabilidade de ocorrência do que em relação às magnitudes intermediárias. Em outras palavras, a fonte libera sua energia em um evento de magnitude “característica" próximo à magnitude máxima $(\mathrm{Mu})$.

Os parâmetros que definem cada fonte sismogênica, necessários na avaliação da ameaça sísmica, são a magnitude mínima $\left(\mathrm{m}_{0}\right)$, a magnitude máxima $(\mathrm{Mu})$, a taxa do número acumulado de sismos que excedem a magnitude mínima (T) e a inclinação da curva ( $\beta$ ). Estes valores são chamados de parâmetros de sismicidade local.

A estimativa dos parâmetros $\beta$ e $\mathrm{T}$ é geralmente feita pelo método da máxima verossimilhança, embora também seja possível usar uma regressão pelo método dos mínimos quadrados, embora certos autores não recomendem sua utilização (McGuire, 2004; Monroy e Bolaños, 2004).

Segundo Monroy e Bolaños (2004) o método da máxima verossimilhança ajusta a distribuição dos sismos de uma determinada fonte de acordo com o valor médio mais provável do conjunto de dados. Quando usados os métodos da máxima verossimilhança e dos mínimos quadrados para a análise da mesma fonte sismogênica, como mostrado na Figura3.4, os resultados indicam um melhor ajuste obtido pelo método da máxima verossimilhança.
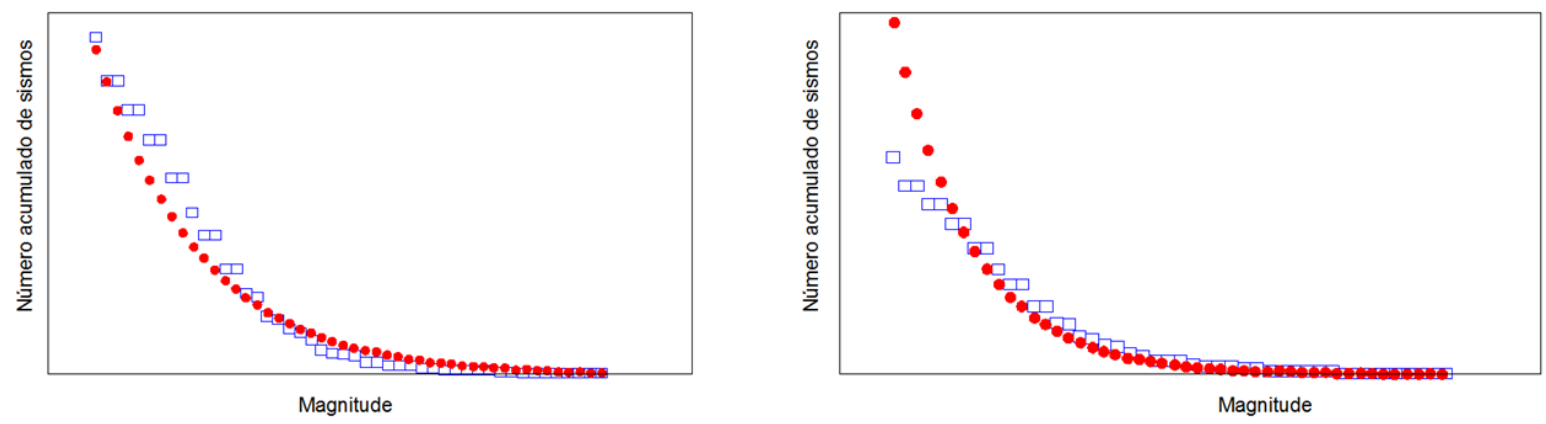

Figura 3.4 - Ajuste pelo método da máxima verossimilhança (esquerda) e pelo método dos mínimos quadrados (direita).

(Fonte: Monroy e Bolaños, 2004) 
De acordo com McGuire (2004) o valor do parâmetro $\beta$ pelo método de máxima verossimilhança é calculado como:

$$
\frac{1}{\beta}=\bar{m}-m_{o}+\frac{\left(M_{u}-m_{o}\right) e^{-\beta\left(M_{u}-m_{o}\right)}}{1-e^{-\beta\left(M_{u}-m_{0}\right)}}
$$

onde $\bar{m}$ é a magnitude média considerando um modelo duplamente truncado.

A estimativa da taxa (T) do número acumulado de sismos que excedem a magnitude mínima, quando feita considerando intervalos de observação desiguais no catálogo sísmico, é dada como uma soma de variáveis de uma distribuição de Poisson expressa por (McGuire, 2004),

$T=N \frac{\sum_{i} e^{-\beta m_{i}}}{\sum_{i} t{ }^{*} e^{-\beta m_{i}}}$

onde $\mathrm{N}$ é o número acumulado de eventos, i representa o número de intervalos de observação e $t^{*}$ o número de anos de cada incremento de magnitude $\mathrm{m}_{\mathrm{i}}$ observado.

A magnitude mínima $\left(\mathrm{m}_{0}\right)$ da fonte sísmica é definida em função da completude do catálogo sísmico e corresponde ao ponto de inflexão da curva de recorrência sísmica, sendo obtida como o ponto da máxima curvatura (Wiemer et al,1999; Wiemer et al, 2000). McGuire (2004) indica que esta magnitude deve considerar também critérios de risco sísmico (i.e., a magnitude mínima que pode causar danos em uma região).

Para cálculo da magnitude máxima (Mu) considera-se a magnitude do maior evento sísmico acontecido na fonte sismogênica (McGuire, 1976). O critério para determinar a magnitude máxima é baseado na hipótese que, se numa área aconteceu um evento extremo, esse evento poderia novamente acontecer no futuro. Na presente pesquisa, a magnitude máxima é definida inicialmente pelo maior valor encontrado nos catálogos, na área de influência de cada fonte sismogênica $\left(\mathrm{M}_{\max }\right)$.

Para considerar a incerteza epistêmica relacionada ao valor da magnitude máxima $\left(\mathrm{M}_{\max } \mathrm{Fi}\right)$ de determinada fonte $\mathrm{Fi}$, o valor da magnitude máxima é então redefinido para uma faixa de valores com desvio de $0,1 \mathrm{Mw}$, ou seja: 


$$
M_{\max F i}=M_{\max i} \pm 0,1 M w
$$

\subsection{4.}

\section{Atenuação de ondas sísmicas}

Uma vez que os parâmetros sismológicos de cada fonte tenham sido calculados, leis de atenuação adequadas devem ser selecionadas. As leis de atenuação são equações matemáticas (equações de previsão do movimento do solo GMPE - Ground Motion Prediction Equations) que relacionam um parâmetro do movimento do terreno (normalmente a aceleração) com parâmetros que definem os sismos: magnitude ou intensidade, a distância entre o foco sísmico e a localização do projeto e uma dispersão estatística do modelo. Algumas relações consideram também outros fatores, como o tipo de solo. Geralmente são desenvolvidas mediante análises de regressão de dados de registros sísmicos; portanto, mudam com o tempo à medida que a base de dados é enriquecida e depurada (Kramer, 1996).

Em zonas de atividade sísmica moderada à baixa, os registros sísmicos disponíveis são limitados e menos representativos. Nos estudos de ameaça sísmica nestes locais é necessário, portanto, selecionar da literatura as leis de atenuação, julgadas adequadas para serem empregadas na estimativa da ameaça sísmica. É importante saber que desta decisão dependerá em grande parte a confiabilidade da ameaça sísmica, pois as leis de atenuação têm uma influência fundamental nos resultados.

\subsection{5.}

\section{Estimativa probabilística da ameaça sísmica}

A metodologia proposta por Cornell (1968), apresentada na equação 3.6, avalia a probabilidade de excedência de um valor limite do movimento, como a aceleração, no local de interesse, devido à atividade de todas as fontes sismogênicas próximas e que possam contribuir ao movimento esperado (Climent et al, 2008).

Considerando $N_{s}$ fontes sismogênicas,

$$
P^{*}(y>Y)=\sum_{i=1}^{N_{s}} P^{*}{ }_{i}(y>Y)=\sum_{i=1}^{N_{s}} v_{i} \iint P_{i}[y>Y / m, r] f_{M i}(m) f_{R i}(r) d m d r
$$


onde a dupla integral tem como limites as magnitudes e as distâncias mínimas e máximas da fonte.

$P^{*}(y>Y)$ : soma das taxas anuais de excedência do movimento $Y$, devido à ocorrência de sismos nas $N_{s}$ fontes. Cada fonte apresenta uma taxa anual de ocorrência de sismos $v_{i}$.

$P_{i}[y>Y / m, r]:$ probabilidade de excedência de $Y$ em função das variáveis $m$ (magnitude) e $r$ (distância).

$f_{M i}(m)$ : função de densidade de probabilidade de magnitude.

$f_{R i}(r)$ : função de densidade de probabilidade de distância.

Admitindo que a probabilidade de excedência de $Y$ só é função das variáveis $m$ e $r$, então o termo $P_{i}[y>Y / m, r]$ só pode ter dois únicos valores: um e zero (Abrahamson, 2000). Quando é atingida a excedência do movimento, os valores das variáveis $m$ e $r$ são tais que $y>Y$, portanto a probabilidade de excedência assume o valor 1 . No caso em que a excedência não seja atingida, então o termo $P_{i}[y>Y / m, r]$ é igual a zero. Matematicamente, esse valor duplo é expresso por meio da função de Heaviside, também chamada de função degrau, que pode ser matematicamente escrita como $H(\ln y-\ln Y)$. Quando $\ln y>\ln Y$ o valor da função $H$ é igual a unidade e para $\ln y<\ln Y$ seu valor é nulo.

A equação (3.6) pode ser reescrita da seguinte forma:

$$
P^{*}(y>Y)=\sum_{i=1}^{N_{S}} P^{*}{ }_{i}(y>Y)=\sum_{i=1}^{N_{S}} v_{i} \iint H(\ln y-\ln Y) f_{M i}(m) f_{R i}(r) d m d r
$$

A avaliação da integral depende das PDFs - funções de densidade de probabilidade - $f_{M i}(m)$ e $f_{R i}(r)$, embora também possam ser usadas funções de distribuição $F(x)$. A função de densidade de probabilidade de magnitude é calculada da lei de Gutenberg-Richter duplamente truncada como:

$$
f_{M i}(m)=\frac{\beta e^{-\beta\left(m-M_{o i}\right)}}{1-e^{-\beta\left(M_{M i}-M_{o i}\right)}} \operatorname{com} \mathrm{m}_{\mathrm{oi}} \leq \mathrm{m} \leq \mathrm{M}_{\mathrm{Mi}}
$$

onde $m_{o i}$ e $M_{M i}$ são a mínima e máxima magnitude da fonte i.

A função de densidade de probabilidade de distância não tem uma expressão analítica e deve ser calculada numericamente. Para uma fonte sismogênica pontual 
$f_{R}(r)=1$ e para uma fonte circular de raio $\mathrm{R}_{\mathrm{MAX}}$, em cujo centro se determina a ameaça sísmica, a função de densidade de probabilidade de distância pode ser expressa como:

$$
f_{R}(r)=\frac{2 r}{R_{M A X}^{2}} \operatorname{com} 0 \leq \mathrm{r} \leq \mathrm{R}_{\mathrm{MAX}}
$$

As integrais da equação 3.7 são resolvidas numericamente considerando as funções de densidade de probabilidade $f_{M i}(m)$ e $f_{R i}(r)$ ou, alternativamente, as funções de distribuição acumulada $F(m)$ e $F(r)$. Quando as funções de distribuição são consideradas, a diferença entre os valores calculados nos extremos de cada intervalo discretos $\Delta m$ e $\Delta r$ (chamados de zonas) fornece a contribuição das respectivas funções de distribuição para a ameaça sísmica.

Tem-se então:

$$
\begin{gathered}
F_{i}\left(\mathrm{~m} / \text { setor }_{u, u+1}\right)=\frac{e^{-\beta\left(M_{u}-m_{0}\right)}-e^{-\beta\left(M_{u+1}-m_{0}\right)}}{1-e^{-\beta\left(M u-m_{0}\right)}} \\
F_{i}\left(r / \text { setor }_{v, v+1}\right)=F\left(r_{v+1}\right)-F\left(r_{v}\right)=\left(r_{v+1}-r_{v}\right)\left(\frac{\Delta A_{v, v+1}}{A}\right)
\end{gathered}
$$

onde $A$ é dependente da tamanho da zona considerada. Logo, substituindo na equação (3.7), obtém-se:

$$
P^{*}(y>Y)=\sum_{i=1}^{N s} v_{i} \sum_{u=M \text { min }}^{M-R \max } \sum_{v=R \min }^{R \max }\left(\frac{e^{-\beta\left(M_{u}-m_{0}\right)}-e^{-\beta\left(M_{u+1}-m_{0}\right)}}{1-e^{-\beta\left(M_{M}-m_{0}\right)}} \cdot\left(r_{v+1}-r_{v}\right) \cdot\left(\frac{\Delta A_{v, v+1}}{A}\right)\right)
$$

A equação (3.12) fornece a estimativa probabilística da ameaça sísmica devido à ação de $N_{s}$ fontes sismogênicas como soma das contribuições das zonas $\Delta m$ e $\Delta r$.

\subsection{6.}

\section{Curva de ameaça sísmica}

Geralmente os resultados dos estudos de ameaça sísmica são apresentados por meio de curvas de ameaça e espectros de resposta uniformemente prováveis. As curvas de ameaça fornecem a probabilidade anual de excedência (nas ordenadas) de um determinado parâmetro do solo versus a aceleração espectral (nas abscissas), como mostra a Figura 3.5. Nesses gráficos, no caso de se desejar 
obter um determinado valor do período de retorno, basta obter a inversa deste valor e ingressá-lo no eixo das ordenadas.

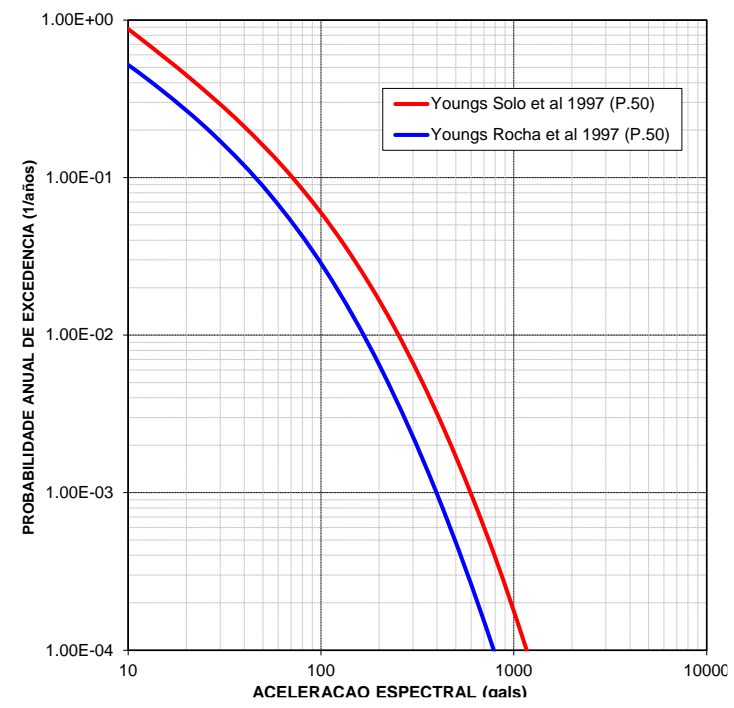

Figura 3.5 - Exemplo de curva de probabilidade de excedência.

(Fonte: Vasquez, 2015)

A partir das curvas de probabilidade de excedência obtidas para diferentes períodos estruturais é possível construir os espectros de resposta uniformemente provável (Figura 3.6), que apresentam valores com a mesma probabilidade de excedência em todos os períodos para um determinado tempo de vida útil, ou tempo de exposição, da estrutura.
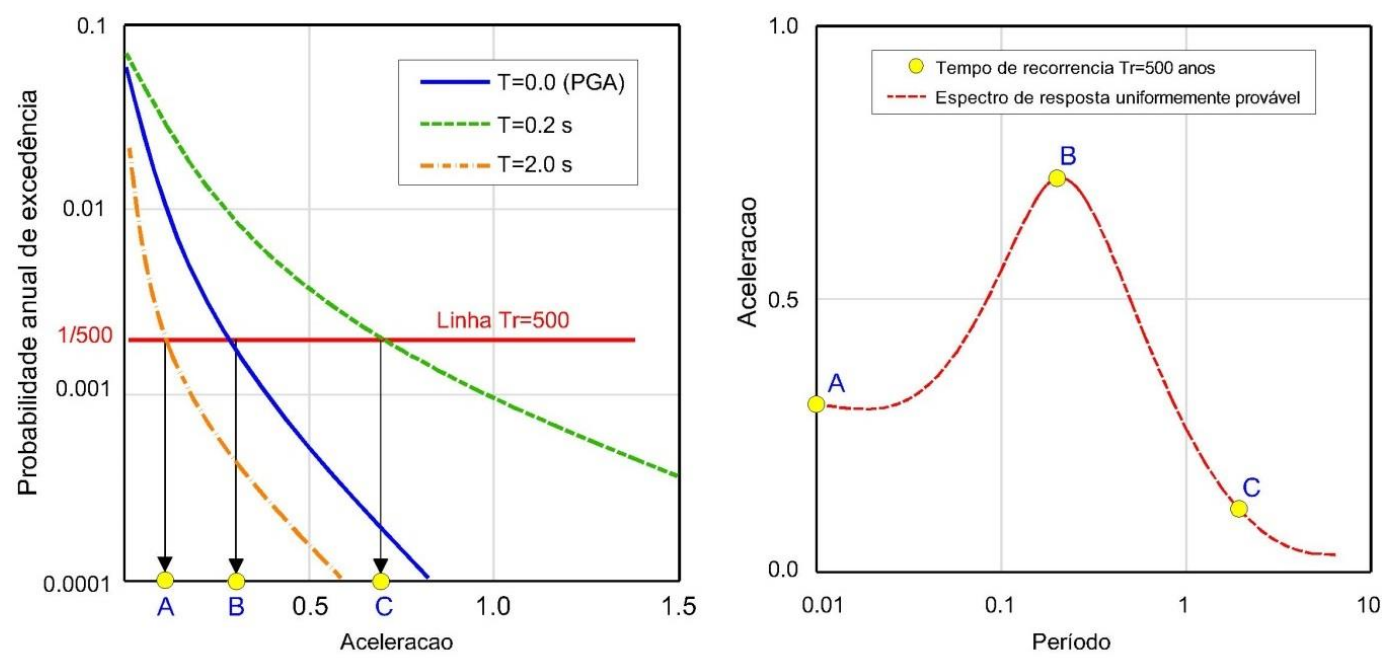

Figura 3.6 - Obtenção do espectro de resposta uniformemente provável a partir das curvas de probabilidades de excedência.

(Fonte: Vasquez, 2015) 
O espectro de resposta uniformemente provável fornece parâmetros de resposta que podem ser usados diretamente no cálculo das acelerações finais das estruturas, já que levam em conta as probabilidades de ocorrência de todos os sismos moderados próximos ao local de estudo, que tendem a produzir movimentos de alta frequência, bem como os sismos distantes de grande magnitude, que tendem a produzir movimentos de baixa frequência.

Deve ser mencionado que na prática é muito utilizado o valor do PGA (Peak Ground Acceleration - máxima aceleração do solo). Este valor é a aceleração que corresponde a um período estrutural $\mathrm{T}=0$, referente a uma estrutura infinitamente rígida, ou seja, correspondente à resposta do solo. No caso dos espectros de resposta uniformemente provável o valor do PGA é o ponto de início do espectro. Por exemplo, na Figura 3.6, o valor do PGA é a aceleração do ponto A. O valor da máxima aceleração do solo obtido de estudos de ameaça sísmica serve como parâmetro de entrada para análises de estabilidade de taludes pelo método pseudoestático, onde o coeficiente sísmico corresponde ao valor PGA normalizado em relação à aceleração da gravidade.

A consideração da ocorrência de eventos sísmicos como uma distribuição de Poisson é um modelo bastante aceito, que permite calcular a probabilidade de um número de sismos acontecer em um intervalo de tempo, desde que conhecida a taxa média de ocorrência de eventos. Uma distribuição de Poisson pressupõe as seguintes hipóteses:

- Independência - dados dois eventos sísmicos A e B, a ocorrência do evento A não é afetada pela ocorrência do evento $B$, nem pelo momento em que ele ocorre, nem pela sua magnitude, o que significa que o processo não tem memória, pois os eventos passados não afetam os eventos futuros;

- $\quad$ Estacionariedade - dado um intervalo de tempo $[t, t+\Delta t]$, a probabilidade de ocorrência de um evento em $\Delta t$ depende do número de eventos ocorridos em $[t, t+\Delta t]$ e do intervalo $\Delta t$, porém não do tempo $t$;

- $\quad$ Não-multiplicidade - a probabilidade de dois ou mais eventos ocorrerem no intervalo de tempo $\Delta t$ tende para zero à medida que o intervalo $\Delta t$ também tende para zero, o que elimina a ocorrência de eventos simultâneos (Lomnitz, 1994).

Da distribuição de Poisson resulta que a probabilidade de excedência $P(y>Y)$ em $t$ anos considerando um período de recorrência $T r$ é dada por, 


$$
P(y>Y)=1-e^{-t / T r}
$$

Por exemplo, um período de recorrência (ou período de retorno) $\operatorname{Tr}=475$ anos, tempo frequentemente utilizado em normas de construção antissísmicas, resulta uma probabilidade de excedência de $10 \%$ em $\mathrm{t}=50$ anos de vida útil da estrutura.

\section{3.}

\section{Openquake na avaliação de ameaça sísmica}

Openquake é um software de código aberto (Python e Java), lançado em 2010 para o cálculo de ameaça e de risco sísmico, desenvolvido pela Fundação GEM - Global Earthquake Model (Monelli et al., 2012; Silva et al., 2012; Crowley et al., 2013). É uma plataforma baseada na web, que oferece um ambiente integrado para modelagem, visualização, exploração e gerenciamento de ameaça e risco sísmicos. Os modelos de ameaça sísmica são atualizados de acordo com os requisitos específicos de cada programa regional de ameaça e risco sísmicos.

O Openquake é constituído por cinco módulos principais, apresentados na Tabela 3.1, com atribuições específicas:

Tabela 3.1 - Descrição dos módulos do software Openquake (Silva, 2012)

\begin{tabular}{|c|l|}
\hline Módulo & \multicolumn{1}{|c|}{ Finalidade } \\
\hline $\begin{array}{c}\text { Cenário de } \\
\text { Risco }\end{array}$ & $\begin{array}{l}\text { Estimativa de perdas, em um único cenário de terremoto para } \\
\text { um grupo de ativos (população, infraestrutura), usada na } \\
\text { elaboração de planos de gestão de situações de emergência e } \\
\text { conscientização social dos níveis de risco. }\end{array}$ \\
\hline $\begin{array}{c}\text { Avaliação } \\
\text { determinística } \\
\text { de danos }\end{array}$ & $\begin{array}{l}\text { Estimativa da distribuição de danos causados em um único } \\
\text { cenário de terremoto, para um grupo de ativos, que pode ser } \\
\text { usada para avaliar quais ativos são, sismicamente, mais }\end{array}$ \\
\hline
\end{tabular}




\begin{tabular}{|c|l|}
\hline $\begin{array}{c}\text { Avaliação } \\
\text { probabilística } \\
\text { de danos }\end{array}$ & $\begin{array}{l}\text { Estimativa da probabilidade de perdas e estatísticas de perdas } \\
\text { para um conjunto de ativos, com base na ameaça probabilística. } \\
\text { modo que perdas simultâneas para um conjunto de ativos } \\
\text { possam ser calculadas por evento. Os resultados podem ser } \\
\text { usados para avaliar as perdas esperadas para um conjunto de } \\
\text { ativos. }\end{array}$ \\
\hline $\begin{array}{c}\text { Ameaça } \\
\text { sísmica } \\
\text { probabilística } \\
\text { clássica }\end{array}$ & $\begin{array}{l}\text { Estimativa da probabilidade de perdas e estatísticas de perda } \\
\text { para ativos individuais, baseada em uma descrição } \\
\text { avaliação comparativa de risco entre ativos em diferentes locais, } \\
\text { que podem ser usados, por exemplo, para priorização dos } \\
\text { esforços de mitigação de risco. }\end{array}$ \\
\hline $\begin{array}{c}\text { Relação } \\
\text { custo - } \\
\text { benefício }\end{array}$ & $\begin{array}{l}\text { Ferramenta de apoio à decisão para verificar se a utilização de } \\
\text { medidas de adaptação ou fortalecimento de um conjunto de } \\
\text { edificações existentes é vantajosa do ponto de vista econômico. } \\
\text { Os resultados podem ser usados para estabelecer prioridades de } \\
\text { adaptação/fortalecimento ou para avaliar qual projeto sísmico é } \\
\text { economicamente o mais adequado. }\end{array}$ \\
\hline
\end{tabular}

Várias abordagens são seguidas pelo componente de ameaça do Openquakeharzard, que calcula a análise de ameaça sísmica (seismic hazard analysis, SHA). Existem três categorias básicas de análise que são:

1. Análise Probabilística Clássica de Ameaça Sísmica (Classical Probabilistic Seismic Hazard Analysis - cPSHA) baseada no tradicional método clássico de integração (Cornell, 1968; McGuire, 1976) com determinação de curvas e mapas de ameaça sísmica, como mencionado por Field et al. (2003).

2. Análise Probabilístico de Ameaça Sísmica baseada em Eventos (EventBased Probabilistic Seismic Hazard Analysis, ePSHA), que calcula os campos de movimento do solo derivados de conjuntos de eventos estocásticos.

3. Análise Determinística de Ameaça Sísmica (Deterministic Seismic Hazard Analysis - DSHA) que estima os movimentos do solo 
considerando um único cenário de evento sísmico, incorporando as incertezas aleatórias por meio de valores de desvio padrão.

Nesta dissertação, a análise probabilística clássica de ameaça sísmica (cPSHA) foi empregada.

\subsubsection{Análise Probabilística Clássica de Ameaça Sísmica (cPSHA)}

O módulo de análise probabilística clássica de ameaça sísmica fornece um conjunto de opções de cálculo, ilustrado no fluxograma da Figura 3.7:

1. Processador de árvore lógica (Logic Tree Processor - LTP): um modelo de fonte sísmica é criado pelo processador de árvore lógica, com descrição das taxas de atividade e a geometria de cada fonte sismogênica, sem consideração de incertezas epistêmicas. Em seguida, um modelo de movimento de solo é criado pelo processador da árvore lógica.

2. Previsão da Ruptura do Terremoto (Earthquake Rupture Forecast, ERF) - estima a probabilidade de ocorrência de terremoto, durante certo período de tempo, para cada fonte sismogênica.

3. Execução da análise probabilística clássica de ameaça sísmica (cPSHA) - o modelo de movimento do solo e o ERF são utilizados pelo módulo cPSHA para a determinação das curvas de ameaça sísmica em cada área especificada nas opções de cálculo.

\subsection{2.}

\section{Tipos de fontes sísmicas}

O software Openquake dispõe de quatro categorias de fontes sísmicas:

1. Fonte de área: o tipo de uso mais frequente em modelos PSHA regionais e nacionais.

2. Fonte de rede: modela sismicidade distribuída podendo substituir fontes de área.

3. Fonte de falha simples: utilizada para a descrição de fontes de falhas ativas superficiais ou corticais. 
4. Fonte de falha complexa: modelagem de fontes de interface de subducção que possuem geometria complexa.

A distribuição da sismicidade nas fontes de área e de falha simples é admitida homogênea e assume-se que os sismos seguem uma distribuição de Poisson.

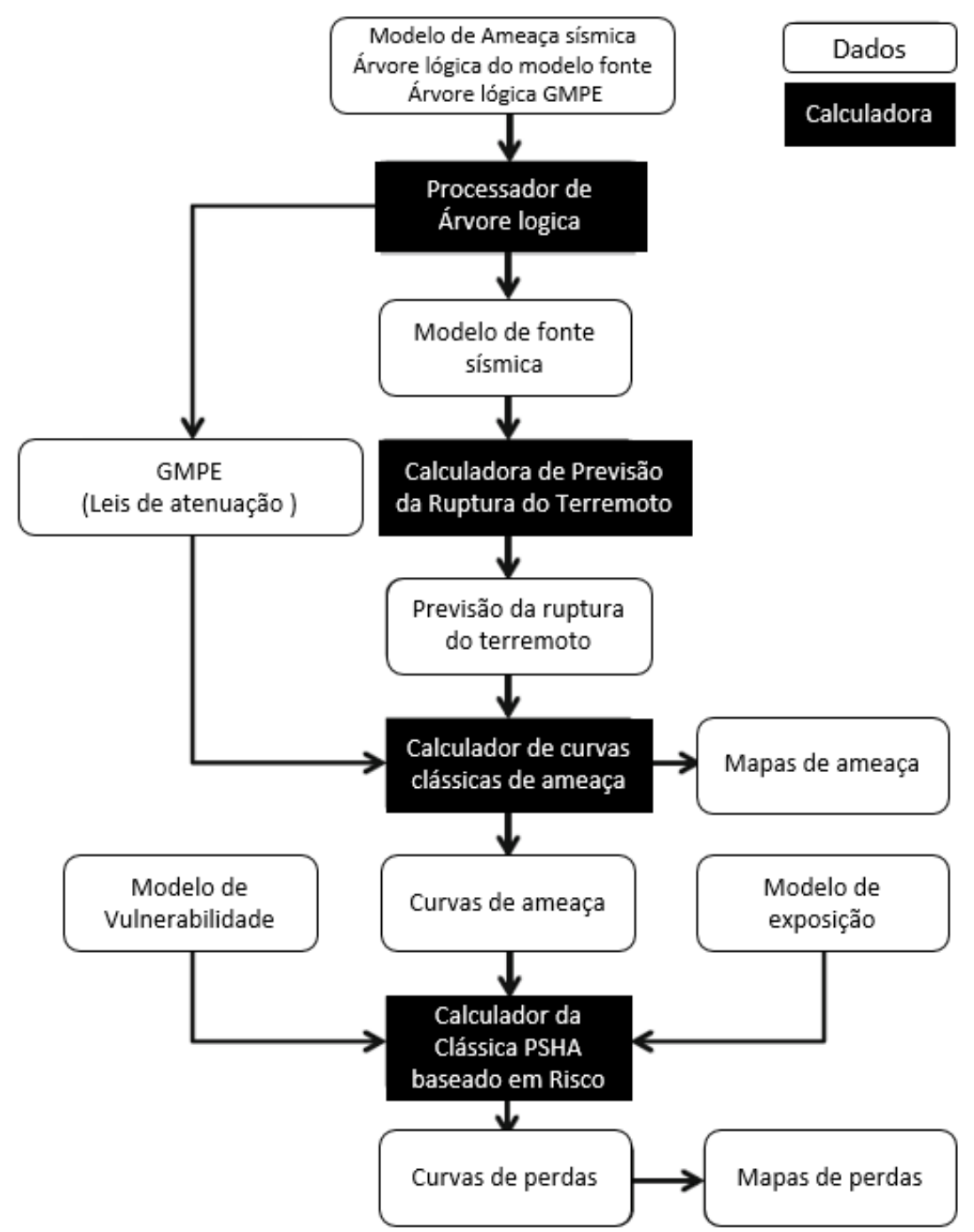

Figura 3.7 - Fluxo de cálculos na análise probabilística clássica de ameaça sísmica.

\subsection{3.}

\section{Árvores lógicas}

Duas formas de árvores lógicas existem no Openquake: a árvore lógica de fontes sísmicas (seismic source logic tree), que lida com as incertezas epistêmicas relacionadas à previsão da ruptura do terremoto, e a árvore lógica dos movimentos do solo (ground motion logic tree), que considera as incertezas relacionadas com a 
aplicação de modelos e leis de atenuação para previsão do movimento do solo (ground motion prediction equations - GMPE). Quando as incertezas epistêmicas são desprezíveis, a estrutura da árvore lógica apresenta uma ramificação.

Um fator importante a ser ressaltado nas análises com o OpenQuake é o parâmetro "a" da lei de recorrência de Gutenberg-Richter, obtido com o programa CRISIS por regressão linear no gráfico $\log (\mathrm{N})$ vs $\mathrm{M}$, onde $\mathrm{N}$ representa o número acumulado de sismos com magnitude maior ou igual a $\mathrm{M}$. No entanto, no Openquake o parâmetro "a" é determinado do gráfico Log (N/ano) vs M, onde N/ano é o número acumulado de sismos por ano com magnitude maior ou igual a M (Figura 3.8). Uma escolha equivocada deste parâmetro pode levar a uma considerável diferença nos valores previstos de ameaça sísmica.

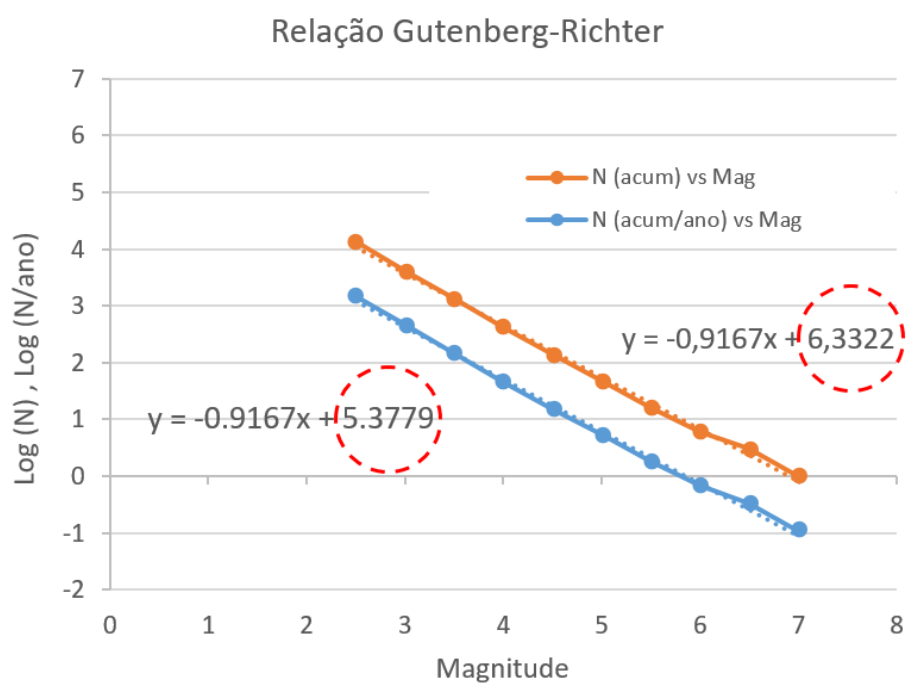

Figura 3.8 - Variação do parâmetro "a" do gráfico de recorrência sísmica para o sul da Califórnia no período 1987-1996.

\subsection{4.}

\section{Descrição de árvores lógicas}

Árvores lógicas são ferramentas com objetivo de lidar com as incertezas epistêmicas dos modelos e parâmetros considerados em análises de ameaça sísmica e de risco. Os principais componentes de uma estrutura de árvore lógica no Openquake são mostrados na Figura 3.9: 
1. Ramo (branch): componente mais simples de uma árvore, representa uma possível interpretação do valor atribuído para um tipo específico de incerteza. É descrito pela peso conferido a um parâmetro ou modelo.

2. Conjunto de ramos (branching set): agrupa um conjunto de ramos, representando interpretações alternativas de um parâmetro ou modelo. Cada conjunto de ramos é definido por um tipo de incerteza e um ou mais ramos.

3. Nível de ramificação (branching level): não é usado na modelagem de incertezas, mas é útil na manutenção de uma lógica e de uma ordem na estrutura da árvore.

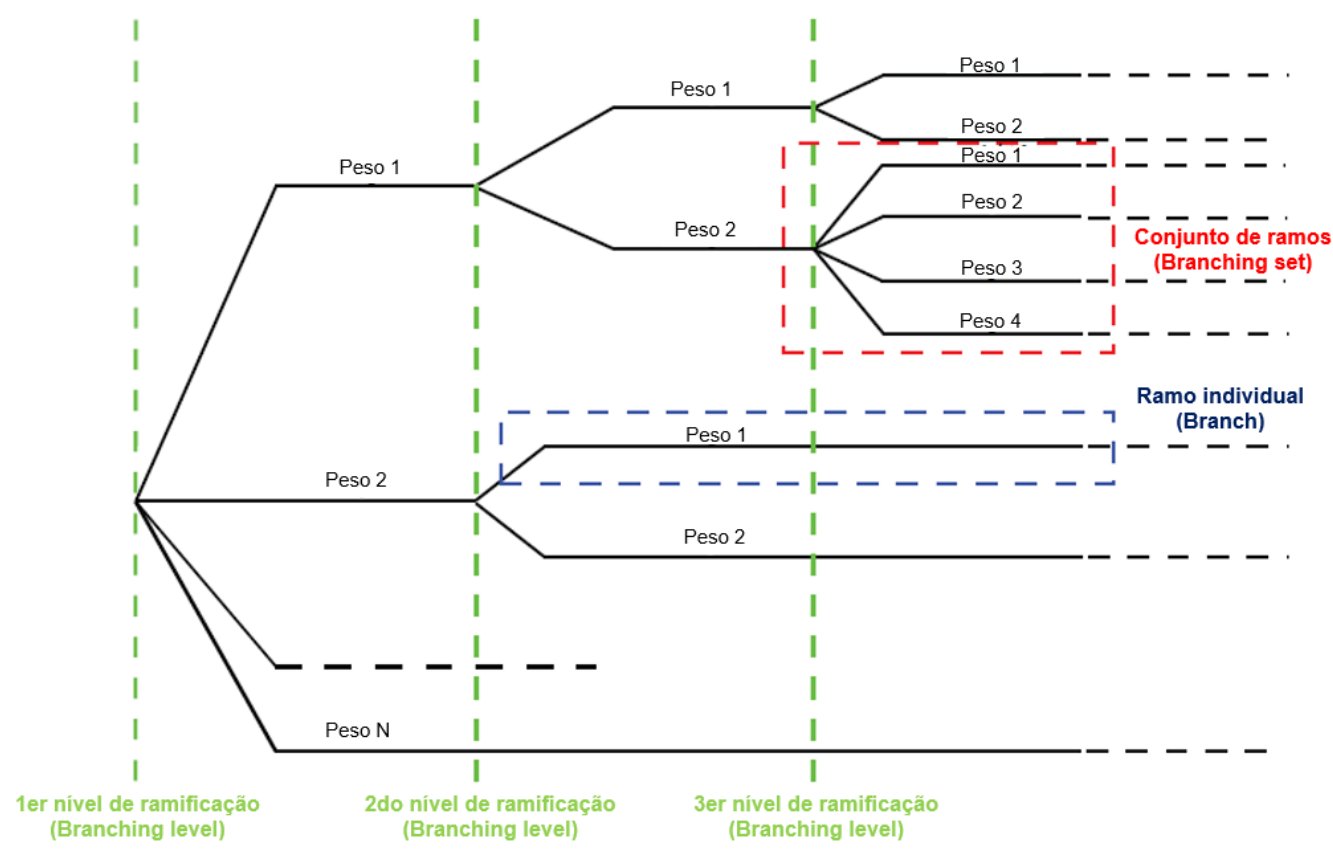

Figura 3.9 - Estrutura de uma árvore lógica - ramos individuais, conjuntos de ramificação e níveis de ramificação.

(Fonte: Crowley et al., 2011)

Um nível de ramificação identifica a posição onde ocorre ramificação enquanto um conjunto de ramos identifica uma coleção de ramos individuais cujos pesos somam 1 .

A distância de um determinado elemento, desde o início da árvore lógica, é expressa pelo nível de ramificação. Pode-se dizer que cada nível de ramificação está conectado com uma incerteza de tipo único, de modo que o número de níveis de ramificação é proporcional à sua complexidade. Um modelo de incertezas é 
descrito por um conjunto de ramos, que contém várias configurações exclusivas e exaustivas (Bommer \& Scherbaum, 2008).

\subsection{5.}

O processador da árvore lógica

A criação de um conjunto de interpretações de fonte sísmicas e de movimento do solo, que representam as combinações permitidas pela estrutura da árvore lógica definida pelo usuário, é o objetivo principal da árvore lógica de Monte Carlo (logic tree Monte Carlo sampler - LTMCS). Os resultados finais refletem as incertezas introduzidas pela falta de parâmetros acurados e de imprecisões na definição do modelo.

O LTMCS cria um modelo de fonte sísmica que processa todos os níveis de ramificação. No primeiro nível, há a seleção do modelo de fonte sísmica inicial, com uma probabilidade igual ao peso da incerteza. Para cada nível seguinte de ramificação, há uma seleção aleatória do valor de incerteza epistêmica para cada fonte sismogênica.

A árvore lógica do movimento do solo define os vários conjuntos de ramificação que incluem diferentes modelos de movimentos do solo. Segue um processo circular sobre as várias categorias de áreas tectônicas definidas pelo usuário. Para cada uma delas, há uma seleção aleatória da lei de atuação considerando seus respectivos pesos.

\subsection{6.}

\section{Cálculo da ameaça sísmica}

A estimativa de ameaça sísmica para um único sítio e em relação a um único parâmetro de movimento do solo (y) é realizada através de um processo iterativo, considerando as rupturas contidas no ERF e localizadas a uma distância de 200 a 300k do sítio de interesse. Durante cada iteração, um cálculo da probabilidade de excedência ( $y$ ) no tempo $(t)$ é feito, em relação a uma ruptura (rup) dentro da fonte $(s r c)$. A Equação 3.1 resume os procedimentos ( Crowley et al., 2011):

$$
P\left(|Y \geq y| t, \text { rup }_{\text {src }}, \text { site }\right)=P\left(\operatorname{rup}_{\text {src }} \mid t\right) P\left(Y \geq y \mid \text { rup }_{\text {src }}, \text { site }\right)
$$


O produto entre a probabilidade condicional de excedência (y) no local e a probabilidade de ocorrência no tempo t corresponde à probabilidade combinada $\mathrm{P}\left(\mathrm{Y} \geq \mathrm{y} \mid t\right.$, rup $_{s r c}$, site $)$. A probabilidade de ocorrência ligada a rup durante a criação de ERF é definida pelo símbolo P(rup src $_{t}$ ) que também pode ser escrita de forma alternativa, considerando a magnitude e o nó correspondentes dentro da fonte $(s r c)$ para cada ruptura.

$$
P\left(Y \geq y \mid t, m, \text { node }_{\text {src }}, \text { site }\right)=P(m, \text { node } \mid t) P\left(Y \geq y \mid m, \text { node }_{\text {src }} \text {, site }\right)
$$

$\mathrm{O}$ produto entre a probabilidade de excedência e a ocorrência de probabilidade de magnitude $m$ no nó (node) corresponde à probabilidade de excedência de $y$ em $t$. Esta é a interpretação da equação 3.15.

Finalmente, o valor da ameaça final em determinado sítio (site) é estimada das contribuições de todas as fontes sísmicas levadas em consideração durante o processo de criação de ERF.

$$
P(Y \geq y \mid t, \text { site })=1-\prod_{\forall \operatorname{src} \text { in } E R F}(1-P(Y \geq y \mid t, \text { src, site })
$$

Field et al. (2003) descrevem como a Equação 3.16 pode ser obtida da formulação probabilística convencional com a hipótese de que mais de uma ocorrência em cada fonte é insignificante durante o período de tempo escolhido. Assim, a Eq. 3.16 é equivalente à formulação convencional quando a probabilidade de duas ou mais ocorrências de cada fonte é efetivamente zero. Para a maioria dos resultados, como nos valores de excedência de $2 \%$ em 50 anos considerados nos mapas de ameaça sísmica dos Estados Unidos (National Hazard Maps), a diferença é insignificante de acordo com Frankel et al. (2003). Em situações onde a fonte provavelmente produza mais de um evento, a diferença pode ser importante. Como os modelos de movimento terrestre possuem componentes de incertezas epistêmicas e aleatórias, então a verificação com ambas as abordagens pode ser necessária. 


\section{4 \\ Ameaça sísmica para a barragem de rejeitos Alpamarca}

\section{1. Introdução}

O Peru está localizado na borda ocidental da placa Sul-Americana, uma das regiões mais sismicamente ativas do mundo. O processo de subducção da placa de Nazca sob a placa Sul-Americana é a principal fonte de terremotos de grande magnitude e de alto poder de destruição no território peruano, sendo portanto necessária uma compreensão adequada dos níveis de ameaça sísmica e a sua divulgação entre a comunidade de engenharia do país.

Este capítulo apresenta os resultados da ameaça sísmica na área do projeto da barragem de rejeitos Alpamarca, localizada na região de Junín. A estimativa da ameaça sísmica foi feita mediante método probabilístico e, para seu desenvolvimento, foram estabelecidas as fontes sismogênicas de subducção e de corticais com geometrias baseadas no estudo de Roncal (2017). Também foram determinados os parâmetros de sismicidade por meio do método da máxima verossimilhança (Weichert, 1980; McGuire, 2004) com auxílio de catálogo sísmico atualizado até 2016.

\section{2.}

\section{Localização da barragem de rejeitos Alpamarca}

A quantidade de rejeitos de mineração do projeto Alpamarca necessita do alteamento da barragem do nível 4670 m para o nível 4703 m acima do nível do mar. Em resposta a esta necessidade, foi encomendado um estudo para conceber o projeto de alteamento do dique da barragem para atender às solicitações do projeto localizado na província peruana de Yauli (Figura 4.1, nas coordenadas $11,21^{\circ}$ de latitude Sul e $76,46^{\circ}$ de longitude Oeste). 


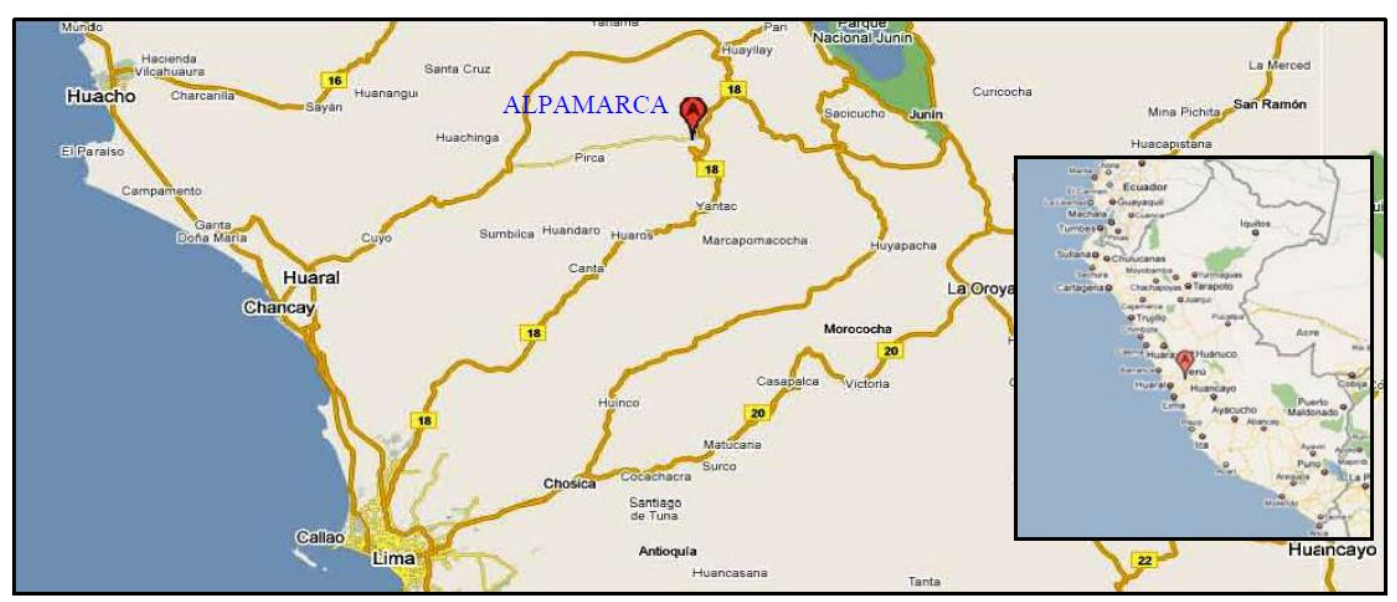

Figura 4.1 - Localização da barragem Alpamarca na região de Junin, província de Yauli, Peru.

\section{3.}

\section{Programa de ensaios de campo}

Durante os anos de 2009 até 2011 foi executado um programa de ensaios de campo com o propósito de obter informações geológicas, geotécnicas e hidrológicas para o desenvolvimento inicial do projeto. Durante 2012 foi construída a primeira fase do projeto e, posteriormente, em 2014, foi realizado o alteamento do dique da cota 4660m até a cota 4664m. Em 2015, um novo alteamento elevou o dique até a cota atual situada 4670m acima do nível do mar.

Um novo programa de ensaios de campo e de laboratório foi feito para o projeto de alteamento da cota atual $4670 \mathrm{~m}$ para a cota projetada $4703 \mathrm{~m}$, um alteamento do dique da barragem de $33 \mathrm{~m}$.

- Levantamento geológico local e medições geomecânicas;

- Escavação de poços de exploração e trincheiras;

- Execução de sondagens rotativas com ensaios de permeabilidade e ensaios de simples reconhecimento (SPT);

- Ensaios de refração sísmica;

- Estudo de canteiros e material de empréstimo para o corpo de alteamento do dique.

As sondagens rotativas realizadas atingiram profundidades entre $15 \mathrm{~m}$ e $70 \mathrm{~m}$ com recuperação das amostras de solo e rocha. Com base nestes ensaios constatou-se que o solo de fundação e formado principalmente por rocha marga (calcário com alto teor de argila) de origem sedimentar. 


\section{4.}

\section{Características gerais do projeto}

$\mathrm{O}$ alteamento da barragem foi projetado a partir do dique atual, composto por desmonte de mineração (nível $4670 \mathrm{~m}$ ) até o alteamento final (4703m), que será realizado em 10 camadas de desmonte de mineração. As configurações atual e projetada apresentam as seguintes características geométricas:

\section{Condições atuais (Figura 4.2)}

- Largura da crista: $6 \mathrm{~m}$

- Talude à montante: $1 \mathrm{~V}: 1,5 \mathrm{H}$

- Talude à jusante: $1 \mathrm{~V}: 2,0 \mathrm{H}$

- Altitude da crista: 4670 m acima do nível do mar

- Material: desmonte de mineração (GC-GP)

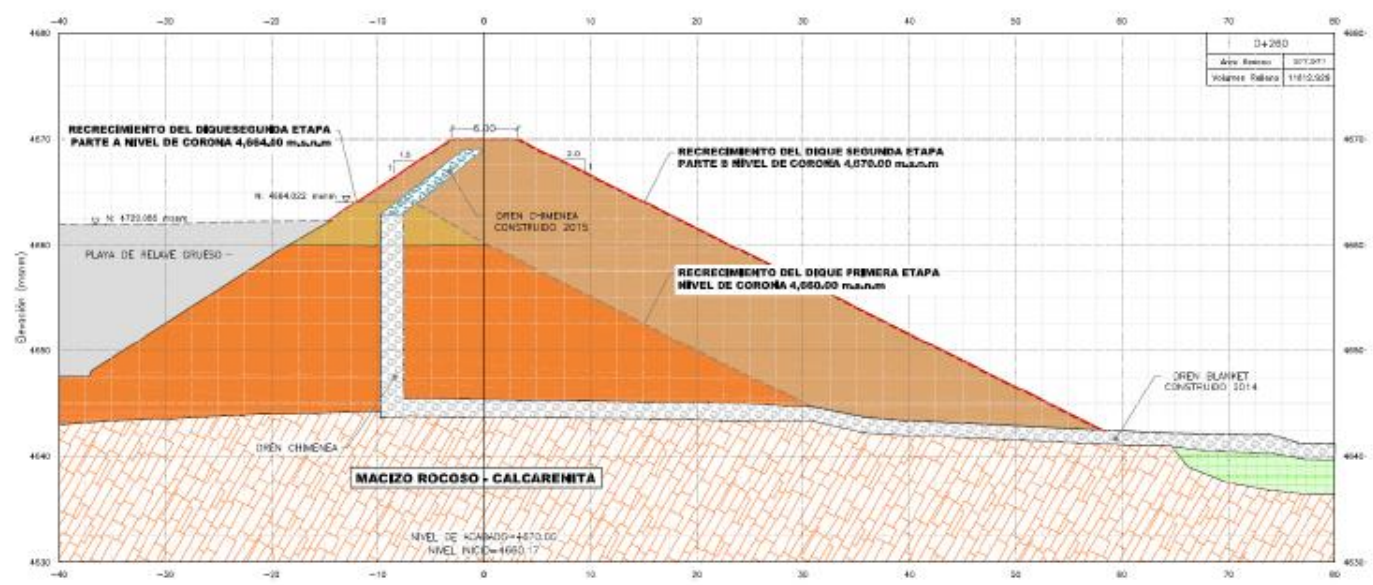

Figura 4.2 - Geometria atual da barragem de rejeitos Alpamarca.

\section{Condições finais (na etapa 10) (Figura 4.3)}

- Largura da crista: $8 \mathrm{~m}$

- Bordo livre: $2 \mathrm{~m}$

- Talude à montante: $1 \mathrm{~V}: 1,5 \mathrm{H}$

- Talude à jusante: $1 \mathrm{~V}: 2,0 \mathrm{H}$

- Altitude da crista: 4703 m acima do nível do mar

- Altitude do armazenamento: $4701 \mathrm{~m}$ acima do nível do mar

- Material: desmonte de mineração (GC-GP) 


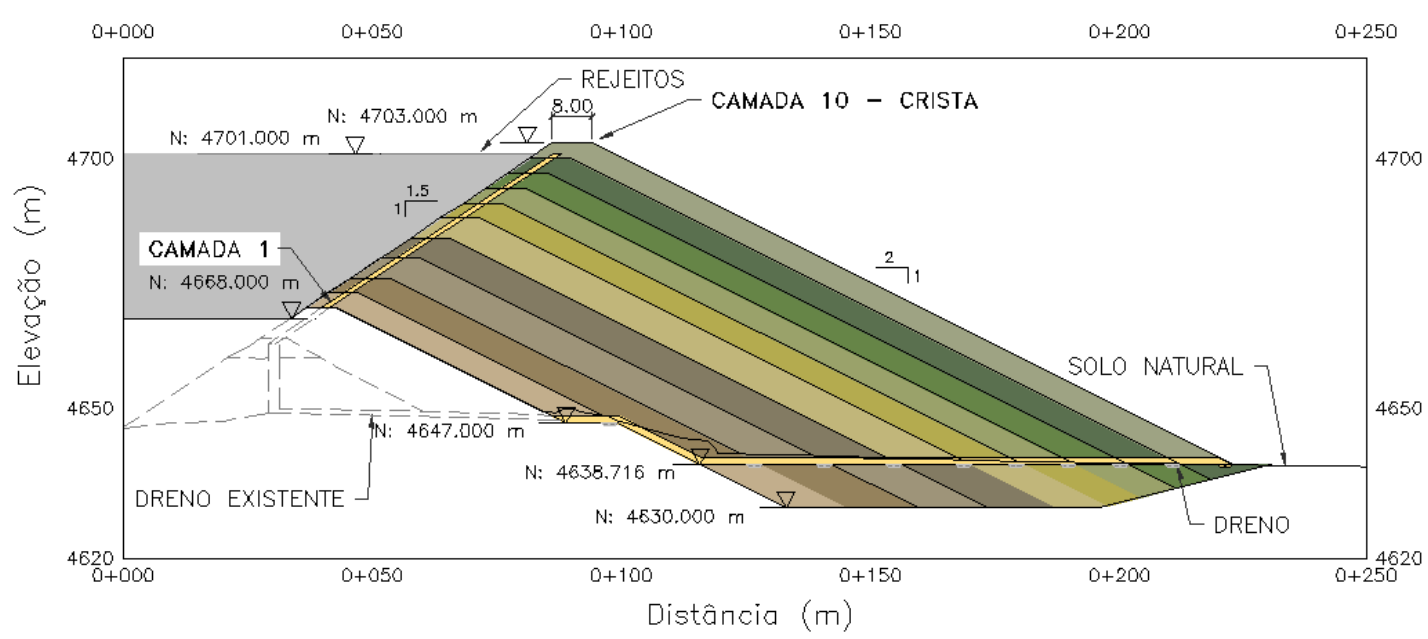

Figura 4.3 - Geometria final do alteamento da barragem de rejeitos Alpamarca.

Com referência ao tipo de solo de fundação existente na área do projeto, os resultados da exploração geotécnica mostraram que o solo de fundação é formado por um Maciço rochoso fraturado. Até esta profundidade máxima (20 m) depois foi detectado um embasamento rochoso não fraturado ou levemente fraturado.

\section{5.}

\section{Características tectônicas}

O processo de subducção da placa de Nazca sob a placa Sul-Americana gera deformações constantes no continente, criando terremotos corticais ao longo da Cordilheira dos Andes. Essa interação constante entre ambas as placas gera deformações e tensões na crosta terrestre, dando origem a várias características tectônicas no território do Peru:

Dorsal de Nazca - é uma antiga cordilheira oceânica observada no fundo do mar, localizada na região sul do Peru, que colide com a placa Sul-Americana, com grande influência na constituição tectônica da parte ocidental. Tem direção NESW perpendicular à linha da trincheira Peru-Chile nas latitudes entre $15^{\circ} \mathrm{S}$ e $24^{\circ}$ $\mathrm{S}$, de modo a que a sua extremidade nordeste está localizada em frente ao departamento de Ica, onde tem uma largura de aproximadamente $220 \mathrm{~km}$ acima da elevação de 2000 m. Sua largura e altitude diminuem gradualmente em direção à extremidade sudoeste. A elevação de $2000 \mathrm{~m}$ da crista está localizada a $50 \mathrm{~km}$ da linha da trincheira, enquanto as elevações mais baixas já subduziram sob a placa continental (Sébrier et al., 1985). Estudos sobre anomalias magnéticas permitem 
considerar a hipótese de que a Dorsal de Nazca deve sua origem a uma antiga zona de criação de crosta que cessou sua atividade acerca de 5 a 10 milhões de anos (Udias e Mezcua, 1997, Marocco, 1980, Sébrier et al. 1985).

Dorsal de Sarmiento e Dorsal de Alvarado - ambas localizadas em frente ao departamento de Piura com uma orientação nordeste e um comprimento aproximado de $400 \mathrm{~km}$ com eixos paralelos entre si. São compostas por lavas tipo basalto toleítico ao alcalino (Castillo e Lonsdale, 2004).

Fratura de Mendaña - localizada no extremo oeste da região central do Peru entre as latitudes $11^{\circ} \mathrm{S}$ e $15^{\circ} \mathrm{S}$. Exibem orientação NE-SW, perpendicular à linha da trincheira peruana-chilena, com um comprimento aproximado de 1100 $\mathrm{km}$, altura média de $1000 \mathrm{~m}$ acima da crosta oceânica e largura aproximada de 80 $\mathrm{km}$. Sua origem está associada a uma antiga zona de divergência entre as placas de Nazca e Sul-Americana (Yamano e Uyeda, 1990).

Fratura de Nazca - localizada em frente ao departamento de Arequipa, ao lado da fratura de Mendaña. Está alinhada na direção NE-SW, perpendicular à trincheira Peru-Chile, com alturas da ordem de $700 \mathrm{~m}$ acima da superfície e profundidades de até 300 metros. (Robinson et al., 2006).

Fratura de Virú - localizada paralelamente à fratura de Mendaña, distanciada $110 \mathrm{~km}$ ao norte. Trata-se de uma falha inversa com orientação $\mathrm{N} 15^{\circ} \mathrm{S}$ (Krabbenhoft et al., 2004).

Depressão de Trujillo - estrutura com largura aproximada de $5 \mathrm{~km}$ no ponto mais alto e $500 \mathrm{~m}$ no mais baixo, com superfície muito acidentada, de 270 km de extensão.

Cadeia Vulcânica - localizada ao sul da cordilheira Ocidental, composta por diferentes vulcões: Coropuna (6425 msnm), Sabancaya (5795 msnm), Misti (5825 msnm), Ubinas (5672 msnm), Huaynaputina (4800 msnm), dentre outros. A cadeia vulcânica só está presente no sul do país, devido ao fato de que o processo de subducção ocorre com maior inclinação nesta região em comparação com a inclinação na qual a placa de Nazca subduz nas regiões central e norte do país.

Cordilheira Andina - distribuída paralelamente ao longo da borda oeste da América do Sul, formada em diferentes processos orogênicos, devido aos constantes esforços de compressão que existem entre as placas Nazca e SulAmericana. No Peru, a cordilheira apresenta duas deflexões, a primeira na latitude $5^{\circ} \mathrm{S}$, chamada deflexão de Huancabamba, e a segunda na latitude $14^{\circ} \mathrm{S}$, na 
deflexão de Abancay. Essas deflexões mudam parcialmente a orientação da cordilheira nas direções NE-SW e E-W, respectivamente (Marocco, 1980, Tavera e Buforn, 1998).

Falhas no Peu - resultado do processo de deformação contínua da crosta continental que gera uma distribuição heterogênea de esforços de tração e compressão. Atualmente, foram identificadas 57 falhas ativas de origem no Quaternário de acordo com o INGEMMET - Instituto Geológico Minero y Metalúrgico do Peru.

Na Figura 4.4, é apresentado o mapa do Peru mostrando os diversos traços das características tectónicas anteriormente mencionadas.

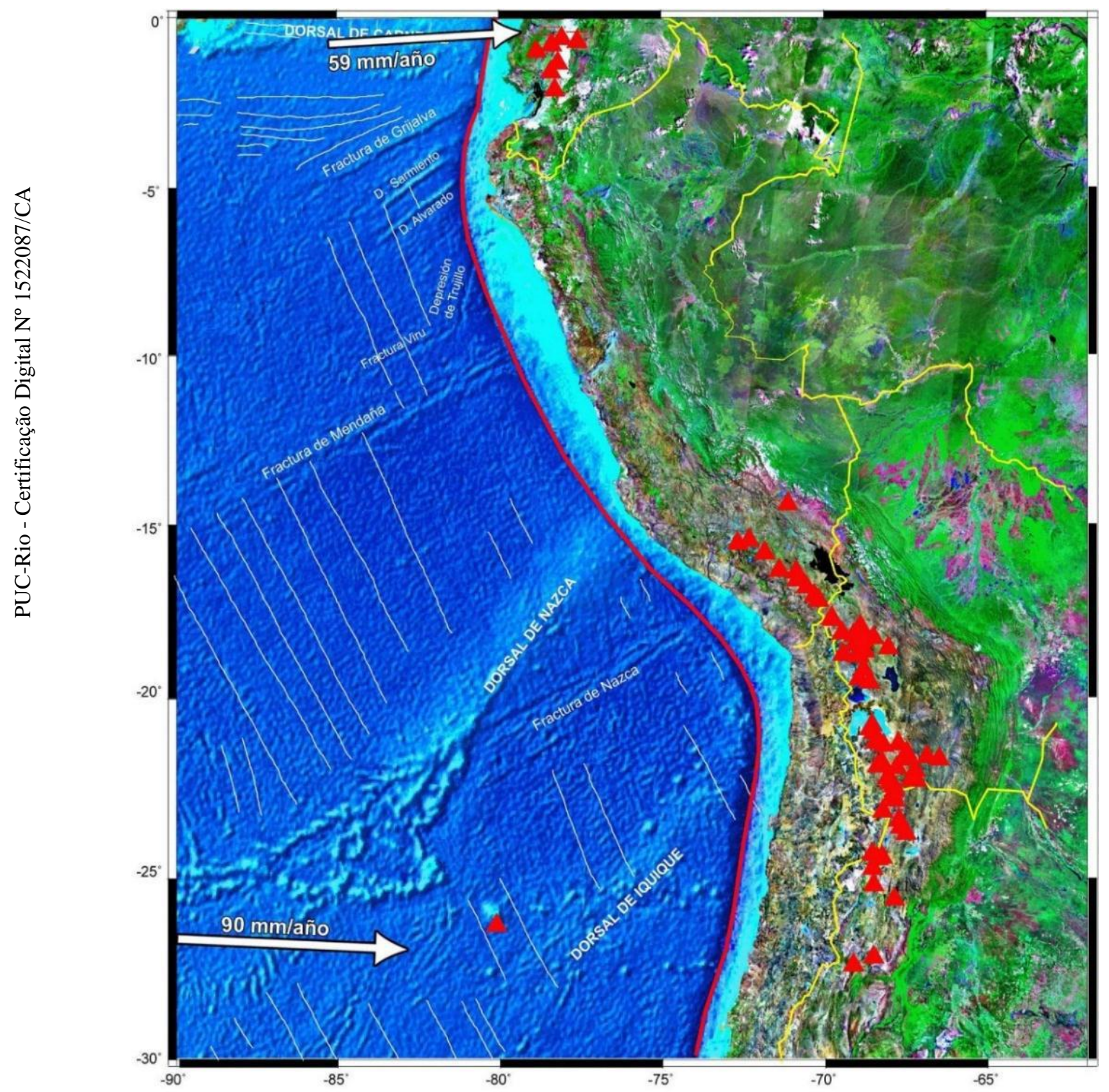

Figura 4.4 - Configuração da Placa de Nazca.

(Fonte: Roncal, 2017) 


\section{6.}

\section{Sismicidade da área de influência}

\subsection{1.}

\section{Catálogos sísmicos}

Para a identificação e determinação dos parâmetros de sismicidade das fontes sismogênicas locais é necessário compilar adequadamente informações disponíveis em catálogos sísmicos. Para o caso da presente investigação, a coleta de dados foi agrupada em três períodos de registro de dados sismológicos:

- Antes de 1900- dados históricos descritivos;

- 1900 - 1963 - dados instrumentais aproximados;

- 1963 - 2016 - dados instrumentais precisos.

As informações sísmicas no Peru (Figura 4.5) foram obtidas dos seguintes catálogos sísmicos:

- Instituto Geofísico do Peru (IGP) - versão revisada do Catálogo Sísmico do Projeto SISRA - 1982 (Sismicidade da Região Andina) entre os anos 1471 - 1982 e atualizado pelo IGP para o período de 1982 - 2001.

- Instituto Geofísico do Peru (IGP) - Catálogo Sísmico do Peru compilado de 1555 até primeiro de janeiro de 2016, com eventos ilustrados na Figura 4.5 (Roncal, 2017);

- Catálogos da National Earthquake Information Center (NEIC), International Seismological Center (ISC), United States Geological Survey (USGS), National Oceanic and Atmospheric Administration (NOAA) e Global Centroid Moment Tensor (Global CMT). 


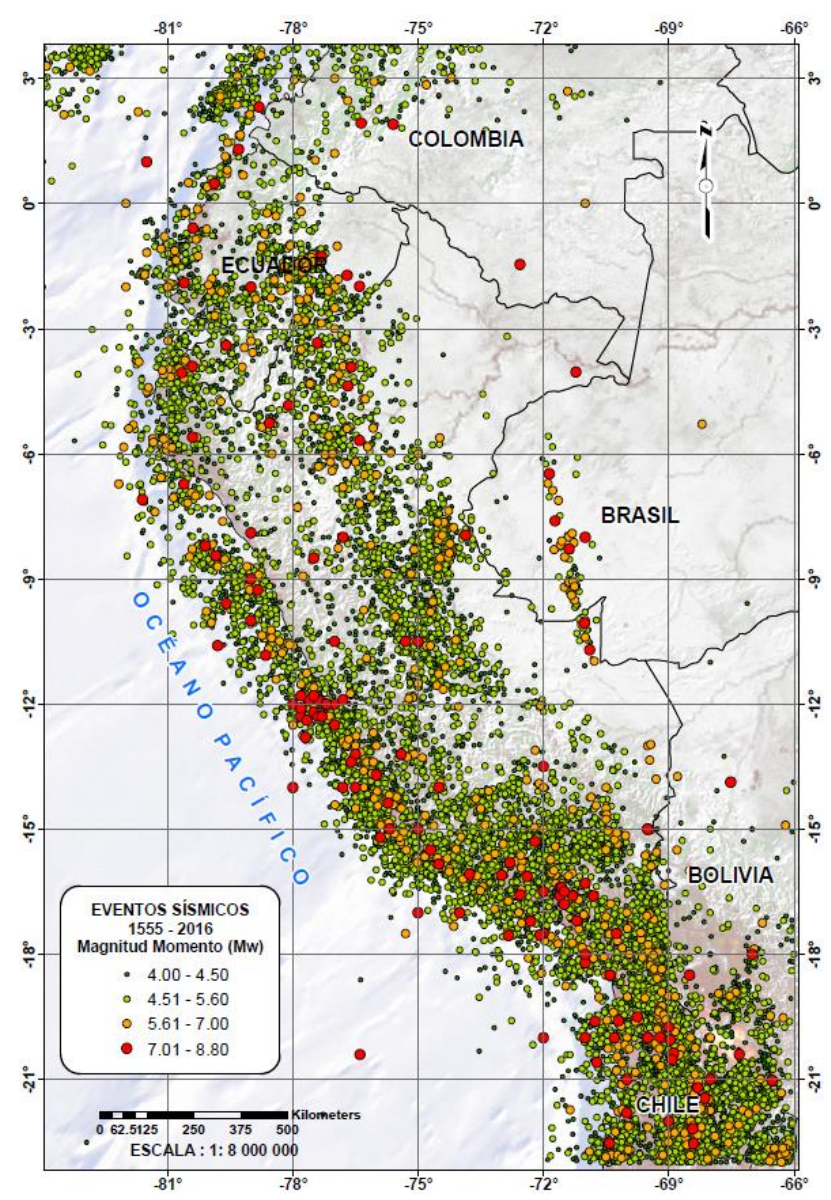

Figura 4.5 - Fontes sismogênicas de subducção e corticais no Peru. (Fonte: Roncal, 2017)

\subsection{2 \\ Fontes sismogênicas}

Neste trabalho, a determinação das fontes sismogênicas foi baseada no mapa de distribuição de epicentros e nas características tectônicas da área de influência ao redor do sítio da barragem. Enquanto as fontes de subducção modelam a interação das placas Sul-americana e de Nazca, as fontes corticais estão relacionadas com a atividade sísmica superficial andina.

$\mathrm{Na}$ presente investigação foram estabelecidas 29 fontes sismogênicas de subducção e corticais, baseadas na pesquisa de Roncal (2017), que realizou uma revisão da sismotectônica do Peru com compilação dos dados sísmicos disponíveis até o ano de 2016. As fontes sismogênicas foram classificados em nove fontes sismogênicas de subducção, nas quais os mecanismos de interface (F1, F2, F3, F4, F5 e F6) e de intraplaca (F7, F8, F9, F10, F11, F12, F13, F14, 
F15, F16, F17, F18, F19 e F20) foram diferenciados, e nove fontes sísmicas continentais (F21, F22, F23, F24, F25, F26, F27, F28 e F29).

A Figura 4.6 mostra as fontes sismogênicas de subducção delimitadas por um raio de $350 \mathrm{~km}$ a partir do local do projeto da barragem Alpamarca, incluindo fontes de interface (F3 e F4), de intraplaca superficial e intraplaca intermediária (F9, F10, F13, F14, F15, F16 e F18) e de crosta ou continentais (F22, F23 e F28). As coordenadas geográficas destas fontes estão apresentadas no Anexo 1.

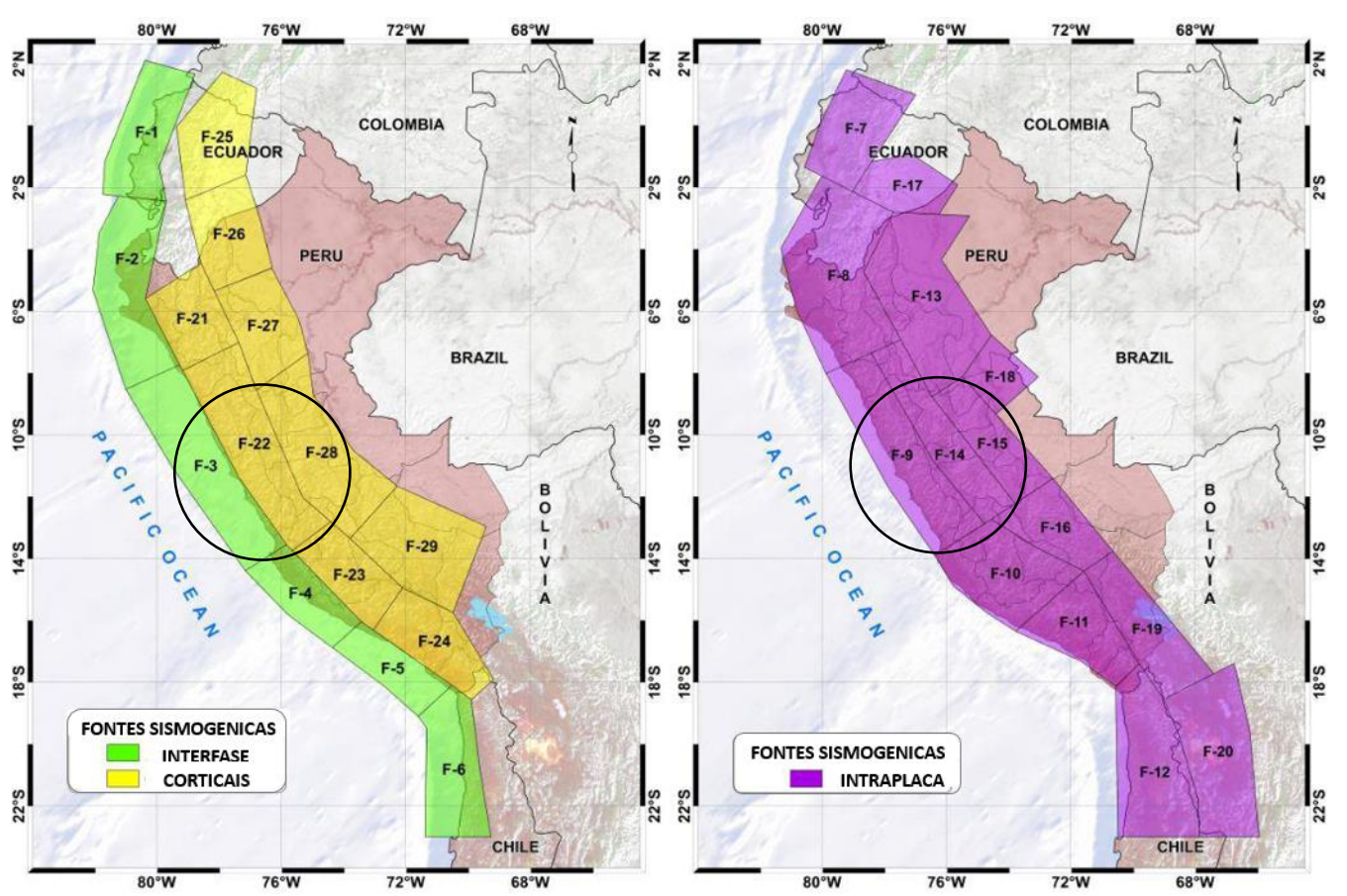

Figura 4.6 - Fontes sismogênicas de subducção e corticais definidas por Aguilar (2017).

\subsection{3.}

\section{Parâmetros de sismicidade local}

Além da depuração do catálogo sísmico do projeto, deve-se levar em consideração que há uma perda da qualidade da informação à medida que se recua no tempo (Climent et al, 2008). Este fato é chamado de falta de completude do banco de dados e influi no processo de cálculo dos parâmetros de sismicidade local. Uma verificação deve ser feita em relação ao tempo necessário para que determinado intervalo de magnitude possa ser considerado completo e adequadamente representado no catálogo.

O valor "b" da lei de recorrência de Gutenberg-Richter (Eq. 3.1) pode ser determinado por dois métodos: o método de mínimos quadrados ou o método de 
máxima verossimilhança. O método de mínimos quadrados ajusta os valores com base na quantidade de dados; portanto, se houver poucos sismos de grande magnitude, a influência destes na soma dos quadrados dos desvios será desproporcional.

O método dos mínimos quadrados deve ser evitado nos casos em que se deseja ajustar os dados de uma distribuição cumulativa, como no caso da relação de Gutenberg-Ritcher, porque pode levar a estimativas instáveis dos valores da amostra (Vere -Jones, Yosihiko 2003).

O método de máxima verossimilhança realiza o ajuste em relação ao valor médio mais provável da amostra, em função de valores atribuídos e pesos de magnitude mínima e máxima. Além disso, como a formulação é baseada em uma função de densidade de probabilidade, sua utilização representa mais fielmente um processo de amostragem do que o método dos mínimos quadrados.

Para o cálculo da taxa $\mathrm{T}$, número acumulado de sismos que excedem a magnitude mínima. Os períodos de completude do catálogo sísmico foram determinados por intervalos de magnitude. Desta forma, verificou-se que o catálogo sísmico está completo para terremotos de várias magnitudes, como mostra a Tabela 4.1.

Tabela 4.1 - Anos de completude do catálogo sísmico.

\begin{tabular}{|l|c|c|c|c|c|}
\hline Magnitude $(\mathrm{Mw})$ & $\leq 5,0$ & $5,1-6,0$ & $6,1-7,0$ & $7,1-8,0$ & $\geq 8,1$ \\
\hline Ano de Referência & 1964 & 1960 & 1954 & 1906 & 1555 \\
\hline
\end{tabular}

Finalmente, a caracterização das fontes sismogênicas foi feita mediante cálculo de seus parâmetros sismológicos, assumindo o modelo exponencial truncado de Gutenberg-Richter, que representa a distribuição magnitude versus número acumulado de sismos, e o modelo de tempo de recorrência de Poisson. Os valores de $\beta$ e T da distribuição exponencial foram calculados utilizando o método da máxima verossimilhança, com o valor de mo, correspondente à magnitude mínima, obtido pelo método de máxima curvatura (Wiemer et al,1999; Wiemer et al, 2000). A magnitude máxima foi assumida igual à maior magnitude histórica associada com a fonte sismogênica.

$\mathrm{Na}$ Tabela 4.2 são apresentados os parâmetros de sismicidade local estimados para as diversas fontes sismogênicas consideradas na presente análise. No Apêndice 1 são encontradas as respectivas planilhas de cálculo. 
Tabela 4.2 - Parâmetros de sismicidade local

\begin{tabular}{|c|c|c|c|c|c|c|}
\hline \multirow{2}{*}{ Fonte } & \multicolumn{6}{|c|}{ Mw } \\
\cline { 2 - 7 } & mo & Mu & $\beta$ & $\mathrm{T}$ & $\mathrm{a}$ & $\mathrm{b}$ \\
\hline F3 & 4,8 & 8,4 & 1,732 & 3,98 & 3,25 & 0,74 \\
\hline F4 & 4,4 & 8,4 & 1,73 & 6,62 & 3,19 & 0,75 \\
\hline F9 & 4,5 & 7,3 & 2,040 & 6,47 & 4,59 & 0,86 \\
\hline F10 & 4,5 & 7 & 1,805 & 6,57 & 4,27 & 0,77 \\
\hline F13 & 4,3 & 7,4 & 1,491 & 3,71 & 3,04 & 0,65 \\
\hline F14 & 4,2 & 6,6 & 1,28 & 2,07 & 2,58 & 0,55 \\
\hline F15 & 4,6 & 6 & 2,334 & 2,52 & 5,04 & 1,01 \\
\hline F16 & 4,1 & 6,9 & 1,307 & 1,25 & 2,28 & 0,59 \\
\hline F18 & 4,8 & 7,1 & 2,413 & 3,13 & 5,21 & 1,04 \\
\hline F22 & 4,1 & 7,2 & 1,068 & 1,32 & 1,7 & 0,46 \\
\hline F23 & 4,5 & 7 & 1,384 & 0,675 & 2,17 & 0,52 \\
\hline F28 & 4,5 & 7 & 1,667 & 2,85 & 3,4 & 0,72 \\
\hline
\end{tabular}

\subsection{4.}

\section{Leis de atenuação (GMPE)}

Uma vez determinados os parâmetros das fontes sísmicas, é necessário avaliar os efeitos que cada terremoto produzirá no sítio de interesse por meio de leis de atenuação das ondas sísmicas.

As equações de previsão do movimento do solo (Ground Motion Predicion Equations - GMPE), também conhecidas como leis de atenuação, podem assumir várias formas. Para estimar a ameaça sísmica no território do Peru, foram estudadas as leis de atenuação de Youngs et al. (1997), Zhao et al. (2006) e BC Hydro (Abrahamson et al., 2016), que diferenciam os mecanismos focais para terremotos de subducção de interface e de intraplaca, e as leis de tenuação propostas por Sadigh et al. (1997), Chiou \& Youngs (2014), Campbell \& Bozorgnia (2014) e Abrahamson et al. (2014-2015), para terremotos continentais ou de crosta terrestre.

\subsubsection{1.}

\section{Lei de atenuação de Youngs et al (1997)}

Youngs et al. (1997) desenvolveram leis de atenuação para regiões de terremotos de interface e de intraplaca, utilizando dados sísmicos registrados no Alasca, Chile,Japão, México, Peru (14 registros) e nas ilhas Salomão, para distâncias entre 10 e $500 \mathrm{~km}$, levando em consideração as características 
regionais. A aplicação desta relação de atenuação é apropriada para terremotos de magnitude 5 ou superior.

Aqueles autores definiram as características geológicas regionais em três grupos: rocha, solo rígido pouco profundo e solo rígido profundo, considerando eventos em rocha para todos aqueles com velocidade de onda $S$ próximas a 750 $\mathrm{m} / \mathrm{s}$, eventos em solo profundo com profundidade de rocha superior a $20 \mathrm{~m}$, com velocidades de ondas $S$ entre 180 e $360 \mathrm{~m} / \mathrm{s}$, e eventos em solo superficial, para profundidades de rocha inferior a $20 \mathrm{~m}$.

A relação de atenuação proposta por Youngs et al. (1997) para rocha, conforme equação 4.1, incluem amortecimento de $5 \%$.

$\operatorname{Ln}(S a)=0.2418+1.414 M+C_{1}+C_{2}(10-M)^{3}+C_{3} \operatorname{Ln}\left(r_{\text {rup }}+1.7818 * e^{0.554 M}\right)+0.00607 H+0.3846 Z t$

onde Sa é a aceleração espectral (g), M a magnitude de momento Mw, $\mathrm{C}_{1}, \mathrm{C}_{2}, \mathrm{C}_{3}$ são coeficientes espectrais, $\mathrm{r}_{\text {rup }}$ a distância mais próxima à área de ruptura $(\mathrm{km}), \mathrm{H}$ a profundidade focal $(\mathrm{km})$ e $\mathrm{Z}_{\mathrm{t}}$ é 0 para sismos de interface e igual a 1 para eventos de intraplaca.

\subsubsection{2.}

\section{Lei de atenuação de Zhao et al. (2006)}

Zhao et al. (2006) propuseram uma lei de atenuação para as regiões de subducção de terremotos de interface e intraplaca, utilizando dados de terremotos registrados basicamente no Japão (até 2003), Irã e na costa ocidental dos Estados Unidos, com um total de 4726 terremotos de subducção da crosta superficial, de interface e de intraplaca.

Usaram cinco classificações de sítios, classificados como SC, I, II, III e IV, correspondendo a quatro classes de materiais: rocha dura, rocha, solo compacto, solo medianamente compacto e solo fofo, conforme Molas \& Yamazaki (1995). Os eventos de rocha foram considerados para todos aqueles com velocidade de onda $\mathrm{S}$ superior a $600 \mathrm{~m} / \mathrm{s}$, eventos em solos compacto com velocidade entre 300 $\mathrm{m} / \mathrm{s}$ e $600 \mathrm{~m} / \mathrm{s}$, em solos medianamente compactos com velocidade entre $200 \mathrm{~m} / \mathrm{s}$ $300 \mathrm{~m} / \mathrm{s}$ e eventos em solos fofos com velocidade de onda $\mathrm{S}$ inferior a $200 \mathrm{~m} / \mathrm{s}$. 
$\log _{e}\left(y_{i, j}\right)=a M_{w i}+b x_{i, j}-\log _{e}\left(r_{i, j}\right)+e\left(h-h_{c}\right) \delta_{h}+F_{R}+S_{I}-S_{S}+S_{S L} \log _{e}\left(x_{i, j}\right)+C_{k}$ $+\xi_{i, j}+\eta_{i}$

com

$$
r_{i, j}=x_{i, j}+c \exp \left(d M_{w i}\right)
$$

onde y é a aceleração espectral $\left(\mathrm{cm} / \mathrm{s}^{2}\right)$, a,b,c,d são coeficientes calculados por meio de regressão linear, $M$ representa a magnitude de momento, $x$ a distância mais próxima à área de ruptura $(\mathrm{km}), \mathrm{h}$ a profundidade focal $(\mathrm{km}), \mathrm{F}_{\mathrm{R}}$ um fator de falhas reversas (fontes corticais), $S_{I}$ um fator para sismos de interface, $S_{S}$ um fator para sismos de intraplaca, $\mathrm{S}_{\mathrm{SL}} \mathrm{um}$ fator independente da magnitude dos terremotos que leva a uma modificação no caso de eventos de intraplaca e $C_{k}$ um fator dependente do tipo de solo. Na presente investigação, a lei de atenuação de Zhao al. (2006) foi utilizada considerando solo B (rocha SC I com Ck = C1). Nas equações 4.2 e 4.3 o subscrito $\mathrm{i}$ indica o número do evento e $\mathrm{j}$ o número do registro do evento $\mathrm{i}$.

\subsubsection{3. Lei de atenuação BC Hydro (Abrahamson 2015)}

Em 2007, a BC Hydro, principal proprietária de barragens na Colúmbia Britânica, Canadá, iniciou uma atualização da avaliação de ameaça sísmica nas áreas de barragens. Uma questão chave foi o movimento de terremotos na zona de subducção de Cascadia, Canadá. Novas equações de previsão do movimento (GMPE) foram desenvolvidas por Abrahamson et al. (2015).

Os dados iniciais de movimento foram retirados de Atkinson e Boore (2003, 2008), que incluem uma compilação referente às leis de atenuação de Crouse et al. (1988), Crouse (1991) e Youngs et al. (1997). Adicionalmente, foram consideradas informações sobre movimentos de solo provocados por terremotos de subducção ocorridos no Japão (Zhao, 2008), Taiwan (Cheng, 2008), América do Sul e América Central (Pacific Engineering, 2008) e México (MacíasCarrasco, 2008). 


$$
\begin{aligned}
& \operatorname{In}\left(S a_{\text {Interface }}\right)=\theta_{1}+\theta_{4} \Delta C_{1}+\left(\theta_{2}+\theta_{3}(M-7,8)\right) \operatorname{In}\left(R_{\text {rup }}+C_{4} \exp \left(\theta_{9}(M-6)\right)\right)+\theta_{6} R_{\text {rup }} \\
& +f_{\text {mag }}(M)+f_{\text {FABA }}\left(R_{\text {rup }}\right)+f_{\text {site }}\left(P G A_{1100}, V s_{30}\right)
\end{aligned}
$$

$\operatorname{In}\left(\operatorname{Sa}_{\text {Intraplaca }}\right)=\theta_{1}+\theta_{4} \Delta C_{1}+\left(\theta_{2}+\theta_{14} F_{\text {event }}+\theta_{3}(M-7,8)\right) \operatorname{In}\left(R_{\text {hypo }}+C_{4} \exp \left(\theta_{9}(M-6)\right)\right)$

$+\theta_{6} R_{\text {hypo }}+\theta_{10} F_{\text {event }}+f_{\text {mag }}(M)+f_{\text {depth }}\left(Z_{h}\right)+f_{\text {FABA }}\left(R_{\text {hypo }}\right)+f_{\text {site }}\left(P G A_{1100}, V s_{30}\right)$

onde y Sa representa a aceleração espectral (g), M a magnitude de momento, $\mathrm{Zh}$ a profundidade hipocentral $(\mathrm{km}), \mathrm{F}_{\text {event }}$ é considerado zero para eventos de interface e 1 para eventos de intraplaca, FFABA depende da localização do evento o em relação ao arco vulcânico, sendo considerado zero para evento pré-arco (forearc) e igual a 1 para evento pós-arco (backarc).

A GMPE considera quebra na escala de magnitudes para grandes magnitudes $\left(\mathrm{C}_{1}=7,8\right)$ :

$f_{\text {mag }}(M)=\theta_{4}\left(M-\left(C_{1}+\Delta C_{1}\right)\right)+\theta_{13}(10-M)^{2}$ para $M \leq C_{1}+\Delta C_{1}$

$f_{\text {mag }}(M)=\theta_{5}\left(M-\left(C_{1}+\Delta C_{1}\right)\right)+\theta_{13}(10-M)^{2}$ para $M>C_{1}+\Delta C_{1}$

e também a influência da profundidade no caso de eventos intraplaca:

$$
f_{\text {depth }}\left(Z_{h}\right)=\theta_{11}\left(\min \left(Z_{h}, 120\right)-60\right) F_{\text {event }}
$$

Considera também diferentes taxas de atenuação para sítios situados no pré-arco (forearc) ou pós-arco (backarc), mas reflete principalmente as condições do Japão:

$f_{F A B A}(R)=\theta_{7}+\theta_{8} \operatorname{Ln}\left(\left(\max \left(R_{\text {hypo }}, 85\right)\right) / 40\right) F_{F A B A}$ com $F_{\text {event }}=1$ para backarc

$f_{F A B A}(R)=\theta_{15}+\theta_{16} \operatorname{Ln}\left(\left(\max \left(R_{\text {rup }}, 100\right)\right) / 40\right) F_{F A B A}$ com $F_{\text {event }}=0$ para forearc

Os efeitos das características geológicas do sítio são relacionadas com a velocidade média de propagação de ondas $\mathrm{S}$ nos primeiros $30 \mathrm{~m}$ de profundidade $\mathrm{V}_{\mathrm{S} 30}$ :

para $V s_{30}<V_{\text {lin }}$ $f_{\text {site }}\left(P G A_{1100}, V s_{30}\right)=\theta_{12} \operatorname{Ln}\left(V_{s} * / V_{\text {lin }}\right)-b \operatorname{Ln}\left(P G A_{1000}+c\right)-b \operatorname{Ln}\left(P G A_{1000}+c\left(V_{s} * / V_{\text {lin }}\right)^{n}\right)$ 
para $V s_{30} \geq V_{\text {lin }}$

$f_{\text {site }}\left(P G A_{1100}, V s_{30}\right)=\theta_{12} \operatorname{Ln}\left(V_{s} * / V_{\text {lin }}\right)+b \operatorname{Ln}\left(V_{s} * / V_{\text {lin }}\right)$

onde $\mathrm{PGA}_{100}$ é o valor médio de PGA para $\mathrm{Vs}_{30}=1000 \mathrm{~m} / \mathrm{s}$, com Vs* $=1000 \mathrm{~m} / \mathrm{s}$ para $\mathrm{Vs}_{30}>1000 \mathrm{~m} / \mathrm{s}$ e Vs$*=\mathrm{Vs}_{30}$ para $\mathrm{Vs}_{30} \leq 1000 \mathrm{~m} / \mathrm{s}$.

\subsubsection{4.}

\section{Lei de atenuação de Chio \& Youngs (2014)}

Chiou e Young desenvolveram uma atualização do modelo proposto em 2008 para aceleração máxima no solo (PGA) e espectro de resposta de acelerações horizontais (5\% de amortecimento) causadas por terremotos continentais. A base de dados para atualização foi restrita principalmente aos movimentos de terremotos corticais na Califórnia, com a inclusão de 18 registros de eventos com magnitude $M \geq 6$. Na nova versão também foram incluídos os efeitos da direção considerando cinco configurações discutidas em Spudich et al. (2013).

\subsubsection{5.}

\section{Lei de atenuação de Abrahamson et al. (2014-2015)}

O modelo empírico de previsão do movimento para a componente horizontal de terremotos corticais em regiões tectônicas ativas foi obtido utilizando a base de dados PEER NGA-West2 (Pacific Earthquake Engineering Research Center - Next Generation Attenuation). O modelo é aplicável para terremotos com magnitude de momento entre 3,0 a 8,5 Mw, distâncias até $300 \mathrm{~km}$ e períodos espectrais de 0 a 10s. Os parâmetros de entrada do modelo são os mesmos usados por Abrahamson e Silva (2008), com as seguintes exceções: o nível de entrada de dados para efeitos não lineares baseia-se na aceleração espectral no período de interesse em vez da PGA; a escala da distância para o efeito de hanging wall (HW - bloco de rocha em repouso em uma falha inclinada) nas extremidades da ruptura inclui uma dependência do azimute da fonte em relação ao sítio. Diferenças regionais de atenuação com a distância e velocidade de propagação da onda $\mathrm{S}\left(\mathrm{Vs}_{30}\right)$ inclui dados da Califórnia, Japão, China e Taiwan. O desvio padrão é dependente da magnitude, com menores magnitudes que levam a desvios padrão maiores em períodos curtos e menores em períodos 
longos. Os efeitos de direção não são incluídos por parâmetros explícitos, mas são capturados pela própria variabilidade dos dados empíricos.

O banco de dados consistiu de 15750 registros de 326 terremotos, dos quais 221 são eventos de deslocamento horizontal, 79 de eventos inversos e 29 de eventos normais, principalmente entre as magnitudes 4,6 $<\mathrm{Mw}<6,0$. Existem quatro diferenças fundamentais na forma como a GMPE foi atualizada em relação à proposta de 2008: (1) o modelo é estendido para pequenas magnitudes; (2) a escala do HW é melhor reproduzida pelas simulações; (3) foram incluídas as diferenças regionais na atenuação de longas distâncias; (4) diferenças regionais na escala $\mathrm{Vs}_{30}$ foram também incluídas.

\subsubsection{6.}

\section{Lei de atenuação de Campbell e Bozorgnia (2014)}

O desenvolvimento deste modelo empírico de movimento, com base no banco de dados global do PEER NGA-West2 (21000 registros), se refere à componente vertical da PGA e PGV, com amortecimento de 5\% na resposta de aceleração espectral (PSA) em faixas de períodos verticais de 0,01 a 10 segundos. O modelo é aplicável para terremotos corticais em regiões tectônicas ativas, para faixas de magnitude de 3,3 a 8,5 Mw, dependendo do tipo de falha, e distâncias de até $300 \mathrm{~km}$ da falha $\left(\mathrm{R}_{\mathrm{RUP}}\right)$..

\subsubsection{7.}

\section{Lei de atenuação de Sadigh et al. (1997)}

Sadigh et al. (1997) desenvolveram leis de atenuação para acelerações máximas do solo e acelerações espectrais de resposta horizontal (5\% de amortecimento) para terremotos continentais. Essas relações baseiam-se principalmente em dados de fortes eventos sísmicos na Califórnia, terremotos de Gazli (Rússia, 1976) e Tabas (Irã, 1978). A GMPE foi desenvolvida para rocha, considerando 121 acelerogramas, para terremotos com magnitude $\mathrm{Mw} \geq 4 \mathrm{e}$ distâncias de até $100 \mathrm{~km}$.

Sadigh et al. (1993) indicaram que, dentro dos $10 \mathrm{~km}$ de superfície de ruptura, existem diferenças sistemáticas entre as componentes de falha normal e falha paralela nos movimentos de longo período. Especificamente, recomendam 
que a componente de falha normal seja aumentada em $20 \%$ em relação aos valores geométricos médios para períodos espectrais de 2.0 segundos ou superiores, e a componente de falha paralela seja $20 \%$ menor do que o valor médio.

Em relação à classificação do site, Sadigh et al. (1993) usaram duas categorias gerais de classificação: rocha e solos profundos, com base em estudos de velocidade de onda $\mathrm{S}$. Rocha é caracterizada por $\mathrm{V}_{\mathrm{S} 30} \geq 750 \mathrm{~m} / \mathrm{s}$ e solos profundos quando o embasamento rochoso se situa a profundidades maiores do que $20 \mathrm{~m}$.

\section{7. \\ Incertezas e a árvore lógica}

A falta de conhecimento aprofundado dos processos físicos envolvidos na geração, propagação e atenuação da energia, a natureza aleatória das variáveis e fenômenos considerados e a imprecisão dos modelos físico-matemáticos utilizados para descrevê-los, são fatores que apresentam grande incerteza nos resultados da análise de ameaças probabilísticas (Schenk, 1989, Budnitz et al., 1997). Dada a impossibilidade de eliminar completamente essas incertezas, foram desenvolvidas técnicas de reconhecimento, quantificação e, na medida do possível, técnicas de dedução. Atualmente, uma análise mais ou menos exaustiva das incertezas é uma prática generalizada nas estimativas da ameaça sísmica. Além disso, porque o conhecimento sobre fenômenos sísmicos é incompleto, é importante chegar a um consenso sobre qual é a informação mais adequada sobre a qual basear uma estimativa confiável de ameaça sísmica.

Existem várias maneiras de classificar as incertezas na ameaça sísmica. A classificação mais utilizada é a que distingue entre incerteza epistêmica e a incerteza aleatória.

As incertezas aleatórias, também designadas como variabilidades, incertezas inerentes ou incertezas estocásticas, descrevem a variação inerente associada ao ambiente em consideração, causada normalmente pela natureza aleatória dos dados disponíveis. Pode ser representada matematicamente por uma distribuição de probabilidade desde que os dados experimentais sejam suficientes (Agarwal et al., 2004). 
As incertezas epistêmicas, também denominadas incertezas subjetivas ou incertezas do modelo, estão associadas a um certo nível de ignorância, ou informação incompleta, do ambiente, sendo empregadas para descrever a falta de conhecimento ou de informações no processo de construção do modelo matemático.

A quantificação das incertezas epistemicas e aleatórias tornou-se parte integral de qualquer análise de ameaça sísmica moderna. Atualmente a árvore lógica é a estrutura mais popular usada para quantificar as incertezas epistémicas. As incertezas nunca devem ser ignoradas, mas sim contabilizadas de forma transparente e sistemática.

Ambos os tipos de incertezas ocorrem nas diferentes fases do cálculo da ameaça: definição de fontes sismogênicas e das relações de recorrência, nas equações de previsão do movimento (GMPE) e efeitos das condições locais do sítio. Para quantificar e aferir essas incertezas, a árvore lógica é uma excelente ferramenta (Cramer, 2001a, Wahlström e Gruntal, 2001).

$\mathrm{Na}$ árvore lógica, cada decisão recebe uma probabilidade estimada de ser correta, sendo definida por meio de um consenso grupal entre especialistas. A adoção de um conjunto de opções de entrada para o cálculo da ameaça sísmica é definida por uma sucessão de ramos pertencentes aos nós sucessivos. A probabilidade de ocorrência do evento representado por esta sucessão de ramos é obtida pelo produto dos pesos (ou probabilidades) de cada um dos ramos.

No presente trabalho, para reduzir as incertezas epistêmicas da análise da recorrência sísmica, foi adotado o modelo de ajuste de máxima verossimilhança e, na árvore lógica, foram incluídas leis de atenuação aplicáveis para terremotos de subducção e corticais, conforme mostra a Figura 4.7. 


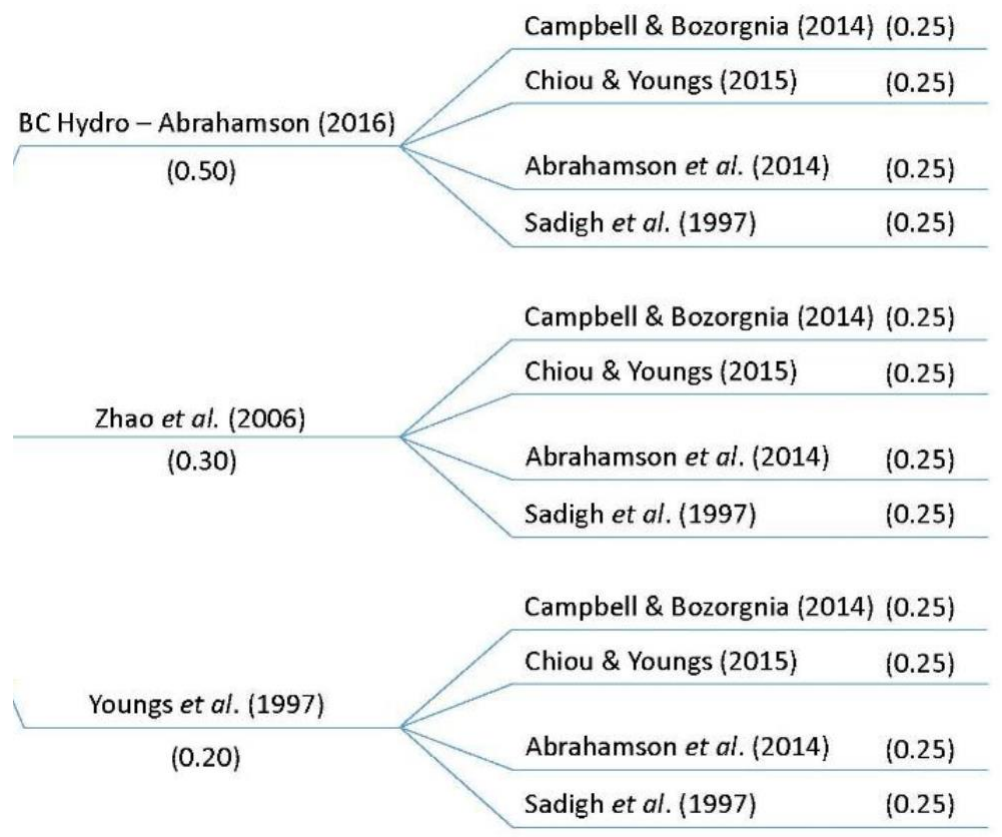

Figura 4.7 - Árvore lógica usada por Aguilar (2017).

\section{8. Estimativa probabilística da ameaça sísmica}

Conhecidas a sismicidade das fontes, as relações de atenuação e a árvore lógica, a ameaça sísmica probabilística pode ser avaliada, considerando a soma dos efeitos das diferentes fontes sismogênicas atuantes sobre o sítio de interesse. Desta forma, o resultado final permitirá obter valores específicos de aceleração horizontal com uma probabilidade de ser ultrapassada em certo período de retorno. Essas acelerações não representam um sismo particular, mas o efeito combinado de todos os terremotos em todas as fontes sismogênicas.

Nesta pesquisa, a ameaça sísmica foi determinada por meio do software CRISIS v.2015, desenvolvido no Instituto de Engenharia da UNAM Universidade Nacional Autônoma do México - por Ordaz et al (1999, 2007) e comparada com a ameaça sísmica calculada com o software de código aberto OpenQuake, desenvolvido pela Fundação GEM - Global Earthquake Model.

Com a finalidade de avaliar e conferir os resultados obtidos da ameaça sísmica baseada nas fontes sismogênicas do Peru, foi realizada uma comparação com as fontes consideradas no projeto SARA - South America Risk Assessment, uma progrma regional promovida pela GEM, entre 2013 a 2015, com objetivo de calcular a ameaça e riscos sísmicos ao longo da costa ocidental da América do Sul (Argentina, Bolívia, Equador, Peru e Colômbia), uma das mais ativa do planeta. 
As fontes sísmicas de subducção de intraplaca e de interface são mostradas na Figura 4.8 e as propriedades das mesmas na Tabela 4.3. A Figura 4.9 ilustra uma representação 3D da geometria final da fonte de subducção no projeto SARA.

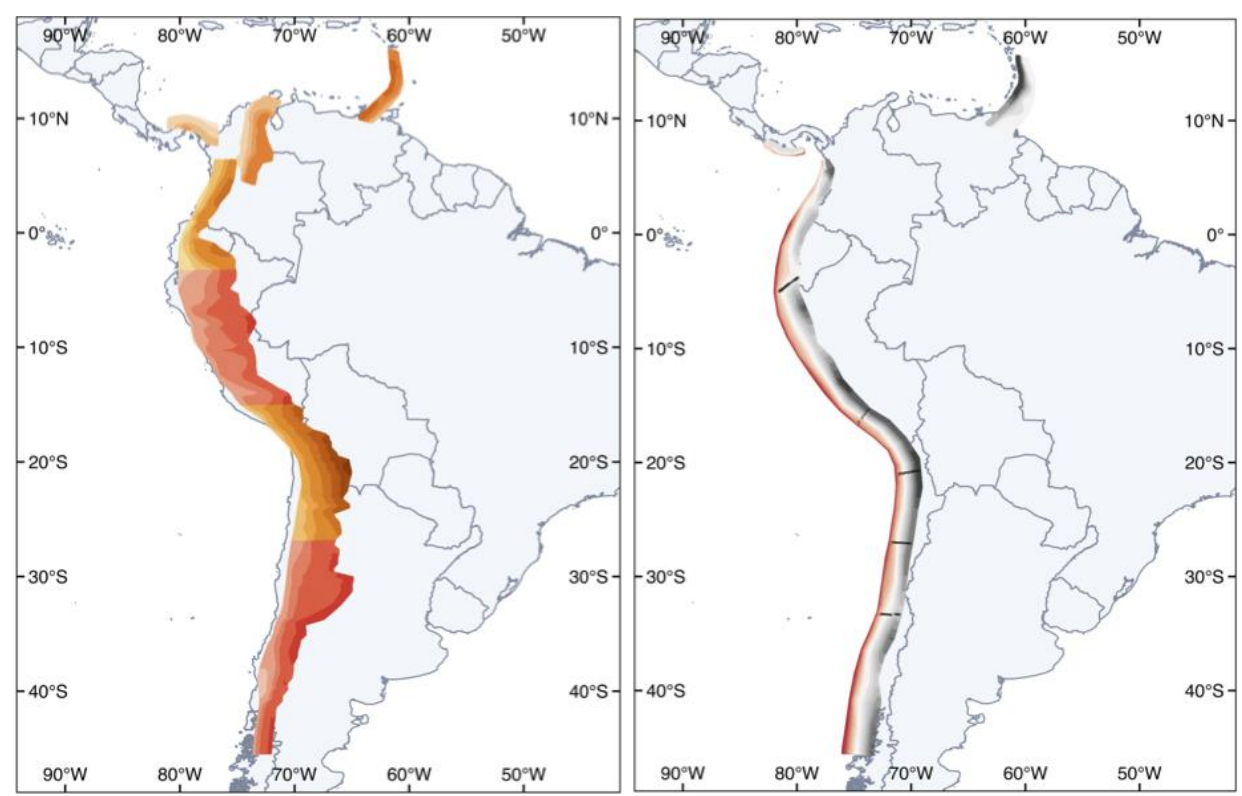

Figura 4.8 - Fontes sísmicas de subducção do projeto SARA; à esquerda as fontes intraplaca e à direita as fontes de interface.

Fonte (https://sara.openquake.org/hazard_rt7)

Tabela 4.3 - Caracterização das fontes de subducção de intraplaca e de interface do projeto SARA

Fonte (https://sara.openquake.org/hazard_rt7)

\begin{tabular}{|c|c|c|c|c|c|c|}
\hline Zona & Tipo de tectônica & Fonte & $\mathrm{a}$ & $\mathrm{b}$ & Mmin & Mmax \\
\hline \multirow{10}{*}{ Costa oeste } & \multirow{6}{*}{ Interface } & Segment 1 & 5,4225 & 0,9967 & 6,5 & $9,1^{* *}$ \\
\hline & & Segment 2 & 5,4225 & 0,9510 & 6,5 & $8,6^{*}$ \\
\hline & & Segment 3 & 4,6544 & 0,8381 & 6,5 & $8,5^{*}$ \\
\hline & & Segment 4 & 5,4870 & 1,0103 & 6,5 & $8,8^{* *}$ \\
\hline & & Segment 5 & 5,6395 & 0,9925 & 6,5 & $8,7^{*}$ \\
\hline & & Segment 6 & 5,4731 & 1,0461 & 6,5 & $8,6^{*}$ \\
\hline & \multirow{4}{*}{ Intraplaca } & Inslab 1 & 5,0636 & 0,8458 & 5,5 & $7,5^{*}$ \\
\hline & & Inslab 2 & 5,5032 & 0,8613 & 5,5 & $8,7^{*}$ \\
\hline & & Inslab 3 & 5,9930 & 1,0443 & 5,5 & $8,0^{*}$ \\
\hline & & Inslab 4 & 4,1176 & 0,4760 & 5,5 & $7,9 *$ \\
\hline
\end{tabular}

(*) Do máximo no sub catálogo +0,5.

(**)Estimativa da área usando Strasser et al. (2010) 


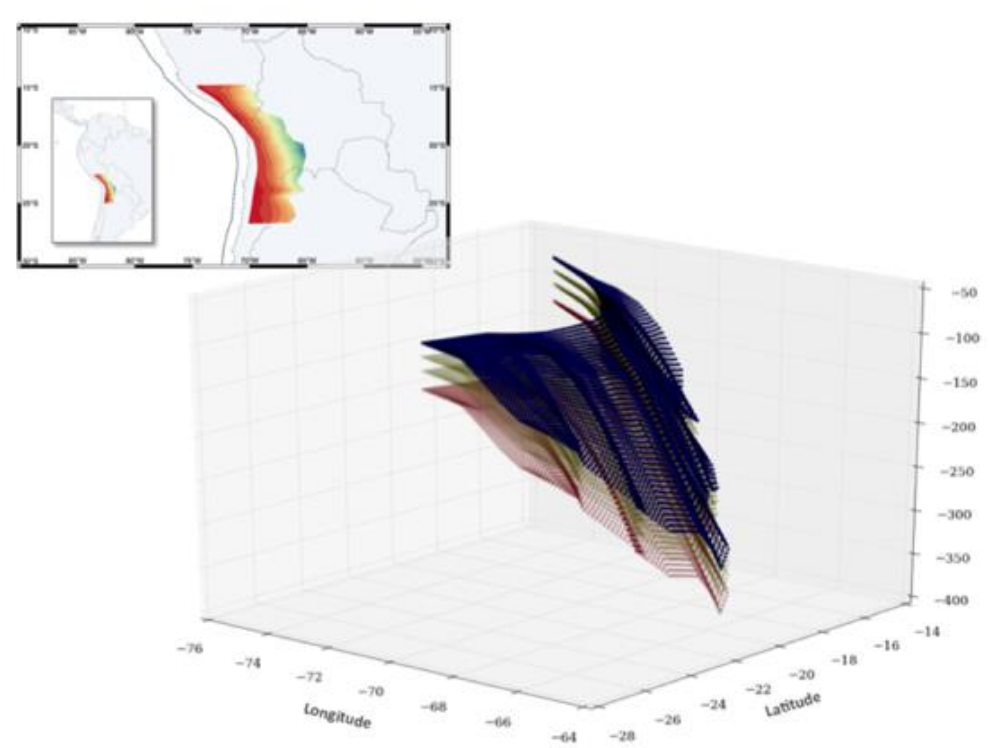

Figura 4.9 - Representação 3D da geometria do modelo de subducção no projeto SARA. Fonte (https://sara.openquake.org/hazard_rt7)

A presença de falhas geológicas distribuídas na zona continental tem sua origem em dobras e fraturas da superfície terrestre produzidas pela colisão de placas tectônicas. Dentro do âmbito regional do projeto Alpamarca, as falhas próximas à área de estudo consideradas no presente estudo com o software Openquake foram as seguintes (Figura 4.10): falhas da cordilheira Branca (PE07a3, PE-07b, PE-07c2, PE-07d1, PE-07d2, PE-07d3, PE-07d4 e PE-07d5), falhas Quiches (PE-08a, PE-08b e PE-08d), falhas Cayesh (PE-11a e PE-11b), falhas Huaytapallana (PE-12a) e falhas Quimbiri-Pichari (PE-63).

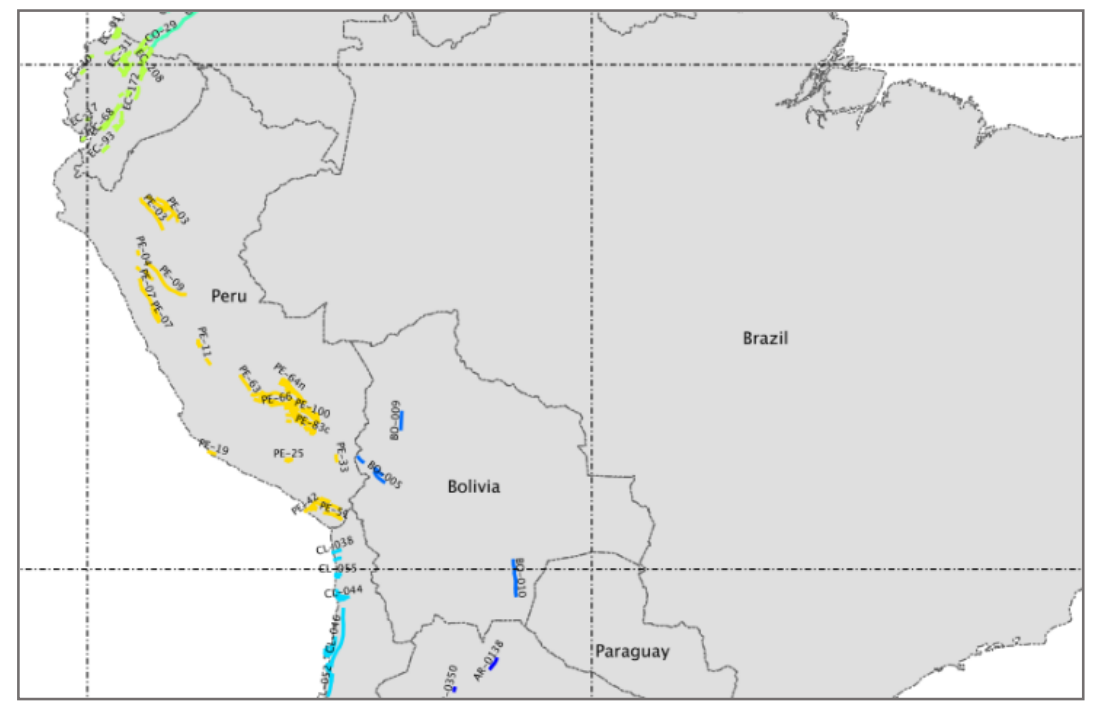

Figura 4.10 - Falhas consideradas no Openquake. Fonte (https://sara.openquake.org/hazard_rt7) 
Nas análises efetuadas foram usadas relações de atenuação que permitiram estimar espectros de resposta uniformemente provável em função dos períodos de retorno considerados. Resultados da avaliação da ameaça sísmica regional possibilitaram construir as curvas de probabilidade de excedência anual de acelerações espectrais para diferentes períodos estruturais. Para obter o espectro correspondente a determinado período de recorrência, bastou obter de cada curva de ameaça sísmica a ordenada espectral correspondente, conforme anteriormente apresentado na Figura 3.6.

A estimativa dos espectros de resposta é feita para um período de recorrência definido por normas técnicas. O Comité Internacional de Grandes Barragens - ICOLD (1989, 2010) define tipos de terremotos baseados nos seguintes critérios:

Sismo Base de Operação (Operating Basis Earthquake, OBE) - definido como o máximo sismo que razoavelmente pode atingir a obra durante sua vida útil, sem causar prejuízos maiores, nem alterar o funcionamento normal (condição de operação da estrutura). Geralmente em barragens corresponde a uma probabilidade de excedência de 50\% em 100 anos de vida útil da estrutura, equivalente a um período de retorno $\operatorname{Tr} \approx 145$ anos.

$$
P(y>Y)=1-e^{-\left(100 / T_{r}\right)}=0,5 \Rightarrow \ln (0,5)=-\left(100 / T_{r}\right) \Rightarrow T_{r} \cong 145
$$

Sismo de Avaliação de Segurança (Safety Evaluation Earthquake, SEE) nível sísmico máximo considerado no projeto, admitindo danos estruturais e deformações, porém mantendo a segurança da barragem e sem mudanças no nível do reservatório. Dependendo das consequências de um colapso potencial é atribuído um período de retorno de 10.000 anos no caso de consequências catastróficas, 3000 anos para consequências moderadas e 1000 anos para baixas consequências. Na revisão do Boletim 72 (ICOLD, 2010) a designação Safety Evaluation Earthquake (SEE) substitui o termo Maximum Design Earthquake (MDE), utilizado na primeira versão (ICOLD, 1989) e o termo Design Basis Earthquake (DBE) utilizado no Boletim 46 (1983) - Seismicity and Dam Design.

Máximo Sismo Esperado (Maximum Credible Earthquake, MCE) - em cenário de condição extrema, considera-se a ocorrência do sismo de maior 
magnitude da compilação de sismicidade histórica regional. Assume-se que a obra será permanentemente afetada, porém sem colapso estrutural. O sismo MCE é utilizado na modelagem de ameaça sísmica determinística.

Com base nestes cenários sísmicos, decidiu-se utilizar a condição do Sismo de Avaliação de Segurança (SEE) recomendado pela norma ICOLD para projetos de barragens. Em função das características da barragem de rejeitos Alpamarca (colapso potencial de baixas consequências) foi admitido um período de retorno de 975 anos para as análises sísmicas em solo tipo B.

$\mathrm{Na}$ presente pesquisa, os espectros de resposta foram gerados com os softwares CRISIS v.2015 e OpenQuake realizando uma comparação com os espectros de resposta. A figura 4.11, mostra as curvas de ameaça sísmica para os diferentes períodos de estrutura, para posteriormente gerar o espectro de resposta uniformemente provável para uma excedência de 5\% ( $\mathrm{Tv}=50$ anos de vida útil, $\operatorname{Tr}=975$ anos) como se mostra na figura 4.12.

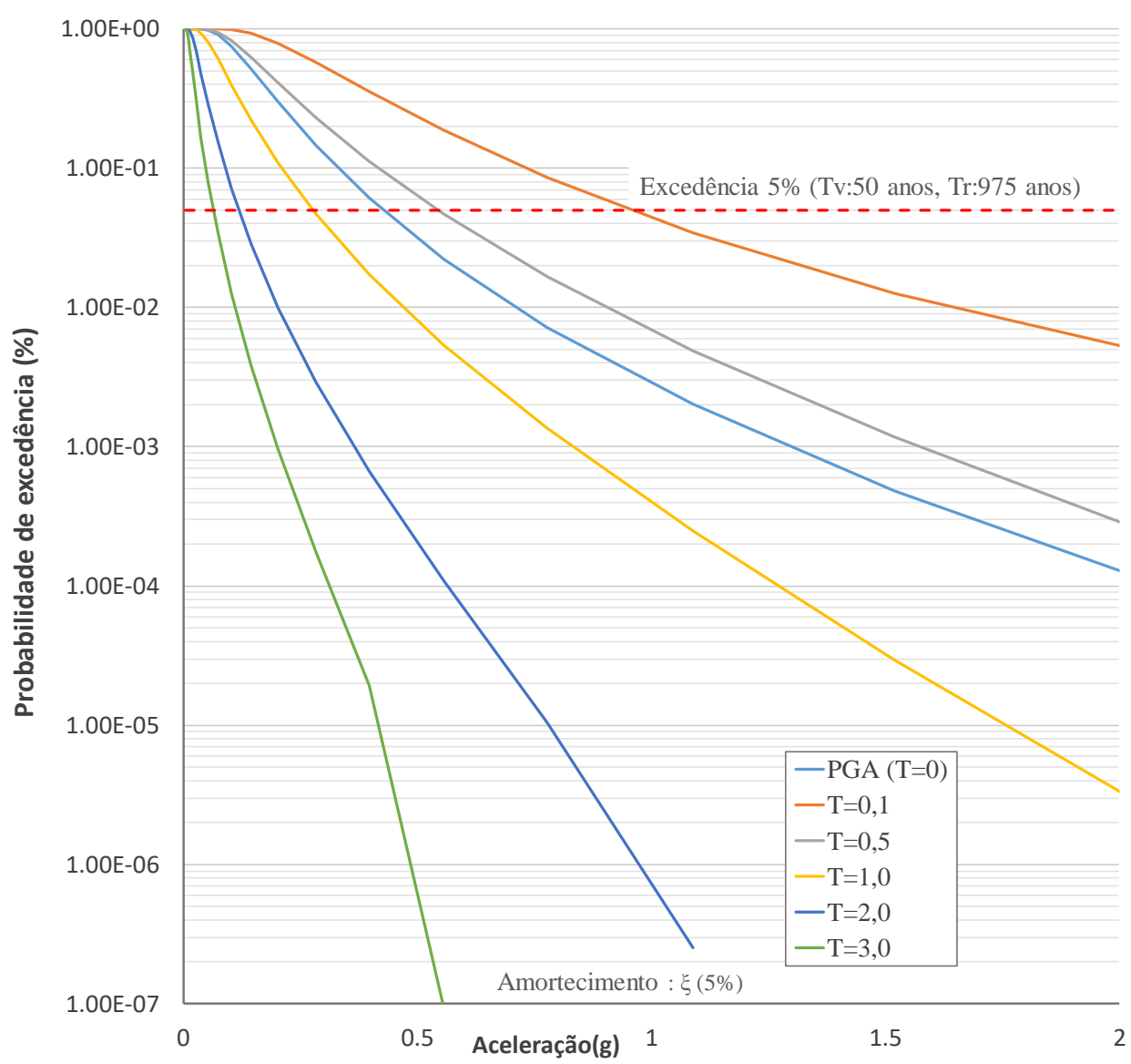

Figura 4.11 - Curvas de ameaça sísmica geradas do Openquake com fontes do projeto SARA. 
Como pode ser observado na Figura 4.12, existe uma similitude entre os espectros de respostas de aceleração (PGA) previstas pelos programas CRISIS e OpenQuake considerando as fontes sismogênicas do Peru (Roncal, 2017).

A figura também compara as previsões computadas com o OpenQuake considerando as fontes sismogências do projeto SARA, além de aquelas previsões computadas disponíveis na internet por meio de aplicativo, na web, desenvolvido pelo SENCICO - Servicio Nacional de Capacitación para la Indústria de la Construcción do Peru (https://www.sencico.gob.pe/publicaciones.php?id=331).

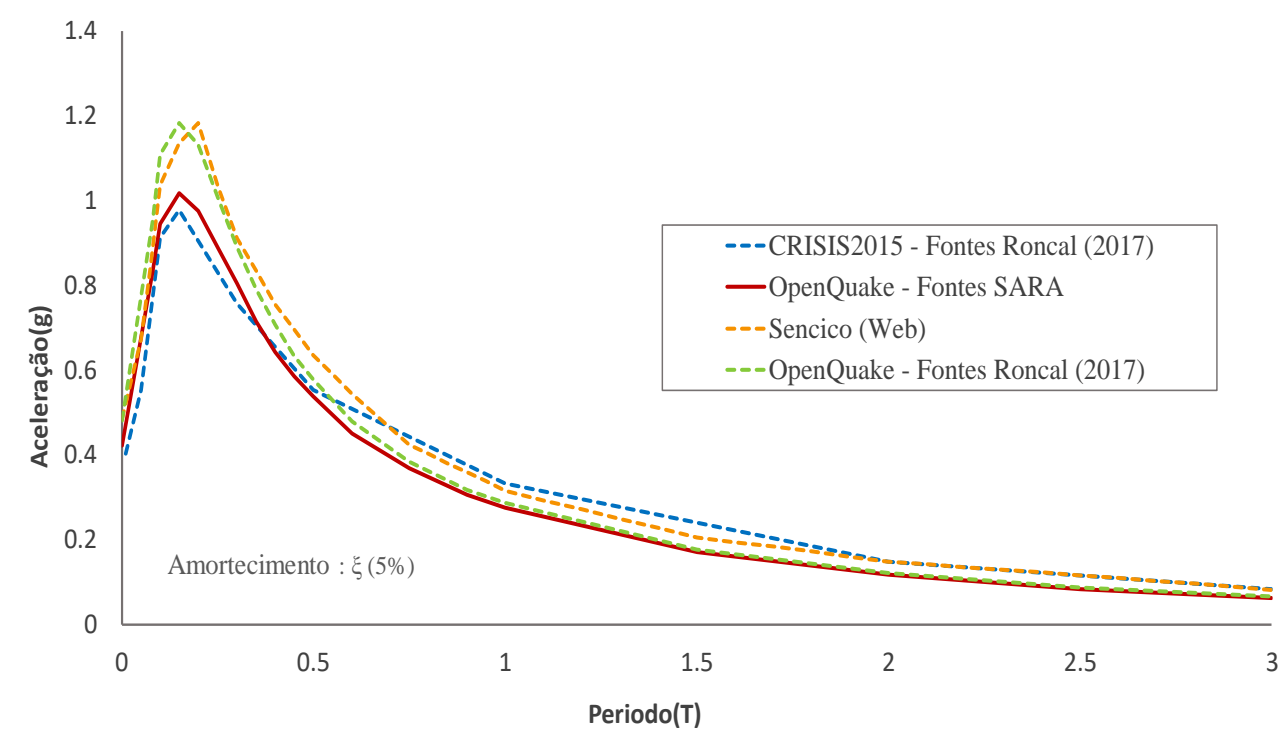

Figura 4.12 - Espectros de resposta em rocha pelos programas CRISIS v.2015 e software OpenQuake e SENCICO, considerando período de retorno de 975 anos. 


\section{5 \\ Simulação numérica das respostas estática e sísmica de barragens}

\section{1.}

\section{Características do programa FLAC 2D v.8}

Nas aplicações numéricas desta pesquisa foi utilizado o programa computacional FLAC v.8. - Fast Lagrangian Analysis of Continua desenvolvido pelo Dr. Peter Cundall desde 1986. O programa surgiu como uma alternativa de resolução de problemas lineares e não lineares baseado no método das diferenças finitas. Resolve a equação do movimento (Eq. 5.1) por meio de sucessivos passos de cálculo considerando um esquema explícito de integração no tempo.

$$
\rho \frac{\partial \dot{u}_{i}}{\partial t}=\frac{\partial \sigma_{i j}}{\partial x_{i}}+\rho g_{i}
$$

onde $\rho$ é a massa específica do material, t o tempo, $x i$ uma componente do vetor posição, $g_{i}$ componente da aceleração da gravidade e $\sigma_{\mathrm{ij}}$, representa o tensor de tensões. A parcela de amortecimento é considerada de forma externa mediante inclusão do amortecimento histerético ou de Rayleigh no modelo numérico.

Ao empregar um esquema explícito, o FLAC não precisa armazenar matrizes na memória do computador, como usualmente é feito em programas computacionais baseado no método dos elementos finitos. $\mathrm{O}$ esquema cíclico do processamento é mostrado na Figura 5.2.

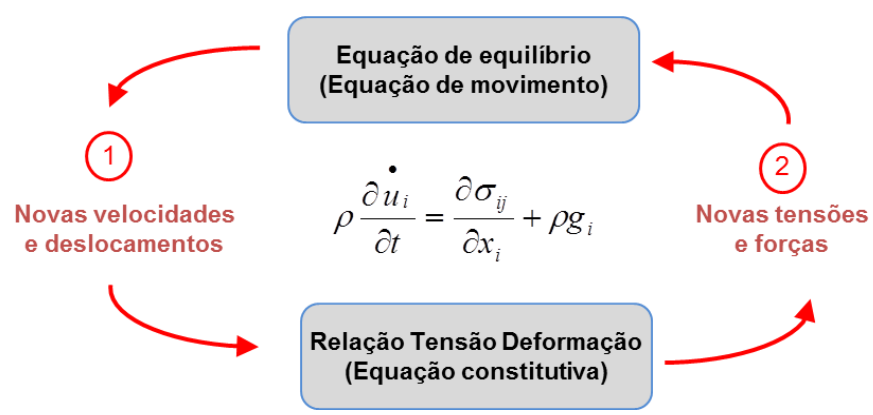

Figura 5.1 - Ciclo de cálculo do FLAC.

(Fonte: Itasca, 2011) 
O programa baseia-se na equação do movimento inclusive para a solução de problemas estáticos, característica que o torna geralmente mais lento em comparação aos programas governados pela equação de equilíbrio estático (Altarejos, 2009). Em contrapartida, tem grande potencial de aplicações em problemas envolvendo aplicações dinâmicas ou em situações envolvendo a ocorrência de grandes deformações.

Como todo software comercial orientado ao estudo do comportamento de geoestruturas, o FLAC v.8 dispõe de vários modelos constitutivos que relacionam as componentes de tensão e deformação, conforme Tabela 5.1. Adicionalmente, ao usuário é permitido agregar outros modelos constitutivos programados na linguagem própria do software chamada FISH.

Tabela 5.1- Modelos constitutivos no programa FLAC

\begin{tabular}{|c|c|}
\hline Modelos Elasto-plásticos & Modelos Visco-elásticos e Visco-plásticos \\
\hline $\begin{array}{ll}\text { - } & \text { Vazio ou nulo (null model) } \\
\text { - } & \text { Elasticidade isotrópica } \\
\text { - } & \text { Elasticidade transversalmente isotrópica } \\
\text { - } & \text { Plasticidade de Drucker-Prager } \\
\text { - } & \text { Plasticidade de Mohr-Coulomb } \\
\text { - } & \text { Plasticidade anisotrópica (ubiquitous-joint } \\
\text { model) } & \text { Plasticidade com endurecimento / } \\
\text { - } & \text { Plasticidade bilinear strain- } \\
\text { amolecimento } \\
\text { - } \quad \text { hardening/softening ubiquitous-joint } \\
\text { - } \quad \text { Plasticidade de escoamento duplo } \\
\text { - } \quad \text { Plasticidade Cam-clay Modificado }\end{array}$ & $\begin{array}{ll}\text { - } & \text { Visco-elástico clássico (Maxwell) } \\
\text { - } & \text { Lei de potência } \\
\text { - } & \text { Creep (WIPP) } \\
\text { - } & \text { Visco-plástico (modelo de Burger) } \\
\text { - } & \text { Visco-plástico (modelo WIPP) } \\
\text { Crushed-salt }\end{array}$ \\
\hline
\end{tabular}

O programa utiliza elementos quadrilaterais, chamados de zonas, internamente subdivididos em dois pares de triângulos. A malha gerada identifica a localização de armazenamento de todas as variáveis do modelo, com as magnitudes de grandezas vetoriais armazenadas nos nós (forças, velocidades, deslocamentos, gradientes) enquanto as magnitudes escalares e de tensão são armazenadas no interior das zonas (tensões, deformações, pressões, propriedades dos materiais). 


\section{2. \\ Etapas de avaliação do comportamento estático}

\subsection{1. Distribuição dos recalques}

A previsão dos campos de tensão e de deformação desenvolvidos durante a fase de construção de uma barragem de terra, tanto no seu próprio corpo, quanto no material de fundação, é um fator importante nesta etapa do projeto. Análises dinâmicas posteriores, de natureza não linear, necessitam da determinação prévia do estado de tensão como condição inicial do problema.

À medida que se constrói a barragem, recalques do solo vão acontecendo. O mecanismo básico para o cálculo de recalques ou deslocamentos verticais de uma barragem pode ser mais bem compreendido considerando um aterro de grande extensão (Law, 1975), como ilustrado na Figura 5.2, onde são assumidas as seguintes hipóteses: os deslocamentos são unidimensionais, não existem efeitos dependentes do tempo no comportamento do recalque (recalque de compressão secundária) e o meio é considerado homogêneo, isotrópico e com comportamento tensão deformação linear elástico.

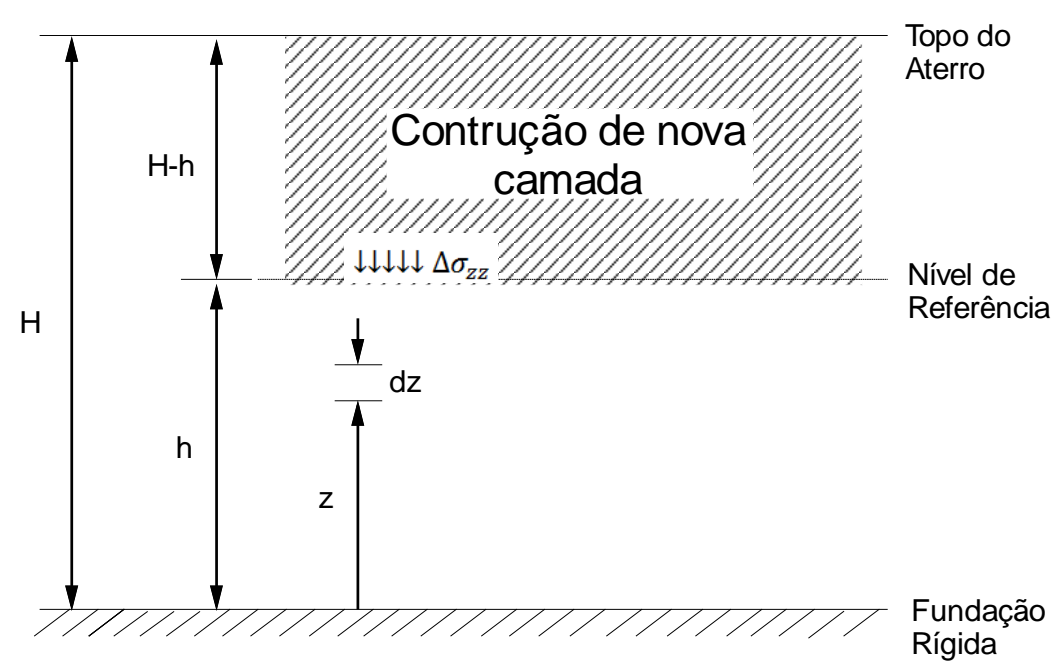

Figura 5.2 - Construção de aterro de grande extensão por camadas sucessivas-Law, 1975.

$\mathrm{O}$ incremento da tensão vertical $\Delta \sigma_{z z}$ em qualquer ponto situado na altura $z \leq h$ devido à construção de uma camada de espessura $H-h$ é considerado constante e é determinado por: 


$$
\Delta \sigma_{z z}=\gamma(H-h)
$$

e o deslocamento vertical (devido a nova camada) do mesmo ponto pode ser calculado integrando-se o incremento de deformação vertical neste ponto ao longo da camada pré-existente usando a lei de Hooke, ou seja:

$$
\Delta \rho=\int_{0}^{h} \Delta \varepsilon_{z z} d z=\int_{0}^{h} \frac{\Delta \sigma_{z z} d z}{E}=\frac{\gamma}{E}(H-h) h
$$

Da equação acima, nota-se que o recalque $\rho$ é uma função da espessura da nova camada $(H-h)$ e do aterro pré-existente $h$, com uma variação parabólica de acordo com a Figura 5.3, com um valor mínimo no topo do aterro $(z=H)$ e um valor máximo na sua altura média $(z=H / 2)$.

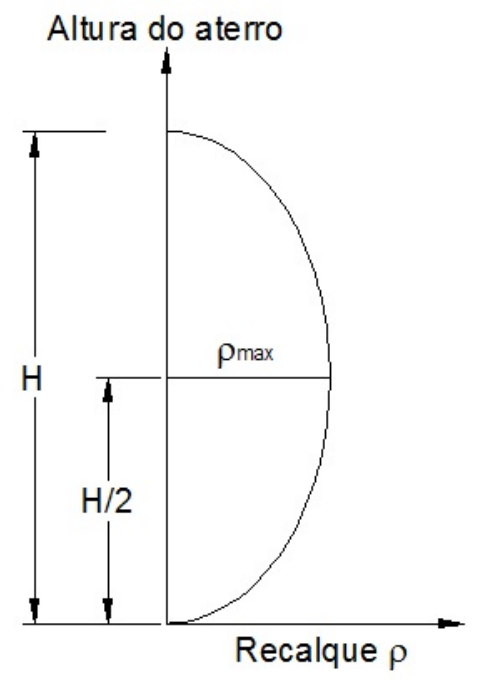

Figura 5.3 - Perfil de recalque em um aterro, com valor máximo na altura média H/2. (Fonte: Law, 1975)

Este padrão é bastante condizente com a distribuição de recalques observados na construção de barragens de terra/enrocamento e muito diferente daquela que seria obtida considerando-se apenas uma etapa de construção, na qual o recalque máximo estaria localizado na crista da barragem. Uma análise qualitativa similar poderia também ser demostrada para casos em que o módulo de elasticidade é considerado dependente do estado de tensão atuante no ponto. 


\subsection{2. \\ Enchimento do reservatório de rejeitos}

Muitas vezes em uma mineração é necessário aumentar a capacidade de armazenamento de uma barragem de rejeito existente, através da construção de alteamentos de acordo com os seguintes métodos construtivos: método à montante, método à jusante e método da linha de centro.

O método de jusante, considerado nesta pesquisa, é um método mais conservador do que o método à montante, desenvolvido para reduzir os riscos de liquefação em zonas de atividade sísmica. Depois da construção do dique de partida, os alteamentos subsequentes são realizados à jusante do mesmo, até atingir a cota de projeto (Figura 5.4). Neste processo construtivo, cada alteamento é estruturalmente independente da disposição do rejeito, melhorando assim a estabilidade da estrutura. Todo o alteamento da barragem pode ser construído com o mesmo material do dique de partida, assim como os sistemas de drenagem internos podem ser também instalados durante o alteamento, permitindo um melhor controle da superfície freática.

A principal desvantagem desde método é o custo de sua implantação, devido ao grande volume de aterro que necessita e a grande área que sua construção ocupa.

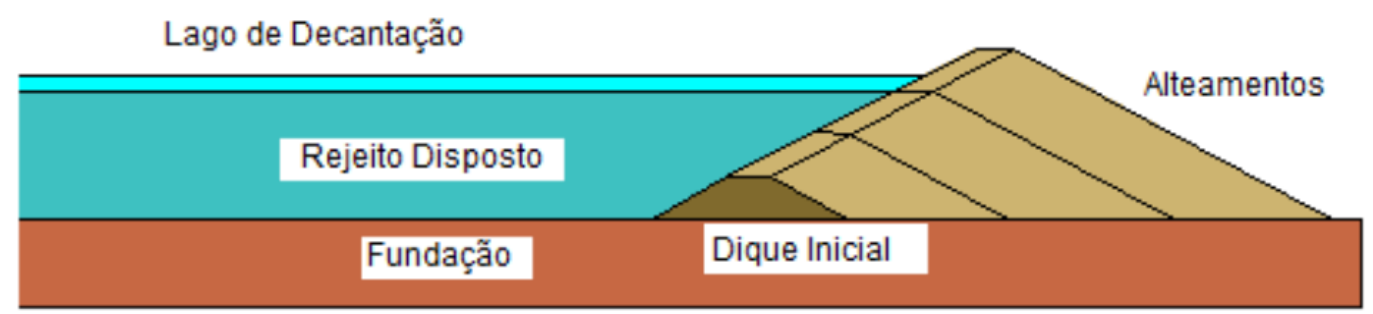

Figura 5.4 - Método construtivo à jusante.

(Fonte: Maxwell.puc-rio)

Neste estágio é possível realizar dois tipos de análise: a análise acoplada, ou hidromecânica, onde as poropressões na água e os estados de tensão e de deformação no esqueleto sólido são obtidos simultaneamente, como resultado da interação entre os dois meios (fluido e sólido) ou, alternativamente, como 
facilmente se pode deduzir, uma análise desacoplada envolvendo separadamente o comportamento tensão vs deformação do esqueleto sólido da análise de fluxo.

Uma análise acoplada, ainda que mais próxima da realidade, tem a desvantagem de requerer um grande tempo de processamento computacional. Nesta pesquisa, se optou por realizar o processo acoplado já que se pode simular uma melhor aproximação do comportamento hidráulico dos rejeitos na etapa do alteamento.

\subsection{3.}

\section{Fator de segurança estático}

O fator de segurança utilizado na análise de estabilidade de taludes é um procedimento necessário na avaliação estática e dinâmica de uma barragem.

Nos problemas de estabilidade de taludes sob condição estática, o método de equilíbrio limite (método das fatias) é geralmente empregado para cálculo do fator de segurança, subdividindo a região de solo delimitada pela potencial superfície de ruptura em um número qualquer de fatias verticais e analisando as condições de equilíbrio estático em cada fatia isoladamente.

Os métodos de equilíbrio limite são baseados em algumas hipóteses, dentre elas: os maciços de solo comportam-se mecanicamente como materiais rígidosperfeitamente plásticos; que o fator de segurança local é o mesmo em todos os pontos da potencial superfície de deslizamento; introduzem simplificações para suplementar as equações de equilíbrio visto que o número de incógnitas do problema é em geral superior ao número de equações fornecidas pela isostática.

Objeções teóricas em relação ao método de equilíbrio limite levaram à utilização de métodos numéricos na investigação da estabilidade de taludes (Figura 5.5) que procuram incorporar as relações tensão-deformação dos diversos solos que formam o maciço do talude.

Dentre as várias técnicas, prevalece o método da simulação do colapso ou da redução da resistência, incorporado em vários programas comerciais de computador, como o FLAC 2D e o Plaxis 2D. O fator de segurança é calculado pela redução progressiva dos parâmetros de resistência de Mohr-Coulomb (equações 5.4 e 5.5) até a iminência da ruptura do talude, i.e. quando o sistema de equações de equilíbrio não mais conseguem atingir a convergência da solução. 
A redução dos parâmetros de resistência dos solos envolvidos na análise é feita por

$$
\begin{aligned}
& c^{*}=\frac{c}{M} \\
& \tan ^{*} \phi=\frac{\tan \phi}{M}
\end{aligned}
$$

onde $\mathrm{M}$ é um parâmetro que varia nas sucessivas análises não lineares, até a ruptura do talude quando $\mathrm{M}=\mathrm{FS}$ (fator de segurança).

Mansour et al. (2011) com dados de 135 taludes calcularam os fatores de segurança por meio do método das fatias (Spencer, Janbu e Bishop Simplificado) e compararam com os valores obtidos no programa computacional FLAC/SLOPE. Os resultados entre os ambos os métodos de cálculo mostraram uma concordância satisfatória em todos os casos analisados.

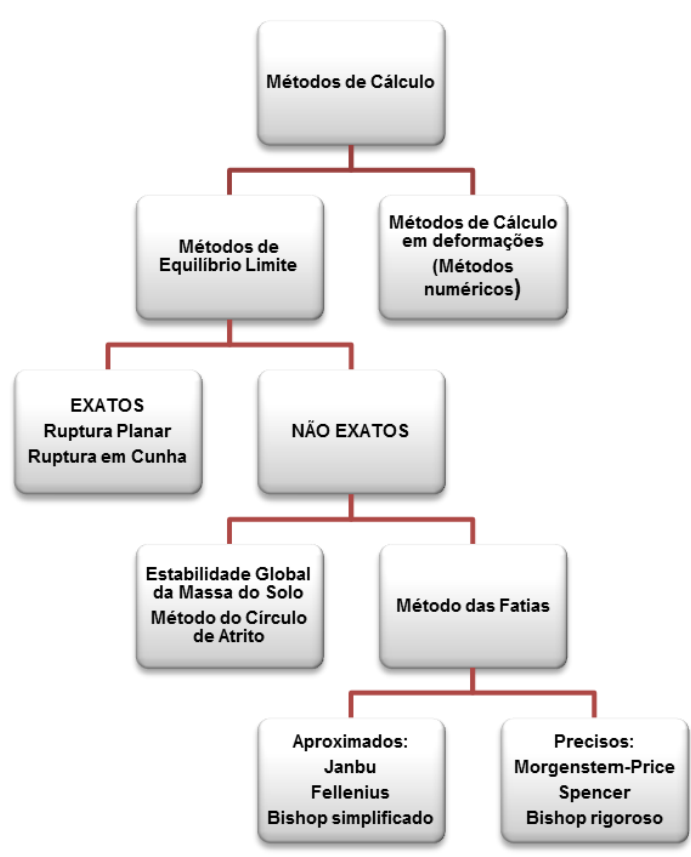

Figura 5.5 - Métodos para a avaliação do fator de segurança em taludes de solo.

(Fonte: Herrera, 2003)

Os fatores de segurança mínimos recomendados para a estabilidade de taludes de barragens de terra são os listados na Tabela 5.2. 
Tabela 5.2- Fatores de segurança mínimos na condição estática

Fonte: US Corps of Engineers.

\begin{tabular}{|l|c|c|}
\hline \multicolumn{1}{|c|}{ Condição de carregamento } & $\begin{array}{c}\text { Fator de segurança } \\
\text { mínimo }\end{array}$ & Talude \\
\hline $\begin{array}{l}\text { I. Ao final da construção para } \\
\text { barragens maiores de 15m }\end{array}$ & $1,30 / 1,40$ & $1,30 / 1,40$ \\
\hline II. Filtração constante & --- & 1,50 \\
\hline III. Rebaixamento Rápido & 1,50 & -- \\
\hline IV. Sismo: Para condições I e II & 1,00 & 1,00 \\
\hline
\end{tabular}

\section{3.}

\section{Etapas de avaliação do comportamento dinâmico}

\subsection{1.}

\section{Fator de segurança pseudo-estático}

Uma aproximação da análise sísmica de estabilidade de taludes é a utilização de uma abordagem pseudo-estática, usada na estimativa da estabilidade sob carregamento sismico há décadas (Kramer, 1996; Ribeiro, 2006; Macedo, 2013), com a primeira aplicação atribuída a Terzaghi (1950).

As diversas soluções de equilíbrio limite para análise da estabilidade de taludes de solo sob carregamento estático são possíveis de serem estendidas para um contexto pseudo-estático adicionando-se forças aplicadas no centroide da massa instável, conservando o mesmo módulo e direção, porém sentido oposto ao das forças inerciais geradas pela propagação da excitação sísmica (princípio de d'Alembert). Neste tipo de análise geralmente a componente vertical da força de inércia é desprezada em função da hipótese de que as ondas cisalhantes incidentes SV são verticais, e a componente horizontal é obtida pela multiplicação do coeficiente sísmico horizontal $k$ pelo peso da massa de solo instável. Um aspecto a observar é que no método pseudo-estático as forças de inércia horizontais são consideradas permanentemente atuantes no mesmo sentido e com o mesmo módulo, quando na realidade sentido e módulo variam ao longo do tempo de duração do terremoto. Dentre as principais recomendações da literatura, o valor mínimo aceitável do coeficiente de segurança pseudo-estático varia entre 1 a 1,15. 


\subsection{2. Modelos constitutivos para carregamentos cíclicos}

Solos são materiais deformáveis, podendo apresentar comportamento tensão $\mathrm{x}$ deformação altamente não linear quando dinamicamente carregados por terremotos de grande magnitude. A utilização de métodos numéricos para análise da resposta dinâmica de barragens dependerá do modelo constitutivo implementado no programa computacional.

Modelos constitutivos para representação do comportamento sísmico de solos podem ser agrupados em 3 classes: modelo linear equivalente, modelos nãolineares cíclicos e modelos elasto-plásticos.

\subsubsection{1.}

\section{Modelo linear equivalente}

É um modelo utilizado em grande parte dos programas computacionais elaborados para investigação da resposta dinâmica de maciços de solo.

A relação tensão $\mathrm{x}$ deformação de solos sob carregamento cíclico exibe normalmente um laço de histerese entre as trajetórias de carregamento e de descarregamento, que pode ser mecanicamente modelado descrevendo-se as trajetórias ou considerando-se parâmetros do material que possam representar de maneira aproximada a forma geral do laço. Na segunda alternativa, adotada no modelo linear equivalente, a inclinação do laço de histerese, proporcional à rigidez do solo, é descrita pelo módulo de cisalhamento secante e a abertura do laço, com área proporcional à energia dissipada no ciclo, pela razão de amortecimento (Figura 5.6)

Ambos os parâmetros, referidos como parâmetros lineares equivalentes, são atualizados iterativamente em função dos níveis de deformação cisalhante induzidos na massa de solo. Para a seleção dos novos valores, utiliza-se uma distorção média ou efetiva empiricamente estimada como $2 / 3$ da deformação cisalhante cíclica máxima (0.65 de acordo com Seed e Martin (1966), ou (M-1) /10, de acordo com Idriss e Sun (1992) onde M é a magnitude do terremoto). 


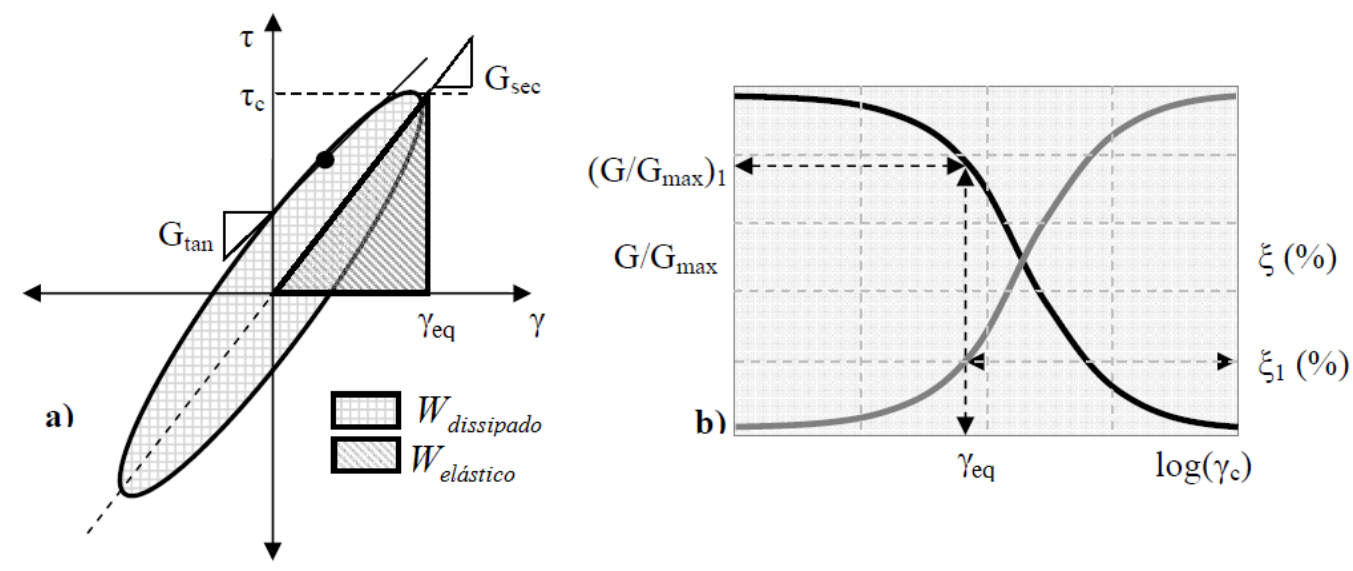

Figura 5.6 - a) módulo de cisalhamento secante; b) degradação do módulo de cisalhamento normalizado G/Gmax e majoração da razão de amortecimento $\xi$ em função da deformação cisalhante cíclica.

Consultando as curvas de variação do módulo de cisalhamento para determinado tipo de solo verifica-se então se o nível de deformação calculado é compatível com os valores das propriedades dinâmicas utilizadas na avaliação da resposta. Se as propriedades do solo não forem compatíveis, as propriedades lineares equivalentes são atualizadas e o processo é repetido até atingir a convergência, o que ocorre geralmente após 3 a 5 iterações (Figura 5.7).

De acordo com Bray et al. (1995) o modelo linear equivalente somente deve ser empregado para movimentos com $\mathrm{PGA}^{\text {rocha }} \leq 0,35 \mathrm{~g}$. Outras informações da literatura, indicam que o modelo linear equivalente não produz resultados confiáveis para situações onde $\mathrm{PGA}^{\text {solo }}>0,4 \mathrm{~g}$ (Ishihara, 1986) ou a deformação cisalhante de pico exceder aproximadamente 2\% (Kavazanjian et al., 1997).

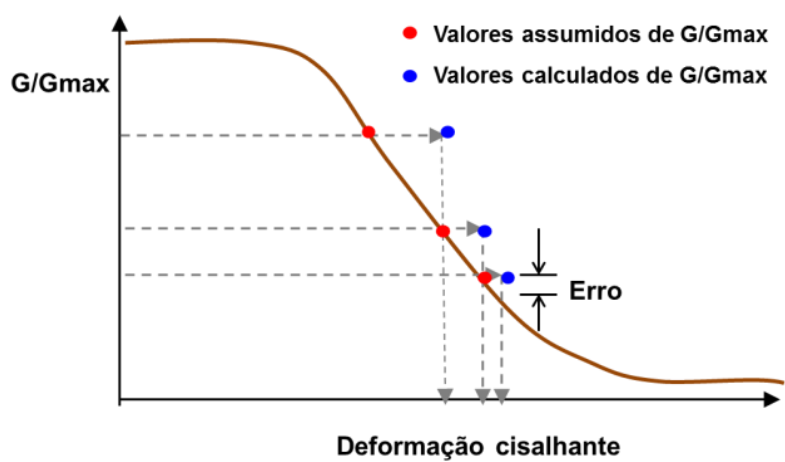

Figura 5.7 - Processo iterativo do modelo linear equivalente.

(Fonte: Vasquez, 2015) 
A relação entre a variação dos parâmetros lineares equivalentes com o nível das deformações cisalhantes foi estudada por vários autores. Até a década de 1980 as reduções de módulo de cisalhamento para solos coesivos e granulares eram tratadas separadamente (Seed e Idriss, 1970), conforme mostra a Figura 5.12 para o caso das areias, com o valor do módulo de cisalhamento $G_{\max }$, calculado pela seguinte expressão:

$$
\begin{aligned}
& G_{\text {max }}=1000 K_{2 \max }\left(\sigma_{m}^{\prime}\right)^{1 / 2} \quad \text { em } \quad p s f \\
& G_{\max }=21.7 K_{2 \max } P_{a t m}\left(\frac{\sigma_{m}^{\prime}}{P_{a t m}}\right)^{1 / 2} \text { em } \quad P a
\end{aligned}
$$

onde $\sigma_{\mathrm{m}}$ ' e a tensão efetiva principal média, $\mathrm{p}_{\mathrm{a}}$ a pressão atmosférica e o coeficiente adimensional $\mathrm{K}_{2 \max }$ (no intervalo entre 30 a 70) é obtido de tabelas (Seed e Idriss, 1970) em função do índice de vazios ou densidade relativa da areia. Para pedregulhos, Seed et al. (1984) indicaram valores de $\mathrm{K}_{2 \max }$ no intervalo entre 80 a 180.

\subsubsection{2 \\ Modelos cíclicos}

O comportamento não-linear do solo é representado por um modelo cíclico que segue a trajetória tensão-deformação durante a aplicação do ciclo de carregamento. Vários modelos deste tipo foram propostos na literatura (Iwan, 1987; Finn et al., 1977; Vucetic, 1990; Pyke (1990), dentre outros) baseados na existência de uma curva tensão x deformação geral (backbone curve) e uma série de regras que governam o comportamento de carregamento-descarregamento, a variação da rigidez do solo, o desenvolvimento de poropressões sob condições não-drenadas, etc. Vários modelos seguem as regras estendidas de Masing (Kramer, 1996) que estabelecem a forma do ciclo para representação das situações de carregamento inicial, descarregamento e recarregamento.

Os modelos cíclicos têm vantagens pois conseguem representar deformações permanentes e a variação da rigidez do solo em função da história de tensões e não somente da amplitude das deformações cisalhantes cíclicas como no modelo linear equivalente, e de também serem capazes de considerar o amortecimento histerético em função da dissipação da energia interna em cada 
ciclo de carregamento - descarregamento (Figura 5.8). Entretanto, sua aplicabilidade é ainda restrita a determinadas trajetórias de tensão.

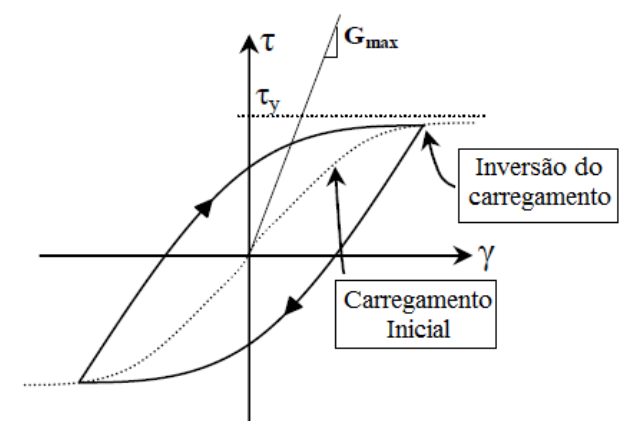

Figura 5.8 - Curvas característica do primeiro ciclo de carregamento em modelo cíclico

\subsubsection{3.}

\section{Modelos elasto-plásticos}

Modelos constitutivos elasto-plásticos avançados são os mais precisos e gerais para representação do comportamento mecânico do solo, permitindo análises com uma grande variedade de história de tensões, comportamento drenado e não-drenado, carregamento cíclico, etc., mas a avaliação experimental dos parâmetros necessários à completa descrição do modelo pode ser de difícil obtenção em ensaios de laboratório. Apesar desta dificuldade de ordem prática, o uso de modelos constitutivos elasto-plásticos avançados tende a aumentar, assim como já vem ocorrendo nas aplicações geotécnicas envolvendo apenas carregamentos estáticos.

Uma das principais dificuldades na modelagem numérica é com relação ao amortecimento do material pois até esta data, no conhecimento deste autor, não há modelo constitutivo que incorpore implícita e plenamente este fenômeno na própria formulação do modelo. Via de regra, na prática são utilizados modelos constitutivos baseados no clássico modelo de Mohr-Coulomb ou em suas adaptações (como o modelo UBCSand para análise de liquefação de solos) com inclusão de parcela adicional de amortecimento viscoso (Rayleigh) ou histerético (modelo linear equivalente).

Nesta dissertação o modelo elasto-plástico de Mohr-Coulomb foi utilizado para representação do comportamento mecânico dos materiais com adição de amortecimento histerético. 


\section{4.}

\section{Aspectos da modelagem numérica em análises sísmicas}

\subsection{1. Convolução e deconvolução do registro sísmico}

As características de um movimento sísmico são comumente obtidas mediante o registro de aceleração (história de acelerações ou simplesmente acelerograma) que é normalmente medido em estações sísmicas sobre afloramento rochoso (outcrop rock) ou solo. Nas análises por modelos numéricos (método dos elementos finitos, método das diferenças finitas) o carregamento sísmico deve ser aplicado na base do modelo, e não na superfície do terreno onde é normalmente medido (Figura 5.9). Uma modificação do registro sísmico é portanto necessária para transportar o sinal da superfície para a profundidade requerida, o que é feito através de um processo de deconvolução, baseado na propagação de ondas verticais SV através de um maciço de solo visco-elástico horizontalmente estratificado, com auxílio de programas computacionais, o mais utilizado dos quais é o SHAKE (Schnabel et al., 1972) ou sua versão mais recente SHAKE2000 (Ordoñez, 2008).

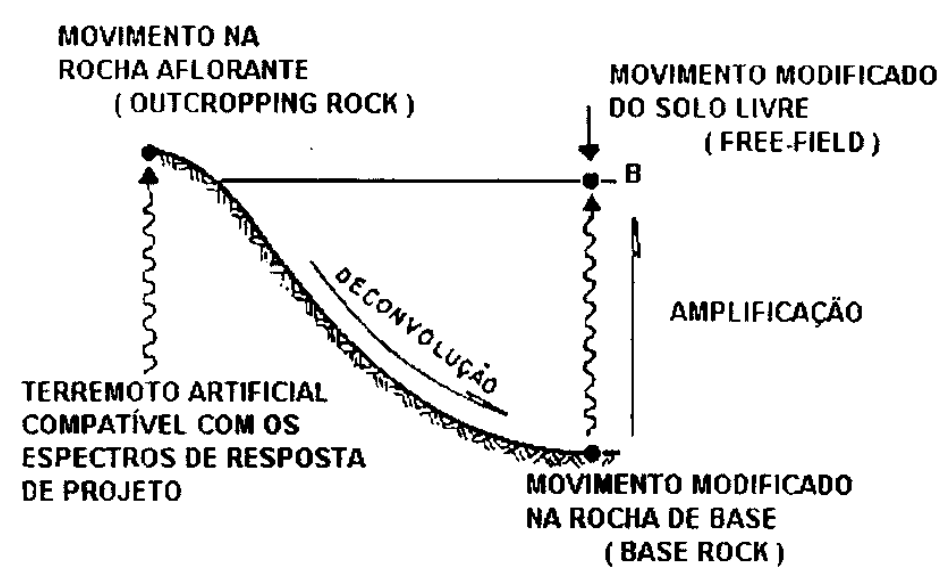

Figura 5.9 - Processo de deconvolução e amplificação (convolução) de registros de aceleração.

(Fonte: Huertas, 2012)

O processo inverso de levar o sinal de certa profundidade (rocha ou solo) até a superfície é chamado de análise de amplificação sísmica ou convolução (Figura 5.9). De acordo com (Huertas, 2012) as análises de convolução são 
frequentemente realizadas para análises dinâmicas quando há necessidade de se limitar o tamanho da malha que representa o modelo numérico, por questões de tempo de processamento ou memória de computador, transportando o registro sísmico para menores profundidades correspondentes à localização da base do modelo.

\subsection{2.}

\section{Base rígida / base flexível}

Há duas alternativas de modelagem para a base da malha no modelo numérico: base rígida (rigid base) ou base flexível (compliant base).

Com a base rígida, o carregamento é prescrito em termos de acelerações ou velocidades enquanto que na alternativa de base flexível é imposto por meio de tensões ou forças. A base rígida reflete para o interior da malha as ondas sísmicas que sobre ela incidem e sua utilização em geral não é recomendada, a não ser que ocorra um alto contraste de impedâncias entre o embasamento rochoso e o solo sobrejacente (Mejia e Dawson, 2006; Itasca, 2011).

Em uma condição de base flexível, o movimento sísmico é aplicado em termos de tensões determinadas em função da velocidade de vibração da partícula de solo,

$$
\begin{aligned}
& \sigma_{n}=2\left(\rho \mathrm{v}_{p}\right) v_{n} \\
& \sigma_{t}=2\left(\rho \mathrm{v}_{s}\right) v_{t}
\end{aligned}
$$

onde $\sigma_{n}$ e $\sigma_{t}$ são as componentes de tensão normal e cisalhante, $\rho$ a massa específica, $\mathrm{v}_{p}$ a velocidade da onda $P, \mathrm{v}_{s}$ a velocidade da onda $\mathrm{S}$ e $\mathrm{v}_{n}$ e $\mathrm{v}_{t}$ as velocidades normal e tangencial da partícula.

O fator 2 que acompanha as equações anteriores considera o fato de que as tensões aplicadas devem ser o dobro das observadas num meio infinito, já que a metade da energia é absorvida pelo contorno silencioso aplicado na base. Em certos casos, se o modelo for superficial, a superfície livre pode originar um incremento na velocidade da base. Assim, na execução da análise dinâmica, devese primeiramente avaliar a resposta na base da estrutura. Se a aceleração ou a velocidade na base não forem similares à do registro sísmico utilizado, então deve-se efetuar um ajuste gradual, alterando o fator 2 até que a resposta da estrutura na base e o sismo de entrada coincidam. Quispe (2008) apresenta um 
exemplo deste caso, usando um fator de 1,15 com o objetivo de concordar os registros na base de modo satisfatório.

\subsection{3.}

\section{Tamanho do elemento (zona)}

A definição do registro sísmico que será utilizado na análise dinâmica da barragem permite também calcular o tamanho máximo das zonas da malha de diferenças finitas de modo a assegurar uma correta transmissão das ondas sísmicas através do modelo. Kuhlemeyer e Lysmer (1973) concluíram que a altura da zona $\Delta \mathrm{l}$ na direção de propagação da onda (onda SV vertical) deve ser menor do que 1/8 a 1/10 do mínimo comprimento de onda presente no problema analisado.

$$
\Delta l \leq \frac{\lambda}{10} a \frac{\lambda}{8}
$$

onde $\lambda$ é o comprimento de onda $S$ associado à máxima frequência do carregamento (frequência de corte $\mathrm{f}_{\mathrm{c}}$ ) obtida do espectro de velocidades de Fourier.

A velocidade de propagação vs de uma onda S é determinada por

$$
v_{s}=\sqrt{\frac{G}{\rho}}
$$

e seu comprimento de onda $\lambda$ por

$$
\lambda=v_{s} f_{c}
$$

onde $\mathrm{G}$ é o módulo de cisalhamento e $\rho$ a massa específica do material.

A limitação da largura da zona não é tão estrita quanto a sua altura, sendo geralmente escolhida entre $3 \Delta \mathrm{L}$ a $5 \Delta \mathrm{L}$ embora seja recomendável manter a razão altura / largura tão próxima da unidade quanto possível. Na equação 5.10 deve-se também observar que o valor de $\mathrm{G}$ se refere ao valor correspondente ao final da análise sísmica, pois em modelagens com amortecimento tipo histerético o módulo de cisalhamento decai com o nível de deformações imposto causado pelo carregamento cíclico. 


\subsection{4. \\ Condições de contorno}

\subsubsection{1. Contornos silenciosos}

A representação de grandes domínios por meio de malhas de tamanho finito sempre foi uma dificuldade na aplicação de métodos numéricos na solução de problemas de geotecnia. Uma técnica bastante utilizada em análises estáticas é truncar a malha a alguma distância e empregar contornos elementares (rígidos) como "aproximação" da real geometria do problema. De fácil implementação, produz resultados desastrosos em análises dinâmicas devido às reflexões de onda ocorridas nestes contornos rígidos artificialmente introduzidos.

Várias técnicas para contornos especiais (silent boundaries) em problemas dinâmicos foram propostas na literatura, dentre as quais a utilização de contornos de transmissão imperfeita (amortecedores) propostos por Lysmer e Kuhlemeyer (1969), que podem ser empregados em análises dinâmicas no domínio do tempo ou da frequência.

Este esquema pode ser interpretado como contornos viscosos conectados aos nós do contorno da malha, cujas propriedades são função do tipo de solo existente naquela localização. Absorvem perfeitamente as onda planas incidentes com ângulo normal $\left(90^{\circ}\right)$ mas perdem gradualmente a eficiência com a diminuição deste ângulo (dai o termo contorno de transmissão imperfeita).

Amortecedores viscosos podem ser utilizados nos contornos laterais e na base da malha para a simulação de uma base flexível. É necessário ressaltar que neste caso não se pode especificar o sismo em termos de aceleração ou de velocidade porque a ação dos contornos silenciosos impediria a propagação das ondas de entrada.

\subsubsection{2.}

\section{Contornos de campo livre}

As condições de contorno de campo livre, aplicadas nas laterais da malha, permitem simular o movimento de um meio de grande extensão, excitado por ondas SV propagando-se verticalmente, que existiria sem a presença da estrutura. As malhas auxiliares de campo livre são discretizadas em n zonas correspondentes ao número de zonas da malha principal junto aos contornos laterais (Figura 5.10). 
As malhas de campo livre vibram considerando a propagação 1D de ondas SV. Com a existência da estrutura, e as consequentes reflexões das ondas sísmicas, bem como as ondas geradas pela vibração da própria estrutura (problema de interação solo-estrutura), os movimentos dos nós da malha principal nos contornos laterais apresentariam movimentos distintos em relação aos calculados pelas malhas auxiliares. Nesta situação, também atuam os amortecedores viscosos nos contornos laterais que, mesmo imperfeitamente, simulam a continuidade dos movimentos, ou sejam representam um depósito de solo de grande extensão lateral com irradiação de ondas para o infinito.

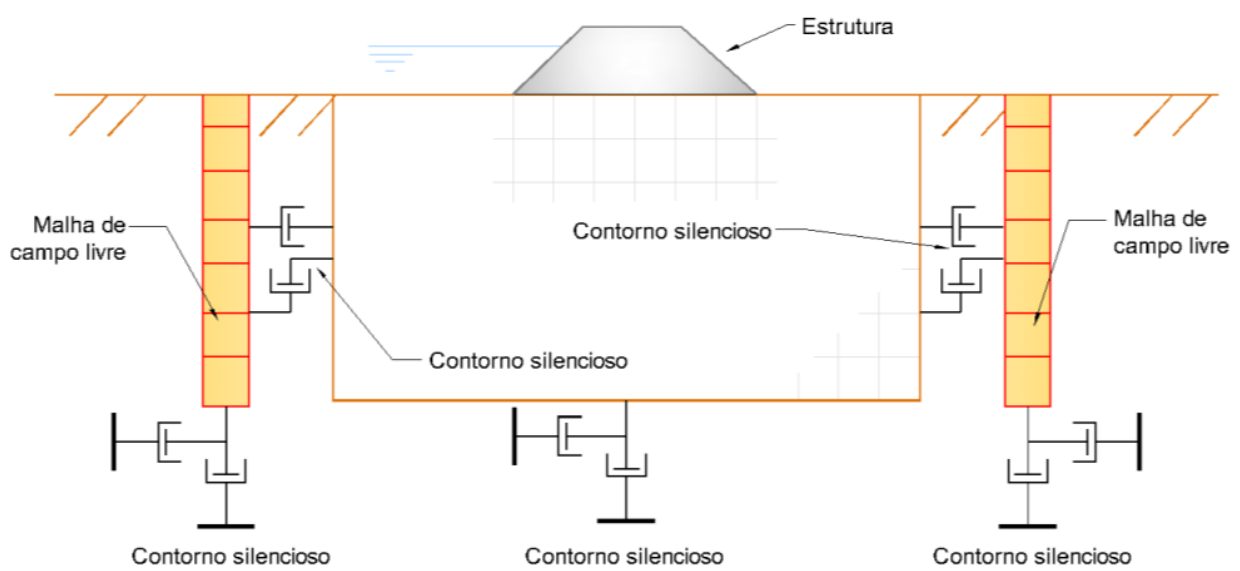

Figura 5.10 - Condição de contorno de campo livre.

(Fonte: Loayza, 2009)

De modo geral, é recomendável utilizar contornos de campo livre para carregamentos de terremoto (excitação aplicada na base da malha) e contornos silenciosos quanto a fonte excitante encontra-se no interior da malha ou na superfície.

\subsubsection{3.}

\section{Amortecimento do material}

Todo material quando submetido a carregamentos dinâmicos apresenta algum grau de amortecimento, caso contrário o sistema oscilaria indefinidamente. $\mathrm{O}$ amortecimento se origina pela perda de energia devido ao atrito interno entre partículas do solo e pela ocorrência de deformações irreversíveis. Na análise de 
problemas sísmicos, dois tipos de amortecimento viscoso são geralmente utilizados: o amortecimento de Rayleigh e o amortecimento histerético.

\section{a) Amortecimento de Rayleigh}

Este tipo de amortecimento foi originalmente utilizado na análise dinâmica de estruturas e corpos elásticos para amortecer os modos de oscilação natural do sistema. Em um intervalo restrito e específico de frequências, o amortecimento de Rayleigh pode ser aproximadamente considerado independente da frequência de vibração. É formulado em termos das contribuições das matrizes de massa e de rigidez,

$$
[C]=\alpha[M]+\beta[K]
$$

onde $C$ é a matriz de amortecimento, $\alpha$ é a constante de amortecimento proporcional à massa e $\beta$ é a constante de amortecimento proporcional à rigidez.

A Figura 5.11 apresenta a variação do amortecimento crítico normalizado em relação à frequência. Para frequências de valores baixos, $\alpha$ é a constante predominante, e consequentemente a massa é o fator prevalecente, enquanto que para frequências com valores elevados a constante $\beta$ domina o sistema e, portanto, a rigidez é a grandeza predominante. Para um único valor de frequência, a chamada frequência mínima $\left(f_{\min }\right)$, o amortecimento de Rayleigh está composto por partes igualmente proporcionais tanto de contribuições da massa quanto da rigidez.

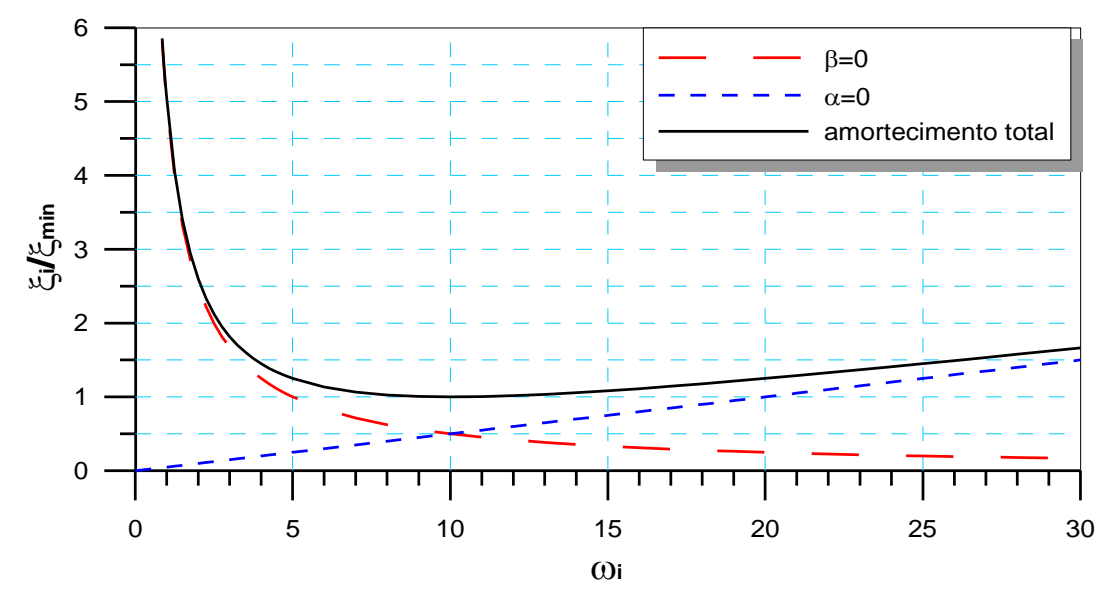

Figura 5.11 - Variação da razão de amortecimento crítico normalizado em relação à frequência angular. (Fonte: Itasca, 2011) 
O amortecimento de Rayleigh somente pode ser usado para um intervalo limitado de frequências e envolve, para soluções explícitas como no programa FLAC, uma redução severa nos passos de tempo e, em consequência, um aumento do tempo de processamento do problema.

\section{b) Amortecimento histerético}

O modelo linear equivalente é usado frequentemente para estimar a resposta dinâmica de maciços de solos e rochas. Não captura diretamente qualquer efeito não linear, pois assume linearidade durante o processo de resolução, por meio de reajustes dos valores do módulo de cisalhamento $\mathrm{G}$ e da razão de amortecimento $\xi$ em sucessivas iterações lineares. A degradação do módulo de cisalhamento (Figura 5.12) e o aumento da razão de amortecimento com os níveis das deformações cisalhantes foram obtidas por meio de ensaios de laboratório para diversos tipos de solos coesivos e granulares bem como para rochas.

O amortecimento histerético independe da frequência de vibração sendo determinado com base nos níveis de deformação cisalhante. O processo de cálculo, além de mais rápido do que a alternativa de amortecimento de Rayleigh, reproduz mais fielmente o comportamento dinâmico de materiais geológicos.

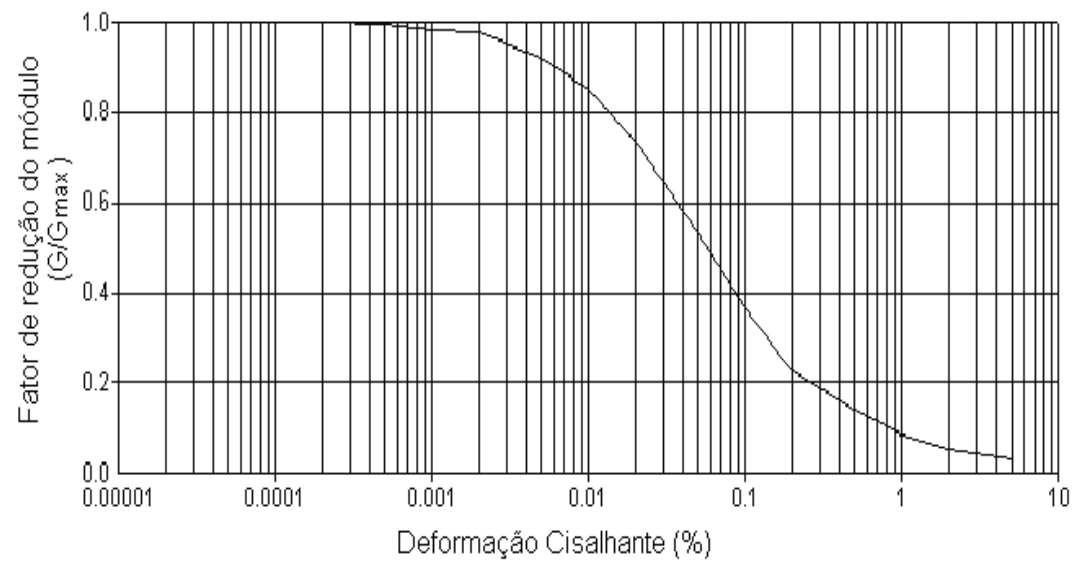

Figura 5.12 - Limite superior da curva de redução do módulo de cisalhamento para areias, proposta por Seed \& Idriss (1970).

A dificuldade de utilização do amortecimento histerético no programa FLAC é que a curva de degradação do módulo $\mathrm{G}\left(\mathrm{ou} \mathrm{G}_{\mathrm{sec}}\right.$ ) é utilizada para uma estimativa teórica do aumento da razão de amortecimento $\xi$ conforme equação 
5.13 , enquanto que em outros programas computacionais ambas as relações obtidas em ensaios de laboratório podem ser introduzidas de modo independente.

$$
\xi=\frac{W_{d}}{4 \pi W_{s}}=\frac{1}{2 \pi} \cdot \frac{A_{\text {laco }}}{G_{\text {sec }} \gamma_{c}^{2}}
$$

onde $\mathrm{W}_{\mathrm{d}}$ é a energia dissipada no ciclo, $\mathrm{W}_{\mathrm{s}}$ é a energia de deformação máxima,

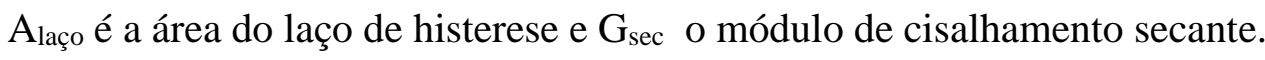

Em consequência, as curvas de aumento da razão de amortecimento são frequentemente incompatíveis, para todo o intervalo de deformações cíclicas cisalhantes, com aquelas obtidas de ensaios de laboratório. Neste caso sugere-se adotar uma solução de compromisso, procurando-se concordar as curvas teóricas e de laboratório no intervalo de deformações esperado para o problema em análise.

Neste processo de calibração o amortecimento histerético em geral apresenta valores menores do que os determinados pela curva experimental da variação da razão de amortecimento, podendo ser produzidos ruídos de baixos níveis, especialmente em altas frequências. Para removê-los aconselha-se utilizar uma pequena quantidade de amortecimento de Rayleigh $(0,2 \%)$ em conjunto com o amortecimento histerético.

\subsection{5.}

\section{Geração de registros sísmicos}

Em uma análise sísmica a definição das características do terremoto de projeto é fundamental. Um registro sísmico criteriosamente selecionado permite obter uma resposta da estrutura mais condizente com a realidade, fornecendo elementos para um dimensionamento que seja tanto técnica quanto economicamente adequados.

A seleção do terremoto de projeto, i.e. a escolha de um carregamento que não se sabe quando atuará, nem qual sua duração ou magnitude, é portanto tarefa complexa. Engenheiros geotécnicos tendem a caracterizar uma análise sísmica como uma estimativa do valor da aceleração horizontal de pico no terreno (PGA), provavelmente porque necessitam deste único valor para cálculo da estabilidade de taludes por métodos pseudo-estáticos, e também tendem a esperar uma 
amplificação da aceleração máxima do terremoto pelas camadas do solo de fundação.

Ora, amplificações ocorrem para frequências próximas à frequência de ressonância das camadas de solo. Caso a frequência predominante do terremoto esteja nesta faixa de valores, então a aceleração horizontal do terremoto será forçosamente amplificada. Caso contrário, as acelerações em outras frequências o serão, gerando eventualmente complicações se estas forem as frequências que concentram a maior energia do terremoto.

Os métodos para seleção do registro sísmico de projeto são basicamente os seguintes (Aguilar, 2001):

- Método da utilização do histórico de registros sísmicos

- Método baseado no modelo de falha

- Método do espectro padrão

O primeiro método consiste de duas alternativas. Na primeira, dispõe-se de um registro sísmico histórico nas proximidades do local do projeto com níveis de aceleração compatíveis com aqueles determinados em estudos de ameaça sísmica regional. O registro sísmico é então utilizado diretamente sem nenhuma modificação.

$\mathrm{Na}$ segunda alternativa, as acelerações do registro sísmico histórico são multiplicadas por uma constante tal que a aceleração máxima coincida com a aceleração máxima prevista no estudo de ameaça sísmica; esta técnica foi muito utilizada no passado (técnica de escalonamento do registro sísmico).

O segundo método baseado no modelo de falha é utilizado para calcular teoricamente as representações da ruptura da falha e a irradiação de ondas sísmicas provocada por esta ruptura. Diversas alternativas de análise podem ser empregadas, baseadas em modelos de fonte sísmicas ou por meio de funções de Green.

O terceiro método, baseado em um espectro padrão, permite gerar registros sísmicos sintéticos por meio da superposição de ondas harmônicas (senoidais) que se ajustam a um espectro de acelerações pré-definido. Uma análise de regressão é usualmente feita baseada no conjunto de registros sísmicos gerados; a aplicabilidade deste método é dependente da quantidade e qualidade dos registros sintéticos assim obtidos. 
Nesta pesquisa foi utilizada a segunda alternativa do primeiro método, i.e. a utilização de registros sísmicos históricos para definição do terremoto de projeto, porém com uma importante modificação. Em vez de apenas fazer a normalização do registro em termos de acelerações máximas, é também feita uma análise de ajuste espectral para que o espectro de resposta do terremoto original esteja tão próximo quanto possível do espectro de resposta uniformemente provável obtido na análise de ameaça sísmica.

Quanto às denominações dos registros sísmicos gerados, Acevedo (2003) estabelece uma diferença nos acelerogramas que não são reais. Acelerogramas sintéticos são aqueles decorrentes dos modelos geológicos de ruptura de falhas, enquanto acelerogramas artificiais são aqueles obtidos pela estimativa no método de ajuste espectral. Portanto, os registros sísmicos considerados nesta investigação correspondem a acelerogramas artificiais.

\subsubsection{1. \\ Método do ajuste espectral}

O método do ajuste espectral modifica o registro sísmico histórico no domínio do tempo procurando torna-lo compatível com o espectro de acelerações especificado pelo usuário. A metodologia foi baseada nas pesquisas de Lilhanand e Tseng (1987), disponível em um código computacional originalmente escrito por Abrahamson (1993) e posteriormente atualizado por Hancock et al. (2006). A modificação do conteúdo de frequências é feita através da adição de pequenas parcelas de onda (wavelets) no domínio do tempo preservando a maior parte das características do registro original. Segundo Meneses (2009) podem acontecer dificuldades neste ajuste nos períodos mais longos do espectro. A Figura 5.13 mostra diferentes espectros de aceleração ajustados a um espectro padrão por meio deste método.

A essência do método de ajuste espectral, conforme Hancock et al (2006), é a seguinte:

- calcula-se a resposta de um espectro com 1 grau de liberdade sob a ação de um registro de aceleração, para cada período e nível de amortecimento desejado; 
- compara-se o pico da resposta do espectro 1D com a amplitude do espectro objetivo para determinar o erro;

- são adicionadas parcelas de ondas (wavelets) no registro da aceleração com amplitudes e fases apropriadas de modo que cada valor do espectro de resposta se ajuste o melhor possível à amplitude do espectro objetivo.

Uma técnica para realização deste ajuste espectral no domínio do tempo encontra-se implementada no software SeismoMatch (SeismoSoft, 2016) com metodologia baseada na metodologia de Hancock et al. (2006), acima resumida.

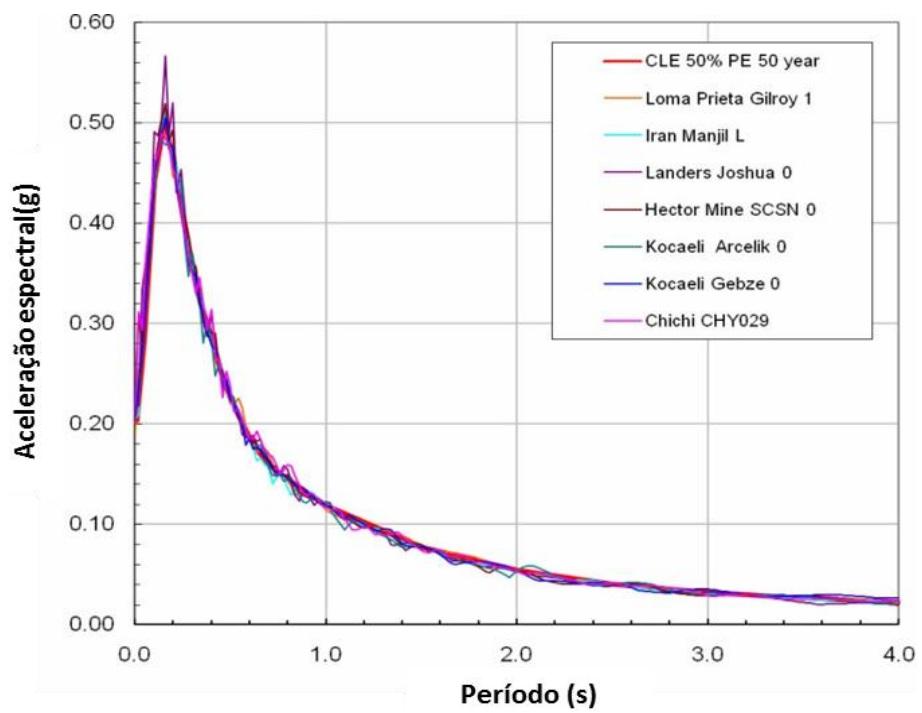

Figura 5.13 - Espectros obtidos por meio do método do ajuste espectral. (Fonte: Meneses, 2009)

Normalmente, é recomendável selecionar um conjunto de três registros para combinar espectralmente para a análise dinâmica de barragens como mínimo para avaliar a variabilidade nas histórias de tempo e compensar picos e vales presentes em diferentes espectros em relação ao alvo (NIST 2011). 


\section{5. Soluções analíticas aproximadas para deslocamentos permanentes em taludes}

\subsection{1. \\ Método de Bray e Travasarou (2007)}

$\mathrm{Na}$ determinação do deslocamento permanente em taludes de solo sob carregamento sísmico, diferentemente da hipótese de bloco rígido do método de Newmark (1965), que ignora a resposta dinâmica de uma massa de solo deformável, Makdisi e Seed (1978) introduziram o conceito de aceleração horizontal equivalente (HEA), que representa a ação sísmica sobre uma potencial massa de solo deformável. O registro da aceleração horizontal equivalente (HEA) aplicado a uma potencial massa rígida produz as mesmas tensões de cisalhamento cíclicas, ao longo da potencial superfície de deslizamento, do que as provocadas quando o mesmo registro é aplicado em uma potencial massa de solo deformável. No método de Makdisi e Seed (1978) os resultados desacoplados são obtidos a partir de uma análise dinâmica executada em dois passos: no primeiro, é determinada a resposta sísmica do talude assumindo que não ocorrem deslocamentos ao longo da superfície de ruptura; no segundo, é aplicado o conceito de bloco rígido deslizante utilizando o registro das acelerações horizontais equivalentes para determinar os deslocamentos permanentes por dupla integração no tempo.

Embora a aproximação desacoplada de Makdisi e Seed (1978) não considere a ocorrência de deslocamentos, sendo os mesmos calculados separadamente com base no método de Newmark (1965), publicações na literatura sugerem que o procedimento pode levar a estimativas razoáveis em alguns casos (Lin e Whitman, 1983; Rathje e Bray, 2000). Em outros, pode produzir superestimativas nas proximidades da frequência de ressonância e subestimativas quando o depósito de solo apresenta um grande período fundamental. A Figura 5.14 mostra um esquema da cada tipo de análise (acoplada e desacoplada) para cálculo dos deslocamentos permanentes induzidos por eventos sísmicos.

Para os métodos que incorporam a resposta sísmica de um bloco deslizante deformável, o período fundamental inicial da massa deslizante (Ts) pode normalmente ser estimado utilizando a expressão $\mathrm{Ts}=4 \mathrm{H} / \mathrm{Vs}$, onde $\mathrm{H}$ é a altura média da massa e Vs a velocidade média da onda de cisalhamento. É admitido 
que a potencial massa deslizante é relativamente grande, na forma de um trapézio ou segmento circular, e que a sua resposta seja predominantemente 1D (Rathje e Bray, 2001). Para o caso especial de uma massa de forma triangular deslizante, a expressão $\mathrm{Ts}=2,6 \mathrm{H} / \mathrm{Vs}$ pode ser empregada. A Figura 5.15 ilustra como o período fundamental Ts pode ser estimado.

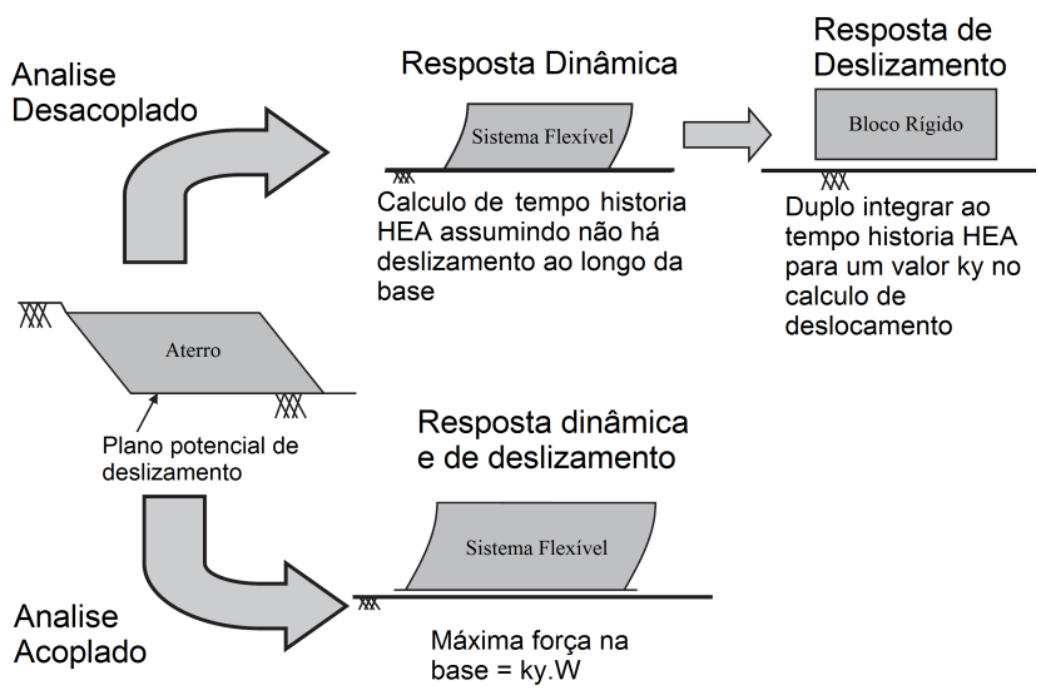

Figura 5.14 -Analises acoplada e desacoplada para determinação dos deslocamentos horizontais permanentes produzidos por evento sísmico.

(Fonte: Bray e Travasarou,2007)

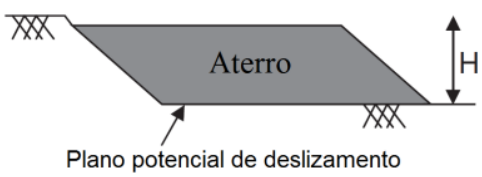

(a) $\mathrm{T}_{\mathrm{s}}=4 \mathrm{H} / \mathrm{V}_{\mathrm{s}}$

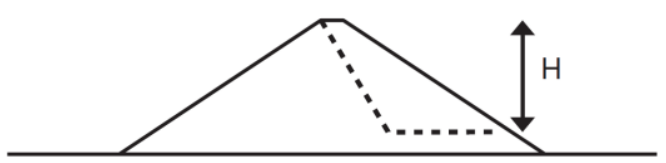

(b) $\mathrm{T}_{\mathrm{s}}=2.6 \mathrm{H} / \mathrm{V}_{\mathrm{s}}$

(c) $\mathrm{T}_{\mathrm{s}}=4 \mathrm{H} / \mathrm{V}_{\mathrm{s}}$

Figura 5.15 - Estimativa do período fundamental para potenciais massas de deslizamento. (Fonte: Bray e Travasarou,2007)

Bray e Travasarou (2007) apresentaram um modelo simplificado, semiempírico e acoplado para estimativa dos deslocamentos permanentes baseado na analogia do bloco rígido de Newmark (1965), como uma proposta de atualização do método simplificado de Makdisi e Seed (1978). Este procedimento envolve um modelo não linear acoplado de bloco deslizante, que pode representar o 
comportamento dinâmico de estruturas geotécnicas como barragens, encostas naturais, aterros compactados e aterros de resíduos sólidos urbanos. Bray e Travasarou (2007) observaram que a maior fonte de incerteza para a avaliação de uma estrutura de terra é o evento sísmico de projeto. Para superar este problema, utilizaram 688 registros sísmicos para calcular os deslocamentos permanentes produzidos e propor um modelo para deslocamentos horizontais permanentes em função do coeficiente sísmico de fluência ky, do período fundamental da estrutura Ts e da aceleração espectral $\mathrm{Sa}(\mathrm{T}=1,5 \mathrm{Ts})$.

O modelo separa a probabilidade de deslocamento "nulo" $(\leq 1 \mathrm{~cm})$, de modo que os valores muito baixos não alteram os resultados finais da previsão. Bray e Travasarou (2007) mostraram que suas estimativas foram consistentes na análise de 16 casos documentados do comportamento sísmico de barragens de terra e de rejeitos.

O modelo proposto pode ser executado considerando abordagens probabilística ou determinística para avaliação dos deslocamentos horizontais permanentes.

\section{a) Avaliação determinística dos deslocamentos horizontais permanentes}

Como mencionado, o modelo consiste em duas etapas de cálculo: (1) a probabilidade de insignificância do movimento (deslocamento horizontal "nulo"); (2) estimativa do deslocamento horizontal permanente "não nulo" ou significativo.

O cálculo da probabilidade de deslocamento nulo é feito de acordo com a equação:

$$
P_{\left(D "^{\prime \prime}\right)}=1-\Phi\left(-1,76-3,22 \ln (k y)-0,484(T s) \ln (k y)+3,52\left(S_{a}(1,5 T s)\right)\right)
$$

onde

$P(D=0)$ é a probabilidade de ocorrência de deslocamento "nulo"

$D$ é o deslocamento horizontal permanente $(\mathrm{cm})$

$\Phi$ a função de distribuição normal de probabilidade acumulada

$k y$ o coeficiente sísmico de fluência

Ts o período fundamental inicial da massa deslizante (segundos)

$S a(1,5 T s)$ a aceleração espectral com $5 \%$ de amortecimento para um período $1,5 \times T s$. 
Se a probabilidade de ocorrência de deslocamento horizontal permanente não nulo for significativa, então este pode ser determinado com a seguinte equação:

$$
\begin{aligned}
& \ln (D)=-1,1-2,83 \ln (k y)-0,333(\ln (k y))^{2}+0,566 \ln (k y) \ln (S a(1,5 T s))+ \\
& +3,04 \ln (S a(1,5 T s))-0,244(\ln (S a(1,5 T s)))^{2}+1,5 T s+0,278(M-7) \pm \varepsilon
\end{aligned}
$$

onde

$\varepsilon$ é a variável aleatória de distribuição normal

$M$ a magnitude do evento sísmico

O coeficiente sísmico de fluência (ky) é estimado em um processo iterativo de análise pseudo-estática de estabilidade de taludes até a obtenção de um fator de segurança igual a 1,0 .

\subsection{2.}

\section{Método de Swaisgood (2013)}

Swaisgood (2013) analisou estatisticamente os casos históricos de deformação de barragens entre 1990-2003 procurando correlacionar os recalques de crista (Figura 5.16) com a aceleração de pico (PGA) e a magnitude de momento (M), envolvendo 82 terremotos com magnitudes entre 5,3 e 9. As relações obtidas por análise de regressão são mostradas nas equações 5.16 e 5.17 .

$$
\% \text { Deslocamento }=e^{(5,70 P G A+0,47 M-7,22)}
$$

$$
\% \text { Deslocamento }=\frac{\text { Deslocamento }}{\text { altura da barragem }+ \text { Espessura da fundação }} \times 100
$$

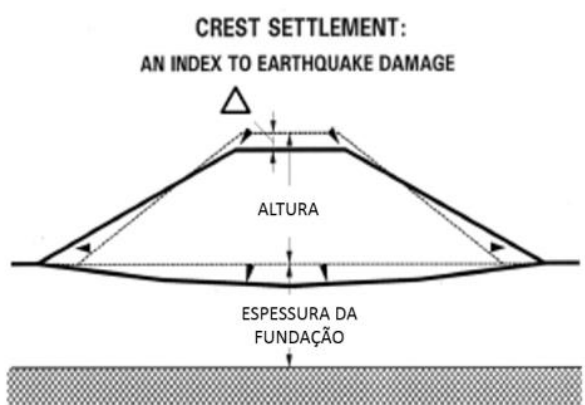

Figura 5.16 - Seção na análise do deslocamento vertical permanente pelo método de Swaisgood (2013). 


\subsection{3.}

\section{Critérios de deslocamentos permanentes permissíveis}

Há poucas informações na literatura relacionando deslocamentos permanentes com funcionalidade de taludes, podendo ser citadas as seguintes:

a) de acordo com a recomendação da California Geological Survey (2008) taludes estáveis apresentam deslocamentos permanentes inferiores a $10 \mathrm{~cm}$ enquanto que taludes com deslocamentos superiores a $100 \mathrm{~cm}$ devem ser classificados como instáveis. No intervalo entre $15 \mathrm{~cm}$ a $100 \mathrm{~cm}$ a deformação do talude pode ser suficiente para causar fissuras e perda de resistência que levem ao colapso pós-sismo, devendo o julgamento do engenheiro, baseado na geometria do talude e nas propriedades dos solos, decidir sobre o nível de segurança do talude nesta situação.

b) de acordo com recomendação do Alaska's Geotechnical Evaluation Criteria Committe (Idriss, 1985) para taludes naturais, cinco classes de danos em função dos deslocamentos permanentes podem ser estabelecidos: dano baixo $(<$ $3 \mathrm{~cm})$, dano moderado $(<15 \mathrm{~cm})$, dano muito alto $(<30 \mathrm{~cm})$, dano extenso $(<$ $80 \mathrm{~cm})$ e dano catastrófico $(<300 \mathrm{~cm})$. 


\section{6 \\ Análises estática e pseudo-estática da barragem de rejeitos Alpamarca}

\section{1. \\ Geometria e propriedades dos materiais}

A análise da barragem de rejeitos Alpamarca é iniciada pelo comportamento na etapa estática, com o alteamento do dique e lançamento dos rejeitos em 10 camadas sucessivas.

A barragem de rejeitos Alpamarca, com altura de $65 \mathrm{~m}$, pode ser classificada como barragem de grande porte de acordo com os critérios da Comissão Internacional de Grandes Barragens (ICOLD, 2012). A análise do seu comportamento é iniciada na condição estática, com o alteamento do dique e lançamento dos rejeitos no reservatório em 10 camadas sucessivas.

A seção transversal utilizada para análise no estado plano de deformação, compreende três tipos de materiais: fundação rochosa (rocha sedimentar), enrocamento do corpo do dique (GC/ GW-GM) e material de rejeitos (ML-CL), com índice de plasticidade IP $=9 \%$.

Ensaios de campo e de laboratório foram realizados, com respectivos valores listados na Tabela 6.1. Na simulação computacional foi considerado o modelo elasto-plástico de Mohr-Coulomb para todos os materiais, definido por quatro parâmetros geotécnicos: módulo de cisalhamento $G$, módulo de deformação volumétrica $K$, ângulo de atrito $\phi$ e coesão c.

O módulo de cisalhamento $G$ para os materiais da fundação foi obtidos de ensaios geofísicos, tais como refracção sísmica executados na região da barragem conferidos com valores obtidos da literatura. Enquanto para os materiais do corpo da barragem e rejeitos foram considerados ensaios de laboratório e valores da literatura. 
Tabela 6.1 - Propriedades dos materiais do dique, rejeitos e fundação.

\begin{tabular}{|l|c|c|c|c|c|}
\hline \multirow{2}{*}{} & Fundação & \multicolumn{2}{|c|}{ Dique } & \multicolumn{2}{c|}{ Rejeitos } \\
\cline { 2 - 6 } & Rocha & Corpo & Dreno & Antigo & Novo \\
\hline Peso específico $\gamma\left(\mathrm{kN} / \mathrm{m}^{3}\right)$ & 25,5 & 23 & 17 & 20 & 18 \\
\hline Módulo de Young E $(\mathrm{MPa})$ & 10000 & 950 & 700 & 56 & 52 \\
\hline Coeficiente de Poisson $v$ & 0,3 & 0,32 & 0,35 & 0,34 & 0,4 \\
\hline Módulo de cisalhamento G $(\mathrm{MPa})$ & 3850 & 360 & 259 & 20,8 & 18,6 \\
\hline $\begin{array}{l}\text { Módulo de deformação volumétrica, } \\
\mathrm{K}(\mathrm{MPa})\end{array}$ & 8333 & 880 & 778 & 59,4 & 86,7 \\
\hline Coesão c $(\mathrm{kPa})$ & 210 & 2 & 0 & 0 & 0 \\
\hline Ângulo de atrito $\phi\left(^{\circ}\right)$ & 27 & 38 & 34 & 28 & 28 \\
\hline Porosidade $\mathrm{n}$ & 0,32 & 0,35 & 0,50 & 0,32 & 0,32 \\
\hline $\begin{array}{l}\text { Coeficiente de permeabilidade } \\
\text { horizontal e vertical } \mathrm{k}_{\mathrm{h}} \mathrm{e} \mathrm{k}_{\mathrm{v}}(\mathrm{m} / \mathrm{s})\end{array}$ & $3,5 \mathrm{E}-05$ & $7,6 \mathrm{E}-07$ & $1,0 \mathrm{E}-03$ & $6,0 \mathrm{E}-08$ & $7,4 \mathrm{E}-07$ \\
\hline
\end{tabular}

A seção transversal representativa da barragem de rejeitos Alpamarca está apresentada na Figura 6.1. A modelagem foi feita em 10 etapas, seguindo o processo construtivo de alteamento do dique pelo método da jusante, indicado na figura, e posterior lançamento dos rejeitos no reservatório sincronizado com cada camada do alteamento de dique. O modelo possui um dreno francês no corpo do dique na região de jusante. A profundidade da fundação no modelo numérico foi estabelecida igual a $30 \mathrm{~m}$, enquanto a dimensão horizontal foi considerada equivalente ou maior ao dobro da altura da barragem $(65 \mathrm{~m})$ de acordo com sugestão de Jiryaei (2010).

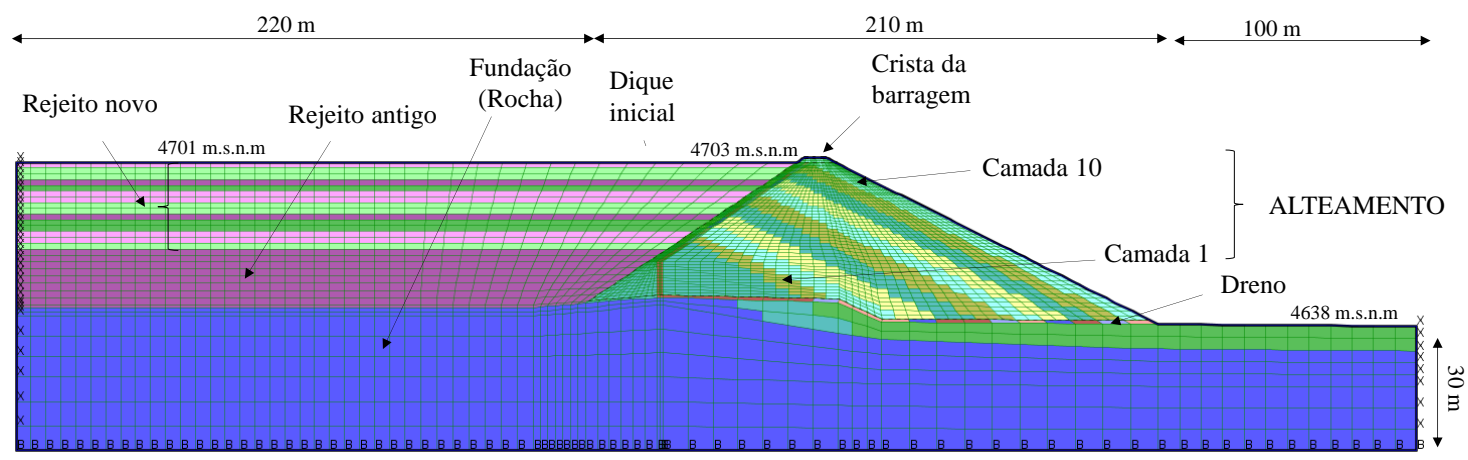

Figura 6.1 - Seção transversal da barragem de rejeitos Alpamarca no modelo numérico 


\section{2.}

\section{Simulação do processo construtivo}

A simulação computacional da construção de aterros e barragens deve ser executada por incrementos de carregamento, devido à natureza não linear da análise e do próprio processo construtivo por etapas da obra. Assim, pode-se representar de maneira mais adequada o comportamento real da estrutura.

Com este procedimento simples e de rápida execução, foram consideradas 10 camadas de solo no alteamento do dique inicial e lançamento dos novos rejeitos em 10 camadas sucessivas.

A Figura 6.2 mostra a distribuição das tensões horizontais após o alteamento final da barragem enquanto a Figura 6.3 se refere ao campo de tensões verticais. As distribuições dos deslocamentos horizontais e verticais nesta etapa de análise encontram-se ilustrados nas Figuras 6.4 e 6.5, respectivamente. Observa-se a ocorrência de maiores deslocamentos horizontais e verticais no reservatório de rejeitos do que o corpo do dique, com a componente vertical atingindo um valor máximo de $0,24 \mathrm{~m}$ na altura média do reservatório, como esperado.

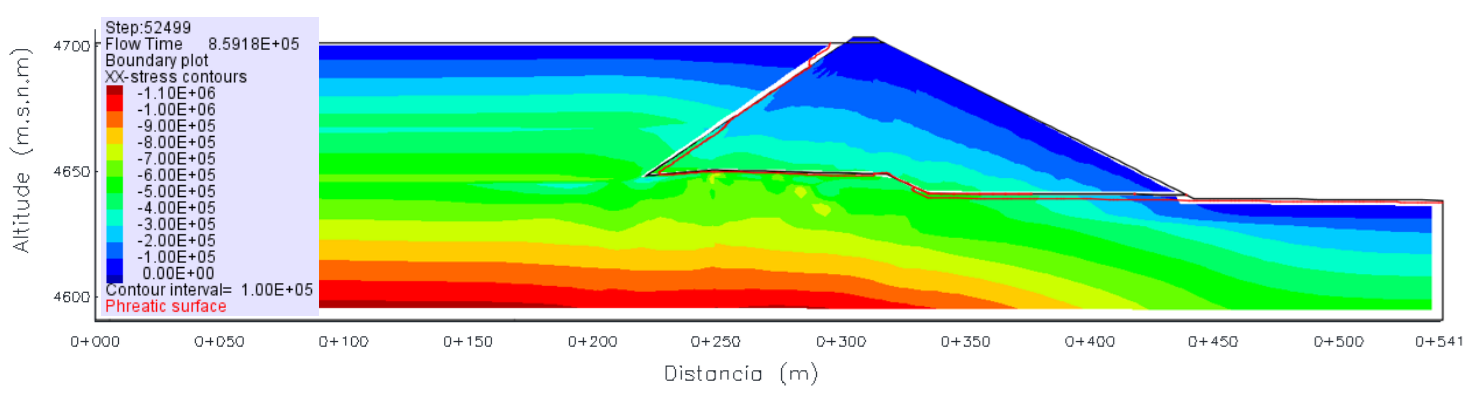

Figura 6.2 - Distribuição das tensões horizontais após o alteamento da barragem de rejeitos.

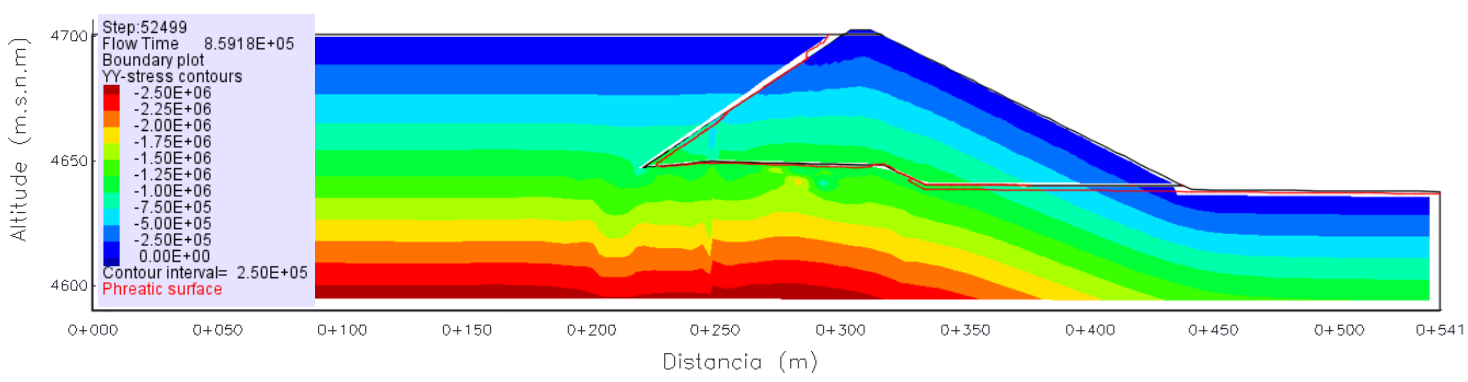

Figura 6.3 - Distribuição das tensões verticais após o alteamento da barragem de rejeitos. 


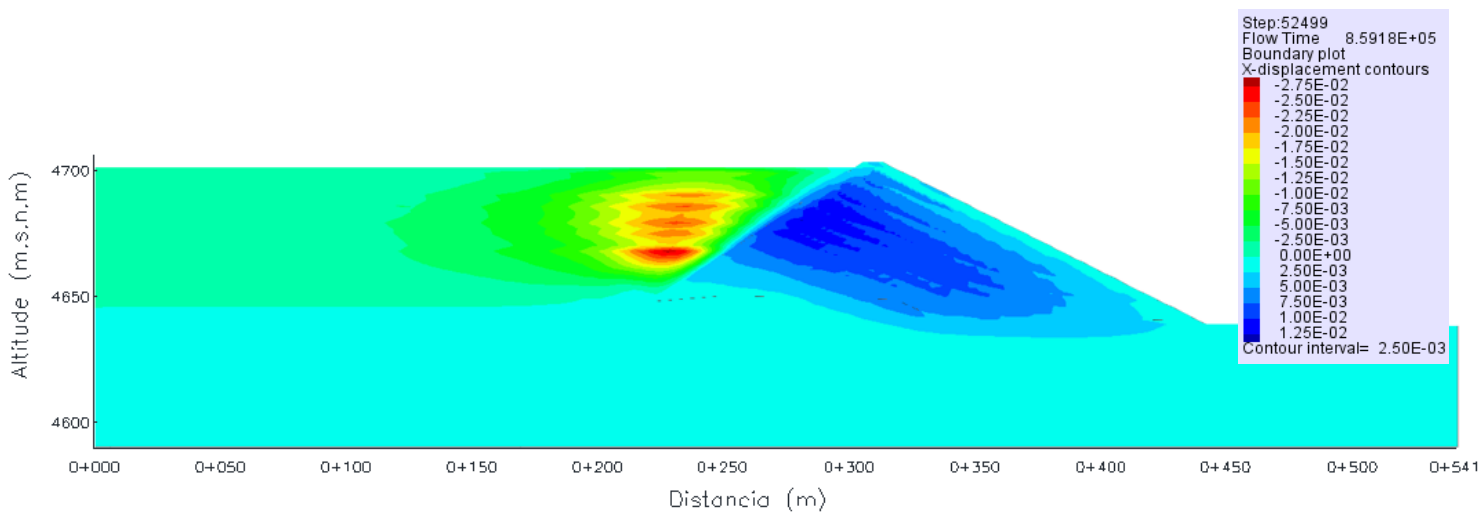

Figura 6.4 - Distribuição dos deslocamentos horizontais após o alteamento da barragem de rejeitos.

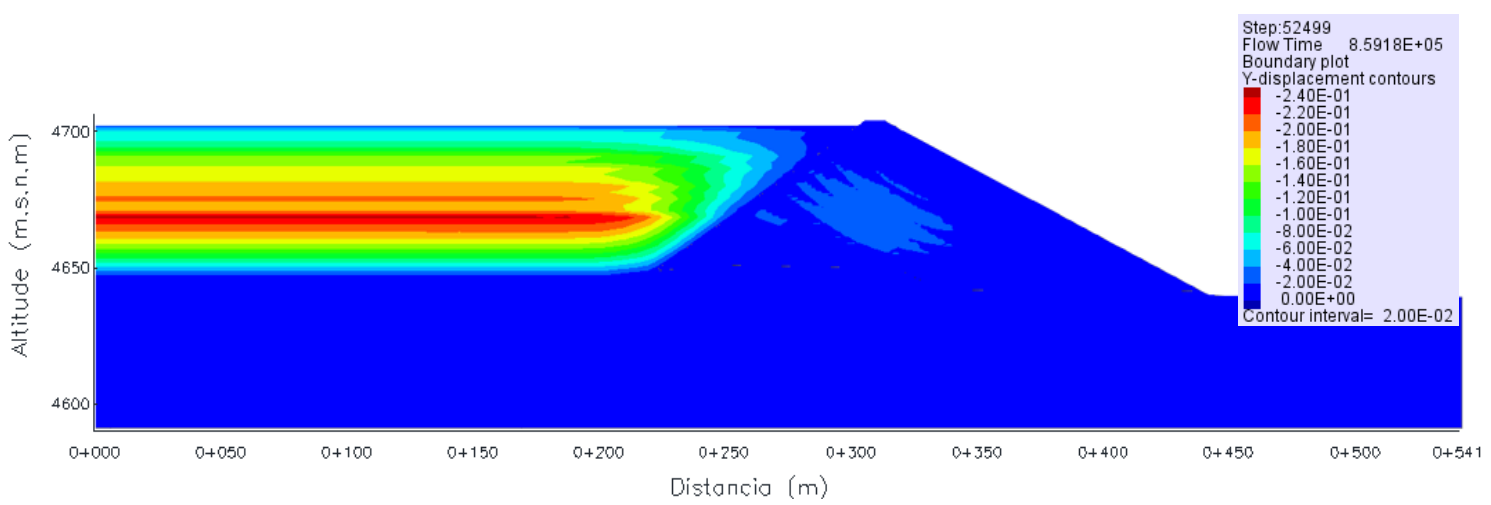

Figura 6.5 - Distribuição dos deslocamentos verticais após o alteamento da barragem de rejeitos.

Em pesquisas passadas na construção incremental de barragens (Contreras, 2014 e Vasquez, 2015) verificou-se que quanto maior o número de camadas consideradas no processo construtivo, tanto maior a definição dos campos de deslocamentos. Para valores baixos do número de camadas, as distribuições mostram-se irregulares, com picos e oscilações, que tendem a desaparecer à medida que o número de camadas é incrementado.

\section{3.}

\section{Fator de segurança estático}

Os valores dos fatores de segurança na análise estática, determinados com a técnica de redução da resistência no programa FLAC 2D, foram calculados ao final do processo construtivo de alteamento da barragem de rejeitos e comparados com os correspondentes valores calculados com o programa SLIDE v.7 (Rocscience, 2017) pelo método das fatias (método de Spencer). 
A comparação entre ambos os resultados (Figuras 6.6 e 6.7) indica fatores de segurança e posições da potencial superfície de ruptura semelhantes. $\mathrm{O}$ valor do fator de segurança é superior a 1,5 indicando a estabilidade do talude de jusante na configuração final do dique.

A vantagem de se empregar um método numérico (diferenças finitas, elementos finitos) é que a forma e a localização da potencial superfície de deslizamento não precisam ser previamente definidas, pois são determinadas durante o processo de solução. Entretanto, várias vezes são produzidos resultados para os quais o colapso detectado pelo programa se refere a superfícies locais, geralmente próximas à crista da geoestrutura, mas que não comprometem a estabilidade global dos taludes. Sempre que rupturas locais superficiais forem identificadas (e descartadas) a estratégia é aumentar a resistência ao cisalhamento dos elementos (ou zonas) localizados nesta região, incrementando os valores da coesão, até a obtenção de uma potencial (e julgada aceitável) superfície de instabilidade global. Este processo muitas vezes requer a comparação dos resultados obtidos numericamente com aqueles determinados por equilíbrio limite.

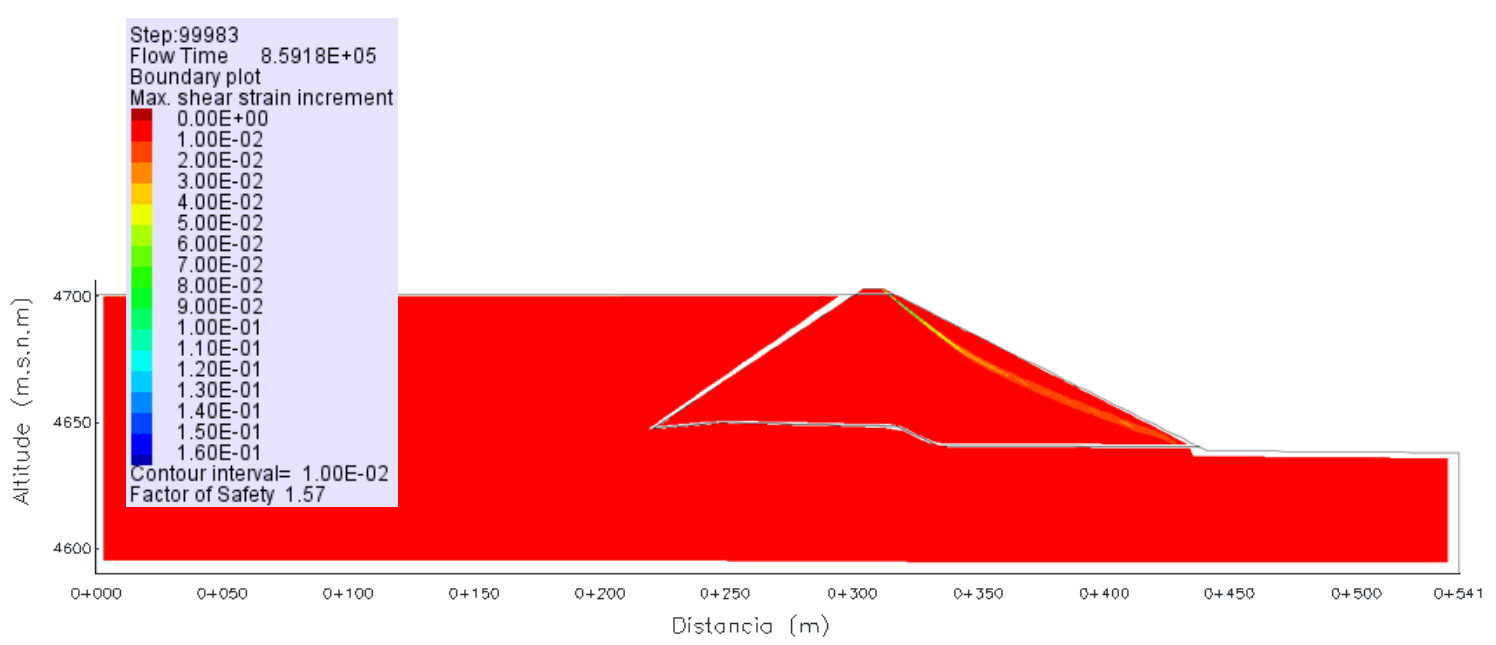

Figura 6.6 - Fator de segurança estático ( $F S=1,57)$ após o término da construção e lançamento dos rejeitos determinado com o programa FLAC 2D. 


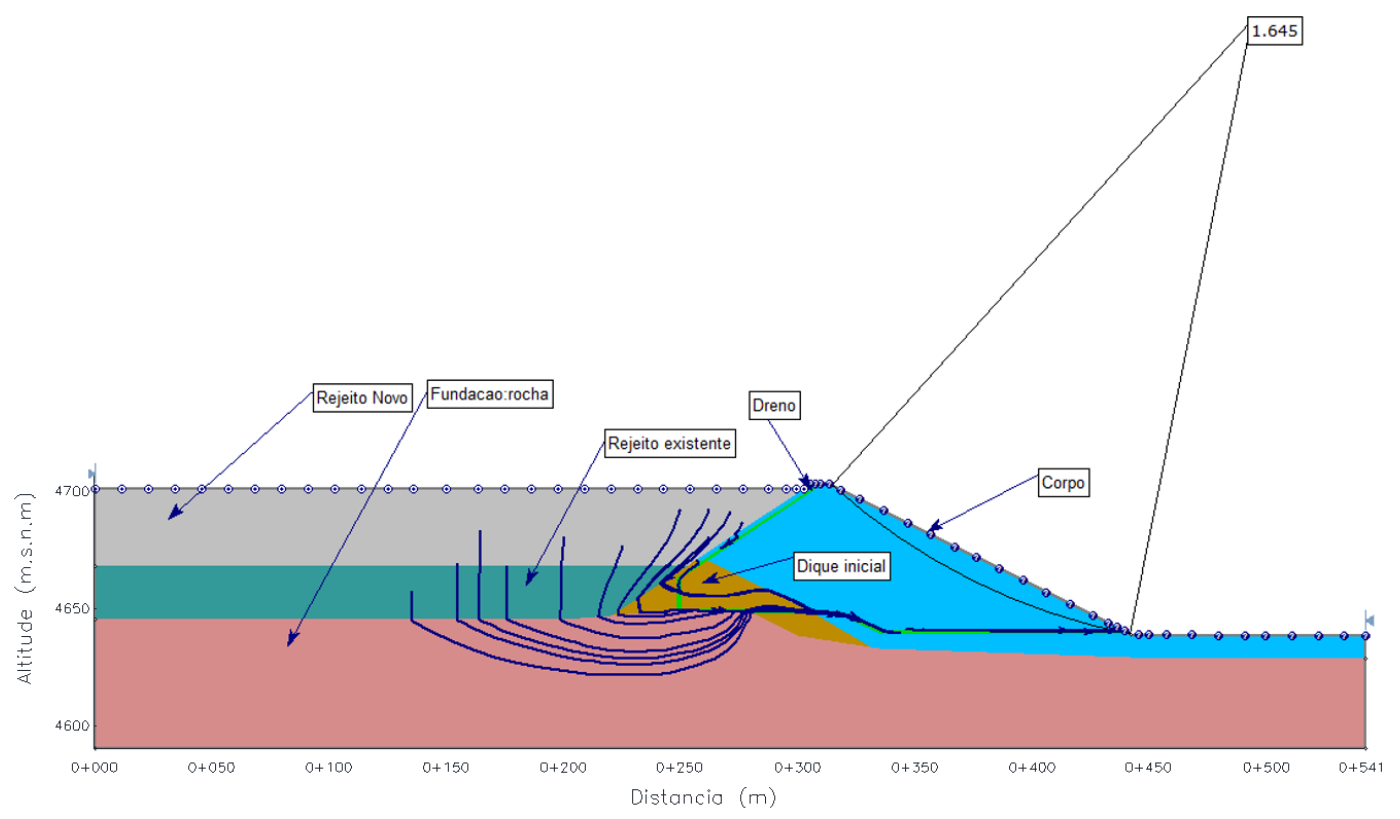

Figura 6.7 - Fator de segurança estático ( $F S=1,64)$ após o término da construção e lançamento dos rejeitos determinado com o método das fatias de Spencer pelo programa SLIDE v.7.

\section{4 . \\ Fator de segurança pseudo-estático}

As diversas soluções de equilíbrio limite para análise das condições de estabilidade de taludes de solo sob carregamento estático, que podem ser consideradas familiares ao engenheiro geotécnico (método das fatias), são possíveis de serem estendidas para um contexto pseudo-estático adicionando-se forças aplicadas no centro de gravidade da massa instável, conservando o mesmo módulo, mesma direção, porém sentido oposto ao das forças inerciais geradas pela propagação da excitação sísmica (princípio de d'Alembert). Neste tipo de análise geralmente a componente vertical da força de inércia é desprezada em função da hipótese de que as ondas cisalhantes incidentes são verticais, e a componente horizontal é obtida pela multiplicação do coeficiente sísmico horizontal $k$ pelo peso total da massa de solo instável (ou peso das respectivas fatias). A escolha adequada do coeficiente sísmico $k$ representa o passo mais importante e difícil no emprego de métodos pseudo-estáticos para análises de estabilidade.

Nesta etapa foi considerado um valor do coeficiente sísmico de acordo com a recomendação de Hynes-Griffin e Franklin (1984), equivalente à 50\% da máxima aceleração em rocha normalizada em relação à aceleração da gravidade. Da investigação de ameaça sísmica, considerando solo tipo B (rocha), o valor da 
máxima aceleração de $0,40 \mathrm{~g}$, para período de recorrência de 975 anos, resulta na adoção de um coeficiente sísmico $\mathrm{k}=0,20$ para aplicação nas análises de estabilidade de taludes por método de equilíbrio limite.

A Figura 6.8 mostra o valor do fator de segurança pseudo-estático determinado no final do alteamento da barragem de rejeitos pelo método das fatias de Spencer com o programa computacional SLIDE. O resultado mostra um valor próximo à unidade $(\mathrm{FS}=1,066)$ indicando que uma análise dinâmica é necessária para melhor verificar o comportamento mecânico da barragem sob carregamento sísmico.

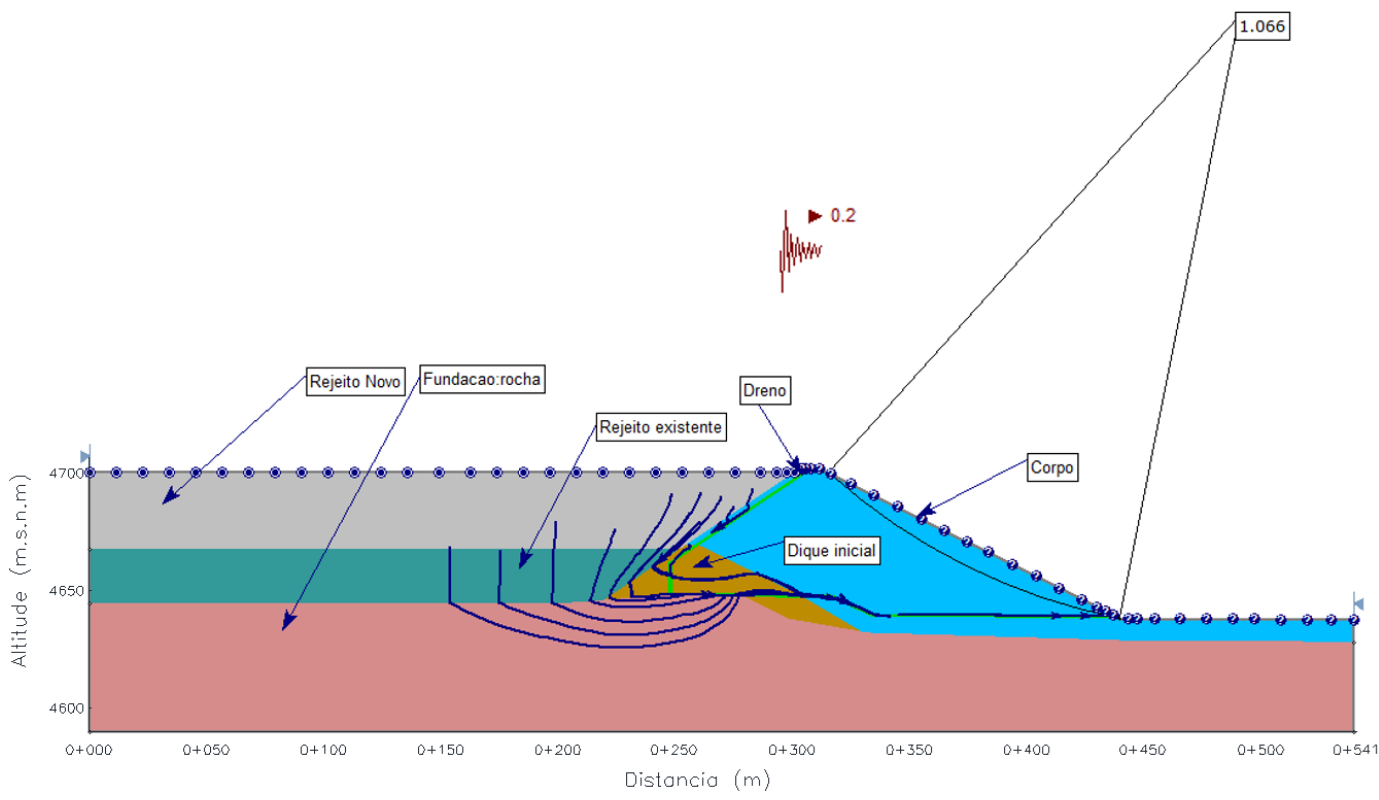

Figura 6.8 - Fator de segurança pseudo-estático $(F S=1,066)$ após o alteamento do dique e lançamento dos rejeitos determinado pelo método das fatias de Spencer com o programa SLIDE v.7. 


\section{7 \\ Análise sísmica da barragem de rejeitos Alpamarca}

\section{1. Introdução}

Neste capítulo são apresentados os resultados da resposta sísmica da barragem de rejeitos Alpamarca, com destaque para seleção e tratamento do sismo de projeto. O procedimento geral é descrito na Figura 7.1, com base na estimativa de ameaça sísmica e do espectro de respostas de aceleração uniformemente provável detalhado no capítulo 3. A geração de acelerogramas artificiais para determinação da resposta sísmica da barragem utilizando o programa computacional FLAC 2D v.8 é discutida no presente capítulo. Os acelerogramas são aplicados diretamente na base do modelo numérico tendo em vista que o material de fundação é rocha. Nas análises computacionais dinâmicas, a opção de fluxo no programa FLAC 2D foi desativada para simular a condição não drenada no comportamento de materiais durante a excitação sísmica.

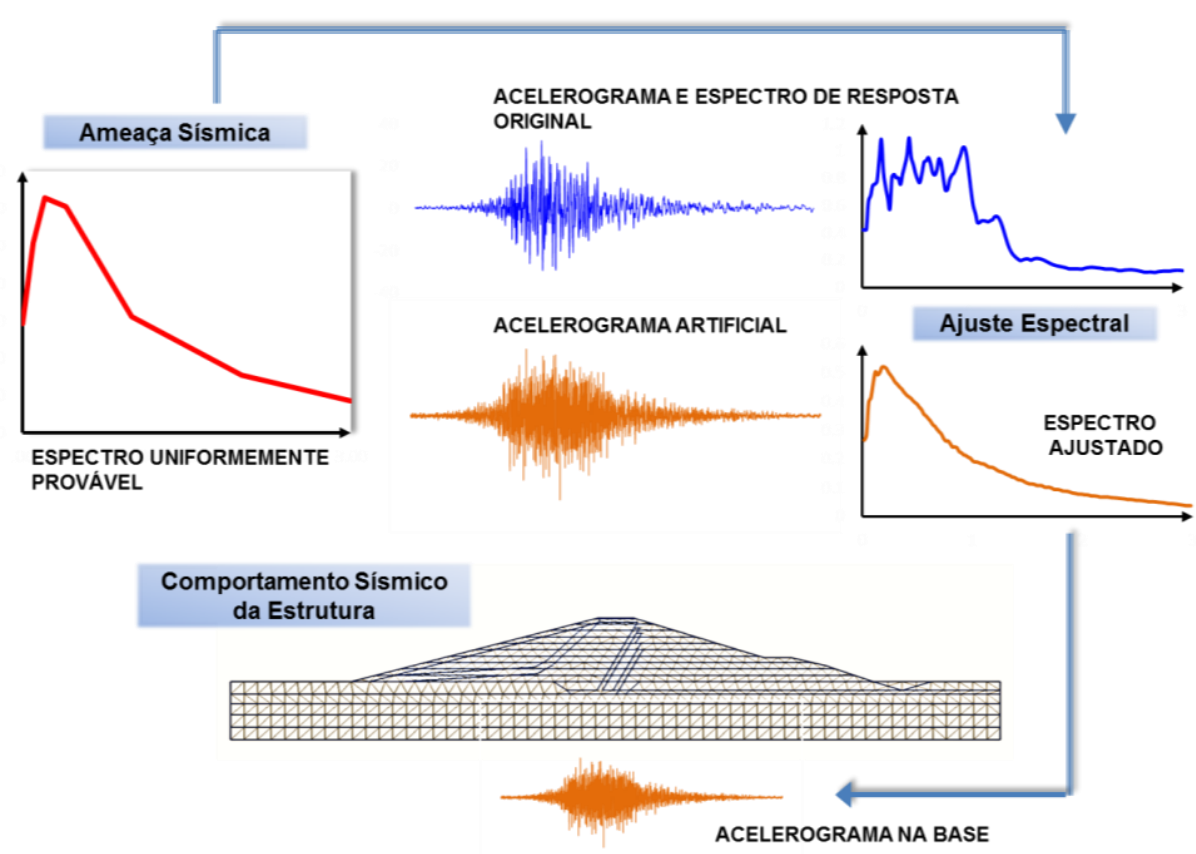

Figura 7.1 - Procedimento geral para análise do comportamento sísmico de uma barragem. 


\section{2.}

\section{Geração de acelerograma artificial}

Os acelerogramas utilizados na modelagem numérica devem incorporar as características da sismicidade local. Será utilizado o método de ajuste espectral (Abrahamson, 1993; Hancock et al, 2006) para geração de acelerogramas artificiais cujos espectros de resposta sejam consistentes com os espectros obtidos no estudo de ameaça sísmica. Os sismos originais empregados no ajuste espectral, para definição do terremoto de projeto, foram registros de terremotos próximos ao local do projeto tais como os sismos de Pisco (2007), Lima (1974) e Costa de Peru (1970) cujas características estão listadas na Tabela 7.1. Para esta pesquisa, foram utilizados os registros de maiores acelerações horizontais, nas direções N-S e EW, totalizando 3 acelerogramas (Figura 7.2) para a realização do ajuste espectral. As localizações dos epicentros desses eventos são mostradas na Figura 7.4.

Tabela 7.1 - Registros sísmicos usados para avaliação dinâmica.

\begin{tabular}{|c|c|c|c|c|c|c|}
\hline SISMO & DATA & MAG $(\mathrm{Mw})$ & MECANISMO & PROF $(\mathrm{km})$ & DIST $(\mathrm{km})$ & ESTAÇÃO \\
\hline $\begin{array}{c}\text { Pisco, Peru } \\
\text { COMP: N-S }\end{array}$ & $\begin{array}{c}15 \text { agosto } \\
2007\end{array}$ & 8,0 & $\begin{array}{c}\text { Subducção } \\
\text { interface }\end{array}$ & 40 & 275 & UNICA \\
\hline $\begin{array}{c}\text { Lima, Peru } \\
\text { COMP: E-W }\end{array}$ & $\begin{array}{c}03 \text { outubro } \\
1974\end{array}$ & 8,1 & $\begin{array}{c}\text { Subducção } \\
\text { interface }\end{array}$ & 13 & 218 & $\begin{array}{c}\text { Parque da } \\
\text { reserva }\end{array}$ \\
\hline $\begin{array}{c}\text { Costa Peru } \\
\text { COMP: E-W }\end{array}$ & $\begin{array}{c}31 \text { maio } \\
1970\end{array}$ & 8,0 & $\begin{array}{c}\text { Subducção } \\
\text { intraplaca }\end{array}$ & 64 & 330 & $\begin{array}{c}\text { Parque da } \\
\text { reserva }\end{array}$ \\
\hline
\end{tabular}
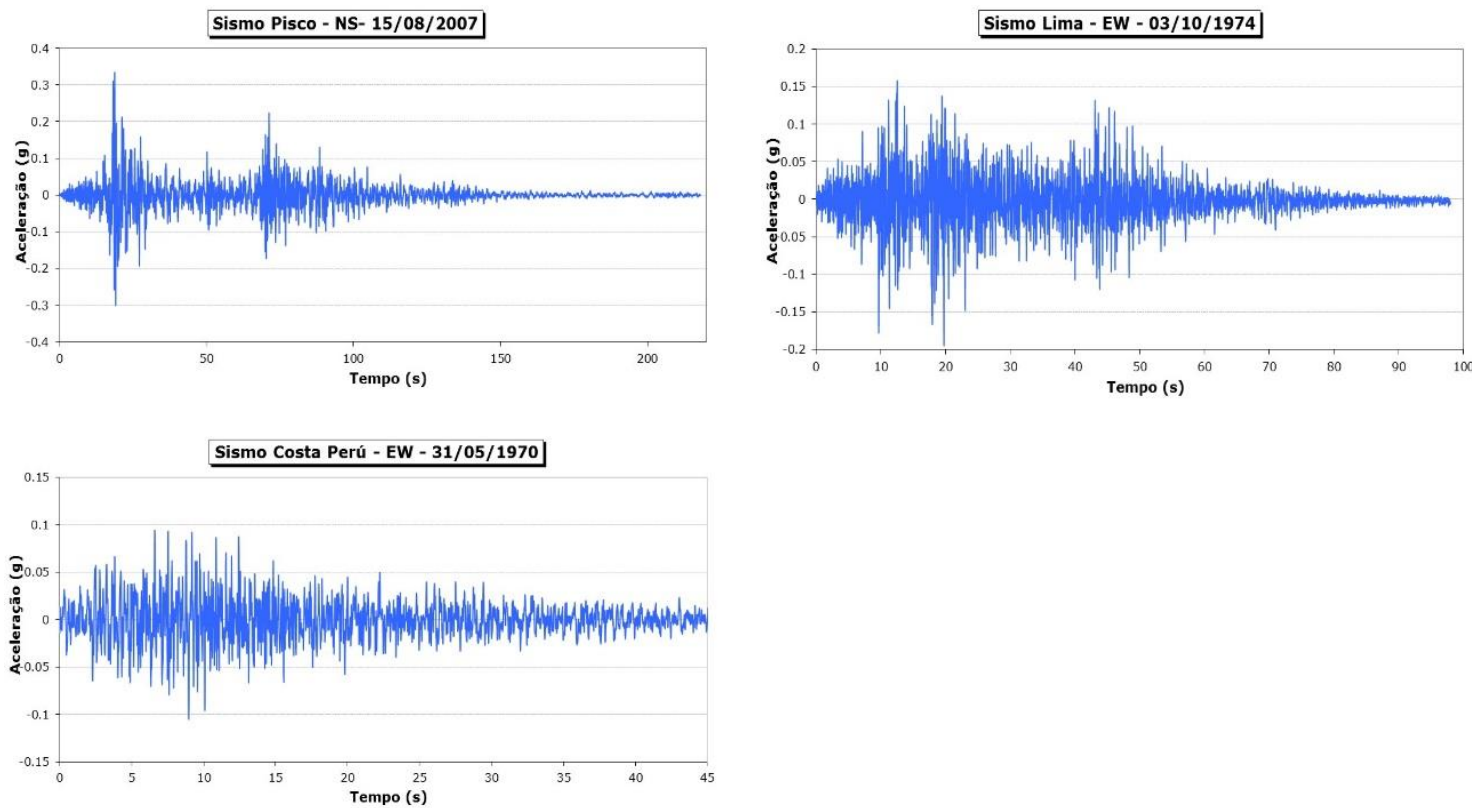

Figura 7.2 - Acelerogramas originais dos sismos de Pisco, Lima e Costa Peru registrados pelas estações ÚNICA e Parque da Reserva. (Fonte: Web CISMID) 

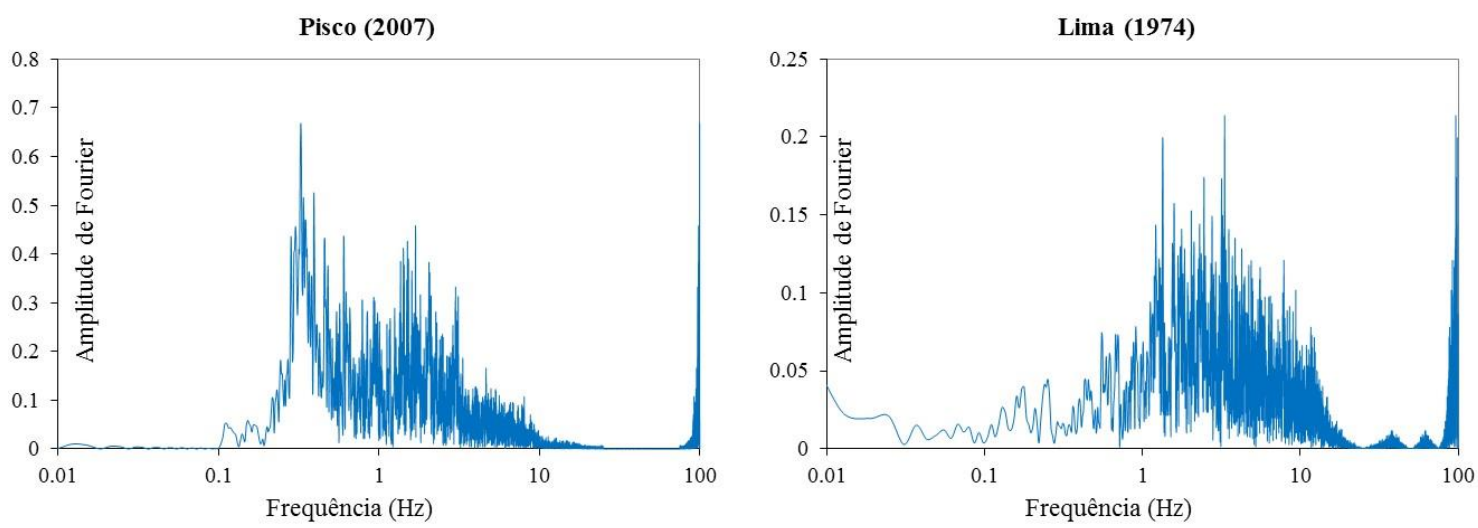

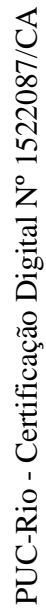

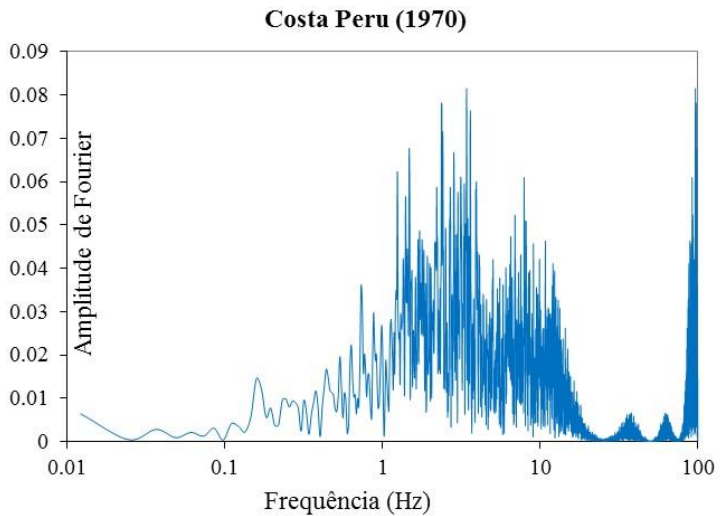

Figura 7.3 - Espectros de Fourier dos acelerogramas originais dos sismos de Pisco, Lima e Costa Peru registrados pelas estações ÚNICA e Parque da Reserva.

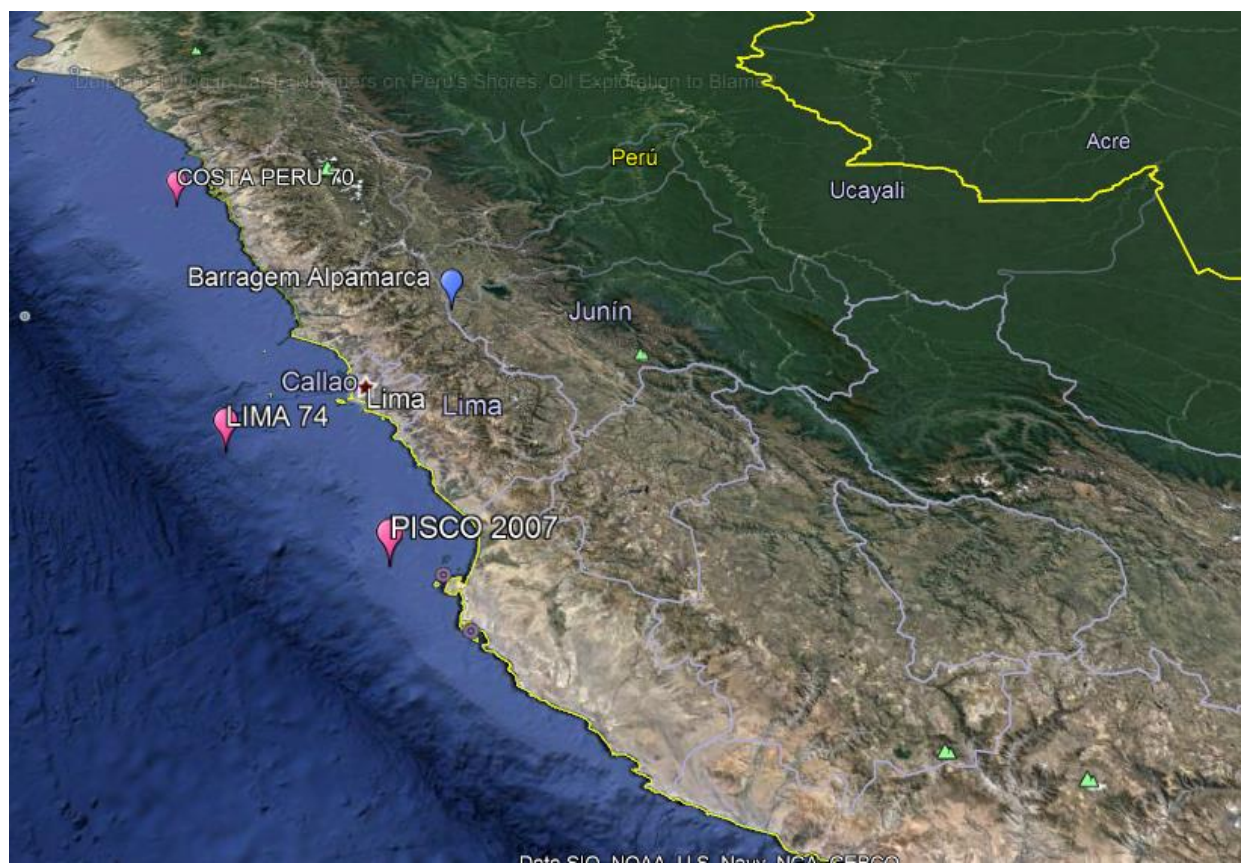

Figura 7.4 - Localizações dos epicentros dos sismos de Pisco, Lima, Costa Peru e do projeto da barragem Alpamarca. 


\section{3.}

\section{Correção da linha base e filtragem}

Os três registros sísmicos foram previamente tratados por correção da linha base e a aplicação de um filtro passa-banda de tipo Butterworth, no intervalo entre 0.1 a $15 \mathrm{~Hz}$, faixa de frequências usualmente considerada em análises sísmicas. Na Figura 7.3 se observou altas frequências que são considerados ruídos. O software utilizado no tratamento de sinais foi o SeismoSignal (SeismoSoft, 2016).

A Figura 7.5 compara as histórias de aceleração, velocidade e deslocamento utilizando os acelerogramas originais e corrigidos pela linha base e filtragem de frequências passa-banda para o sismo de Pisco N-S.
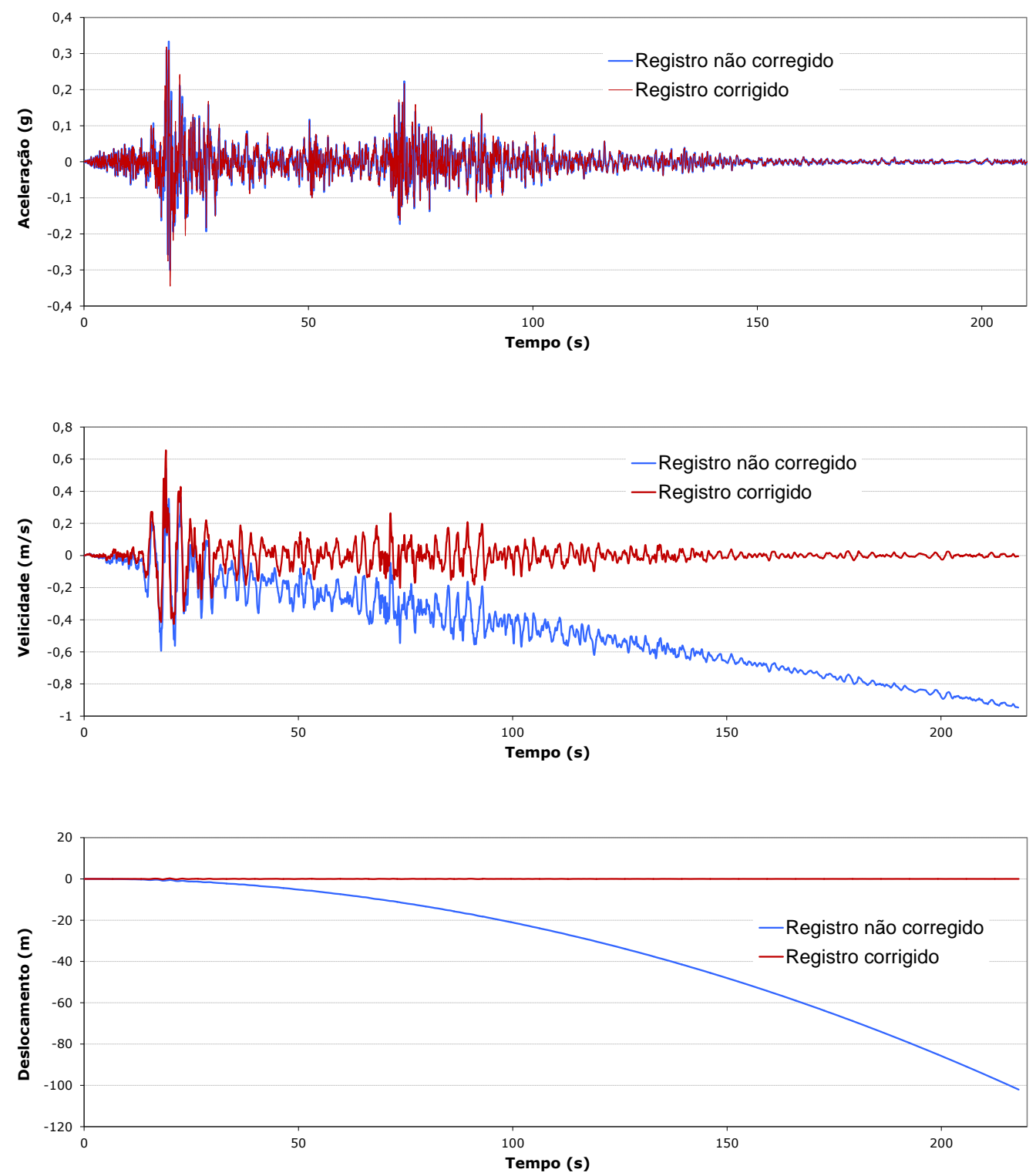

Figura 7.5 - Histórias de aceleração, velocidade e deslocamento originais e corrigidas pela linha base e filtragem para o sismo Pisco N-S. 
Similarmente, foram processados os acelerogramas de Lima E-W e Costa Peru E-W para obter o sismo de projeto na base do modelo numérico, corrigindoo pela linha base e filtragem, como pode ser observado na Figura 7.6.
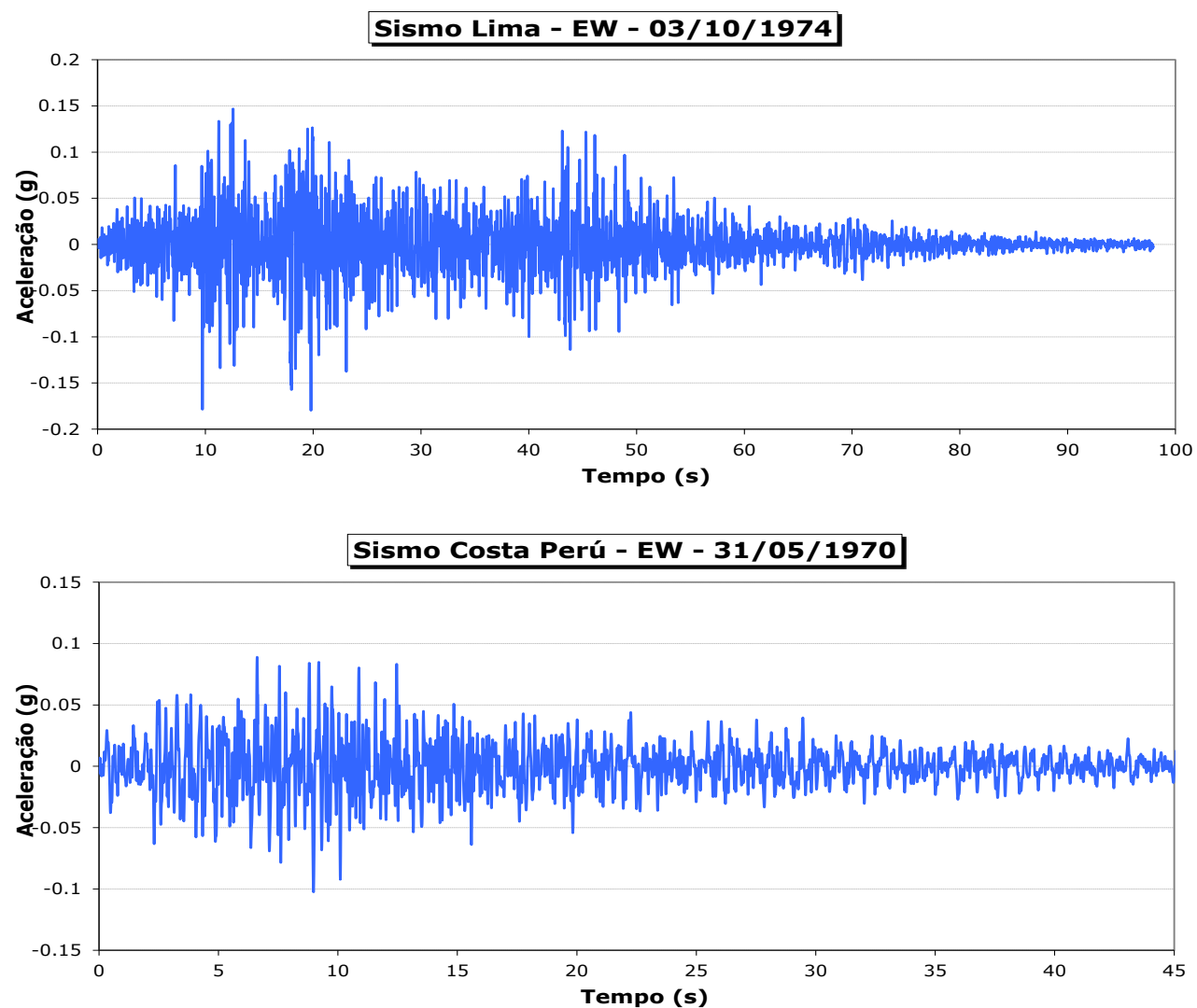

Figura 7.6 - Histórias de aceleração corrigidas pela linha base e filtragem para os sismos Lima E-W e Costa Perú E-W.

\section{4.}

Ajuste espectral

Finalmente, com o objetivo de obter um sismo de projeto compatível com as caraterísticas sísmicas locais, foi feito um ajuste espectral no domínio do tempo, considerando um período de retorno de 975 anos, com auxílio do programa de computador SeismoMatch (Seismosoft, 2016), seguindo o procedimento descrito na seção 5.6.1. Os acelerogramas artificiais assim obtidos estão apresentados na Figura 7.7.

Observa-se também na Figura 7.8 que os espectros de resposta originais estão bem ajustados em relação ao espectro padrão da ameaça sísmica no sítio da barragem de rejeitos Alpamarca. Leves variações aparecem em períodos próximos 
de zero e superiores a $2.0 \mathrm{~s}$. Em geral, estas diferenças podem ser desconsideradas porque os intervalos de períodos estruturais analisados não atingem tais valores.
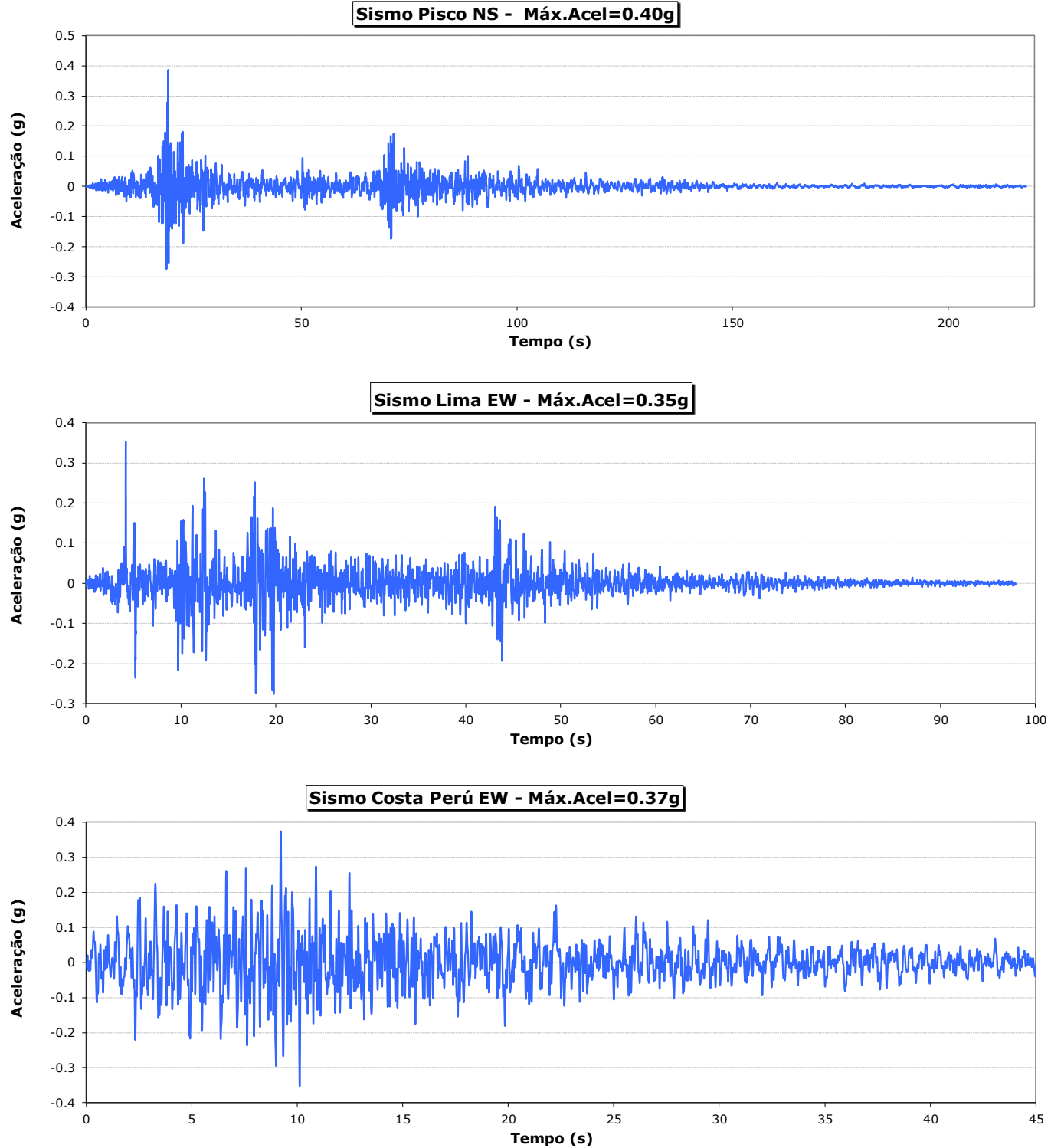

Figura 7.7 - Registros sísmicos artificiais no domínio do tempo correspondentes aos ajustes espectrais dos sismos de Pisco, Lima e Costa Peru. 


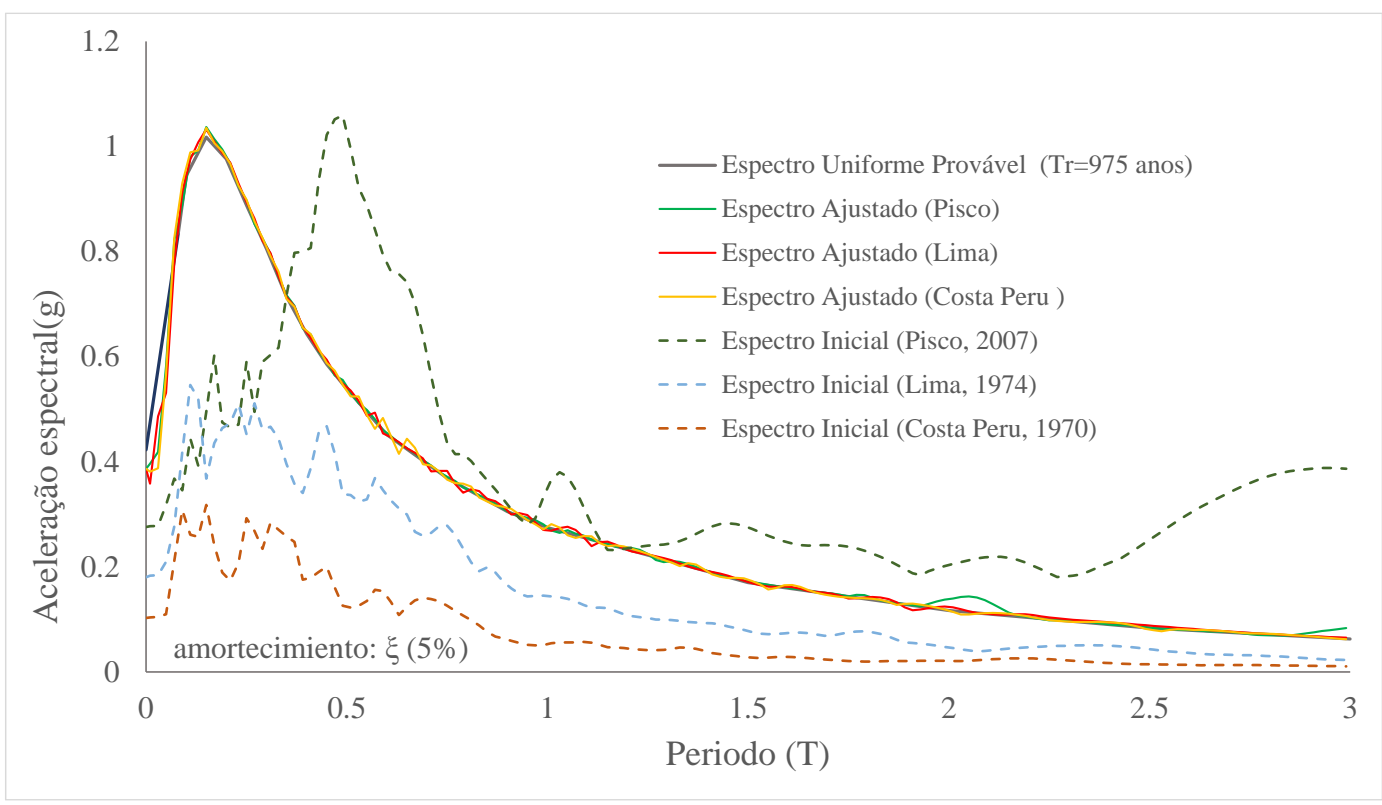

Figura 7.8 - Ajuste espectral no domínio do tempo dos registros de aceleração dos sismos de Pisco, Lima e Costa Peru.

\section{5.}

\section{Frequência de corte e tamanho máximo de zona na discretização}

Para a modelagem da barragem de rejeitos Alpamarca é necessário prescrever que o tamanho máximo do elemento (ou zona) não deve ultrapassar 1/8 do menor comprimento de onda S. Este valor depende da frequência máxima contido no registro sísmico. Para evitar um número excessivo de pequenos elementos na discretização e, consequentemente, reduzir o tempo de processamento das análises, é feita uma pesquisa para verificar até qual frequência limite, conhecida como frequência de corte, o registro sísmico aplicado na base da malha pode ser filtrado sem comprometer significativamente a energia gerada pelo sismo.

Para isto é analisado o espectro de potência do registro de velocidades, já que na análise sísmica da barragem Alpamarca será considerada uma condição de base flexível sendo, portanto, necessário inserir o carregamento em termos de tensões cisalhantes as quais são função do registro de velocidades. Define-se a frequência de corte como aquele valor que permite truncar o espectro de potência do registro sísmico sem mudar significativamente a energia contida na excitação, considerando-se aceitável uma variação de até 5\% no espectro de potência (Itasca, 2011). Os valores de frequência de corte e os correspondentes espectros de potência dos sismos considerados neste trabalho estão apresentados na Figura 7.9, 
com as frequências de corte determinadas para conservação de $99 \%$ da energia dos sismos.
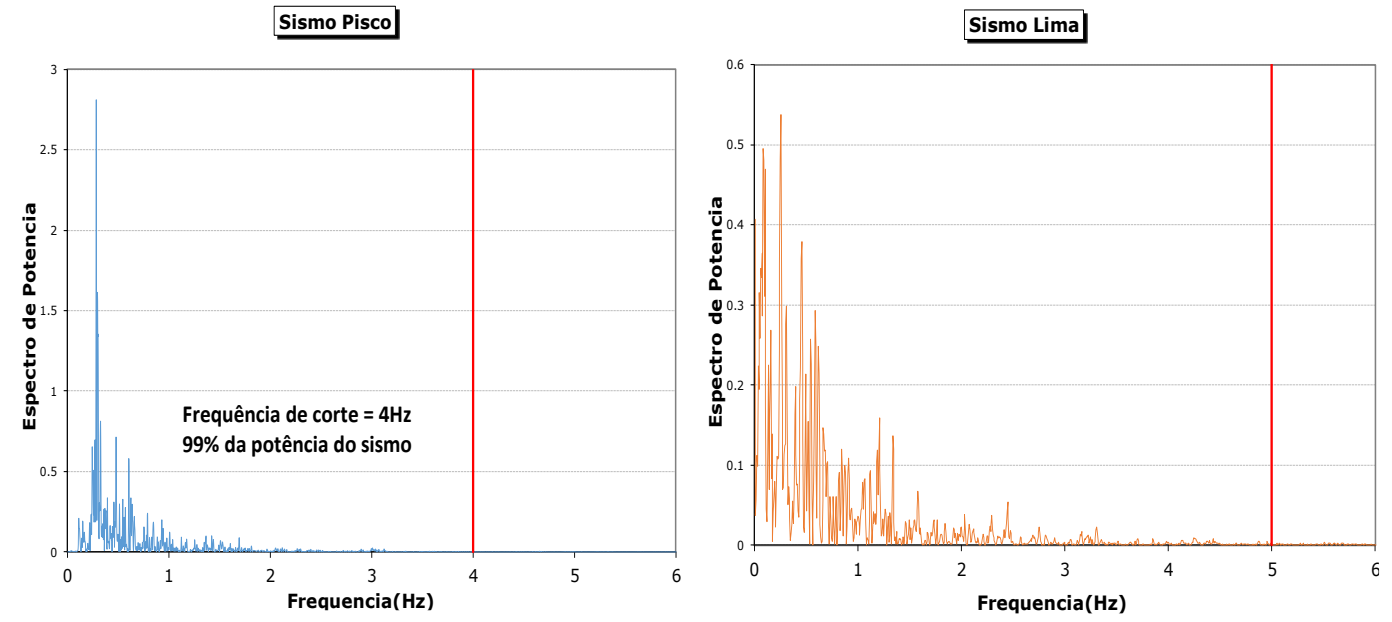

Sismo Costa Peru

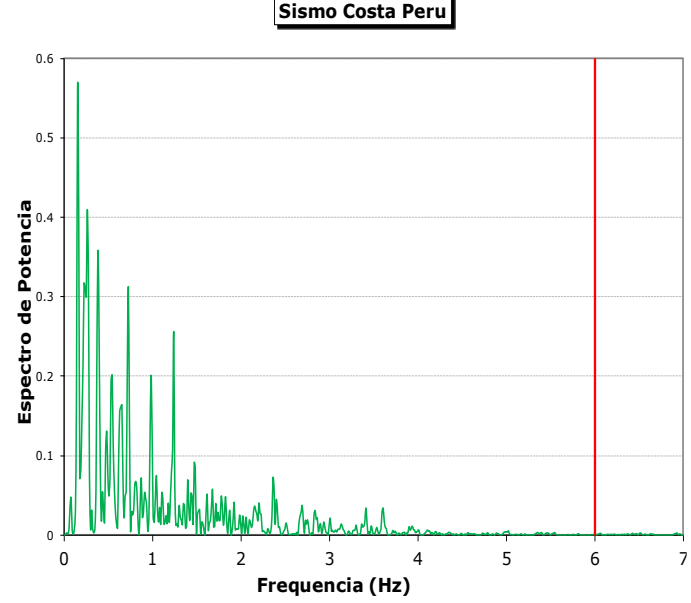

Figura 7.9 - Espectros de potência das velocidades dos registros sísmicos na base do modelo e suas respectivas frequências de corte.

Determinada a frequência de corte $f_{c}$, para cada sismo, e conhecidas as velocidades das ondas de cisalhamento $\mathrm{v}_{\mathrm{s}}$ nos diversos materiais que formam a barragem, é possível calcular o máximo comprimento do elemento na direção de propagação da onda sísmica (direção vertical). Dos 3 sismos considerados, a frequência de corte trabalhada foi $\mathrm{fc}=6 \mathrm{~Hz}$, com valores de máximo comprimento do elemento variando entre $2 \mathrm{~m}$ a $16 \mathrm{~m}$, conforme Tabela 7.2.

A Figura 7.10 apresenta a geometria da seção transversal analisada e a correspondente discretização, formada por 4270 zonas quadrilaterais ou elementos. Em relação à simulação estática anterior, as condições nos contornos laterais foram estabelecidas em termos de campo livre e a condição de contorno 
rígida na base foi substituída por conjunto de amortecedores simulando base flexível.

Tabela 7.2 - Características do modelo numérico para o sismo de Costa Peru (1970).

\begin{tabular}{|l|c|c|c|c|c|c|}
\hline \multirow{2}{*}{ Propriedade } & Fundação & \multicolumn{5}{c|}{ Barragem } \\
\cline { 2 - 8 } & Rocha & $\begin{array}{c}\text { Condição } \\
\text { atual }\end{array}$ & $\begin{array}{c}\text { Alteamento } \\
\text { Corpo }\end{array}$ & $\begin{array}{c}\text { Dreno } \\
\text { Rejeito } \\
\text { Antigo }\end{array}$ & $\begin{array}{c}\text { Rejeito } \\
\text { Novo }\end{array}$ \\
\hline Peso específico, $\gamma(\mathrm{kN} / \mathrm{m} 3)$ & 25,5 & 21 & 23 & 17 & 20 & 18 \\
\hline Mód. Cisalhante, Gmax $(\mathrm{MPa})$ & 2400 & 400 & 400 & 260 & 79 & 47 \\
\hline Onda Cisalhante, Vs $(\mathrm{m} / \mathrm{s})$ & 980 & 436 & 417 & 391 & 199 & 162 \\
\hline Freq. Corte, fc $(\mathrm{Hz})$ & & & & & & 3 \\
\hline Comprimento onda $\lambda(\mathrm{m})$ & 163 & 73 & 70 & 65 & 33 \\
\hline Comprimento zona $\lambda / 10(\mathrm{~m})$ & 16 & 7 & 7 & 7 & 3 & 3 \\
\hline
\end{tabular}

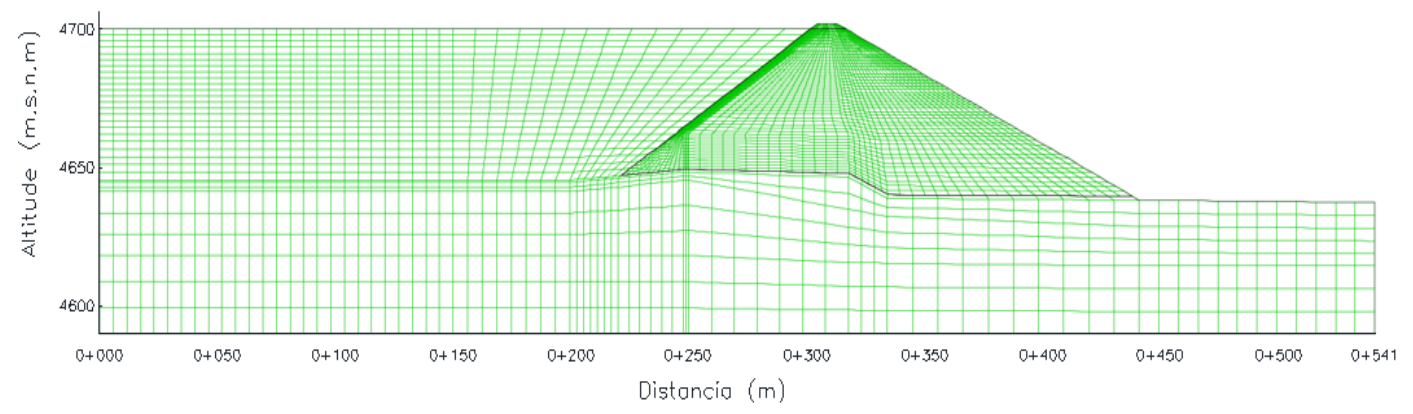

Figura 7.10 - Discretização da malha da seção transversal da barragem de rejeitos Alpamarca.

Em novo procedimento, foi aplicado o filtro passa-baixa, com auxílio do programa computacional SeismoSignal (Seismosoft, 2016), retirando da história de velocidades do sismo de projeto as contribuições das frequências superiores a 4 $\mathrm{Hz}$ para o sismo de Pisco, a $5 \mathrm{~Hz}$ para o sismo de Lima e $6 \mathrm{~Hz}$ para o sismo de Costa Peru. Os novos registros sísmicos, transformados em tensões cisalhantes a serem aplicadas na base do modelo numérico, estão apresentados na Figura 7.11. 

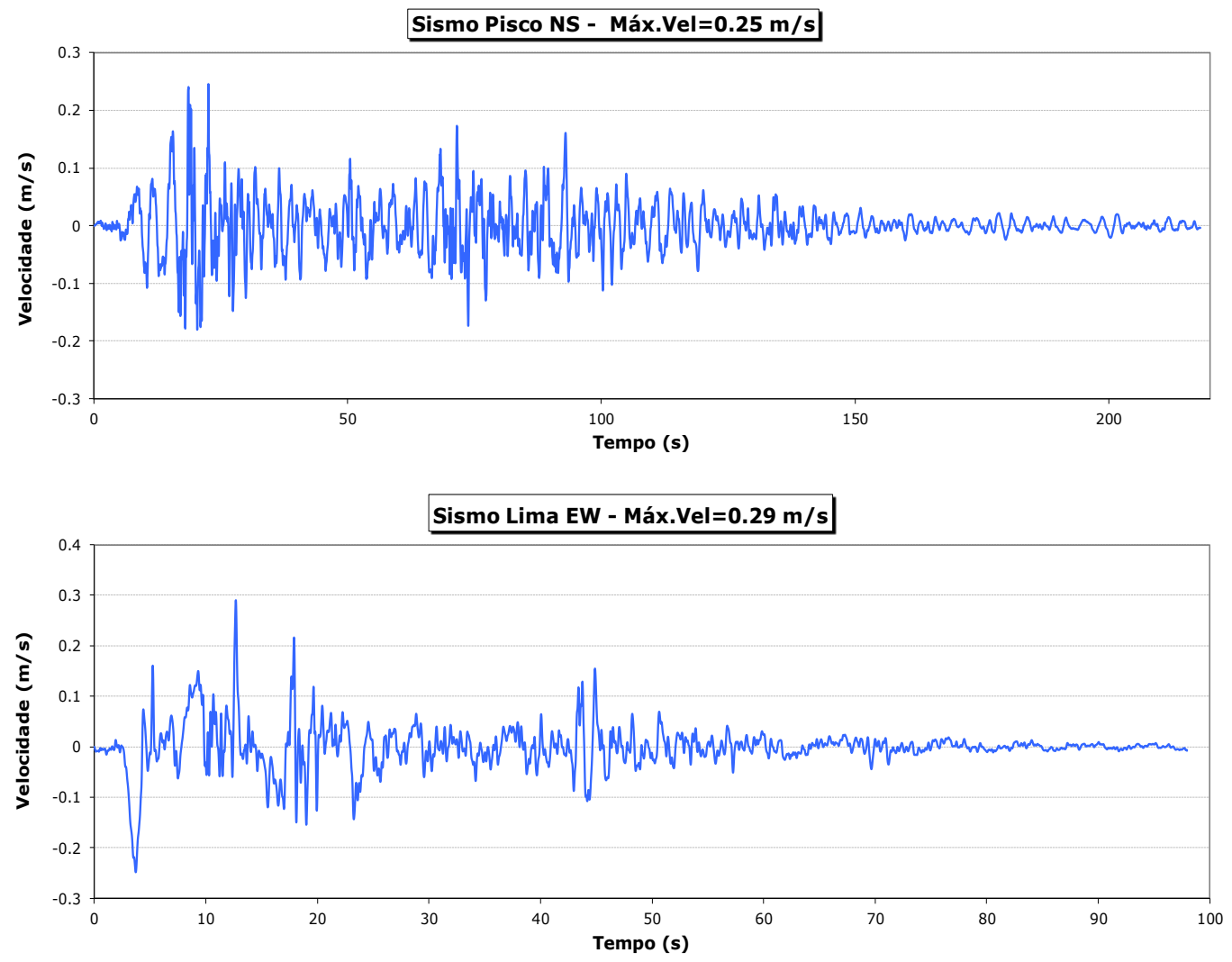

Sismo Costa Perú EW - Máx.Vel=0.19 m/s

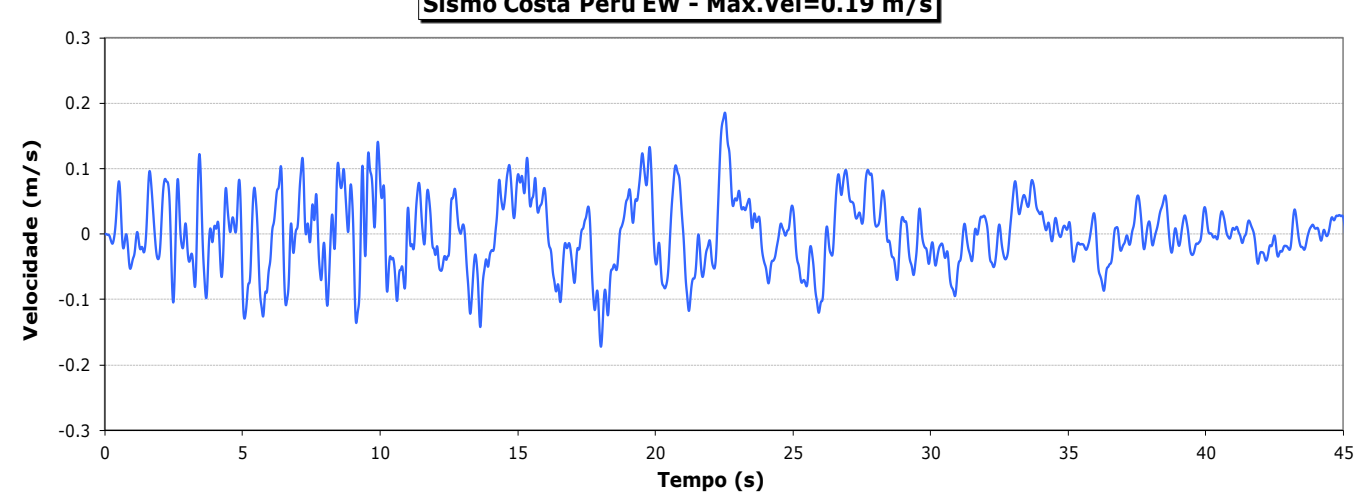

Figura 7.11 - Histórias de velocidades finais dos sismos de projeto

\section{6.}

\section{Módulo de cisalhamento máximo Gmax}

Antes do início da análise sísmica propriamente dita, um esclarecimento em relação ao módulo de cisalhamento máximo. Os valores listados de G na Tabela 6.1 se refere à fase de construção do alteamento da barragem de rejeitos e análise estática do seu comportamento, tendo sido considerados constantes e independentes do estado de tensão.

No entanto, na etapa de análise sísmica, devido ao modelo de amortecimento histerético considerado, os módulos de cisalhamento sofrem 
degradação com a deformação cisalhante cíclica e seus valores iniciais $\left(\mathrm{G}_{\max }\right)$ também não são considerados constantes mas dependentes do estado de tensões efetivas iniciais (final de construção) de acordo com sugestões publicadas na literatura. Este valor de $G_{\max }$ foi considerado para obter o cumprimento máximo apresentado na Tabela 7.2.

Para as areias, Seed e Idriss (1970) propuseram a seguinte expressão para cálculo do valor máximo do módulo de cisalhamento $\mathrm{G}_{\max }$,

$$
\begin{aligned}
& G_{\max }=1000 K_{2 \max }\left(\sigma_{m}{ }^{\prime}\right)^{1 / 2}(\mathrm{em} \mathrm{psf}) \\
& G_{\max }=21.7\left(K_{2, \max }\right) p_{a}\left(\frac{\sigma_{m}^{\prime}}{p_{a}}\right)^{0.5}(\mathrm{em} \mathrm{Pa})
\end{aligned}
$$

onde $\sigma_{\mathrm{m}}$ ' e a tensão efetiva principal média, $\mathrm{p}_{\mathrm{a}}$ a pressão atmosférica e o coeficiente adimensional $\mathrm{K}_{2 \max }$ (no intervalo entre 30 a 70) é obtido de tabelas (Seed e Idriss, 1970) em função do índice de vazios ou densidade relativa da areia. Para pedregulhos, Seed et al. (1984) indicaram valores de $\mathrm{K}_{2 \max }$ no intervalo entre 80 a 180 enquanto que para solos coesivos estimativas preliminares de G são obtidas com base no índice de plasticidade IP, razão de pré-adensamento OCR e da resistência ao cisalhamento não-drenada.

Para areias e materiais granulares grossos Kokusho et al (1981), com base em ensaios triaxiais cíclicos, sugeriram

$$
G_{\max }=8400 \frac{(2.17-e)^{2}}{1+e}\left(\sigma_{m}^{\prime}\right)^{0.6}
$$

onde e representa o índice de vazios, $\mathrm{G}_{\max }$ é o módulo cisalhante $(\mathrm{kPa})$ e $\sigma_{\mathrm{m}}^{\prime}$ é tensão efetiva média $(\mathrm{kPa})$.

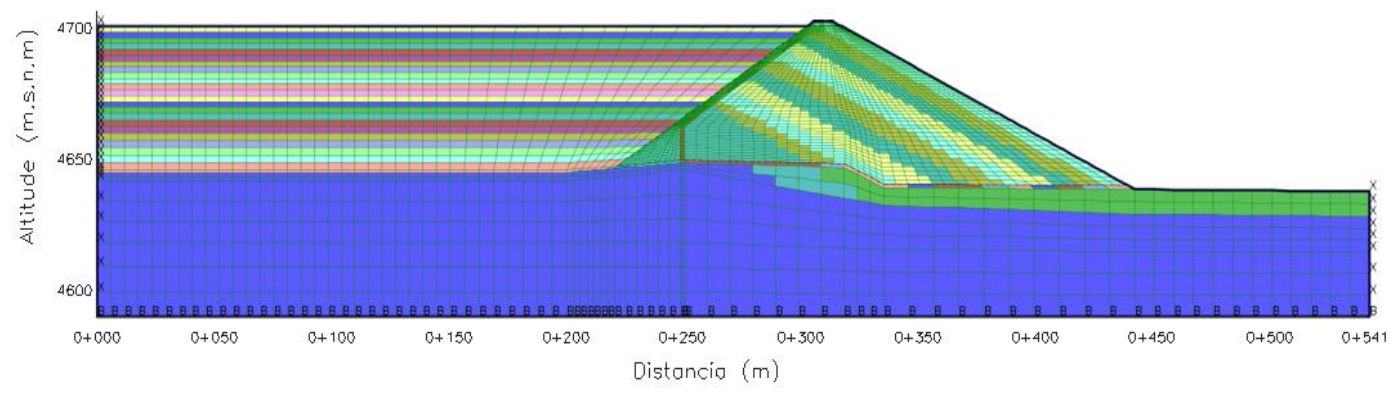

Figura 7.12 - Modelo para analises dinâmico, baseado nas mudanças do módulo de cisalhamento máximo em função da variação da tensão normal efetiva média nos rejeitos. 


\section{7.}

\section{Amortecimento histerético e Railegh}

No programa FLAC 2D o amortecimento histerético, representado pela curva de aumento da razão de amortecimento com a deformação cisalhante efetiva, pode ser matematicamente expresso pela função sigmoidal Sig3 definida por três constantes $a, b, c$ em função do tipo de solo.

Nesta pesquisa foram escolhidas as curvas de degradação do módulo de cisalhamento para pedregulhos propostas por Seed et al (1984), ajustadas por Vasquez (2015), enquanto as curvas de degradação para os rejeitos foram obtidas de ensaios cíclicos de laboratório para diferentes tensões de confinamento, executados por Winckler (2014) e ajustadas para as tensões de confinamento de 240 e $480 \mathrm{kPa}$. As curvas de aumento da razão de amortecimento com o nível das deformações cisalhantes cíclicas para ambos os materiais também são disponíveis de ensaios de laboratório mas, como explicado anteriormente, estas são obtidas por meio de relações teóricas no programa FLAC com considerações de energia em um ciclo de histerese.

Os parâmetros calculados com a função Sig3 estão apresentados na Tabela 7.3 e as respectivas curvas mostradas na Figura 7.13. Pode-se observar que, enquanto as curvas de degradação do módulo de cisalhamento obtidas em laboratório e ajustadas com a função Sig3 exibem uma concordância razoável, as curvas de aumento da razão de amortecimento, principalmente no caso dos rejeitos, são algo discrepantes, em função da metodologia teórica adotada no programa FLAC.

Tabela 7.3 - Parâmetros de ajuste dos materiais com a função sigmoidal Sig3

\begin{tabular}{|c|c|c|c|}
\hline Curva & $\mathrm{a}$ & $\mathrm{b}$ & $\mathrm{c}$ \\
\hline $\begin{array}{c}\text { Dique - Pedregulho } \\
\text { (Seed et al, 1984) }\end{array}$ & 0,98 & $-0,65$ & $-1,6$ \\
\hline $\begin{array}{c}\text { Rejeitos antigos } \\
\text { (Winckler, 2014) }\end{array}$ & 1,005 & $-0,47$ & $-1,008$ \\
\hline $\begin{array}{c}\text { Rejeitos novos } \\
\text { (Winckler, 2014) }\end{array}$ & 1,005 & $-0,478$ & $-1,058$ \\
\hline
\end{tabular}




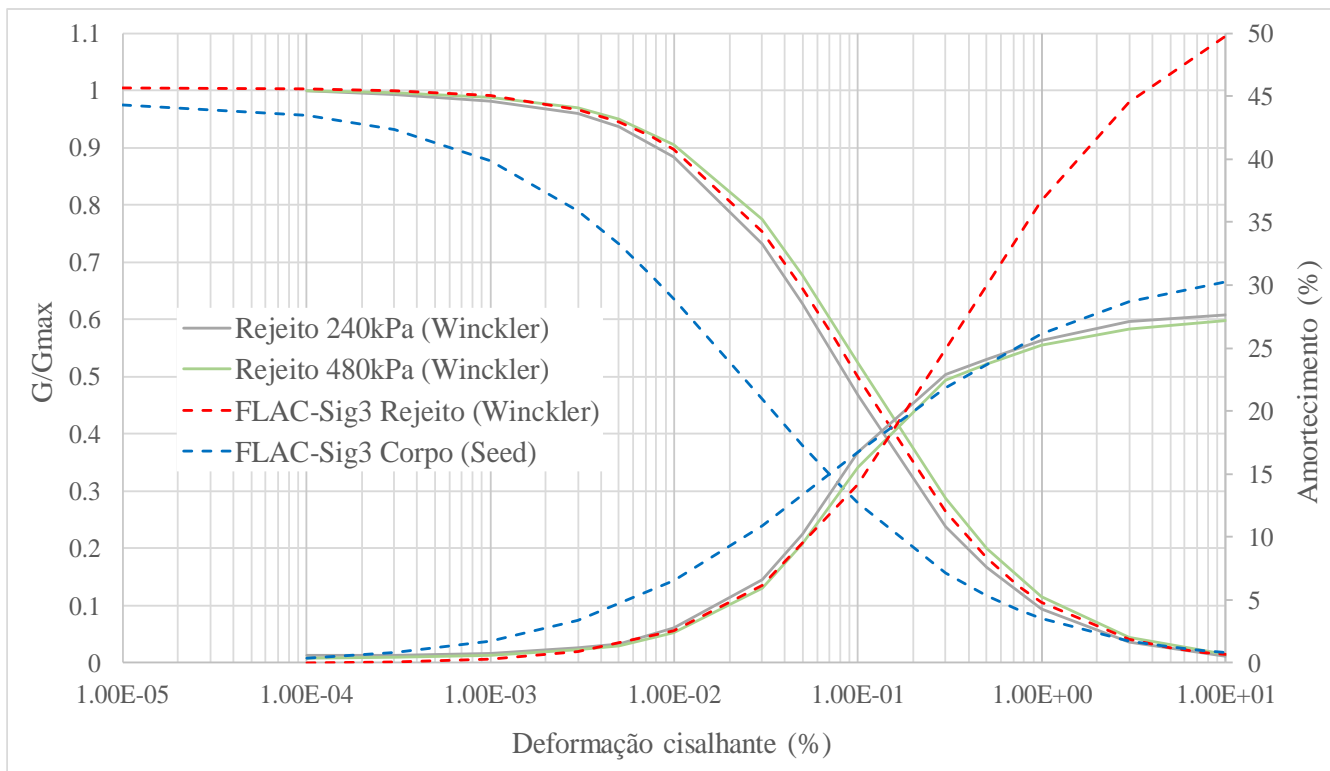

Figura 7.13 - Comparação entre as curvas de degradação do módulo de cisalhamento e do aumento da razão de amortecimento, experimentais e ajustadas, com a sigmoide Sig3.

Geralmente existe um limite para a redução de modulo cisalhante $\left(G / G_{\max }\right)$ que não deve ser excedido e ser menor do que aproximadamente 0,4 a 0,6 ; isto corresponde tipicamente a uma deformação cisalhante cíclica de $0,1 \%$. Na presente pesquisa resolveu-se priorizar a concordância das curvas experimentais e ajustadas no intervalo de pequenas deformações entre $10^{-5}$ a $10^{-3}$. Esta hipótese pode ser comprovada posteriormente pela verificação dos níveis de deformação que o carregamento sísmico provocou na barragem.

\section{8.}

\section{Simulação elástica (não amortecida)}

A simulação elástica não amortecida permite fazer uma estimativa da frequência natural dos materiais constituintes da barragem, que é necessário conhecer quando for utilizado o amortecimento de Rayleigh. Também permite verificar a adequabilidade do fator 2 na transformação de velocidades da partícula em tensões cisalhantes aplicadas na base do modelo quando a opção de base flexível for utilizada no programa FLAC 2D.

O registro de velocidades filtrado da Figura 7.11, foi convertido em registro de tensões cisalhantes cíclicas por meio da Equação 5.8, considerando inicialmente o valor teórico $\mathrm{a}=2$. No entanto, diferenças entre o registro de velocidades prescrito na base (implicitamente pelo registro de tensões cisalhantes 
cíclicas) e o registro de velocidades computado na base pelo programa FLAC 2D foram significativas, o que motivou, por um processo de tentativa e erro, a variação no valor de " $a$ " até ocorrer uma concordância razoável entre ambas as histórias de velocidades (Figura 7.14), o que aconteceu com $a=1,1$. Nesta etapa de calibração não precisou trabalhar com o registro sísmico total, bastou só a parte de maior intensidade do sismo (60s).

Similarmente, foram feitos os ajustes da constante $a$ para os sismos de Lima E-W e Costa Perú E-W determinando-se, em todos os casos, $a=1,1$.

Sismo (Pisco)

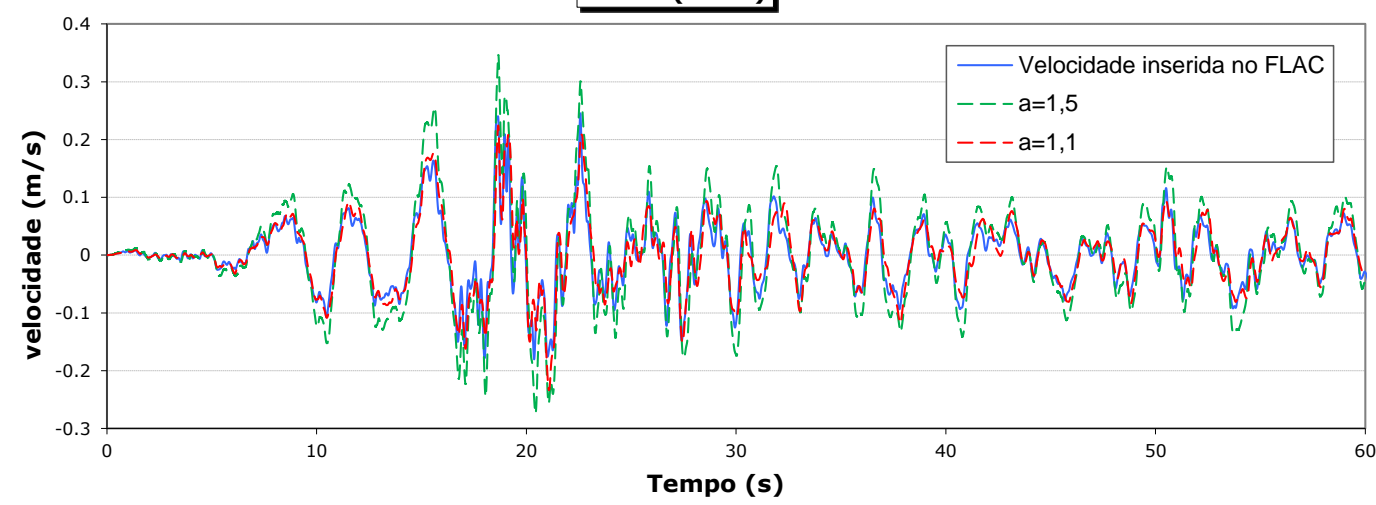

Figura 7.14 - Ajuste da constante a para obter a concordância dos registros de velocidade prescrito e computado na base do modelo.

Para a avaliação da frequência natural não amortecida ou frequências predominantes no sistema, foram estimados os registros de velocidade em pontos representativos dos materiais da barragem e gerados os respectivos espectros de Fourier, que permitem obter os maiores valores de frequência. A Figura 7.15 mostra os espectros de Fourier correspondentes a pontos da fundação, rejeitos antigos, rejeitos novos, corpo de crista do dique. Observou-se que as frequências predominantes variavam entre $0,30 \mathrm{~Hz}$ a $0,95 \mathrm{~Hz}$. 


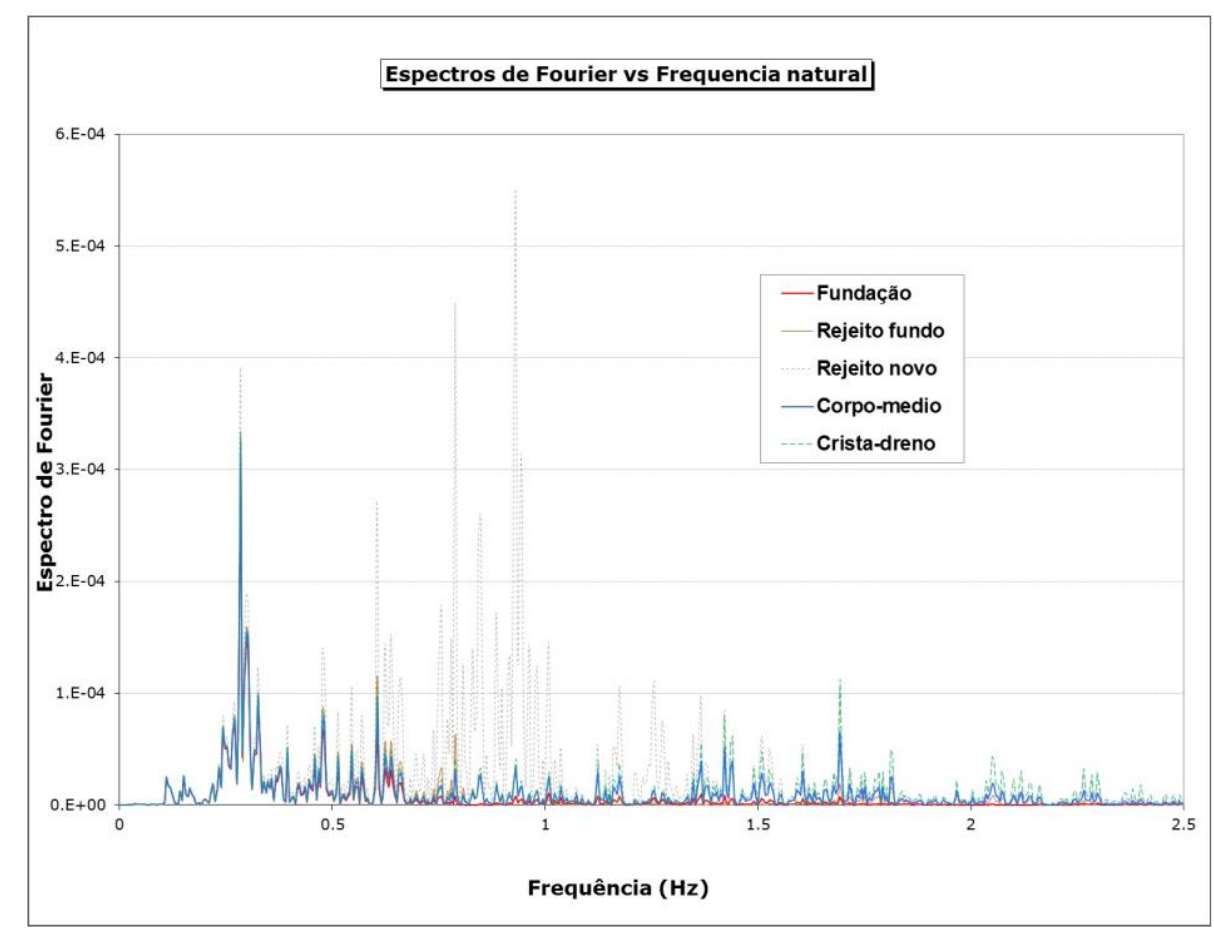

Figura 7.15 - Espectros de Fourier da história de velocidades determinados em análise elástica não amortecida para diferentes pontos da barragem de rejeitos

Os espectros de Fourier são idênticos em todas as situações e mostram um pico máximo próximo à frequência de $0,25 \mathrm{~Hz}$, que foi desconsiderado por representar um período natural de aproximadamente $4 \mathrm{~s}$, que não corresponde ao período natural esperado da barragem. Adicionalmente, como no caso de aplicação do amortecimento de Rayleigh a frequência natural deve ser definida em uma faixa de frequências aproximadamente constante, decidiu-se considerar o pico intermediário presente no espectro de Fourier como frequência natural não amortecida do sistema $(0,5 \mathrm{~Hz}$ com período de $2 \mathrm{~s})$.

\section{9.}

\section{Modelo numérico para obtenção da resposta sísmica}

O objetivo da análise sísmica da barragem de rejeitos Alpamarca foi determinar o comportamento dinâmico dos rejeitos, os deslocamentos produzidos na crista e no corpo do dique bem como a verificação da estabilidade do talude de jusante.

Nesta etapa da análise foram consideradas as curvas de amortecimento histerético ajustadas pela função Sig3 e exibidas na Figura 7.12, com 
amortecimento adicional de Rayleigh da ordem de $0,2 \%$ para uma frequência de $0,5 \mathrm{~Hz}$ com a finalidade de absorver ruídos provocados por altas frequências. Este procedimento corresponde a um processo típico de análise sísmica de problemas geotécnicos.

\subsection{1. \\ Deslocamentos permanentes}

Os resultados para os sismos de Pisco (2007), Lima (1974), Costa Peru (1970) em termos de deslocamentos permanentes horizontais e verticais, na condição de reservatório cheio, estão apresentados nas Figuras 7.15, 7.17 e 7.18. Com respeito aos deslocamentos verticais permanentes, o máximo ocorreu na zona de rejeitos $(0,80 \mathrm{~m})$ enquanto que no dique o valor atingiu $0,24 \mathrm{~m}$ no talude de jusante na análise com o sismo de Pisco. Para os sismos de Lima e da Costa Peru os correspondentes valores foram $0,12 \mathrm{~m}$ no rejeito e $0,15 \mathrm{~m}$ no talude.
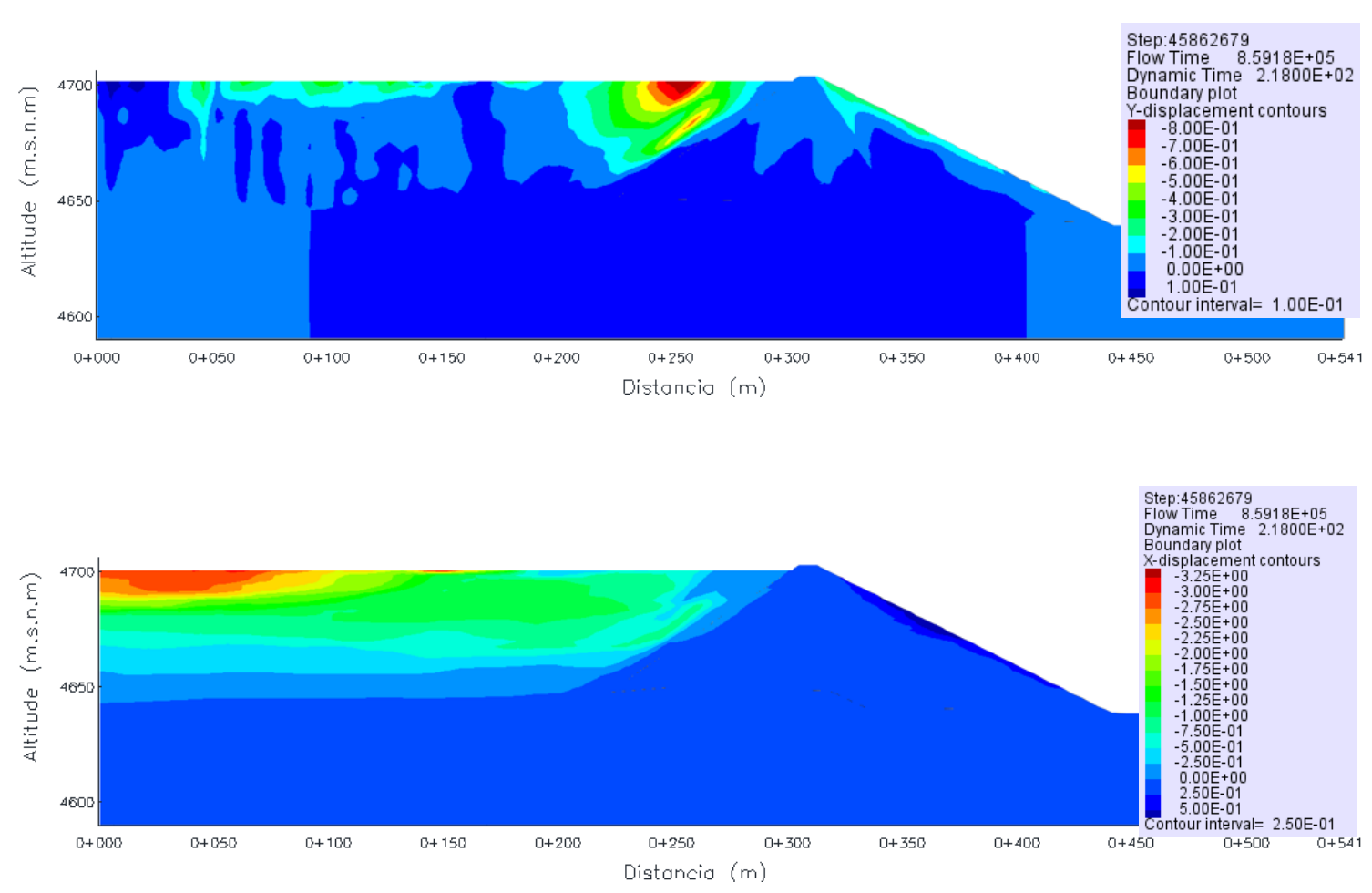

Figura 7.16 - Distribuição dos deslocamentos permanentes verticais (acima) e horizontais (abaixo) na barragem Alpamarca provocados pelo sismo de Pisco (2007). 

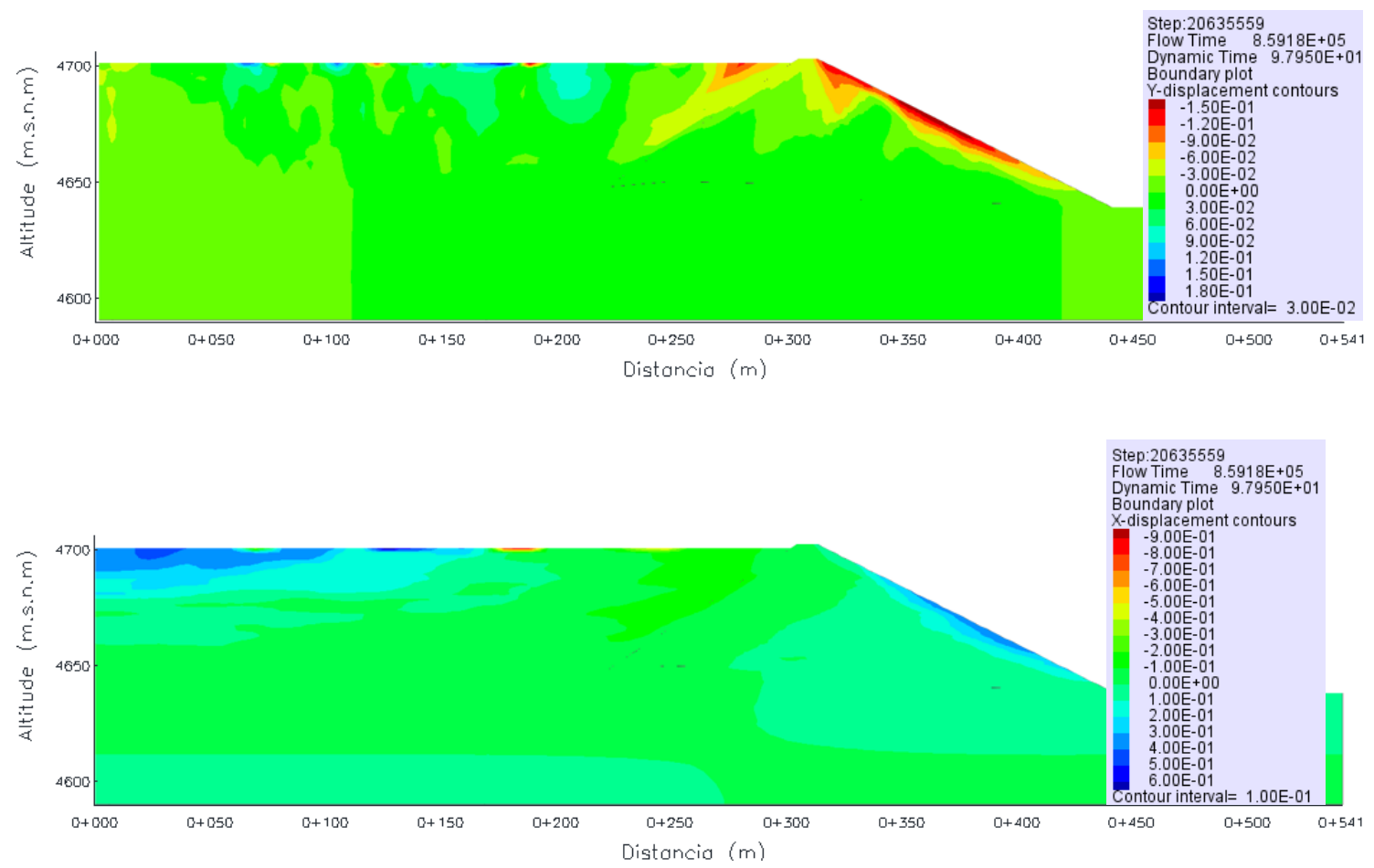

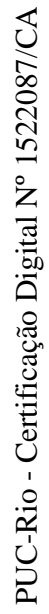

Figura 7.17 - Distribuição dos deslocamentos permanentes verticais (acima) e horizontais (abaixo) na barragem Alpamarca provocados pelo sismo de Lima (1974).
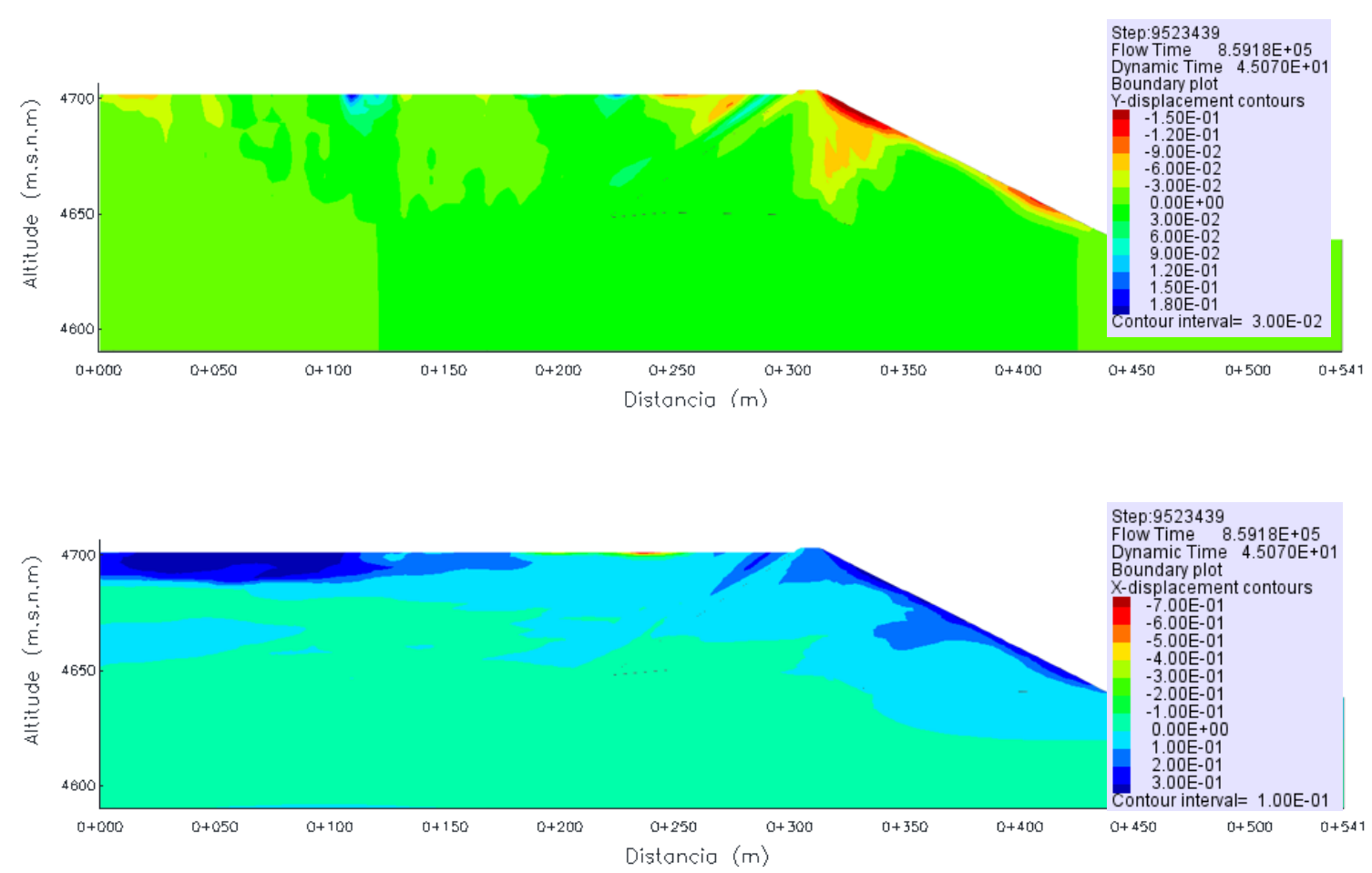

Figura 7.18 - Distribuição dos deslocamentos permanentes verticais (acima) e horizontais (abaixo) na barragem Alpamarca provocados pelo sismo da Costa Peru (1970). 
Em relação aos deslocamentos horizontais permanentes, o máximo ocorre na zona de rejeitos $(2,50 \mathrm{~m})$ enquanto que o deslocamento máximo no dique $(0,50 \mathrm{~m})$ acontece no talude de jusante $(0,50 \mathrm{~m})$ para o sismo de Pisco. Para o sismo de Lima os correspondentes valores são $0,90 \mathrm{~m}$ e $0,40 \mathrm{~m}$, enquanto que para o sismo da Costa Peru são 0,30m e 0,30m, respectivamente.

Os valores dos deslocamentos horizontais foram consideráveis para o caso do sismo de Pisco, então decidiu-se realizar uma simulação dinâmica com a seção total do modelo (Figura 7.19) com a finalidade de conferir os resultados dos deslocamentos horizontais obtidos nas simulações apresentadas nas Figuras 7.15, 7.17 e 7.18 .

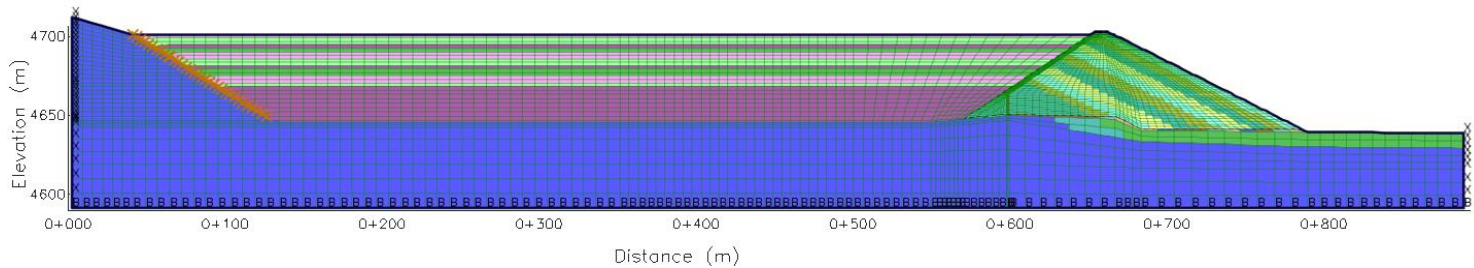

Figura 7.19 - Modelo da seção total para analises dinâmico da barragem

Das Figuras 7.20, 7.21 e 7.22 pode-se observar que os deslocamentos horizontais máximos no talude da jusante do dique são os mesmos que os apresentados no modelo anterior. Enquanto os deslocamentos máximos horizontais na zona de rejeitos são de $1,50 \mathrm{~m}, 0,40 \mathrm{~m}$ e $0,30 \mathrm{~m}$ para os sismos de Pisco, Lima e Costa Peru, respectivamente. Os deslocamentos horizontais diferem como os apresentados anteriormente, na zona de rejeitos para os sismos de Pisco e Lima.

Pode-se concluir que é recomendável trabalhar com a seção total do modelo, para uma barragem de rejeitos, devido a que os rejeitos apresentam propriedades de compressibilidade relativamente baixas em comparação com a rocha e o corpo do dique.

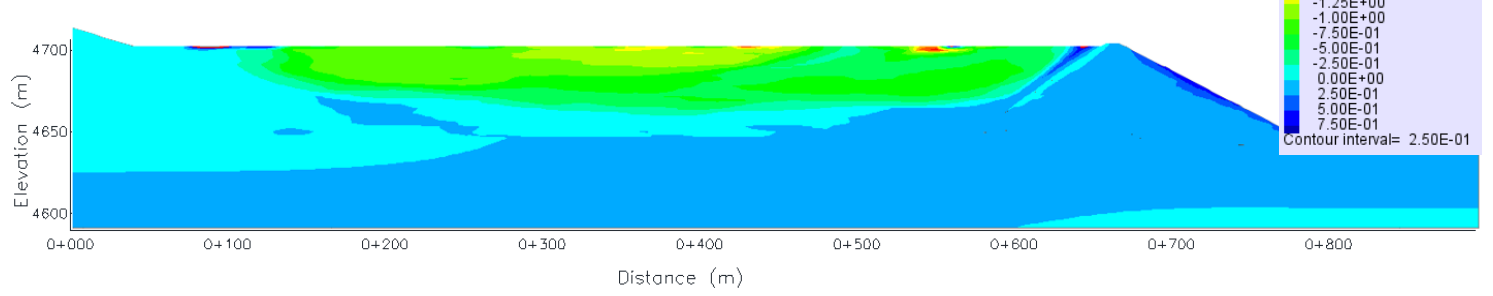

Figura 7.20 - Deslocamentos permanentes horizontais Pisco - Seção total 


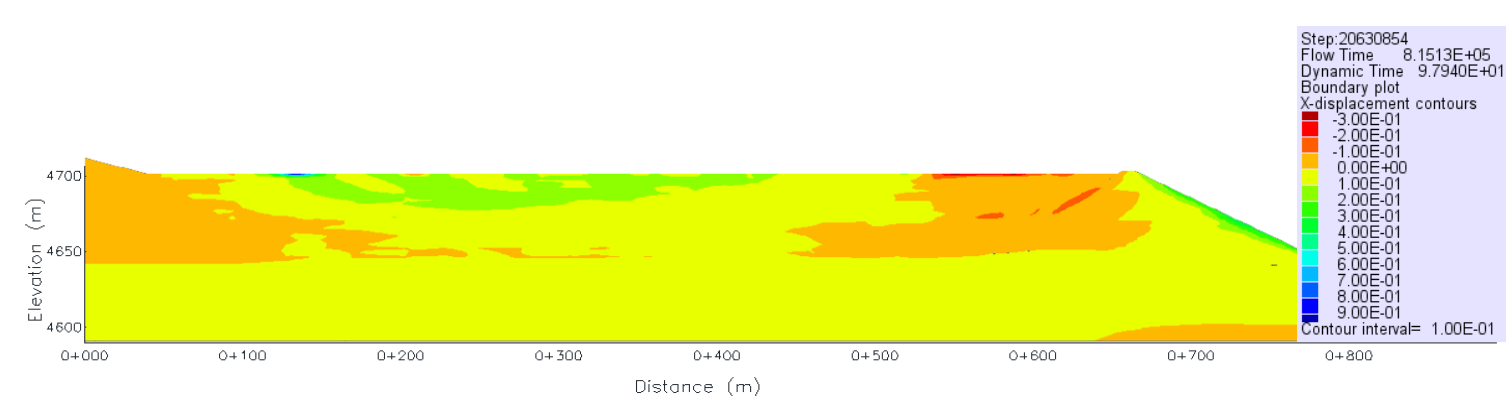

Figura 7.21 - Deslocamentos permanentes horizontais Lima - Seção total

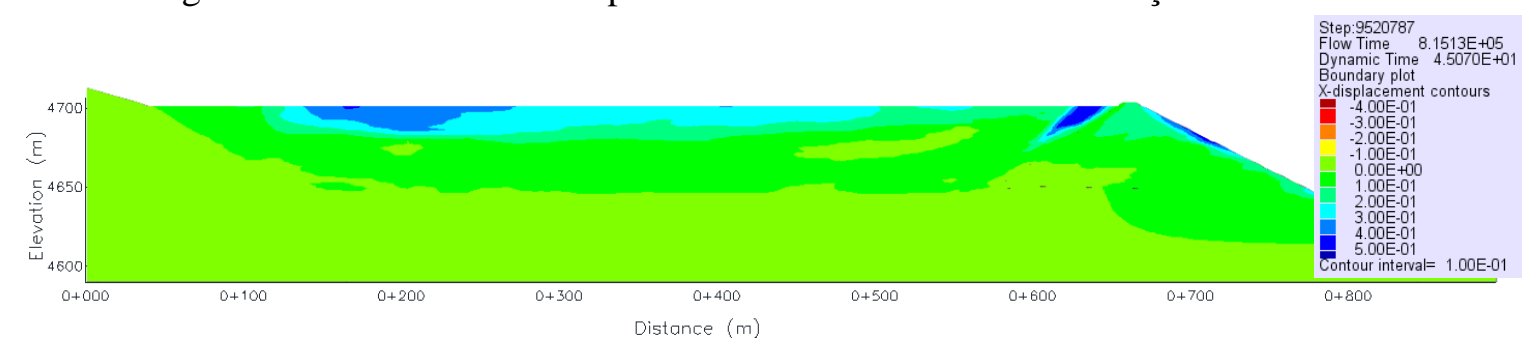

Figura 7.22 -Deslocamentos permanentes horizontais Costa Peru - Seção total

Como a estabilidade da barragem é controlada pelo dique, foram monitoradas as histórias dos deslocamentos no dique (corpo e crista), conforme resultados mostrados na Figura 7.23, para deslocamentos verticais, e Figura 7.24, para deslocamentos horizontais. Para os três sismos, o deslocamento vertical permanente na crista do dique variou de $0,08 \mathrm{~m}$ a $0,13 \mathrm{~m}$.
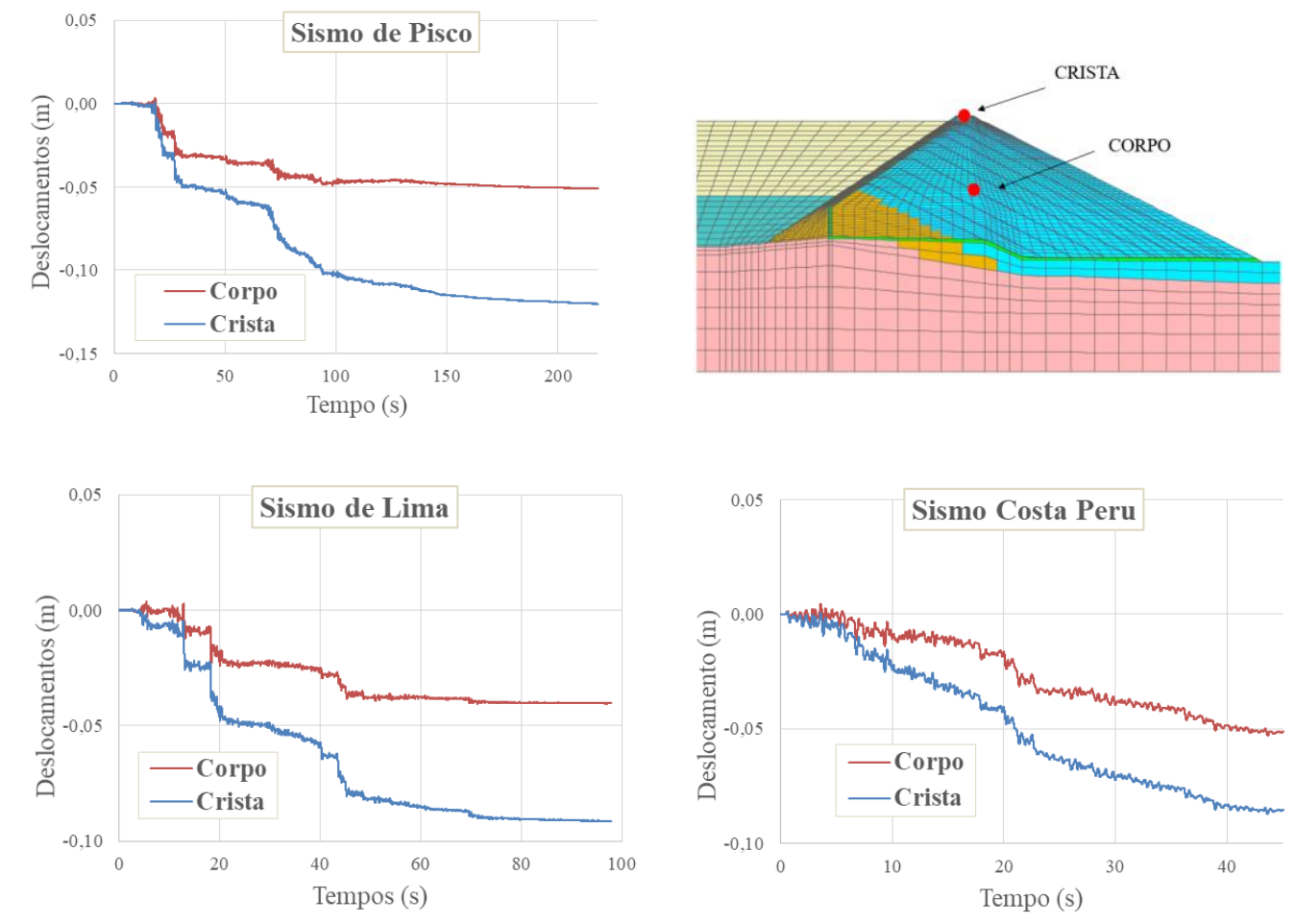

Figura 7.23 -Variação no tempo dos deslocamentos verticais causados pelo sismo de Pisco, Lima e Costa Peru em pontos da crista e corpo do dique. 

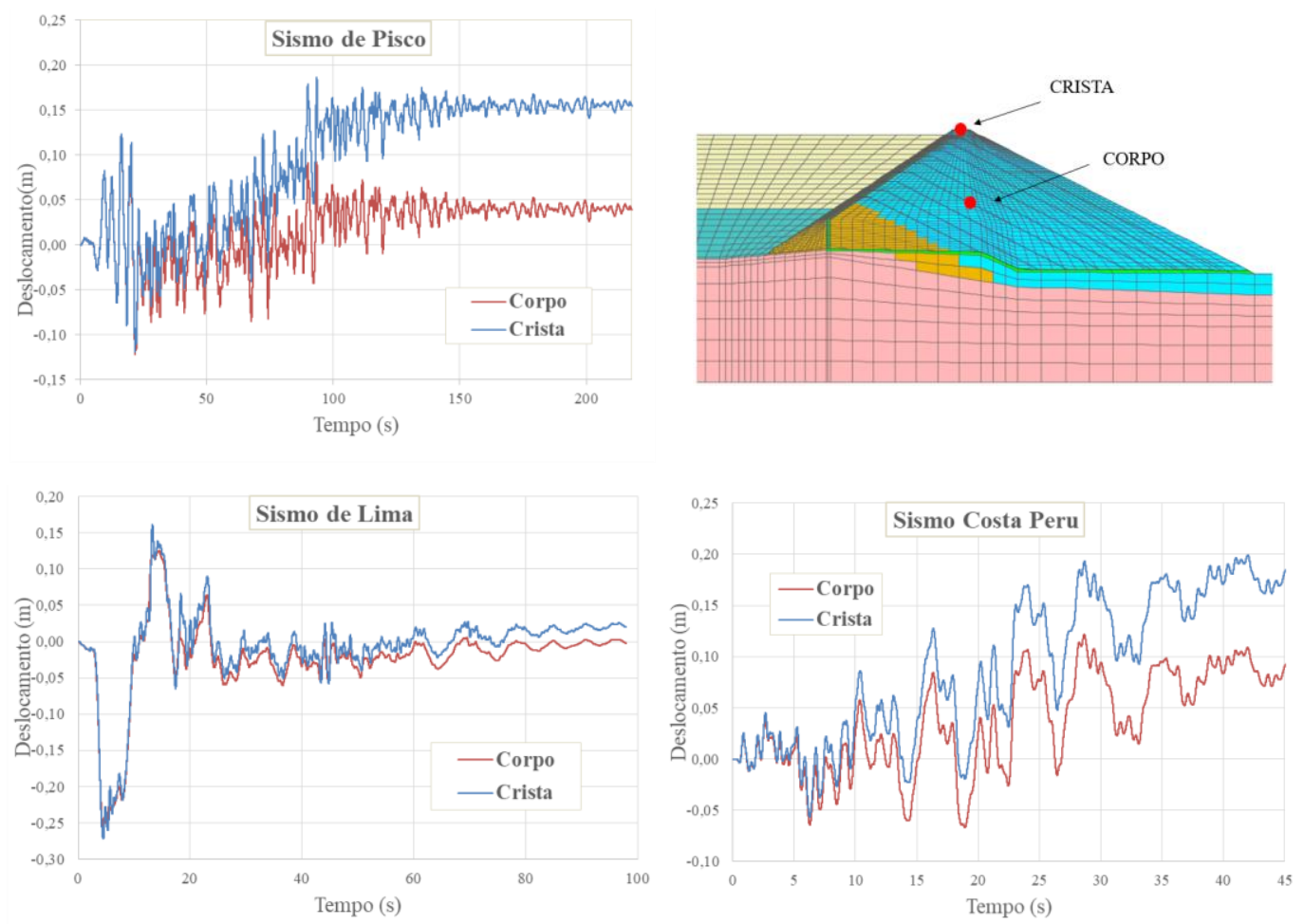

Figura 7.24 -Variação no tempo dos deslocamentos horizontais causados pelo sismo de Pisco, Lima e Costa Peru na crista e corpo do dique.

\subsubsection{Potencial de ruptura cíclica de poropressão}

Em solos finos há considerável evidência que a condição crítica de estabilidade nem sempre ocorre durante o terremoto mas pode, de fato, acontecer minutos ou horas após o sismo. A barragem de rejeitos analisada apresenta espaldares de enrocamento (com dissipação praticamente instantânea dos excessos de propressão), mas o material de rejeito é constituído por argila siltosa (ML-CL) com índice de plasticidade IP=9\%.

De acordo com Boulanger e Idriss (2004), para fins práticos solos finos com IP $<7$ podem ser classificados como areia, suscetíveis à liquefação dinâmica, ou como argilas para índice de plasticidade IP $\geq 7$, suscetíveis à ruptura cíclica. Os termos liquefação e ruptura cíclica não implicam significativas diferenças no comportamento tensão $\mathrm{x}$ deformação durante um carregamento cíclico não drenado, mas são usados apenas para referenciar tipos de solo (areia, argila) cujos comportamentos mecânicos fundamentais são diferentes entre si. 
Assim, decidiu-se examinar o potencial de ruptura cíclica da barragem imediatamente após o final do terremoto, calculando-se o valor do parâmetro de poropressão ru definido por

$$
r_{u}=\frac{\Delta u}{\sigma_{c 0}^{\prime}}
$$

onde $\Delta \mathrm{u}$ representa a variação da poropressão causada pelo sismo e $\sigma^{\prime}$ co a tensão normal efetiva octaédrica inicial. Nos pontos onde ru $>1$ a ruptura cíclica aconteceria, i.e. o valor do excesso de poropressão ultrapassaria o valor da tensão normal $\sigma_{\text {co. }}$

A Figura 7.25 mostra as regiões com maior potencial de ruptura, mas os valores são baixos $(\mathrm{ru}<1)$, porém sem causar colapso por ruptura cíclica.

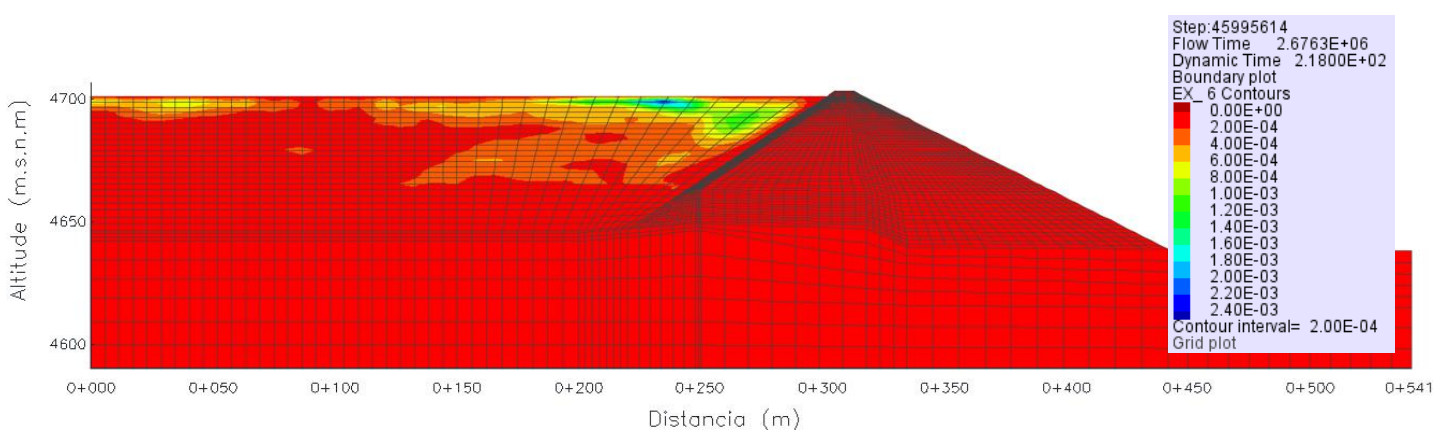

Figura 7.25 - Distribuição do parâmetro de poropressão ru imediatamente após a ocorrência do terremoto.

\subsection{3.}

\section{Acelerações horizontais}

A resposta do modelo numérico da barragem em termos de acelerações horizontais é mostrada na Figura 7.26, com acelerações máximas na crista do dique iguais a 0,33g (sismo de Pisco), 0,28g (sismo de Lima) e 0,32g (sismo Costa Peru), não sofrendo grandes amplificações em relação aos valores máximos aplicados na base dos modelos $(0,40 \mathrm{~g}$ para sismo de Pisco, $0,35 \mathrm{~g}$ para sismo de Lima e $0,37 \mathrm{~g}$ para sismo de Costa Perú). Este comportamento também ocorreu com os rejeitos.

Nas Figuras 7.27, 7.28 e 7.29 pode-se observar dos espectros de resposta, que os rejeitos contribuíram na absorção de energia ao mesmo tempo em que filtraram o conteúdo de altas frequências (períodos curtos) presentes no acelerograma, razão pela qual as acelerações não são muito amplificadas. Os 
espectros de resposta da crista e do corpo do dique tem comportamento semelhante para os três sismos analisados.
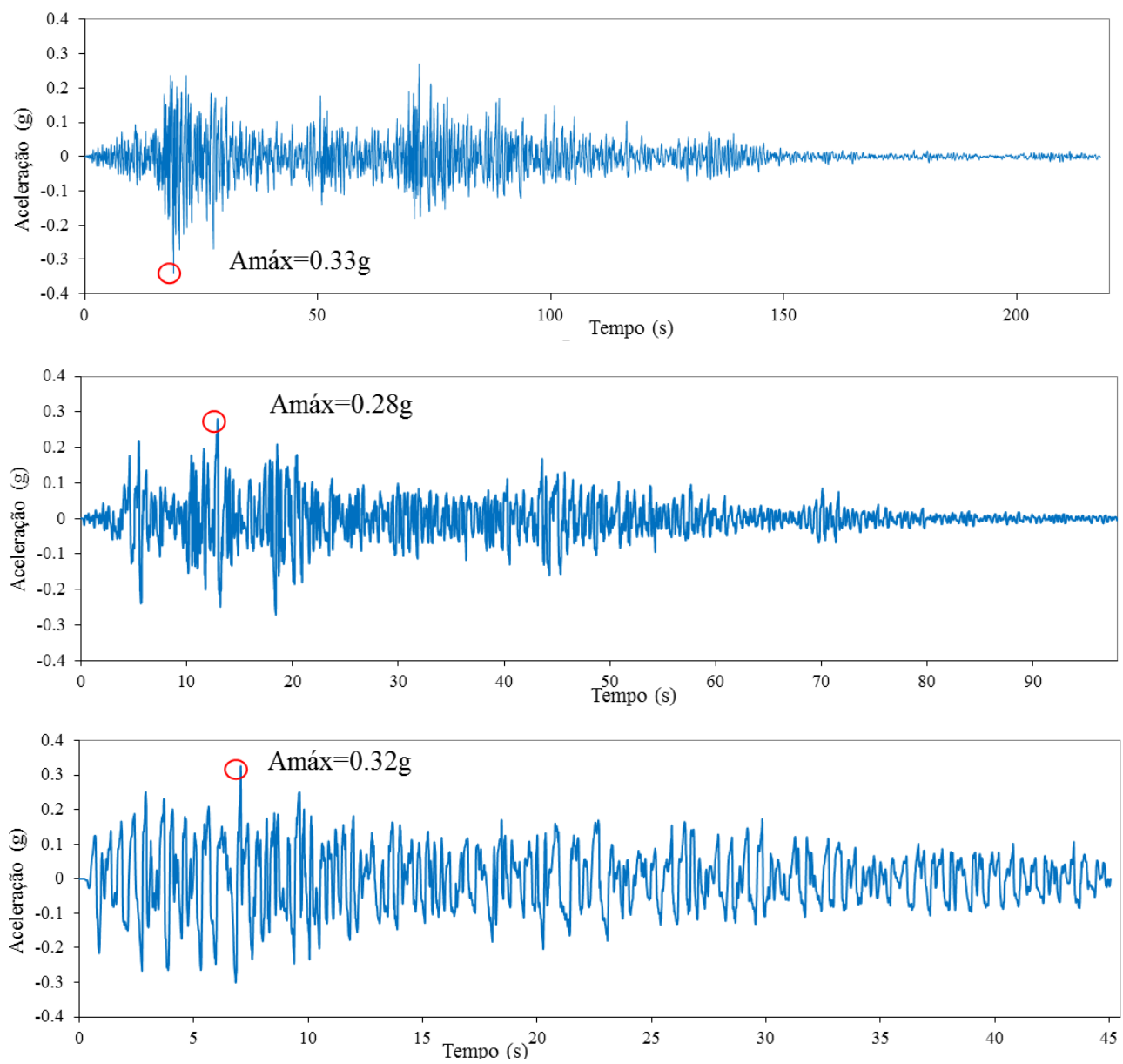

Figura 7.26 - História das acelerações computadas na crista do dique para os sismos de Pisco, Lima e Costa Perú. 


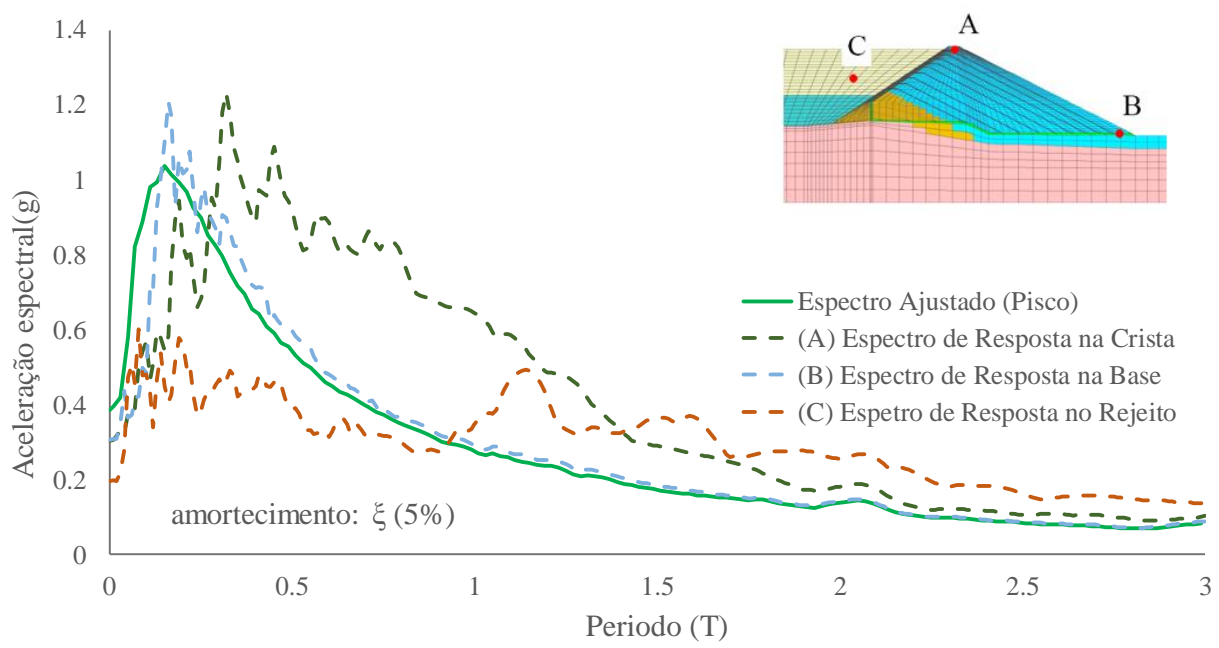

Figura 7.27 - Distribuição dos espectros de resposta de aceleração para o sismo de Pisco.

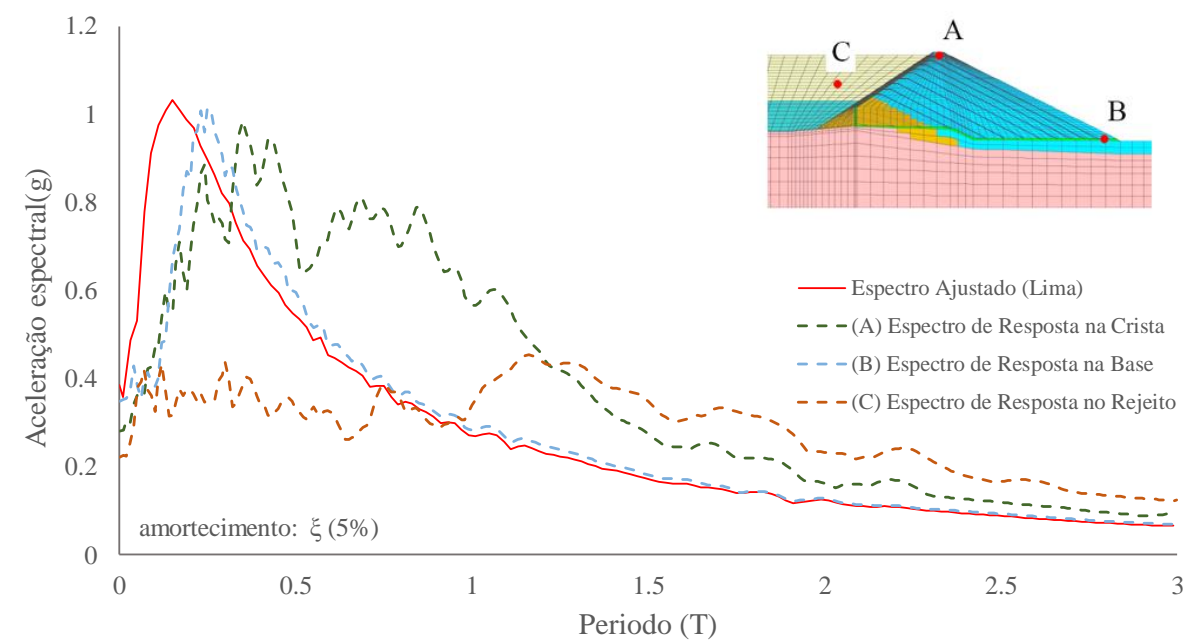

Figura 7.28 - Distribuição dos espectros de resposta de aceleração para o sismo de Lima.

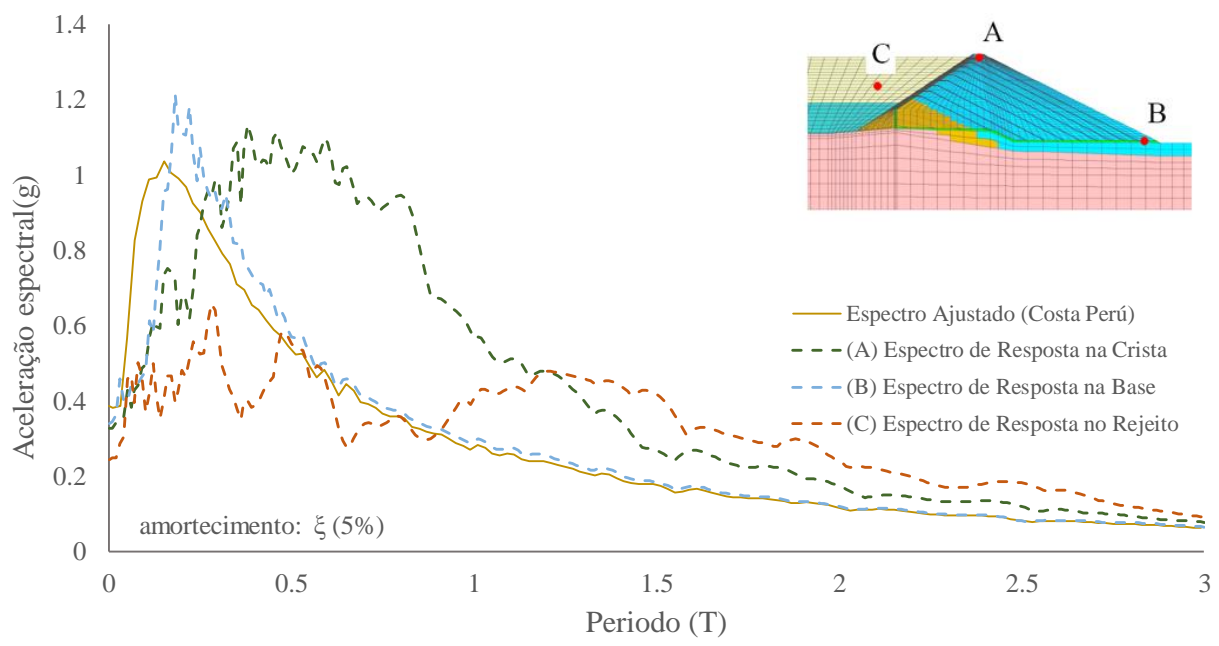

Figura 7.29 - Distribuição dos espectros de resposta de aceleração para o sismo de Costa Peru. 


\subsection{0.}

\section{Efeitos da duração do registro sísmico}

Um fator importante em análises sísmicas é a escolha da duração dos registros sísmicos das acelerações porque o processamento do registro completo pode levar um tempo considerável.

$\mathrm{Na}$ literatura, a definição de duração pode ser categorizada em três diferentes tipos: duração delimitada (bracketed duration), duração uniforme e duração significativa. A duração delimitada mede a duração do movimento da primeira à última ocorrência que a aceleração ultrapassa determinado valor, como 0,03g (Ambraseys e Sarma,1967) ou 0,05g (Page et al., 1972).

A duração delimitada tem várias desvantagens, a principal delas que para muitos acelerogramas o tempo de duração é altamente sensível a pequenas variações da aceleração de ultrapassagem. Adicionalmente, a mesma duração poderia ser estabelecida para dois acelerogramas com conteúdo de energia muito diferentes entre si, pois a duração delimitada ignora a natureza do registro durante sua parte mais intensa.

Um aperfeiçoamento, que considera as características de todo o registro, é a duração uniforme que é a soma dos intervalos de tempo durante os quais a aceleração ultrapassa determinado valor, conforme proposta de Bolt (1973) usando valores de $0,05 \mathrm{~g}$ e $0,1 \mathrm{~g}$. Esta definição tem a vantagem que a duração não varia subitamente com pequenas modificações do valor de ultrapassagem, mas também não define uma janela de tempo contínuo onde a excitação mais intensa do registro ocorre.

A duração significativa é baseada na intensidade de Arias $\left(\mathrm{I}_{\mathrm{A}}\right)$, uma medida da energia relacionada com a produção da ruptura da falha (Arias, 1970):

$$
I_{A}=\frac{\pi}{2 g} \int_{0}^{T} a^{2}(t) d t
$$

onde a(t) é a variação da aceleração no tempo e $\mathrm{T}$ a duração total do acelerograma.

Uma curva mostrando o aumento de $\mathrm{I}_{\mathrm{A}}$ em função do tempo é referida como gráfico Husid (Husid et al., 1969). O gráfico para acelerogramas horizontais normalmente consiste de uma parte inicial pouco inclinada, correspondendo à chegada das ondas $\mathrm{P}$, uma parte central mais íngreme, correspondendo à energia 
das ondas S, seguida por uma parte final também pouco inclinada, associada a chegada indireta de ondas de corpo, ondas de superfície ou energia aprisionada por características topográficas ou camadas sedimentares.

Medidas de duração significativa são baseadas em intervalos nos quais determinada parcela da intensidade Arias é atingida. Husid et al. (1969) utilizaram 95\%, Donovan (1972) considerou o intervalo de 0 a 90\% enquanto Trifunac e Brady (1975) modificaram este intervalo para 5\% a 95\% (SD595) também utilizado por Dobry et al. (1978). Abrahamson e Silva (1996) definiram o intervalo 5\% a 75\% (SD575) como uma medida estatisticamente mais estável da duração significativa.

Vários investigadores desenvolveram relações empíricas para duração significativa SD595 e SD575 como função da magnitude do terremoto, distância e características do sítio.

$\mathrm{Na}$ presente pesquisa foi considerado o registro sísmico de Pisco (2007) e, auxílio do programa de computador SeismoSignal (Seismosoftm 2016), foi obtido o gráfico da variação porcentual da intensidade Arias com o tempo do registro, como apresentado na Figura 7.30. Pode-se observar que os tempos para $\mathrm{I}_{\mathrm{A}}=5 \%$, $\mathrm{I}_{\mathrm{A}}=75 \%$ e $\mathrm{I}_{\mathrm{A}}=95 \%$ são $\mathrm{T} 5=17,25 \mathrm{~s}, \mathrm{~T} 75=72,04 \mathrm{~s}$ e $\mathrm{T} 95=102,74 \mathrm{~s}$, respectivamente.

O processo de geração do acelerogramas artificiais é repetido novamente, mas durante a fase de ajuste espectral se observou que, tanto para o caso D575 quanto para o caso SD595, o ajuste à curva de espectro de resposta uniformemente provável, obtida da ameaça sísmica, foi insatisfatório. Para fins de comparação entre um registro sísmico completo e registros onde se acumula a maior energia do sismo, se realizou um ajuste para os registros SD95 e SD75 excluindo o tempo inicial correspondente a 5\% no gráfico Husid de intensidade Arias, observando-se uma melhoria no ajuste espectral durante a geração dos acelerogramas artificiais. As Figuras 7.31 e 7.32 mostram os deslocamentos horizontais e verticais permanentes para os registros SD95 e SD75 respectivamente. 


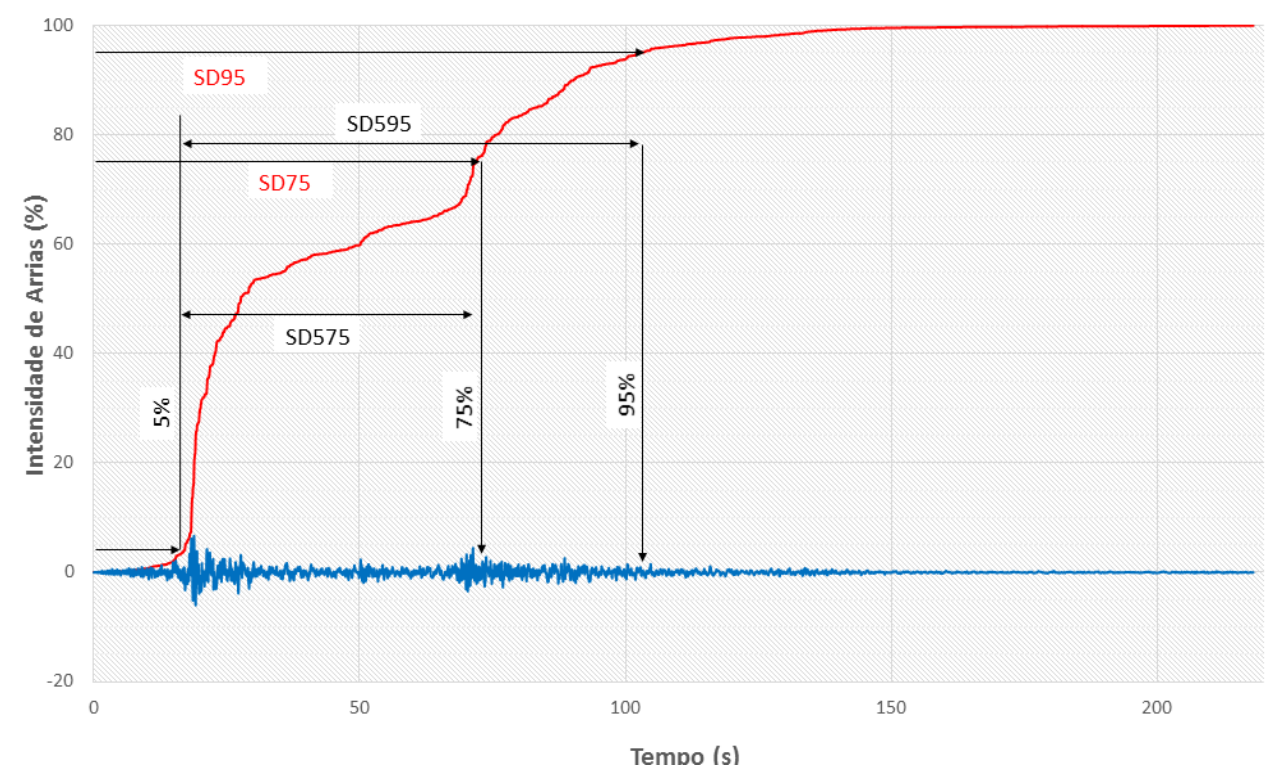

Figura 7.30 - Duração significante SD595 e SD575 para o registro sísmico de Pisco (2007) no gráfico de Intensidade de Arias.
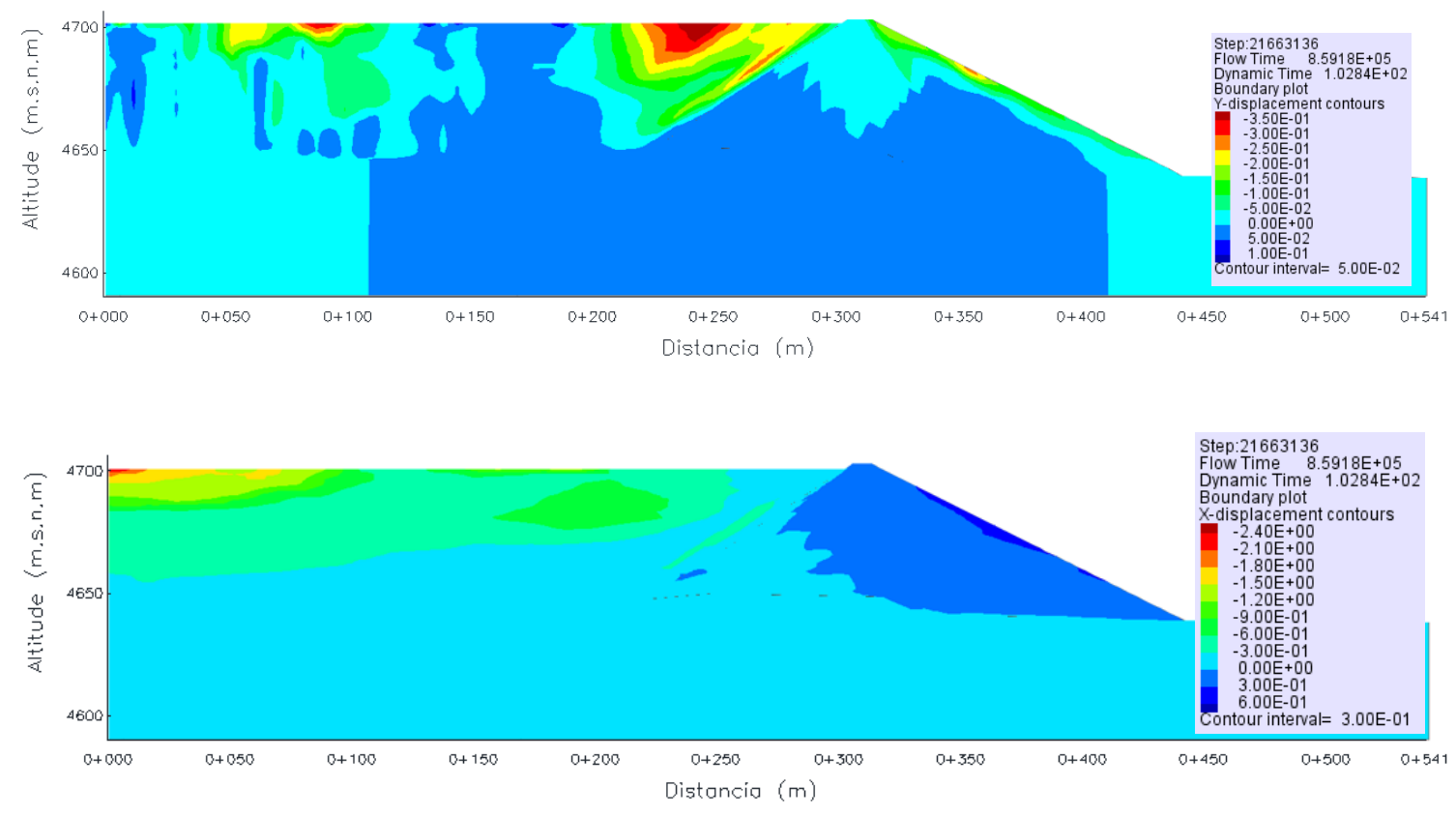

Figura 7.31 - Distribuição dos deslocamentos permanentes verticais (acima) e horizontais (abaixo) na barragem Alpamarca provocados pelo sismo de Pisco com duração significativa SD595. 

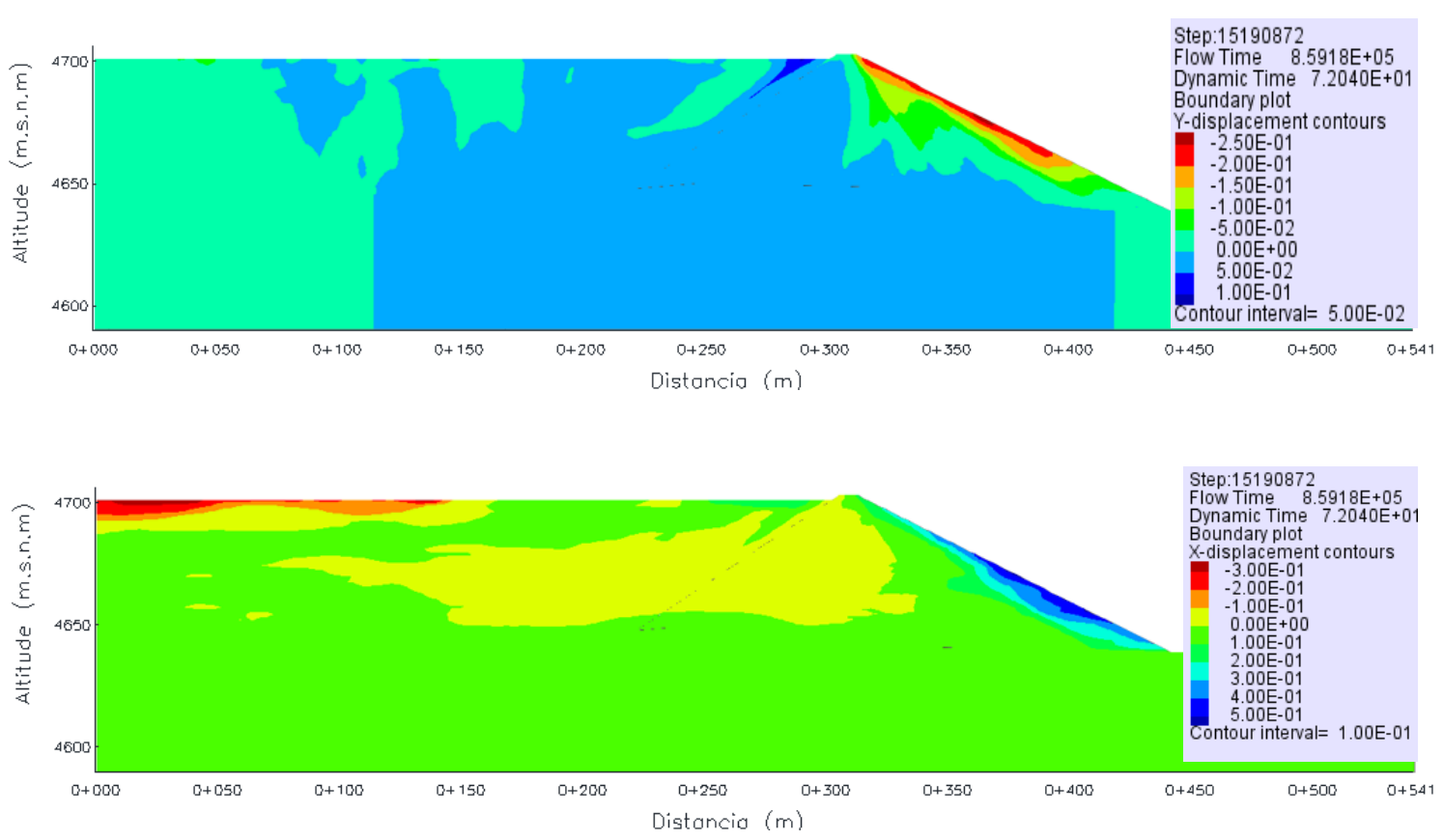

Figura 7.32 - Distribuição dos deslocamentos permanentes verticais (acima) e horizontais (abaixo) na barragem Alpamarca provocados pelo sismo de Pisco com a duração significativa SD575.

A distribuição dos deslocamentos para o registro de Pisco com duração significativa SD595 (Figura 7.30) indica deslocamento vertical permanente máximo na região dos rejeitos igual a $0,35 \mathrm{~m}$ e no talude de jusante do dique de 0,20m, e deslocamento horizontal permanente máximo na região dos rejeitos de $2,10 \mathrm{~m}$ e no talude de jusante do dique de $0,40 \mathrm{~m}$.

Para o sismo de Pisco com duração significativa SD575, os valores correspondentes dos deslocamentos verticais foram $0,05 \mathrm{~m}$ e $0,20 \mathrm{~m}$, respectivamente, os deslocamentos horizontais máximos correspondentes de $0,30 \mathrm{~m}$ e $0,40 \mathrm{~m}$.

Dos resultados, verifica-se que a utilização do registro SD575 ocorreu uma grande diferença nos deslocamentos vertical e horizontal nos rejeitos, mantendo praticamente os mesmos valores para os deslocamentos previstos no dique.

O registro original do sismo de Pisco contém duas faixas de maiores acelerações no tempo; possivelmente, para um registro sísmico de única faixa de maior intensidade, as previsões com a duração SD575 e SD595 poderiam ter melhor concordância com aquelas calculadas com o registro total. 


\subsection{1.}

Modelo analítico para obtenção da resposta sísmica

Dos métodos analíticos apresentados na seção 5.5, os deslocamentos horizontais permanentes induzidos por eventos sísmicos foram estimados com o método de Bray e Travasarou (2007) e o método de Swaisgoog (2013). O método de Bray e Travasarou (2007) apresentou resultados mais próximos com os valores computados numericamente com o programa FLAC 2D, conforme Tabela 7.4. (detalhes de cálculo no anexo 2)

Tabela 7.4 - Deslocamentos e acelerações na barragem de rejeitos Alpamarca

\begin{tabular}{|c|c|c|c|c|}
\hline Análise & $\begin{array}{c}\text { Deslocamento } \\
\text { Vertical } \\
\text { Crista (m) }\end{array}$ & $\begin{array}{c}\text { Deslocamento } \\
\text { Horizontal } \\
\text { Crista (m) }\end{array}$ & $\begin{array}{c}\text { Deslocamento } \\
\text { Vertical } \\
\text { Talude (m) }\end{array}$ & $\begin{array}{c}\text { Deslocamento } \\
\text { Horizontal } \\
\text { Talude (m) }\end{array}$ \\
\hline $\begin{array}{c}\text { Numérica } \\
\text { Pisco (2007) }\end{array}$ & 0,13 & 0,16 & 0,24 & 0,50 \\
\hline $\begin{array}{c}\text { Numérica } \\
\text { Lima (1976) }\end{array}$ & 0,09 & 0,15 & 0,15 & 0,40 \\
\hline $\begin{array}{c}\text { Numérica } \\
\text { Costa Peru } \\
(1970)\end{array}$ & 0,09 & 0,17 & 0,15 & 0,30 \\
\hline $\begin{array}{c}\text { Bray \& } \\
\text { Travasarou } \\
(2007)\end{array}$ & -- & $0,02-0,11$ & -- & -- \\
\hline $\begin{array}{c}\text { Swaisgoog } \\
(2013)\end{array}$ & 0,17 & - & -- & - \\
\hline
\end{tabular}

$\mathrm{Na}$ barragem de rejeitos Alpamarca, os deslocamentos permanentes no talude de jusante chegam a ultrapassar $50 \mathrm{~cm}$, mas não comprometem a segurança global da estrutura. 


\section{8 \\ Conclusões e Sugestões}

A presente dissertação teve como foco principal a previsão numérica do comportamento sísmico da barragem de rejeitos Alpamarca, considerando a avaliação de ameaça sísmica numa região de alta atividade no Peru. A sismicidade do país é determinada predominantemente pelo processo de subducção da placa Nazca sob a placa Sul-Americana que gera eventos sísmicos de subducção de interface e de intraplaca.

A análise de ameaça sísmica foi fundamental para definição dos sismos de projeto, obtidos por meio de acelerogramas artificiais gerados pelo método de ajuste espectral. As dificuldades na realização do estudo com o programa de código aberto Openquake decorreram da falta de familiaridade com o software, bastante versátil mas complexo, com muitas opções de cálculo disponíveis para o usuário.

As principais conclusões desta pesquisa foram as seguintes:

a. A análise de ameaça sísmica probabilístico foi desenvolvida usando equações de previsões de movimento do solo (GMPE) apropriadas para mecanismos de subducção de interface, subducção de intraplaca e mecanismos corticais. A ponderação das contribuições dessas fontes foi feita com base em uma árvore lógica de decisões, dada a grande sensibilidade que as incertezas epistêmicas influenciam nos resultados.

b. A estimativa da ameaça sísmica foi executada com os programas CRISIS v. 2015 e OpenQuake para as fontes sismogênicas mencionadas neste trabalho. Além disso, foi realizada uma comparação com as fontes sismogênicas definidas no projeto SARA, um programa regional promovido por iniciativa da Fundação GEM, responsável pelo software Openquake. Concluiu-se que as acelerações máximas horizontais (PGA) para um período de retorno 
de 975 anos (5\% de probabilidade de excedência em 50 anos) variaram aproximadamente entre 0,40 a $0,42 \mathrm{~g}$. Estas acelerações foram consideradas para cenários sísmicos em barragens de acordo com recomendações do ICOLD (2010).

c. Os deslocamentos permanentes determinados na análise numérica com o programa FLAC 2D foram semelhantes aos valores obtidos com metodologias simplificadas (Bray e Travasarou, Swaisgood). Os deslocamentos permanentes computados não indicam que a estabilidade da estrutura esteja comprometida, de acordo com recomendações da California Geological Survey (2008) ou do Alaska’s Geotechnical Evaluation Criteria Committe (Idriss, 1985).

d. A distribuição dos deslocamentos horizontais, na zona de rejeitos, é diferente entre a seção trabalhada nesta pesquisa e a seção total. Então é recomendável trabalhar com a seção total, mas nesta pesquisa o comportamento do dique da barragem é prioridade.

e. A resposta dinâmica mais elevada encontra-se na altura média do talude da jusante do dique e na região dos rejeitos.

f. Os espectros de respostas no reservatório de rejeitos demostraram que esses materiais contribuíram na absorção de energia, ao mesmo tempo em que filtraram o conteúdo de altas frequências (períodos curtos) presentes no acelerograma. A maioria dos sismos peruanos é de períodos curtos.

g. A análise dinâmica pode também ser desenvolvida considerando uma duração significativa do registro sísmico total, que captura a energia potencial contida no acelerograma em função da intensidade Arias. Verificou-se que os resultados para um registro de SD95 são semelhantes aos obtidos com o registro sismo total, mas com diminuição do tempo de processamento.

Como sugestões para trabalhos futuros nesta linha de pesquisa recomendase uma avaliação das fontes sismogênicas do Peru para gerar uma fonte de falha complexa 3D para, sequencialmente, em processo de desagregação, determinar fontes pontuais com propriedades distintas, como feito no projeto SARA. 


\section{9}

\section{Referências bibliográficas}

ABRAHAMSON, N. A. Spatial variation of multiple support inputs. Proceedings, 1st U. S. Seminar on Seismic Evaluation and Retrofit of Steel Bridges, Department of Civil Engineering and California Department of Transportation, University of California at Berkeley, San Francisco, California, 1993.

ABRAHAMSON, N.A., Bommer, J.J. Opinion paper: probability and uncertainty in seismic hazard analysis. Earthquake spectra, Vol. 21, no.2, pp. 1-5, 2005.

ACEVEDO J., ANA B. Seismological criteria for selecting and scaling real accelerograms for use in engineering analysis and design, Dissertation Master Degree, European School of Advanced Studies in Reduction of Seismic Risk, June, 2003.

AGUILAR, Z. Análisis de peligro sísmico y estimado del movimiento sísmico de diseño, Centro de Investigaciones Sísmicas y Mitigación de Desastres, CISMID, 2001.

AGUILAR, Z. Probabilistic Seismic Hazard Assessment in the Peruvian Territory, Proceedings of the 16th World Conference on Earthquake Engineering, Santiago - Chile, 2017.

ARIAS, A. A Measure of Earthquake Intensity. Ed. R.J. Hansen. Seismic Design for Nuclear Power Plants. MIT Press, pp. 438-483,1969.

ALTAREJOS-GARCÍA, L. Contribución a la estimación de la probabilidad de fallo de presas de hormigón en el contexto del análisis de riesgos. $\mathrm{PhD}$ thesis, Universidad Politécnica de Valencia, 2009.

AMBRASEYS N.N. and SARMA S.K. The Response of Earth Dams to Strong Earthquakes, Geotechnique, London, Vol. 17, pp. 180-213, 1967.

ATKINSON, G. M., BOORE, D. M. Empirical ground-motion relations for subduction zone earthquakes and their application to Cascadia and other regions, Bulletin of the Seismological Society of America, 93:4, 1703-1729, 2003 
BOLT, B. A. Duration of strong motion, Proceedings of the Fifth World Conference on Earthquake Engineering, v.1, 1304 - 1315.

BRASIL. Ministério da Integração Nacional (MIN). Manual de Segurança e Inspeção de Barragens. Brasília. 2002, 148p.

BRAY, J. D., AUGELlO, A. J., LEONARDS, G. A., REPETTO, P. C. and BYRNE, R. J. Seismic Stability Procedures for Solid-Waste Landfills. J. Geotech. Engrg., ASCE, , Vol. 121, No. 2, pp. 139-151, 1995.

Bray, J., \& Travasarou, T.. Simplified procedure for estimating earthquakeinduced deviatoric slope displacements. Journal of Geotechnical and Geoenvironmental Engineering, ASCE, 135: 1336-1340, 2007.

BOORE, D. M. AND JOYNER W.B. The empirical prediction of ground motion, Bull. Seism. Soc. Am. 72, 269-286, 1982.

BOMMER, J., Scherbaum, F. The use and misuse of logic trees in probabilistic seismic hazard analysis. Earthquake Spectra: November 2008, Vol.24, no.4, pp.997-1009, 2008.

CALIFORNIA GEOLOGICAL SURVEY. Guidelines for evaluating and mitigating seismic hazards in California, Special Publication 117a, http://www.conservation.ca.gov/cgs/shzp/webdocs/Documents/sp117.pdf. 2008.

CASTILlo J. Peligro Sísmico en el Perú. (Tesis de Grado). Universidad Nacional de Ingeniería, Lima, 1993.

CLIMENT, A., ROJAS, W., ALVARADO, G., BENITO, B. Proyecto RESIS II: Evaluación de la amenaza sísmica en América Central, Centro de Coordinación para la Prevención de los Desastres Naturales en América Central (CEPREDENAC), 2008

CLOUGH, R., WOODWARD, R. - Analysis of embankment stresses and deformations, JSMFD, ASCE, No. SM4, 1967, pp.529-549, 1967.

CORNELL, A. Engineering Seismic Risk Analysis, Bulletin of the Seismological Society of America", Vol. 58, N`5 págs. 1538 - 1606, 1968.

CROWLEY, H., Cerisara, A., Jaiswal, K., Keller, N., Luco, N., Pagani, M., Porter, K., Silva, V., Wald, D., B., W. GEM1 seismic risk report: part 2. GEM Technical Report 2010-5. GEM Foundation, Pavia, Italy, 2010a. 
CROWLEY, H., Colombi, M., Crempien, J., Erduran, E., Lopez, M., Liu, H., Mayfield, M., Milanesi, M. GEM1 seismic risk report: part 1. GEM Technical Report 20105. GEM Foundation, Pavia, Italy, $2010 \mathrm{~b}$.

CROWLEY, H., Monelli, D., Pagani, M., Silva, V., Weatherill, G. OpenQuake book. The GEM Foundation, Pavia, Italy, 2011.

CROWLEY, H., Monelli, D., Pagani, M., Silva, V., Weatherill, G. OpenQuake engine user instruction manual. GEM Foundation, Pavia, Italy, 2013.

FIELD, E.H., Jordan, T.H., Cornell, C.A. OpenSHA - A developing community modeling environment for seismic hazard analysis. Seismological Research Letters, 74:406-419, 2003.

FRANKEL, A. D., C. S. Mueller, T. P. Barnhard, E. V. Leyendecker, R. L. Wesson, S. C. Harmsen, F. W. Klein, D. M. Perkins, N. C. Dickman, S. L. Hanson, and M. Hopper USGS National Seismic Hazard Maps, Earthquake Spectra 16, 1-20, 2000.

GAMARRA, C. A. Nuevas Fuentes Sismogénicas para la Evaluación del Peligro Sísmico y Generación de Espectros de Peligro Uniforme en el Perú, Tesis de Grado, Facultad de Ingeniería Civil, Universidad Nacional de Ingeniería Lima, 2009.

GODINHO, J. Probabilistic seismic hazard analysis - an introduction to theoretical bases and applied methodology. Department of Civil Engineering, University of Patras, Greece., 2007.

GUTENBERG, R.; RICHTER, C. F. Frequency of Earthquakes in California. Bulletin of the Seismological Society of America, Volume 34, p. 185-188, 1944.

HANCOCK, J., WATSON-LAMPREY, J.A., ABRAHAMSON, N.A., BOMMER, J.J., MARKATIS, A., MCCOY, E. and MENDIS, R. An improved method of matching response spectra of recorded earthquake ground motion using wavelets. Journal of Earthquake Engineering, 10:Special Issue 1, pp. 67-89, 2006.

HARDIN B O, BLACK W L. Vibration modulus of normally consolidated clay: design equation and curves. Journal of the Soil Mechanics and Foudations Engineering Division, ASCE, 1968. 94(2):353-369.

HERRERA, F. Introducción a la estabilidade de taludes, Curso de Geotecnia, Noviembre 2013. 
HYNES-GRIFFIN M.; FRANKLIN A. Razionalizing the seismic coefficient method. U.S. Army Engineer Waterways Experiment Station, Miscellaneous Paper GL-84-13, Vicksburg, MS. 1984.

HUDSON, D. E. Reading and Interpreting Strong Motion Accelerograms. EERI Engineering Monographs on Earthquake Criteria, Structural design, and Strong Motion Records, Vol.1, 1979.

HUERTAS, J. Procedimentos de análise não-linear para previsão de resposta sísmica em geoestruturas, Dissertação de Doutorado. Programa de PósGraduação em Engenharia Civil. PUC-Rio, 2012.

ICOLD, Selecting seismic parameters for large dams, Bulletin 72, 1989.

ICOLD, Selecting seismic parameters for large dams, Bulletin 72, 2010.

IDRISS, I.M. Evaluating of seismic risk in engineering practice, Proc. 11th International Conference on Soil Mechanics and Foundation Engineering, San Francisco, v.1, pp. 255-320, 1985.

IDRISS, I. M.; SUN, J. I. User's manual for SHAKE91. University of California, Davis, California, 1992, 13p.

ISHIHARA, K. Evaluation of Soil Properties for Use in Earthquakes Response Analysis, In: Geomechanical Modeling in Engineering Practice, R. Dungar and J.A. Studer, Eds., A.A. Balkema, Rotterdam, the Netherlans, 1986.

INSTITUTO GEOFÍSICO DEL PERÚ (IGP). Estudio de Peligro Sísmico en Perú - Primera Versión. Setiembre, 2012.

INTERNATIONAL BUILDING CODE (IBC), International Code Council, Inc., 2012.

ITASCA Consulting Group Inc. FLAC, V.8.0 Mannual. Minneapolis, 2011.

JIRYAEI, M. The effect of Geometry Dimensions on the Earthquake

Response of the Finite Element Method. World Academy of Science, Engineering and Technology. Pag 206-210. 2010.

KAVAZANJIAN, E., MATASOVIC, N., HADJ-HAMOU, T., SABATINI, P. J.

Geotechnical engineering circular no. 3; design guidance: geotechnical earthquake engineering for highways; volume I - design principles. Rpt. No. FHWA-SA-97-076, U.S. Dept. of Trans., Fed. Hwy. Admin., Wash., DC, 1997. 
KOKUSHO, T., YOSHIDA, Y. and ESASHI, Y. Dynamic properties of soft clays for wide strain range. Soil and Foundations. Vol. 22, N 4, pp. 1-18, 1981.

KRAMER, S.L. Geotechnical Earthquake Engineering. Prentice - Hall, New Jersey, 1996, p. 653, 1996.

KUHLEMEYER, R. L.; LYSMER, J. Finite Element Method Accuracy for Wave Propagation Problems. Journal of the Soil Mechanics \& Foundation Division, ASCE, v. 99, n. SM5, 1973, p. 421-427.

LAW, TEAM-CHIE. Deformations of earth dams during construction, Ph.D. Thesis, University of Alberta, Edmonton, 1975.

LI, S. Computer Simulation of Sequential Impoundment Process of Concretefaced Rockfill Dam, Journal of Computers, Vol. 7, N 8, August 2012.

LILHANAND, K.; TSENG, W. S. Generation of Synthetic Time Histories Compatible With Multiple-Damping Response spetra, SMIRT-9, Lausanne, 1987.

LOAYZA, F. Modelagem do Comportamento Pós-Sismo de uma Barragem de Rejeito. Dissertação de Mestrado. Departamento de Engenharia Civil, Pontifícia Universidade Católica do Rio de Janeiro, Rio de Janeiro, 2009, $167 \mathrm{p}$.

LOMNITZ, C. Fundamentals of earthquake prediction. New York: John Wiley \& Sons, Inc., 1994.

LYSMER, J.; KUHLEMEYER R.L. Finite dynamic model for infinite media. ASCE, Journal of Engineering and Mechanical Division, 1969, p. 859-877.

MACEDO, J. Evaluación de la respuesta sísmica de presas de tierra en términos de la variabilidad de los espectros de diseño, Tesis de Maestría, Facultad de Ingeniería Civil, Universidad Nacional de Ingeniería Lima, 2013.

MANSOUR, Z., KALANTARY, B. Traditional Methods vs. Finite Difference Method for Computing Safety Factors of Slope Stability, Electronic Journal of Geotechnical Engineering, Vol. 16, pp.1119-1130, 2011.

MAKDISI, F. I.; SEED, H. B. Simplified Procedure for Estimating Dam and Embankment Earthquake-Induced Deformations, Journal of the Geotechnical Engineering Division, ASCE volume 104, No. GT7, 1978, p. 849-867.

MCGUIRE, R. K. Seismic hazard and risk analysis, Earthquake Engineering Research Institute, 2004. 
MCGUIRE, K.K. Fortran computer program for seismic risk analysis. Open-file report 67-76, United States, Department of the Interiors, Geological Survey. 102 pages, 1976.

MEJIA, L. H.; DAWSON E. M. Earthquake deconvolution for FLAC, $4^{\text {th }}$ International FLAC Symposium on Numerical Modeling in Geomechanics 2006 - Hart \& Verona eds., paper n. 04-10, Itasca Consulting Group, Inc., Minneapolis, ISBN 0-9767577-0-2, 2006.

MENESES, J. Evaluación del peligro sísmico y determinación de acelerogramas de diseño, Colegio de Ingenieros del Perú, Julio 2009

MONELLI, P., Pagani, M., Weatherill, G., Silva, V., Crowley, H The hazard component of OpenQuake: the calculation engine of the Global Earthquake Model. Proceedings of the 15th World Conference on Earthquake Engineering, Lisbon, Portugal, 2012.

MONROY O, BOLAÑOS A. Espectros de Peligro Sísmico Uniforme. Dissertação de mestrado, Pontifícia Universidade Católica do Peru, 2004.

NEWMARK, N. Effects of Earthquakes on Dams and Embankments, Geotechnique, Volume 115, No. 2, p. 139-160, 1965.

NIST - Selecting and scaling earthquake ground motions for performing responsehistory analyses. National Institute of Standards and Technology , 2011.

ORDAZ, M.; AGUILAR, A.; ARBOLEDA, J. CRISIS2007: Program for Computing Seismic Hazard. Instituto de Ingeniería. Universidad Nacional Autónoma de México, 1999, 2007.

QUISPE, E. Análise Dinâmica de un Aterro Reforçado com Geossintéticos. Dissertação de Mestrado, Departamento de Engenharia Civil, Pontifícia Universidade Católica do Rio de Janeiro, Rio de Janeiro, 2008, 134p.

RIBEIRO, P. M. Uma metodologia analítica para a avaliação do campo de tensões em barragens de concreto durante terremotos, Dissertação de Mestrado, Departamento de Engenharia Civil e Ambiental, Universidade de Brasília, pp. 162, Março, 2006.

RONCAL, Determinación del peligro sísmico em el território nacional y elaboración de aplicativo web, Titulo professional de ingenieria civil, UNIFIC, 2017.

SADIGH, K., CHANG, C., EGAN, J., MAKDISI, F. AND YOUNGS, R. Attenuation Relationships for Shallow Crustal Earthquakes Based on 
California Strong Motion Data. Seismological Research Letters 68:1, 180189, 1997.

SAUTER, F. Introducción a la Sismología, Editorial Tecnológica de Costa Rica, 1989.

SCHNABEL, P. B.; LYSMER, J; SEED, H. B. SHAKE: A Computer Program for Earthquake Response Analysis of Horizontally Sites, Report No. UCB/EERC-72/12, Earthquake Engineering Research Center, University of Caligfornia, Berkeley, 1972, 120p.

SCHWARTZ, D. P. AND K. J. COPPERSMITH. Fault behavior and characteristic earthquakes: examples from the Wasatch and San Andreas faults, J. Geophys. Res. 89, 5681-5698, 1984.

SCORDILIS, E. Empirical global relations converting Ms and mb to moment magnitude, Journal of Seismology 10: pp. 225-236, 2006

SEED, H. B. Soil Liquefaction and Cyclic Mobility Evaluation for Level Ground During Earthquakes, Journal of the Geotechnical Engineering Division, ASCE, Vol. 105, No. GT2, pp. 201-255, 1979.

SEED, H.B. and IDRISS, I.M. Soil moduli and damping factors for dynamic response analysis, Report No. EERC 70-10, University of California, Berkeley, 1970.

SEED, H. B., IDRISS, I. M., LEE, K. L., MAKDISI, F.I. Dynamic Analysis of the Slide in the Lower San Fernando Dam During the Earthquake of February 9, 1971, Journal of Geotechnical Engineering Division, ASCE, Vol. 101, No. 9, pp. 889-911, 1975.

SEED H.B. and MARTIN G.R. The Seismic Coefficient in Earth Dam Design, Journal of the Soil Mechanics and Foundation Division, ASCE, Vol. 92 SM3, pp. 25-58, 1966.

SEED, H.B., IDRISS, I.M. and KIEFER, F. W. Characteristics of rock motions during earthquakes, Jour. of the Soil Mech. and Found. Div., ASCE, Vol. 103, N GT6, pp. 607-625, 1969.

SEED, H.B., MAKDISI, I.F. and DE ALBA, P. - Performance of earth dams during earthquakes, JGED, ASCE, Vol. 104, No. GT7, pp.967-998, 1978.

SEED, H.B. WONG, R.T., IDRISS, I.M. and TOKIMATSU, K. - Moduli and damping factors for dynamic analysis of cohesionless soils, Report No. EERC 84-14, University of California, Berkeley, 1984. 
SEISMOSOFT LTD. SeismoMatch's Help System, 2016.

SEISMOSOFT LTD. SeismoSignal's Help System, 2016.

SILGADO E. Historia de los Sismos más Notables ocurridos en el Perú 19551970, Geofísica Panamericana, Vol 2 pp. 179-243, 1973.

SILGADO E. Historia de los Sismos más Notables ocurridos en el Perú (15131974), Instituto de Geología y Minería, Boletín №3, Serie $C$, Geodinámica e Ingeniería Geológica, Lima, Perú, 1978.

SILGADO E. Investigación de Sismicidad Histórica en la América del Sur en los Siglos XVI, XVII, XVIII y XIX, CONCYTEC, Lima, Perú, 1992.

SILVA, V., Crowley, H., Pagani, M., Monelli, D., Pinho, R Development and application of OpenQuake, an open source software for seismic risk assessment. Proceedings of the 15th World Conference on Earthquake Engineering, Lisbon, Portugal, paper n.4917. (2012).

SLIDE v.2016, 2D Limit Equilibrium Slope Stability Analysis, Rocscience Inc. 2016.

TSOMPANAKIS, Y., Lagaros, N.D., Stavroulakis, G.E. Soft computing techniques in parameter identification and probabilistic seismic analysis of structures. Advances in Engineering Software, 39, 612-624, 2008.

TERZAGHI, K. Mechanism of landslides, in application of geology to engineering practice, Berkey Vol., Geological Society of America, p.83$123,1950$.

U.S. GEOLOGICAL SURVEY (USGS). Preliminary Seismic Hazard Model for South America, Conferencia Internacional. Homenaje a Alberto Giesecke Matto, 2010.

VASQUEZ, J. Aplicação da ameaça sísmica na previsão da resposta dinâmica de uma barragem de terra. Dissertação de Mestrado, Departamento de Engenharia Civil, Pontifícia Universidade Católica do Rio de Janeiro, Rio de Janeiro, 2015.

VENEGAS C., FRANCISCO, J. Respuesta sísmica reciente en balsas de relaves chilenas y presas de material suelto, Trabajo de Fin de Master, Escuela de caminos, Canales y Puertos, Universidad Politécnica de Madrid, Junio, 2011. 
WEICHERT, D. H. Estimation of the earthquake recurrence parameters for unequal observation periods for different magnitudes, Bull. Seism. Soc. Am. 70, 1337-1346, 1980.

WIEMER, S., AND K. KATSUMATA. Spatial variability of seismicity parameters in aftershock zones, J. Geophys. Res. 104, 13,135-13,151, 1999.

WIEMER, S., AND M. WYSS. Minimum magnitude of complete reporting in earthquake catalogs: examples from Alaska, the Western United States, and Japan, Bull. Seism. Soc. Am. 90, 859-869, 2000.

WIEMER, S. AND ZÚÑIGA, R. ZMAP - a software package to analyze seismicity, EOS, Transactions, Fall Meeting, AGU, 75, 456., 1994.

Winckler et.al.; CPTu-Based State Characterization of Tailings Liquefaction Susceptibility-Reducing Risk of Aging Infrastructure under Extreme Loading Conditions, 34th Annual USSD Conference, Dams and Extreme Events, San Francisco, California, April 7-11, 2014.

WOOD, H. and NEUMANN F. Modified Mercalli Intensity Scale of 1931, Bulletin of the Seismological Society of America, v. 21, No. 4, p. 277-283. Dec. 1931.

YOUNGS, R. R., CHIOU. S. J., SILVA, W. J. AND HUMPREY, J. R. Strong Ground Motion Attenuation Relationships for Subduction Zone Earthquakes, Seismological Research Letters, Vol. 68, Numb. 1, Pp. 58 73, USA, 1997.

ZHAO, J., ZHANG, J., ASANO, A., OHNO, Y., OOUCHI, T. Attenuation Relations of Strong Ground Motion in Japan Using Site Classification Based on Predominant Period, Bulletin of the Seismological Society of America, Vol. 96, No. 3, pp. 898 - 913, June 2006. 
Anexo 1.

Coordenadas geográficas das fontes sismogênicas consideradas no projeto

\begin{tabular}{|c|c|c|c|}
\hline \multirow[b]{2}{*}{ Fontes } & \multicolumn{3}{|c|}{ COORDENADAS GEOGRÁFICAS } \\
\hline & $\begin{array}{l}\text { Longitude } \\
\text { (W) }\end{array}$ & $\begin{array}{l}\text { Latitud } \\
\text { (S) }\end{array}$ & \begin{tabular}{|c} 
Profundidade \\
$(\mathrm{km})$
\end{tabular} \\
\hline \multirow{6}{*}{$\begin{array}{c}\text { F3 } \\
\text { (Interfase) }\end{array}$} & -80.991 & -8.528 & 25 \\
\hline & -80.022 & -10.322 & 25 \\
\hline & -77.184 & -14.412 & 25 \\
\hline & -75.856 & -13.563 & 60 \\
\hline & -77.824 & -10.464 & 60 \\
\hline & -79.267 & -7.74 & 60 \\
\hline \multirow{5}{*}{$\begin{array}{c}\text { F4 } \\
\text { (Interfase) }\end{array}$} & -75.8 & -15.8 & 25 \\
\hline & -74.36 & -16.88 & 25 \\
\hline & -73.43 & -16.039 & 65 \\
\hline & -75.834 & -13.548 & 65 \\
\hline & -77.155 & -14.392 & 25 \\
\hline \multirow{6}{*}{$\begin{array}{c}\text { F9 } \\
\text { (Intraplaca) }\end{array}$} & -78.423 & -7.352 & 100 \\
\hline & -79.881 & -8.015 & 60 \\
\hline & -78.003 & -11.728 & 60 \\
\hline & -76.381 & -13.899 & 60 \\
\hline & -74.775 & -12.871 & 120 \\
\hline & -76.441 & -10.831 & 130 \\
\hline \multirow{7}{*}{$\begin{array}{c}\text { F10 } \\
\text { (Intraplaca) }\end{array}$} & -73.778 & -16.347 & 70 \\
\hline & -71.584 & -14.405 & 140 \\
\hline & -73.127 & -13.631 & 125 \\
\hline & -74.555 & -12.725 & 120 \\
\hline & -76.381 & -13.899 & 60 \\
\hline & -75.782 & -14.883 & 60 \\
\hline & -74.709 & -15.75 & 60 \\
\hline \multirow{7}{*}{$\begin{array}{c}\text { F13 } \\
\text { (Intraplaca) }\end{array}$} & -77.716 & -2.798 & 200 \\
\hline & -78.667 & -4.725 & 120 \\
\hline & -76.472 & -8.763 & 130 \\
\hline & -75.489 & -8.12 & 140 \\
\hline & -74.558 & -6.771 & 150 \\
\hline & -76.164 & -4.332 & 130 \\
\hline & -75.255 & -2.911 & 150 \\
\hline \multirow{6}{*}{$\begin{array}{c}\text { F14 } \\
\text { (Intraplaca) }\end{array}$} & -76.441 & -10.831 & 130 \\
\hline & -74.775 & -12.871 & 120 \\
\hline & -73.794 & -12.219 & 130 \\
\hline & -76.472 & -8.763 & 130 \\
\hline & -77.474 & -6.92 & 120 \\
\hline & -78.423 & -7.352 & 120 \\
\hline
\end{tabular}

\begin{tabular}{|c|c|c|c|}
\hline \multirow[b]{2}{*}{ Fontes } & \multicolumn{3}{|c|}{ COORDENADAS GEOGRÁFICAS } \\
\hline & $\begin{array}{l}\text { Longitude } \\
\text { (W) }\end{array}$ & $\begin{array}{l}\text { Latitud } \\
\text { (S) }\end{array}$ & $\begin{array}{c}\text { Profundidade } \\
(\mathbf{k m})\end{array}$ \\
\hline \multirow{7}{*}{$\begin{array}{c}\text { F15 } \\
\text { (Intraplaca) }\end{array}$} & -75.116 & -10.513 & 145 \\
\hline & -73.794 & -12.219 & 130 \\
\hline & -72.577 & -11.41 & 135 \\
\hline & -73.319 & -10.572 & 150 \\
\hline & -74.417 & -9.331 & 150 \\
\hline & -75.489 & -8.12 & 140 \\
\hline & -76.472 & -8.763 & 130 \\
\hline \multirow{5}{*}{$\begin{array}{c}\text { F16 } \\
\text { (Intraplaca) }\end{array}$} & -73.119 & -13.635 & 120 \\
\hline & -71.584 & -14.405 & 150 \\
\hline & -70.646 & -13.766 & 135 \\
\hline & -72.575 & -11.405 & 135 \\
\hline & -74.584 & -12.77 & 125 \\
\hline \multirow{4}{*}{$\begin{array}{c}\text { F18 } \\
\text { (Intraplaca) }\end{array}$} & -75.489 & -8.12 & 140 \\
\hline & -74.417 & -9.331 & 150 \\
\hline & -73.051 & -8.124 & 185 \\
\hline & -74.558 & -6.771 & 180 \\
\hline \multirow{8}{*}{$\begin{array}{c}\text { F22 } \\
\text { (Corticais) }\end{array}$} & -79.173 & -7.916 & 30 \\
\hline & -77.824 & -10.464 & 30 \\
\hline & -76.318 & -12.881 & 30 \\
\hline & -75.677 & -13.764 & 30 \\
\hline & -74.411 & -12.807 & 30 \\
\hline & -75.315 & -12.019 & 30 \\
\hline & -76.798 & -8.551 & 30 \\
\hline & -77.365 & -7.009 & 30 \\
\hline \multirow{5}{*}{$\begin{array}{c}\text { F23 } \\
\text { (Corticais) }\end{array}$} & -75.677 & -13.764 & 30 \\
\hline & -73.09 & -16.383 & 30 \\
\hline & -72.106 & -14.949 & 30 \\
\hline & -73.789 & -13.349 & 30 \\
\hline & -74.411 & -12.807 & 30 \\
\hline \multirow{7}{*}{$\begin{array}{c}\text { F28 } \\
\text { (Corticais) }\end{array}$} & -76.798 & -8.551 & 30 \\
\hline & -75.315 & -12.019 & 30 \\
\hline & -73.789 & -13.349 & 30 \\
\hline & -72.276 & -11.656 & 30 \\
\hline & -73.668 & -10.523 & 30 \\
\hline & -74.957 & -8.744 & 30 \\
\hline & -75.145 & -7.359 & 30 \\
\hline
\end{tabular}


Anexo 2.

Deslocamentos permanentes

\section{Braye Tavasarou (2007)}

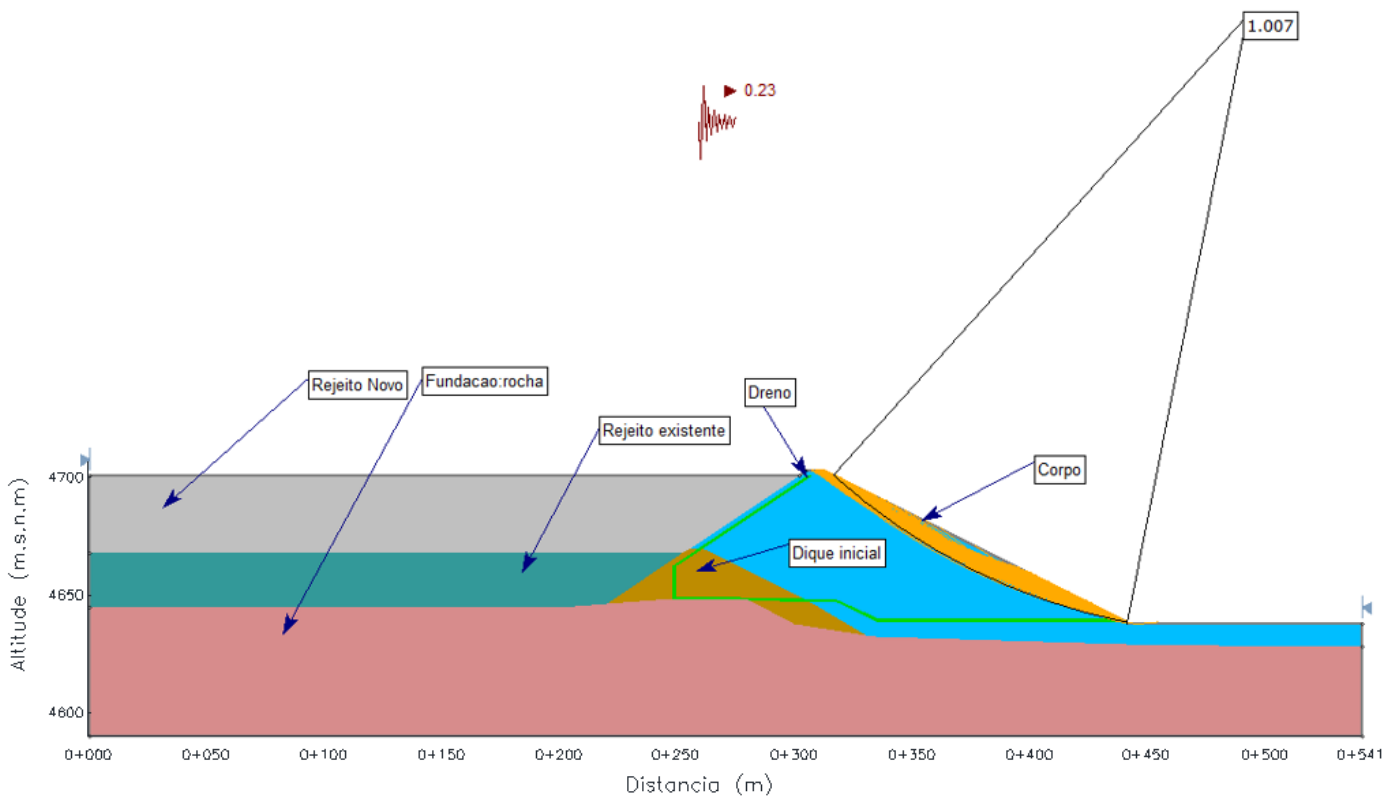

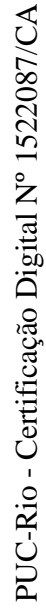

O valor de o coeficiente de fluencia (ky) para um fator de seguranca (FS) igual a 1 é de 0,23 . Proceso iteratitivo usango o programa SLIDE.

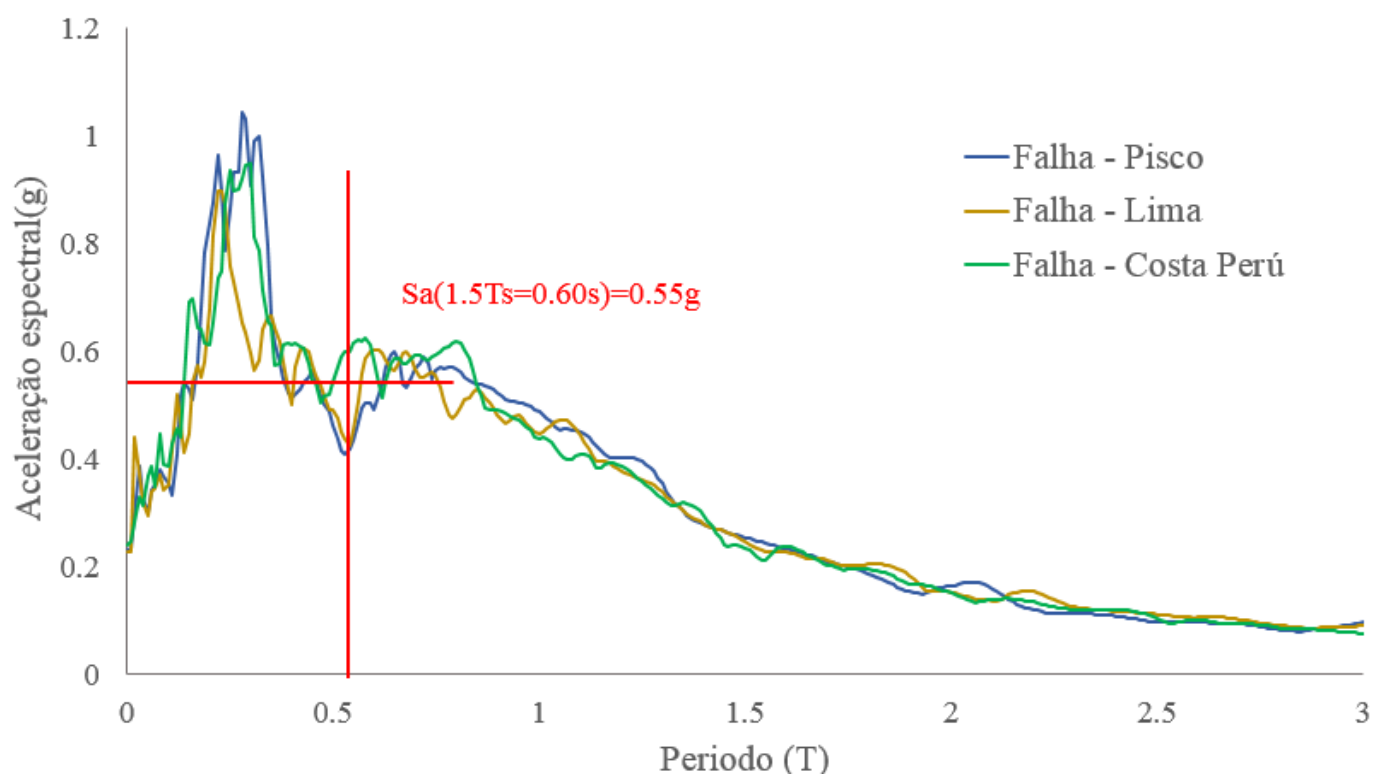

Espectros de acelerações num ponto da superfície de falha considera para os deslocamentos permanentes pelo método de Bray e Travasarou (2007) 
Simplified Procedure for Estimating Earthquake Induced Deviatoric Slope Displacements

by Jonathan D. Bray and Thaleia Travasarou

SEE NOTES BEL OV FOR GUIONCE NV THE USE OF SPREAOSHEET

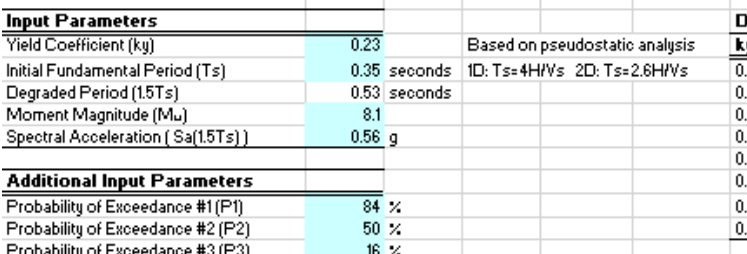

\begin{tabular}{|c|c|c|c|c|c|}
\hline \multicolumn{2}{|c|}{ Dependence on kg } & \multirow[b]{2}{*}{$D(\mathrm{~cm})$} & \multirow{2}{*}{ Dmedian (cm } & \multirow{2}{*}{ D-84\% $[\mathrm{cm})$} & \multirow{2}{*}{ D-16\% (cm) } \\
\hline ky & $P\left(D=0^{-}\right)$ & & & & \\
\hline 0.020 & 0.00 & 171.5 & 171.5 & 330.7 & 89.0 \\
\hline 0.05 & 0.00 & 78.2 & 78.2 & 150.7 & 40.5 \\
\hline 0.07 & 0.00 & 50.9 & 50.9 & 98.1 & 26.4 \\
\hline 0.1 & 0.00 & 29.7 & 29.7 & 57.3 & 15.4 \\
\hline 0.15 & 0.00 & 14.6 & 14.5 & 28.0 & 7.5 \\
\hline 0.2 & 0.05 & 8.2 & 7.9 & 15.5 & 3.7 \\
\hline 0.3 & 0.39 & 3.3 & 1.8 & 5.1 & $<1$ \\
\hline 0.4 & 0.76 & 1.6 & $<1$ & 1.3 & $<1$ \\
\hline
\end{tabular}

\begin{tabular}{ll} 
Probability of Exceedance \#3 (P3) & $16 \%$ \\
\hline Displacement Threshold (d_threshold) & $5 \mathrm{~cm}$
\end{tabular}

Intermediate Calculated Parameters

Standard Deviation of Non-Zero Seismicl $\quad 0.66$

Results

\begin{tabular}{llll}
$\mathrm{D} 1$ & 2.0 & $\mathrm{~cm}$ & eq. (j) using eq. (7) \\
\hline $\mathrm{D} 2$ & 5.5 & $\mathrm{~cm}$ & calo usinge. (7)
\end{tabular}

\begin{tabular}{llll}
$\mathrm{D} 2$ & $5.5 \mathrm{~cm}$ & calc. using eq. (7) \\
\hline $\mathrm{D3}$ & $11.1 \mathrm{~cm}$ & calc. usingeq. (7)
\end{tabular}

\begin{tabular}{|c|c|c|c|}
\hline$P(D>d$ threshold & 11.1 & $\mathrm{~cm}$ & calc. using \\
\hline
\end{tabular}

Notes

1. Volues highlighted in bluc are input parometere, and resulte are presented in the toble with the yellow hesding 2. Probability of Exceedance is the desired probability of exceeding a particular diepplacement value

3. Dieplacemente $D 1, D 2$, and $\mathrm{D} 3$ correspond to $P 1, \mathrm{P} 2$, and $\mathrm{P} 3$, respectively.

(c.g. the probsbility of excesding displasement Dis $\mathrm{P}$ )

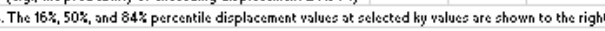

5.

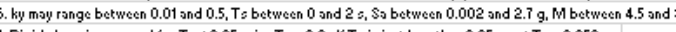

8. When op

9. ky may be estimated ysing the simplified equations shown below.

10. Ex m

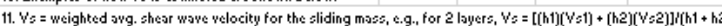
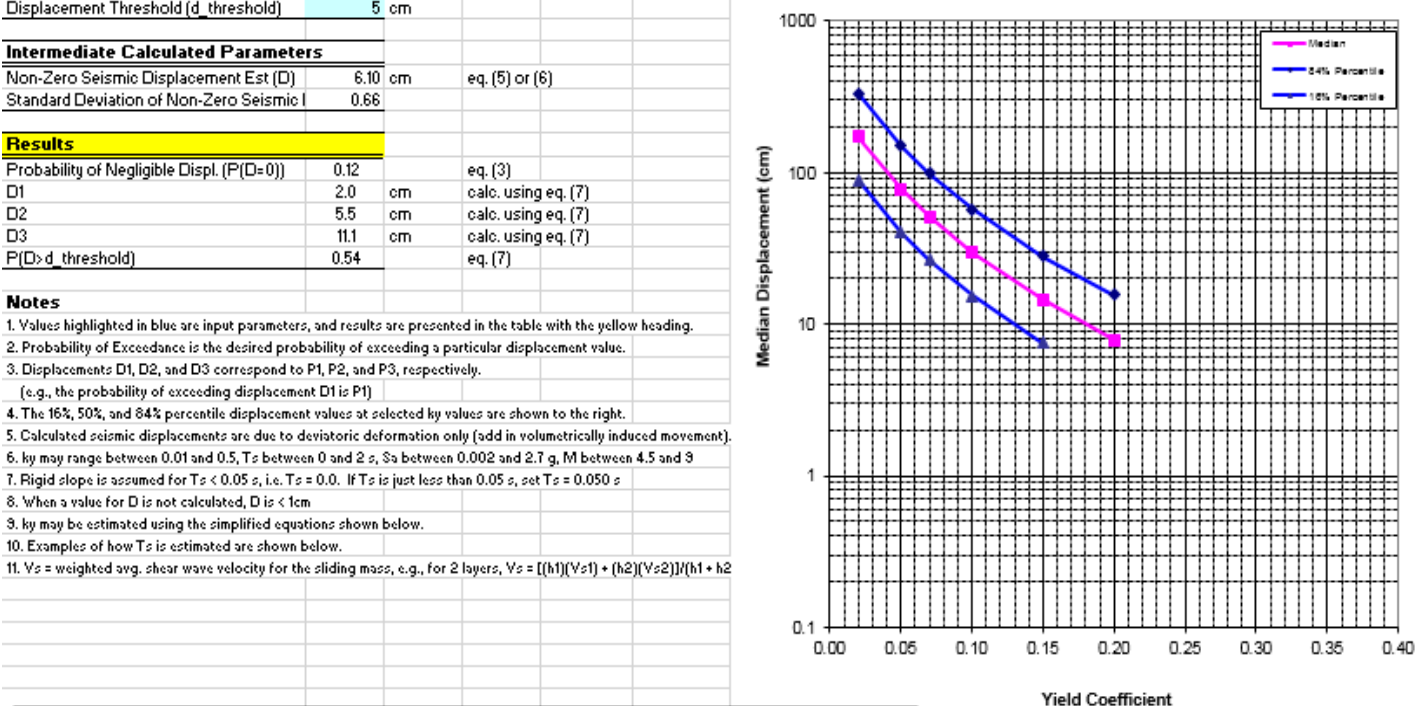

$\underline{\text { Swaisgood (2013) }}$

$$
\begin{aligned}
& \% \text { Deslocamento }=e^{(5,70 P G A+0,47 M-7,22)} \\
& \% \text { Deslocamento }=\frac{\text { Deslocamento }}{\text { alturada barragem }+ \text { Espessura da fundação }} \times 100 \\
& \text { CREST SETTLEMENT: } \\
& \text { AN INDEX TO EARTHOUAKE DAMAGE }
\end{aligned}
$$

PGA

$M$

Altura da barragem

Fundação

\%Deslocamento

Deslocamento $(\mathrm{m}) \quad 0.177136 \mathrm{~m}$

\section{$0.4 \mathrm{~g}$}

8.1

$55 \mathrm{~m}$

$0 \mathrm{~m}$

6




\section{Apêndice 1.}

$\underline{\text { Parâmetros de sismicidade F-3 }}$

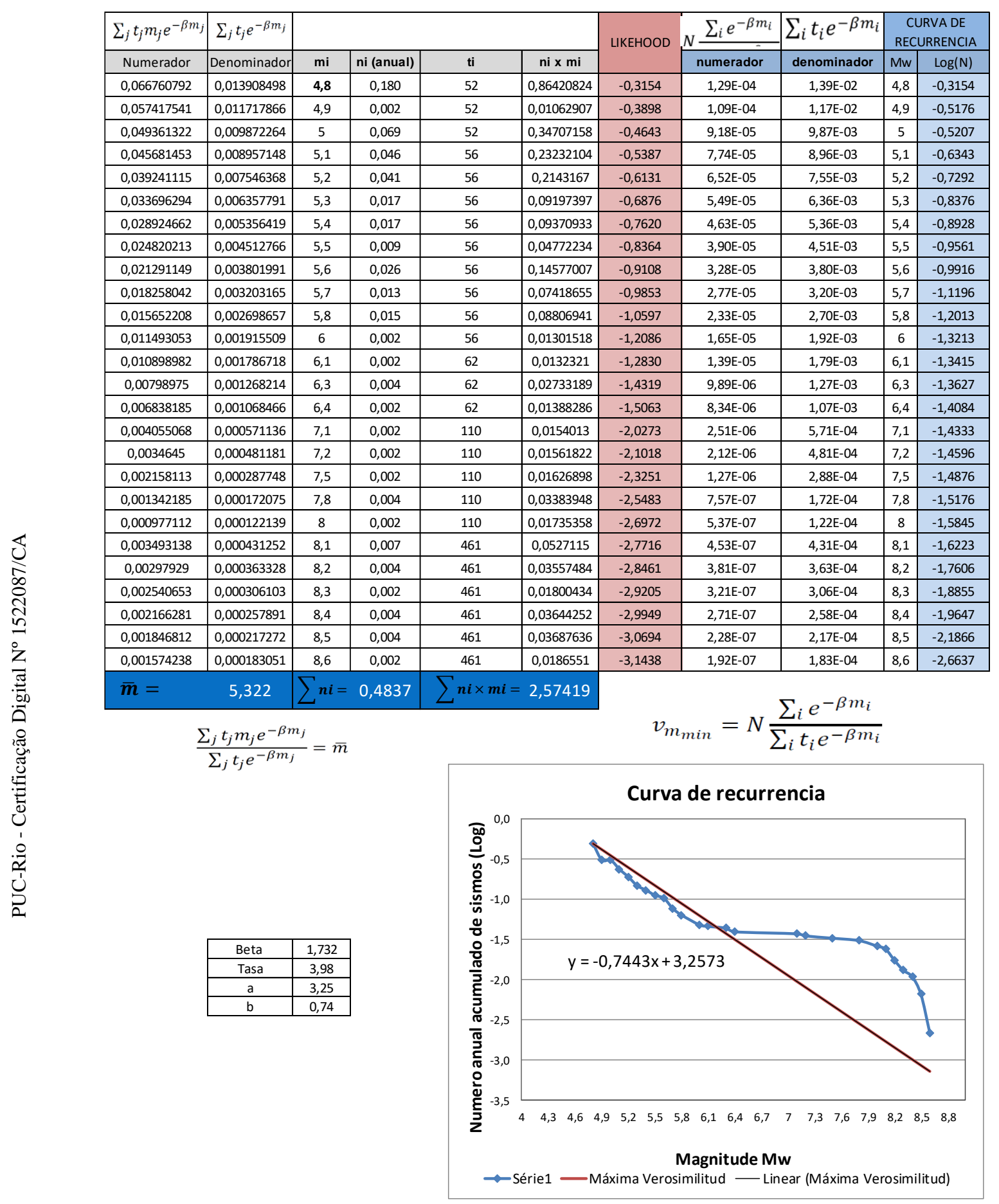


Parâmetros de sismicidade F-4

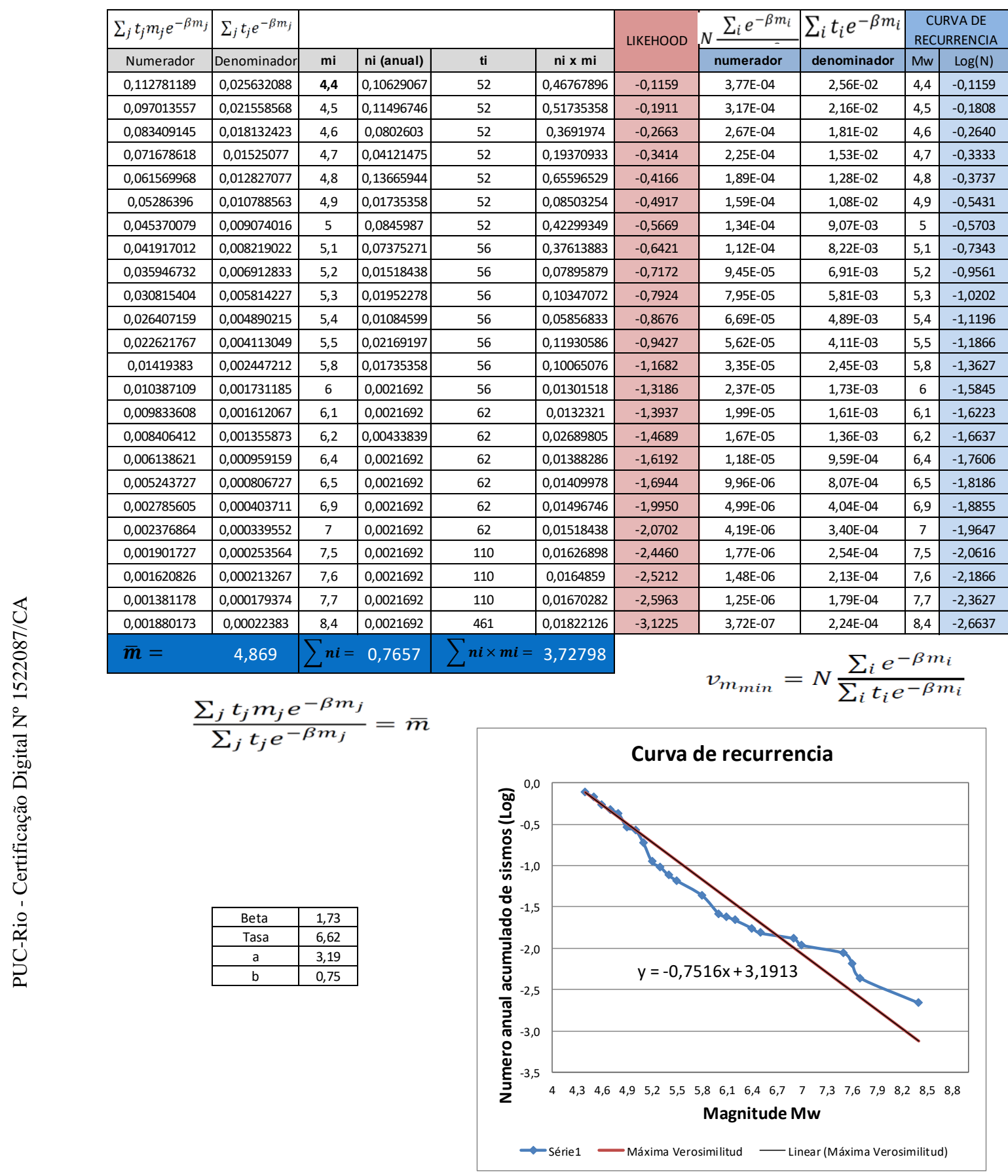


Parâmetros de sismicidade F-9

\begin{tabular}{|c|c|c|c|c|c|c|c|c|c|c|}
\hline \multirow{2}{*}{$\frac{\sum_{j} t_{j} m_{j} e^{-\beta m_{j}}}{\text { Numerador }}$} & \multirow{2}{*}{\begin{tabular}{|l|}
$\sum_{j} t_{j} e^{-\beta m_{j}}$ \\
Denominador
\end{tabular}} & \multirow[b]{2}{*}{$\mathrm{mi}$} & \multirow[b]{2}{*}{ ni (anual) } & \multirow[b]{2}{*}{$\mathrm{ti}$} & \multirow[b]{2}{*}{ ni $x \mathrm{mi}$} & \multirow[t]{2}{*}{ LIKEHOOD } & \multirow{2}{*}{$N \frac{\sum_{i} e^{-\beta m_{i}}}{\text { numerador }}$} & \multirow{2}{*}{\begin{tabular}{|l}
$\sum_{i} t_{i} e^{-\beta m_{i}}$ \\
denominador
\end{tabular}} & \multicolumn{2}{|c|}{$\begin{array}{c}\text { CURVA DE } \\
\text { RECURRENCIA } \\
\end{array}$} \\
\hline & & & & & & & & & $M w$ & $\log (\mathrm{N})$ \\
\hline 0,028903896 & \begin{tabular}{|l|}
0,006423088 \\
\end{tabular} & 4,5 & 1,0645161 & 52 & \begin{tabular}{|l|l|}
4,79032258 \\
\end{tabular} & 0,6862 & $6,00 E-04$ & $6,42 \mathrm{E}-03$ & 4,5 & 0,6862 \\
\hline 0,02419087 & \begin{tabular}{|l|}
0,005258885 \\
\end{tabular} & 4,6 & 0,6612903 & 52 & \begin{tabular}{|l|l|}
, 04193548 \\
\end{tabular} & 0,5993 & 4,91E-04 & $5,26 \mathrm{E}-03$ & 4,6 & 0,5787 \\
\hline 0,020236775 & \begin{tabular}{|l|}
0,004305697 \\
\end{tabular} & 4,7 & 0,0645161 & 52 & \begin{tabular}{|l|}
0,30322581 \\
\end{tabular} & 0,5125 & $4,02 E-04$ & $4,31 \mathrm{E}-03$ & 4,7 & 0,4954 \\
\hline 0,016921329 & \begin{tabular}{|l|}
0,003525277 \\
\end{tabular} & 4,8 & 1,1612903 & 52 & 5,57419355 & 0,4256 & $3,29 E-04$ & 3,53E-03 & 4,8 & 0,4864 \\
\hline 0,011815792 & \begin{tabular}{|l|}
0,002363158 \\
\end{tabular} & 5 & 0,3870968 & 52 & 1,93548387 & 0,2519 & $2,21 \mathrm{E}-04$ & $2,36 \mathrm{E}-03$ & 5,0 & 0,2795 \\
\hline 0,010626677 & \begin{tabular}{|l|}
0,002083662 \\
\end{tabular} & 5,1 & 0,3064516 & 56 & \begin{tabular}{|l}
1,56290323 \\
\end{tabular} & 0,1651 & 1,81E-04 & $2,08 \mathrm{E}-03$ & 5,1 & 0,1807 \\
\hline 0,00887116 & \begin{tabular}{|l|}
0,001705992 \\
\end{tabular} & 5,2 & 0,2419355 & 56 & 1,25806452 & 0,0782 & $1,48 \mathrm{E}-04$ & $1,71 \mathrm{E}-03$ & 5,2 & 0,0827 \\
\hline 0,007402915 & \begin{tabular}{|l|}
0,001396776 \\
\end{tabular} & 5,3 & 0,1935484 & 56 & \begin{tabular}{|l|}
1,02580645 \\
\end{tabular} & $-0,0086$ & $1,21 \mathrm{E}-04$ & $1,40 \mathrm{E}-03$ & 5,3 & $-0,0142$ \\
\hline 0,006175476 & \begin{tabular}{|l|}
0,001143607 \\
\end{tabular} & 5,4 & 0,1774194 & 56 & \begin{tabular}{|l|}
0,95806452 \\
\end{tabular} & $-0,0955$ & 9,91E-05 & $1,14 \mathrm{E}-03$ & 5,4 & $-0,1112$ \\
\hline 0,005149785 & 0,000936325 & 5,5 & 0,0806452 & 56 & 0,44354839 & $-0,1823$ & $8,12 \mathrm{E}-05$ & 9,36E-04 & 5,5 & $-0,2242$ \\
\hline 0,004293033 & 0,000766613 & 5,6 & 0,0967742 & 56 & 0,54193548 & $-0,2692$ & 6,65E-05 & 7,67E-04 & 5,6 & $-0,2872$ \\
\hline 0,003577675 & \begin{tabular}{|l|}
0,000627662 \\
\end{tabular} & 5,7 & \begin{tabular}{|l|}
0,016129 \\
\end{tabular} & 56 & 0,09193548 & $-0,3560$ & $5,44 E-05$ & $6,28 \mathrm{E}-04$ & 5,7 & $-0,3774$ \\
\hline 0,002980601 & \begin{tabular}{|l|}
0,000513897 \\
\end{tabular} & 5,8 & 0,1290323 & 56 & \begin{tabular}{|l}
0,7483871 \\
\end{tabular} & $-0,4429$ & 4,46E-05 & $5,14 \mathrm{E}-04$ & 5,8 & $-0,3945$ \\
\hline 0,002482433 & \begin{tabular}{|l|}
0,000420751 \\
\end{tabular} & 5,9 & 0,0322581 & 56 & \begin{tabular}{|l|}
0,19032258 \\
\end{tabular} & $-0,5297$ & $3,65 \mathrm{E}-05$ & $4,21 \mathrm{E}-04$ & 5,9 & $-0,5619$ \\
\hline 0,002066934 & 0,000344489 & 6 & 0,0322581 & 56 & 0,19354839 & $-0,6166$ & 2,99E-05 & 3,44E-04 & 6,0 & $-0,6163$ \\
\hline 0,001904841 & 0,000312269 & 6,1 & 0,0645161 & 62 & 0,39354839 & $-0,7034$ & $2,45 \mathrm{E}-05$ & 3,12E-04 & 6,1 & $-0,6784$ \\
\hline 0,00158515 & \begin{tabular}{|l|}
0,000255669 \\
\end{tabular} & 6,2 & \begin{tabular}{|l|}
0,016129 \\
\end{tabular} & 62 & 0,1 & $-0,7903$ & $2,00 E-05$ & $2,56 \mathrm{E}-04$ & 6,2 & $-0,8381$ \\
\hline 0,001096878 & \begin{tabular}{|l|}
0,000171387 \\
\end{tabular} & 6,4 & 0,0645161 & 62 & 0,41290323 & $-0,9640$ & $1,34 \mathrm{E}-05$ & $1,71 \mathrm{E}-04$ & 6,4 & $-0,8893$ \\
\hline 0,000912098 & \begin{tabular}{|l|}
0,000140323 \\
\end{tabular} & 6,5 & 0 & 62 & 0 & $-1,0508$ & $1,10 \mathrm{E}-05$ & $1,40 \mathrm{E}-04$ & 6,5 & $-1,1903$ \\
\hline 0,000523704 & 7,70154E-05 & 6,8 & \begin{tabular}{|l|l|}
0,016129 \\
\end{tabular} & 62 & 0,10967742 & $-1,3114$ & 6,03E-06 & 7,70E-05 & 6,8 & $-1,1903$ \\
\hline 0,000435087 & 6,30561E-05 & 6,9 & 0,0322581 & 62 & 0,22258065 & $-1,3982$ & 4,94E-06 & 6,31E-05 & 6,9 & $-1,3153$ \\
\hline 0,000361389 & 5,1627E-05 & 7 & \begin{tabular}{|l|}
0,016129 \\
\end{tabular} & 62 & 0,11290323 & $-1,4851$ & 4,04E-06 & $5,16 \mathrm{E}-05$ & 7,0 & $-1,7924$ \\
\hline$\overline{\boldsymbol{m}}=$ & 4,946 & $\sum n$ & 4,8548 & $\sum n$ & 24,0113 & & & $\Gamma$ & & \\
\hline
\end{tabular}

$$
\frac{\sum_{j} t_{j} m_{j} e^{-\beta m_{j}}}{\sum_{j} t_{j} e^{-\beta m_{j}}}=\bar{m}
$$

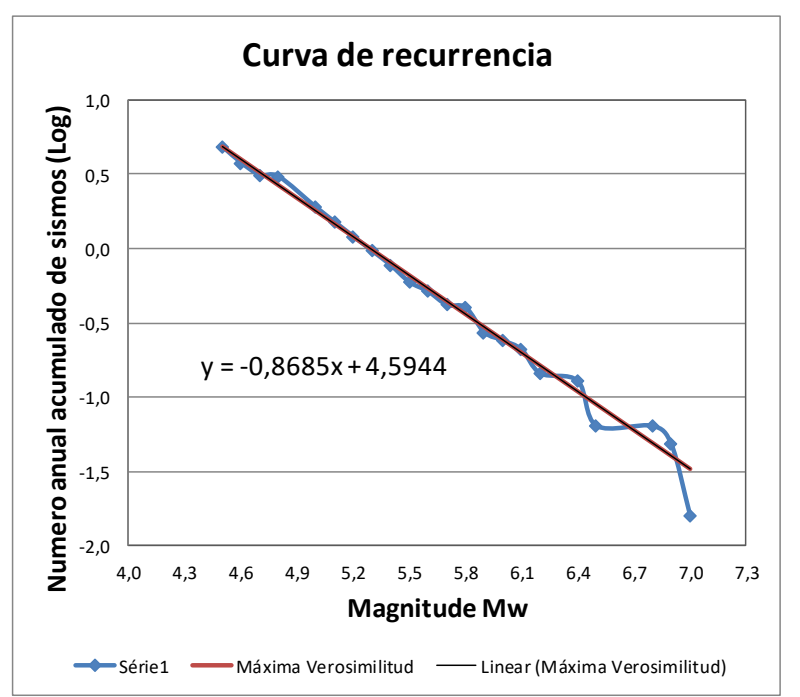


$\underline{\text { Parâmetros de sismicidade F-10 }}$

\begin{tabular}{|c|c|c|c|c|c|c|c|c|c|c|}
\hline \multirow{2}{*}{\begin{tabular}{|c|}
$\sum_{j} t_{j} m_{j} e^{-\beta m_{j}}$ \\
Numerador
\end{tabular}} & \multirow{2}{*}{\begin{tabular}{|l|}
$\sum_{j} t_{j} e^{-\beta m_{j}}$ \\
Denominador \\
\end{tabular}} & \multirow[b]{2}{*}{$\mathrm{mi}$} & \multirow[b]{2}{*}{ ni (anual) } & \multirow[b]{2}{*}{$\mathrm{ti}$} & \multirow[b]{2}{*}{ ni $x$ mi } & \multirow[t]{2}{*}{ LIKEHOOD } & \multirow{2}{*}{$N \frac{\sum_{i} e^{-\beta m_{i}}}{\text { numerador }}$} & \multirow{2}{*}{$\frac{\sum_{i} t_{i} e^{-\beta m_{i}}}{\text { denominador }}$} & \multicolumn{2}{|c|}{$\begin{array}{c}\text { CURVA DE } \\
\text { RECURRENCIA }\end{array}$} \\
\hline & & & & & & & & & $\mathrm{Mw}$ & $\log (\mathrm{N})$ \\
\hline 0,07343419 & 0,016318709 & 4,5 & 0,88709677 & 52 & 3,99193548 & 0,7746 & $1,87 \mathrm{E}-03$ & $1,63 E-02$ & 4,5 & 0,7746 \\
\hline 0,062746879 & 0,013640626 & 4,6 & 0,70967742 & 52 & 3,26451613 & 0,6968 & $1,56 \mathrm{E}-03$ & $1,36 \mathrm{E}-02$ & 4,6 & 0,7045 \\
\hline 0,053589617 & 0,011402046 & 4,7 & 0,19354839 & 52 & 0,90967742 & 0,6189 & $1,31 \mathrm{E}-03$ & $1,14 \mathrm{E}-02$ & 4,7 & 0,6390 \\
\hline 0,045748044 & 0,009530843 & 4,8 & 1,48387097 & 52 & 7,12258065 & 0,5411 & $1,09 \mathrm{E}-03$ & $9,53 \mathrm{E}-03$ & 4,8 & 0,6192 \\
\hline 0,033296478 & 0,006659296 & 5 & 0,5483871 & 52 & 2,74193548 & 0,3854 & $7,62 \mathrm{E}-04$ & $6,66 \mathrm{E}-03$ & 5 & 0,4277 \\
\hline 0,030572549 & 0,005994617 & 5,1 & 0,35483871 & 56 & 1,80967742 & 0,3075 & $6,37 E-04$ & 5,99E-03 & 5,1 & 0,3282 \\
\hline 0,026056334 & 0,005010833 & 5,2 & 0,43548387 & 56 & 2,26451613 & 0,2297 & 5,33E-04 & $5,01 \mathrm{E}-03$ & 5,2 & 0,2490 \\
\hline 0,022199048 & 0,0041885 & 5,3 & 0,41935484 & 56 & 2,22258065 & 0,1518 & $4,45 \mathrm{E}-04$ & 4,19E-03 & 5,3 & 0,1267 \\
\hline 0,018906047 & 0,00350112 & 5,4 & 0,17741935 & 56 & 0,95806452 & 0,0740 & $3,72 \mathrm{E}-04$ & $3,50 \mathrm{E}-03$ & 5,4 & $-0,0365$ \\
\hline 0,016096007 & 0,002926547 & 5,5 & 0,17741935 & 56 & 0,97580645 & $-0,0039$ & $3,11 \mathrm{E}-04$ & $2,93 \mathrm{E}-03$ & 5,5 & $-0,1296$ \\
\hline 0,013699099 & 0,002446268 & 5,6 & 0,20967742 & 56 & 1,17419355 & $-0,0817$ & $2,60 \mathrm{E}-04$ & $2,45 \mathrm{E}-03$ & 5,6 & $-0,2483$ \\
\hline 0,011655404 & 0,002044808 & 5,7 & 0,01612903 & 56 & 0,09193548 & $-0,1596$ & 2,17E-04 & $2,04 \mathrm{E}-03$ & 5,7 & $-0,4500$ \\
\hline 0,009913544 & 0,001709232 & 5,8 & 0,12903226 & 56 & 0,7483871 & $-0,2374$ & $1,82 \mathrm{E}-04$ & $1,71 \mathrm{E}-03$ & 5,8 & $-0,4702$ \\
\hline 0,008429493 & 0,001428728 & 5,9 & 0,0483871 & 56 & 0,28548387 & $-0,3153$ & $1,52 \mathrm{E}-04$ & $1,43 E-03$ & 5,9 & $-0,6784$ \\
\hline 0,007165545 & 0,001194257 & 6 & 0,03225806 & 56 & 0,19354839 & $-0,3931$ & $1,27 \mathrm{E}-04$ & $1,19 \mathrm{E}-03$ & 6 & $-0,7924$ \\
\hline 0,006741864 & 0,001105224 & 6,1 & 0,0483871 & 62 & 0,29516129 & $-0,4710$ & $1,06 \mathrm{E}-04$ & $1,11 \mathrm{E}-03$ & 6,1 & $-0,8893$ \\
\hline 0,004131194 & 0,000645499 & 6,4 & 0,01612903 & 62 & 0,10322581 & $-0,7045$ & $6,20 \mathrm{E}-05$ & $6,45 \mathrm{E}-04$ & 6,4 & $-1,0934$ \\
\hline 0,003507175 & 0,000539565 & 6,5 & 0,01612903 & 62 & 0,10483871 & $-0,7824$ & $5,18 \mathrm{E}-05$ & $5,40 \mathrm{E}-04$ & 6,5 & $-1,1903$ \\
\hline 0,002142883 & 0,00031513 & 6,8 & 0,01612903 & 62 & 0,10967742 & $-1,0159$ & 3,03E-05 & $3,15 \mathrm{E}-04$ & 6,8 & $-1,3153$ \\
\hline 0,001541291 & 0,000220184 & 7 & 0,03225806 & 62 & 0,22580645 & $-1,1717$ & $2,11 E-05$ & $2,20 \mathrm{E}-04$ & 7 & $-1,4914$ \\
\hline
\end{tabular}

\begin{tabular}{ll|l|l|l|}
$\overline{\boldsymbol{m}}=\quad 4,972$ & $\sum n \boldsymbol{i}=5,9516$ & $\sum n \boldsymbol{n} \times \boldsymbol{m i}=29,5935$
\end{tabular}

$$
v_{\text {min }}=N \frac{\sum_{i} e^{-\beta m_{i}}}{\sum_{i} t_{i} e^{-\beta m_{i}}}
$$$$
\frac{\sum_{j} t_{j} m_{j} e^{-\beta m_{j}}}{\sum_{j} t_{j} e^{-\beta m_{j}}}=\bar{m}
$$

\begin{tabular}{|c|c|}
\hline Beta & 1,805 \\
\hline Tasa & 6,57 \\
\hline a & 4,27 \\
\hline b & 0,77 \\
\hline
\end{tabular}

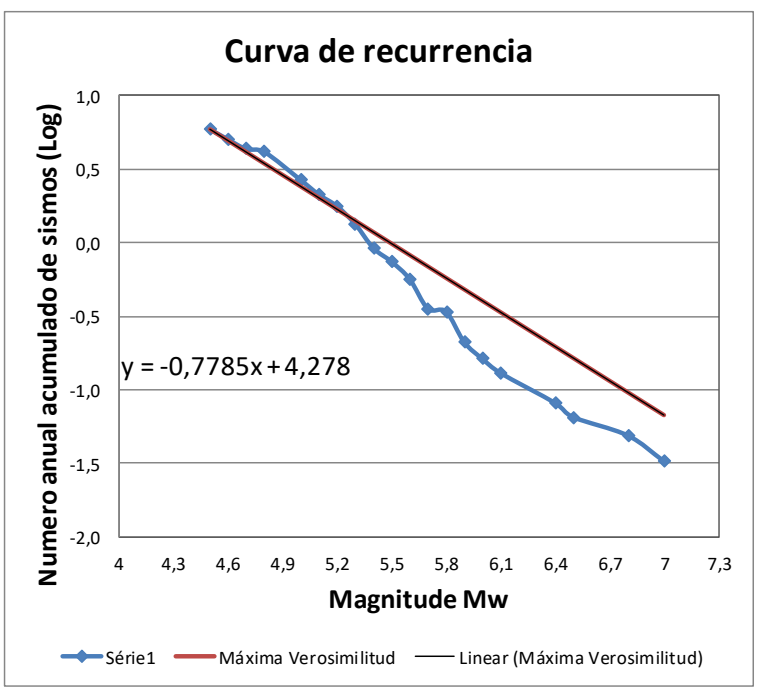


$\underline{\text { Parâmetros de sismicidade F-13 }}$

\begin{tabular}{|c|c|c|c|c|c|c|c|c|c|c|}
\hline$\sum_{j} t_{j} m_{j} e^{-\beta m_{j}}$ & $\Sigma_{j} t_{j} e^{-\beta m_{j}}$ & & & & & LIKEHOOD & $N \sum_{i} e^{-\beta m_{i}}$ & $\sum_{i} t_{l} e^{-\beta m_{i}}$ & & $\begin{array}{l}\text { RVA DE } \\
\text { IRRENCIA }\end{array}$ \\
\hline Numerador & Denominador & $\mathrm{mi}$ & ni (anual) & ti & ni $x$ mi & & numerador & denominador & Mw & $\log (\mathrm{N})$ \\
\hline 0,367432258 & 0,085449362 & 4,3 & 0,2545455 & 52 & 1,09454545 & 0,2575 & $2,97 \mathrm{E}-03$ & $8,54 \mathrm{E}-02$ & 4,3 & 0,2575 \\
\hline 0,323899642 & 0,073613555 & 4,4 & 0,2363636 & 52 & 1,04 & 0,1927 & $2,56 \mathrm{E}-03$ & $7,36 \mathrm{E}-02$ & 4,4 & 0,1916 \\
\hline 0,285377198 & 0,063417155 & 4,5 & 0,1363636 & 52 & 0,61363636 & 0,1280 & $2,21 \mathrm{E}-03$ & $6,34 \mathrm{E}-02$ & 4,5 & 0,1200 \\
\hline 0,251312189 & 0,054633084 & 4,6 & 0,1727273 & 52 & 0,79454545 & 0,0632 & $1,90 E-03$ & $5,46 \mathrm{E}-02$ & 4,6 & 0,0726 \\
\hline 0,221208873 & 0,047065718 & 4,7 & 0,0272727 & 52 & 0,12818182 & $-0,0015$ & $1,64 \mathrm{E}-03$ & $4,71 \mathrm{E}-02$ & 4,7 & 0,0039 \\
\hline 0,194623325 & 0,040546526 & 4,8 & 0,2909091 & 52 & 1,39636364 & $-0,0663$ & $1,41 \mathrm{E}-03$ & $4,05 E-02$ & 4,8 & $-0,0080$ \\
\hline 0,171158588 & 0,034930324 & 4,9 & 0,0272727 & 52 & 0,13363636 & $-0,1310$ & $1,22 \mathrm{E}-03$ & $3,49 \mathrm{E}-02$ & 4,9 & $-0,1606$ \\
\hline 0,150460182 & 0,030092036 & 5 & 0,1090909 & 52 & 0,54545455 & $-0,1958$ & $1,05 \mathrm{E}-03$ & $3,01 \mathrm{E}-02$ & 5 & $-0,1781$ \\
\hline 0,142382103 & 0,027918059 & 5,1 & 0,1363636 & 56 & 0,69545455 & $-0,2605$ & $9,02 \mathrm{E}-04$ & $2,79 \mathrm{E}-02$ & 5,1 & $-0,2561$ \\
\hline 0,125065504 & 0,024051058 & 5,2 & 0,0727273 & 56 & 0,37818182 & $-0,3253$ & $7,77 \mathrm{E}-04$ & $2,41 \mathrm{E}-02$ & 5,2 & $-0,3786$ \\
\hline 0,109814333 & 0,020719685 & 5,3 & 0,0909091 & 56 & 0,48181818 & $-0,3900$ & $6,69 \mathrm{E}-04$ & $2,07 E-02$ & 5,3 & $-0,4616$ \\
\hline 0,096388646 & 0,017849749 & 5,4 & 0,0272727 & 56 & 0,14727273 & $-0,4548$ & $5,77 \mathrm{E}-04$ & $1,78 \mathrm{E}-02$ & 5,4 & $-0,5942$ \\
\hline 0,084575345 & 0,015377335 & 5,5 & 0,0454545 & 56 & 0,25 & $-0,5196$ & $4,97 \mathrm{E}-04$ & $1,54 \mathrm{E}-02$ & 5,5 & $-0,6435$ \\
\hline 0,074185338 & 0,013247382 & 5,6 & 0,0090909 & 56 & 0,05090909 & $-0,5843$ & $4,28 \mathrm{E}-04$ & $1,32 \mathrm{E}-02$ & 5,6 & $-0,7404$ \\
\hline 0,065050984 & 0,011412453 & 5,7 & 0,0181818 & 56 & 0,10363636 & $-0,6491$ & $3,69 \mathrm{E}-04$ & $1,14 \mathrm{E}-02$ & 5,7 & $-0,7626$ \\
\hline 0,057023776 & 0,009831686 & 5,8 & 0,0272727 & 56 & 0,15818182 & $-0,7138$ & $3,18 \mathrm{E}-04$ & $9,83 \mathrm{E}-03$ & 5,8 & $-0,8109$ \\
\hline 0,043780141 & 0,00729669 & 6 & 0,0090909 & 56 & 0,05454545 & $-0,8433$ & $2,36 \mathrm{E}-04$ & $7,30 \mathrm{E}-03$ & 6 & $-0,8953$ \\
\hline 0,042452999 & 0,006959508 & 6,1 & 0,0090909 & 62 & 0,05545455 & $-0,9081$ & $2,03 \mathrm{E}-04$ & $6,96 \mathrm{E}-03$ & 6,1 & $-0,9274$ \\
\hline 0,037172279 & 0,005995529 & 6,2 & 0,0090909 & 62 & 0,05636364 & $-0,9728$ & $1,75 \mathrm{E}-04$ & $6,00 E-03$ & 6,2 & $-0,9622$ \\
\hline 0,03253996 & 0,005165073 & 6,3 & 0,0090909 & 62 & 0,05727273 & $-1,0376$ & $1,51 \mathrm{E}-04$ & $5,17 \mathrm{E}-03$ & 6,3 & $-1,0000$ \\
\hline 0,028477732 & 0,004449646 & 6,4 & 0,0090909 & 62 & 0,05818182 & $-1,1023$ & $1,30 \mathrm{E}-04$ & $4,45 E-03$ & 6,4 & $-1,0414$ \\
\hline 0,024916541 & 0,003833314 & 6,5 & 0,0181818 & 62 & 0,11818182 & $-1,1671$ & $1,12 \mathrm{E}-04$ & $3,83 E-03$ & 6,5 & $-1,0872$ \\
\hline 0,019061064 & 0,002844935 & 6,7 & 0,0181818 & 62 & 0,12181818 & $-1,2966$ & $8,30 E-05$ & $2,84 E-03$ & 6,7 & $-1,1963$ \\
\hline 0,016665955 & 0,002450876 & 6,8 & 0,0090909 & 62 & 0,06181818 & $-1,3613$ & $7,15 E-05$ & $2,45 \mathrm{E}-03$ & 6,8 & $-1,3424$ \\
\hline 0,014568651 & 0,002111399 & 6,9 & 0,0090909 & 62 & 0,06272727 & $-1,4261$ & $6,16 \mathrm{E}-05$ & $2,11 \mathrm{E}-03$ & 6,9 & $-1,4393$ \\
\hline 0,017244501 & 0,00239507 & 7,2 & 0,0090909 & 110 & 0,06545455 & $-1,6203$ & $3,94 \mathrm{E}-05$ & $2,40 \mathrm{E}-03$ & 7,2 & $-1,5643$ \\
\hline 0,013153696 & 0,001777526 & 7,4 & 0,0090909 & 110 & 0,06727273 & $-1,7498$ & $2,92 \mathrm{E}-05$ & $1,78 E-03$ & 7,4 & $-1,7404$ \\
\hline 0,011484876 & 0,001531317 & 7,5 & 0,0090909 & 110 & 0,06818182 & $-1,8146$ & $2,52 \mathrm{E}-05$ & $1,53 \mathrm{E}-03$ & 7,5 & $-2,0414$ \\
\hline$\overline{\boldsymbol{m}}=$ & 4,897 & $\sum n i=$ & 1,80909 & $\sum n i \times m i=$ & 8,859091 & & & $\Sigma$ & & \\
\hline
\end{tabular}

$$
\frac{\sum_{j} t_{j} m_{j} e^{-\beta m_{j}}}{\sum_{j} t_{j} e^{-\beta m_{j}}}=\bar{m}
$$

\begin{tabular}{|c|c|}
\hline Beta & 1,491 \\
\hline Tasa & 3,71 \\
\hline a & 3,04 \\
\hline b & 0,65 \\
\hline
\end{tabular}

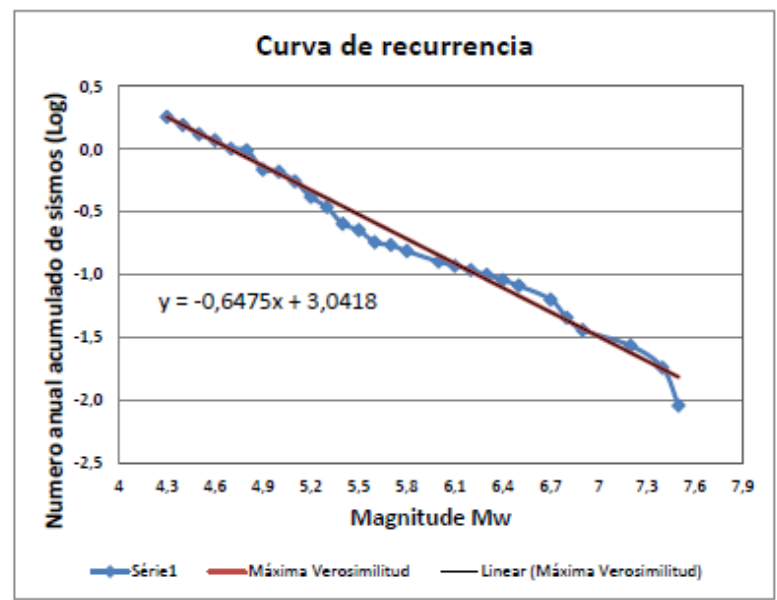


Parâmetros de sismicidade F-14

\begin{tabular}{|c|c|c|c|c|c|c|c|c|c|c|}
\hline$\sum_{j} t_{j} m_{j} e^{-\beta m_{j}}$ & $\sum_{j} t_{j} e^{-\beta m_{j}}$ & & & & & LIKEHOOD & $N \sum_{i} e^{-\beta m_{i}}$ & $\sum_{i} t_{i} e^{-\beta m_{i}}$ & & $\begin{array}{l}\text { RVA DE } \\
\text { RRENCIA }\end{array}$ \\
\hline Numerador & Denominador & $\mathrm{mi}$ & ni (anual) & $\mathrm{ti}$ & ni $x$ mi & & numerador & denominador & $\mathrm{Mw}$ & $\log (\mathrm{N})$ \\
\hline 1,012034284 & 0,240960544 & 4,2 & 0,2580645 & 52 & 1,08387097 & 0,2490 & $8,22 \mathrm{E}-03$ & $2,41 \mathrm{E}-01$ & 4,2 & 0,2490 \\
\hline 0,911678251 & 0,212018198 & 4,3 & 0,1935484 & 52 & 0,83225806 & 0,1934 & $7,23 E-03$ & $2,12 \mathrm{E}-01$ & 4,3 & 0,1807 \\
\hline 0,820829621 & 0,186552187 & 4,4 & 0,1129032 & 52 & 0,49677419 & 0,1379 & $6,36 \mathrm{E}-03$ & $1,87 \mathrm{E}-01$ & 4,4 & 0,1214 \\
\hline 0,738652313 & 0,164144958 & 4,5 & 0,1451613 & 52 & 0,65322581 & 0,0823 & $5,60 \mathrm{E}-03$ & $1,64 \mathrm{E}-01$ & 4,5 & 0,0827 \\
\hline 0,664373933 & 0,144429116 & 4,6 & 0,1935484 & 52 & 0,89032258 & 0,0267 & 4,93E-03 & $1,44 \mathrm{E}-01$ & 4,6 & 0,0272 \\
\hline 0,597282534 & 0,12708139 & 4,7 & 0,0322581 & 52 & 0,1516129 & $-0,0289$ & $4,34 \mathrm{E}-03$ & $1,27 \mathrm{E}-01$ & 4,7 & $-0,0600$ \\
\hline 0,536723238 & 0,111817341 & 4,8 & 0,3709677 & 52 & 1,78064516 & $-0,0844$ & $3,82 \mathrm{E}-03$ & $1,12 \mathrm{E}-01$ & 4,8 & $-0,0764$ \\
\hline 0,432846166 & 0,086569233 & 5 & 0,1129032 & 52 & 0,56451613 & $-0,1956$ & 2,95E-03 & $8,66 \mathrm{E}-02$ & 5 & $-0,3300$ \\
\hline 0,418355646 & 0,082030519 & 5,1 & 0,0806452 & 56 & 0,41129032 & $-0,2512$ & $2,60 \mathrm{E}-03$ & $8,20 \mathrm{E}-02$ & 5,1 & $-0,4500$ \\
\hline 0,33659351 & 0,063508209 & 5,3 & 0,0645161 & 56 & 0,34193548 & $-0,3623$ & $2,01 \mathrm{E}-03$ & $6,35 \mathrm{E}-02$ & 5,3 & $-0,5619$ \\
\hline 0,301752469 & 0,055880087 & 5,4 & 0,0483871 & 56 & \begin{tabular}{|l}
0,26129032 \\
\end{tabular} & $-0,4179$ & $1,77 \mathrm{E}-03$ & $5,59 \mathrm{E}-02$ & 5,4 & $-0,6784$ \\
\hline 0,27042508 & 0,049168196 & 5,5 & 0,016129 & 56 & 0,08870968 & $-0,4734$ & $1,56 \mathrm{E}-03$ & $4,92 \mathrm{E}-02$ & 5,5 & $-0,7924$ \\
\hline 0,242269927 & 0,043262487 & 5,6 & 0,0483871 & 56 & 0,27096774 & $-0,5290$ & $1,37 \mathrm{E}-03$ & $4,33 \mathrm{E}-02$ & 5,6 & $-0,8381$ \\
\hline 0,216976921 & 0,038066126 & 5,7 & 0,016129 & 56 & 0,09193548 & $-0,5846$ & $1,21 \mathrm{E}-03$ & $3,81 \mathrm{E}-02$ & 5,7 & $-1,0142$ \\
\hline 0,194264697 & 0,033493913 & 5,8 & 0,016129 & 56 & 0,09354839 & $-0,6402$ & $1,06 \mathrm{E}-03$ & $3,35 E-02$ & 5,8 & $-1,0934$ \\
\hline 0,155586371 & 0,025931062 & 6 & 0,016129 & 56 & 0,09677419 & $-0,7513$ & 8,22E-04 & $2,59 \mathrm{E}-02$ & 6 & $-1,1903$ \\
\hline 0,110131804 & 0,017208094 & 6,4 & 0,0322581 & 62 & 0,20645161 & $-0,9736$ & 4,92E-04 & $1,72 \mathrm{E}-02$ & 6,4 & $-1,3153$ \\
\hline 0,087928796 & 0,013322545 & 6,6 & 0,016129 & 62 & 0,10645161 & $-1,0847$ & $3,81 \mathrm{E}-04$ & $1,33 \mathrm{E}-02$ & 6,6 & $-1,7924$ \\
\hline
\end{tabular}

\begin{tabular}{ll|l|l|l}
$\overline{\boldsymbol{m}}=\quad 4,747$ & $\sum n \boldsymbol{i}=1,7742$ & $\sum n \boldsymbol{n} \times \boldsymbol{m i}=8,42258$
\end{tabular}

$$
v_{\text {min }}=N \frac{\sum_{i} e^{-\beta m_{i}}}{\sum_{i} t_{i} e^{-\beta m_{i}}}
$$

\begin{tabular}{|c|c|}
\hline Beta & 1,28 \\
\hline Tasa & 2,07 \\
\hline a & 2,58 \\
\hline b & 0,55 \\
\hline
\end{tabular}

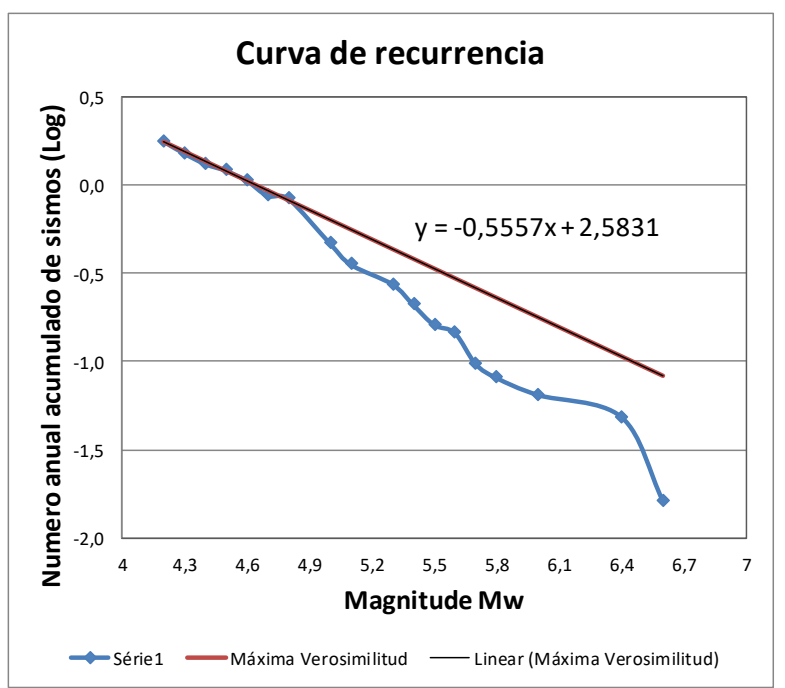


Parâmetros de sismicidade F-15

\begin{tabular}{|c|c|c|c|c|c|c|c|c|c|c|}
\hline$\sum_{j} t_{j} m_{j} e^{-\beta m_{j}}$ & $\sum_{j} t_{j} e^{-\beta m_{j}}$ & & & & & LIKEHOOD & $N \sum_{i} e^{-\beta m_{i}}$ & $\sum_{i} t_{i} e^{-\beta m_{i}}$ & & $\begin{array}{l}\text { RVA DE } \\
\text { JRRENCIA }\end{array}$ \\
\hline Numerador & Denominador & $\mathrm{mi}$ & ni (anual) & ti & ni $x \mathrm{mi}$ & & numerador & denominador & $\mathrm{Mw}$ & $\log (\mathrm{N})$ \\
\hline 0,00520086 & 0,001130622 & 4,6 & 0,5714286 & 52 & 2,62857143 & 0,3789 & $5,20 \mathrm{E}-05$ & $1,13 \mathrm{E}-03$ & 4,6 & 0,3789 \\
\hline 0,004207775 & 0,000895271 & 4,7 & 0,1071429 & 52 & 0,50357143 & 0,2776 & $4,12 \mathrm{E}-05$ & $8,95 \mathrm{E}-04$ & 4,7 & 0,2604 \\
\hline 0,003402774 & 0,000708911 & 4,8 & 0,7678571 & 52 & 3,68571429 & 0,1762 & $3,26 \mathrm{E}-05$ & $7,09 \mathrm{E}-04$ & 4,8 & 0,2341 \\
\hline 0,002750586 & 0,000561344 & 4,9 & 0,0178571 & 52 & 0,0875 & 0,0748 & $2,58 \mathrm{E}-05$ & $5,61 \mathrm{E}-04$ & 4,9 & $-0,0239$ \\
\hline 0,002222472 & 0,000444494 & 5 & 0,2857143 & 52 & 1,42857143 & $-0,0265$ & $2,05 E-05$ & 4,44E-04 & 5 & $-0,0322$ \\
\hline 0,001933119 & 0,000379043 & 5,1 & 0,1607143 & 56 & 0,81964286 & $-0,1279$ & $1,62 \mathrm{E}-05$ & $3,79 \mathrm{E}-04$ & 5,1 & $-0,1919$ \\
\hline 0,001560734 & 0,000300141 & 5,2 & 0,1071429 & 56 & 0,55714286 & $-0,2293$ & $1,28 \mathrm{E}-05$ & $3,00 E-04$ & 5,2 & $-0,3168$ \\
\hline 0,001259618 & 0,000237664 & 5,3 & 0,1071429 & 56 & 0,56785714 & $-0,3306$ & $1,02 E-05$ & $2,38 \mathrm{E}-04$ & 5,3 & $-0,4260$ \\
\hline 0,001016234 & 0,000188192 & 5,4 & 0,1071429 & 56 & 0,57857143 & $-0,4320$ & $8,04 \mathrm{E}-06$ & $1,88 \mathrm{E}-04$ & 5,4 & $-0,5721$ \\
\hline 0,000819596 & 0,000149018 & 5,5 & 0,0178571 & 56 & 0,09821429 & $-0,5333$ & $6,37 E-06$ & $1,49 \mathrm{E}-04$ & 5,5 & $-0,7939$ \\
\hline 0,000660789 & 0,000117998 & 5,6 & 0,0714286 & 56 & 0,4 & $-0,6347$ & $5,04 \mathrm{E}-06$ & $1,18 \mathrm{E}-04$ & 5,6 & $-0,8451$ \\
\hline 0,000532582 & $9,34355 \mathrm{E}-05$ & 5,7 & 0,0357143 & 56 & 0,20357143 & $-0,7361$ & $3,99 \mathrm{E}-06$ & $9,34 \mathrm{E}-05$ & 5,7 & $-1,1461$ \\
\hline 0,00027834 & $4,63899 \mathrm{E}-05$ & 6 & 0,0357143 & 56 & 0,21428571 & $-1,0402$ & $1,98 \mathrm{E}-06$ & $4,64 \mathrm{E}-05$ & 6 & $-1,4472$ \\
\hline$\overline{\boldsymbol{m}}=$ & 4,920 & $\sum n i=$ & 2,39286 & $\sum n i \times m i=$ & 11,77321 & & & $\sum_{i} e^{-1}$ & & \\
\hline
\end{tabular}

$$
\frac{\sum_{j} t_{j} m_{j} e^{-\beta m_{j}}}{\sum_{j} t_{j} e^{-\beta m_{j}}}=\bar{m}
$$

\begin{tabular}{|c|c|}
\hline Beta & 2,334 \\
\hline Tasa & 2,52 \\
\hline $\mathrm{a}$ & 5,04 \\
\hline $\mathrm{b}$ & 1,01 \\
\hline
\end{tabular}

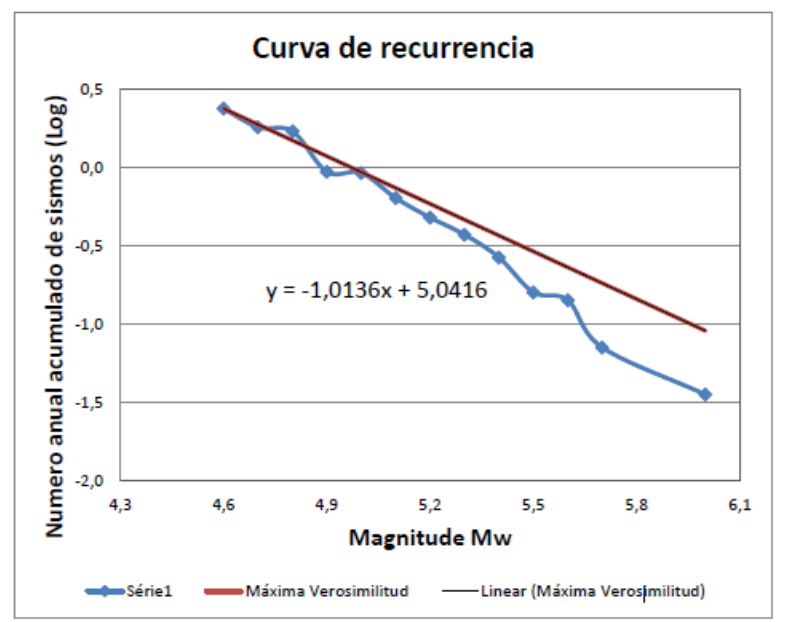


$\underline{\text { Parâmetros de sismicidade F-16 }}$

\begin{tabular}{|c|c|c|c|c|c|c|c|c|c|c|}
\hline \multirow{2}{*}{\begin{tabular}{|c|}
$\sum_{j} t_{j} m_{j} e^{-\beta m_{j}}$ \\
Numerador
\end{tabular}} & \multirow{2}{*}{\begin{tabular}{|l|}
$\sum_{j} t_{j} e^{-\beta m_{j}}$ \\
Denominador \\
\end{tabular}} & \multirow[b]{2}{*}{$\mathrm{mi}$} & \multirow[b]{2}{*}{ ni (anual) } & \multirow[b]{2}{*}{$\mathrm{ti}$} & \multirow[b]{2}{*}{ ni $x$ mi } & \multirow[t]{2}{*}{ LIKEHOOD } & \multirow{2}{*}{$N \frac{\sum_{i} e^{-\beta m_{i}}}{\text { numerador }}$} & \multirow{2}{*}{$\frac{\sum_{i} t_{i} e^{-\beta m_{i}}}{\text { denominador }}$} & \multicolumn{2}{|c|}{$\begin{array}{c}\text { CURVA DE } \\
\text { RECURRENCIA }\end{array}$} \\
\hline & & & & & & & & & Mw & $\log (N)$ \\
\hline 0,629951688 & 0,146500392 & 4,3 & 0,12903226 & 52 & 0,55483871 & $-0,2609$ & $1,54 \mathrm{E}-03$ & $1,47 \mathrm{E}-01$ & 4,3 & $-0,2609$ \\
\hline 0,562322307 & 0,127800524 & 4,4 & 0,11290323 & 52 & 0,49677419 & $-0,3202$ & $1,35 \mathrm{E}-03$ & $1,28 \mathrm{E}-01$ & 4,4 & $-0,3774$ \\
\hline 0,501694104 & 0,111487579 & 4,5 & \begin{tabular}{|l|}
0,0483871 \\
\end{tabular} & 52 & \begin{tabular}{|l}
0,21774194 \\
\end{tabular} & $-0,3795$ & $1,18 \mathrm{E}-03$ & $1,11 \mathrm{E}-01$ & 4,5 & $-0,5136$ \\
\hline 0,447381645 & 0,097256879 & 4,6 & 0,08064516 & 52 & 0,37096774 & $-0,4388$ & $1,03 \mathrm{E}-03$ & 9,73E-02 & 4,6 & $-0,5883$ \\
\hline 0,398760412 & 0,084842641 & 4,7 & 0,01612903 & 52 & 0,07580645 & $-0,4981$ & $8,95 \mathrm{E}-04$ & $8,48 \mathrm{E}-02$ & 4,7 & $-0,7510$ \\
\hline 0,355262415 & 0,074013003 & 4,8 & 0,01612903 & 52 & 0,07741935 & $-0,5574$ & $7,81 \mathrm{E}-04$ & $7,40 \mathrm{E}-02$ & 4,8 & $-0,7924$ \\
\hline 0,269863674 & 0,052914446 & 5,1 & \begin{tabular}{|l|}
0,0483871 \\
\end{tabular} & 56 & 0,24677419 & $-0,7354$ & $5,18 \mathrm{E}-04$ & $5,29 \mathrm{E}-02$ & 5,1 & $-0,8381$ \\
\hline 0,213421327 & 0,040268175 & 5,3 & 0,01612903 & 56 & 0,08548387 & $-0,8540$ & $3,94 \mathrm{E}-04$ & 4,03E-02 & 5,3 & $-1,0142$ \\
\hline 0,189692235 & 0,035128192 & 5,4 & 0,01612903 & 56 & \begin{tabular}{|l}
0,08709677 \\
\end{tabular} & $-0,9133$ & $3,44 \mathrm{E}-04$ & $3,51 \mathrm{E}-02$ & 5,4 & $-1,0934$ \\
\hline 0,168543625 & 0,030644296 & 5,5 & 0,01612903 & 56 & 0,08870968 & $-0,9726$ & $3,00 E-04$ & $3,06 \mathrm{E}-02$ & 5,5 & $-1,1903$ \\
\hline 0,149703349 & 0,026732741 & 5,6 & 0,01612903 & 56 & 0,09032258 & $-1,0319$ & $2,62 \mathrm{E}-04$ & 2,67E-02 & 5,6 & $-1,3153$ \\
\hline 0,117993797 & 0,020343758 & 5,8 & 0,01612903 & 56 & \begin{tabular}{|l|}
0,09354839 \\
\end{tabular} & $-1,1505$ & $1,99 \mathrm{E}-04$ & 2,03E-02 & 5,8 & $-1,4914$ \\
\hline 0,0346032 & 0,005014957 & 6,9 & 0,01612903 & 62 & 0,11129032 & $-1,8029$ & 4,44E-05 & $5,01 E-03$ & 6,9 & $-1,7924$ \\
\hline
\end{tabular}

\begin{tabular}{ll|l|l|l}
$\overline{\boldsymbol{m}}=$ & 4,735 & $\sum n i=0,54839$ & $\sum n i \times m i=2,59677$
\end{tabular}

$$
v_{\text {min }}=N \frac{\sum_{i} e^{-\beta m_{i}}}{\sum_{i} t_{i} e^{-\beta m_{i}}}
$$

$$
\frac{\sum_{j} t_{j} m_{j} e^{-\beta m_{j}}}{\sum_{j} t_{j} e^{-\beta m_{j}}}=\bar{m}
$$

\begin{tabular}{|c|c|}
\hline Beta & 1,307 \\
\hline Tasa & 1,25 \\
\hline $\mathrm{a}$ & 2,28 \\
\hline $\mathrm{b}$ & 0,59 \\
\hline
\end{tabular}

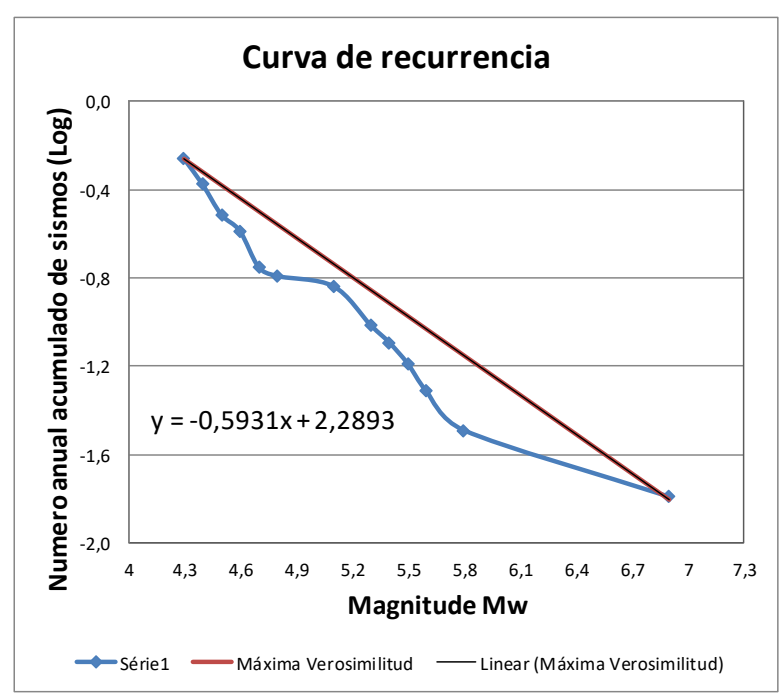


$\underline{\text { Parâmetros de sismicidade F-18 }}$

\begin{tabular}{|c|c|c|c|c|c|c|c|c|c|c|}
\hline$\sum_{j} t_{j} m_{j} e^{-\beta m_{j}}$ & $\sum_{j} t_{j} e^{-\beta m_{j}}$ & & & & & LIKEHOOD & $N \underline{\sum_{i} e^{-\beta m_{i}}}$ & $\sum_{i} t_{i} e^{-\beta m_{i}}$ & $\begin{array}{r}\mathrm{CU} \\
\mathrm{RECl} \\
\end{array}$ & $\begin{array}{l}\text { RVA DE } \\
\text { IRRENCIA }\end{array}$ \\
\hline Numerador & Denominador & $\mathrm{mi}$ & ni (anual) & ti & ni $x$ mi & & numerador & denominador & $\mathrm{Mw}$ & $\log (N)$ \\
\hline 0,002327905 & 0,00048498 & 4,8 & 0,55454545 & 52 & 2,66181818 & 0,1891 & $1,44 \mathrm{E}-05$ & $4,85 \mathrm{E}-04$ & 4,8 & 0,1891 \\
\hline 0,001496577 & 0,000299315 & 5 & 0,19090909 & 52 & 0,95454545 & $-0,0205$ & $8,90 \mathrm{E}-06$ & $2,99 \mathrm{E}-04$ & 5 & $-0,0040$ \\
\hline 0,001291476 & 0,000253231 & 5,1 & 0,17272727 & 56 & 0,88090909 & $-0,1253$ & 6,99E-06 & $2,53 \mathrm{E}-04$ & 5,1 & $-0,0969$ \\
\hline 0,00103448 & 0,000198938 & 5,2 & 0,10909091 & 56 & 0,56727273 & $-0,2301$ & $5,49 \mathrm{E}-06$ & 1,99E-04 & 5,2 & $-0,2025$ \\
\hline 0,000828318 & 0,000156286 & 5,3 & 0,18181818 & 56 & 0,96363636 & $-0,3349$ & $4,31 \mathrm{E}-06$ & $1,56 \mathrm{E}-04$ & 5,3 & $-0,2855$ \\
\hline 0,000663006 & 0,000122779 & 5,4 & 0,13636364 & 56 & 0,73636364 & $-0,4397$ & $3,39 \mathrm{E}-06$ & $1,23 \mathrm{E}-04$ & 5,4 & $-0,4732$ \\
\hline 0,000530504 & 9,64554E-05 & 5,5 & 0,02727273 & 56 & 0,15 & $-0,5445$ & $2,66 \mathrm{E}-06$ & 9,65E-05 & 5,5 & $-0,6990$ \\
\hline 0,000424343 & $7,57755 \mathrm{E}-05$ & 5,6 & 0,00909091 & 56 & 0,05090909 & $-0,6493$ & $2,09 \mathrm{E}-06$ & $7,58 \mathrm{E}-05$ & 5,6 & $-0,7626$ \\
\hline 0,000271245 & 4,67664E-05 & 5,8 & 0,04545455 & 56 & 0,26363636 & $-0,8589$ & $1,29 \mathrm{E}-06$ & $4,68 \mathrm{E}-05$ & 5,8 & $-0,7861$ \\
\hline 0,000216765 & 3,67398E-05 & 5,9 & 0,00909091 & 56 & 0,05363636 & $-0,9637$ & $1,01 \mathrm{E}-06$ & 3,67E-05 & 5,9 & $-0,9274$ \\
\hline 0,000173177 & $2,88628 \mathrm{E}-05$ & 6 & 0,02727273 & 56 & 0,16363636 & $-1,0685$ & $7,97 \mathrm{E}-07$ & $2,89 \mathrm{E}-05$ & 6 & $-0,9622$ \\
\hline $7,78991 \mathrm{E}-05$ & $1,21717 \mathrm{E}-05$ & 6,4 & 0,02727273 & 62 & 0,17454545 & $-1,4877$ & $3,03 \mathrm{E}-07$ & $1,22 \mathrm{E}-05$ & 6,4 & $-1,0872$ \\
\hline $6,21539 \mathrm{E}-05$ & 9,56214E-06 & 6,5 & 0,00909091 & 62 & 0,05909091 & $-1,5925$ & $2,38 \mathrm{E}-07$ & 9,56E-06 & 6,5 & $-1,2632$ \\
\hline 4,95794E-05 & $7,51204 \mathrm{E}-06$ & 6,6 & 0,02727273 & 62 & 0,18 & $-1,6973$ & $1,87 E-07$ & $7,51 \mathrm{E}-06$ & 6,6 & $-1,3424$ \\
\hline $2,00293 \mathrm{E}-05$ & $2,86133 \mathrm{E}-06$ & 7 & 0,00909091 & 62 & 0,06363636 & $-2,1165$ & $7,13 \mathrm{E}-08$ & $2,86 \mathrm{E}-06$ & 7 & $-1,7404$ \\
\hline $1,7968 \mathrm{E}-05$ & $2,46137 \mathrm{E}-06$ & 7,3 & 0,00909091 & 110 & 0,06636364 & $-2,4309$ & $3,46 \mathrm{E}-08$ & $2,46 \mathrm{E}-06$ & 7,3 & $-2,0414$ \\
\hline $\bar{m}=$ & 5,170 & $\sum n i=$ & 1,5455 & $\sum n$ & 7,99 & & & $Z_{i} \epsilon$ & & \\
\hline
\end{tabular}

$$
\frac{\sum_{j} t_{j} m_{j} e^{-\beta m_{j}}}{\sum_{j} t_{j} e^{-\beta m_{j}}}=\bar{m}
$$

\begin{tabular}{|c|c|}
\hline Beta & 2,413 \\
\hline Tasa & 3,13 \\
\hline $\mathrm{a}$ & 5,21 \\
\hline $\mathrm{b}$ & 1,04 \\
\hline
\end{tabular}

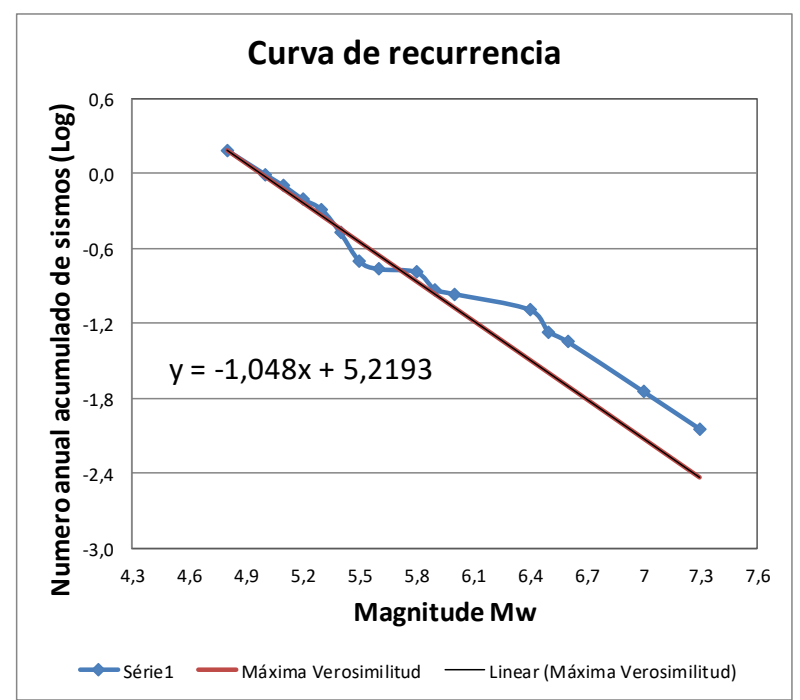


Parâmetros de sismicidade F-22

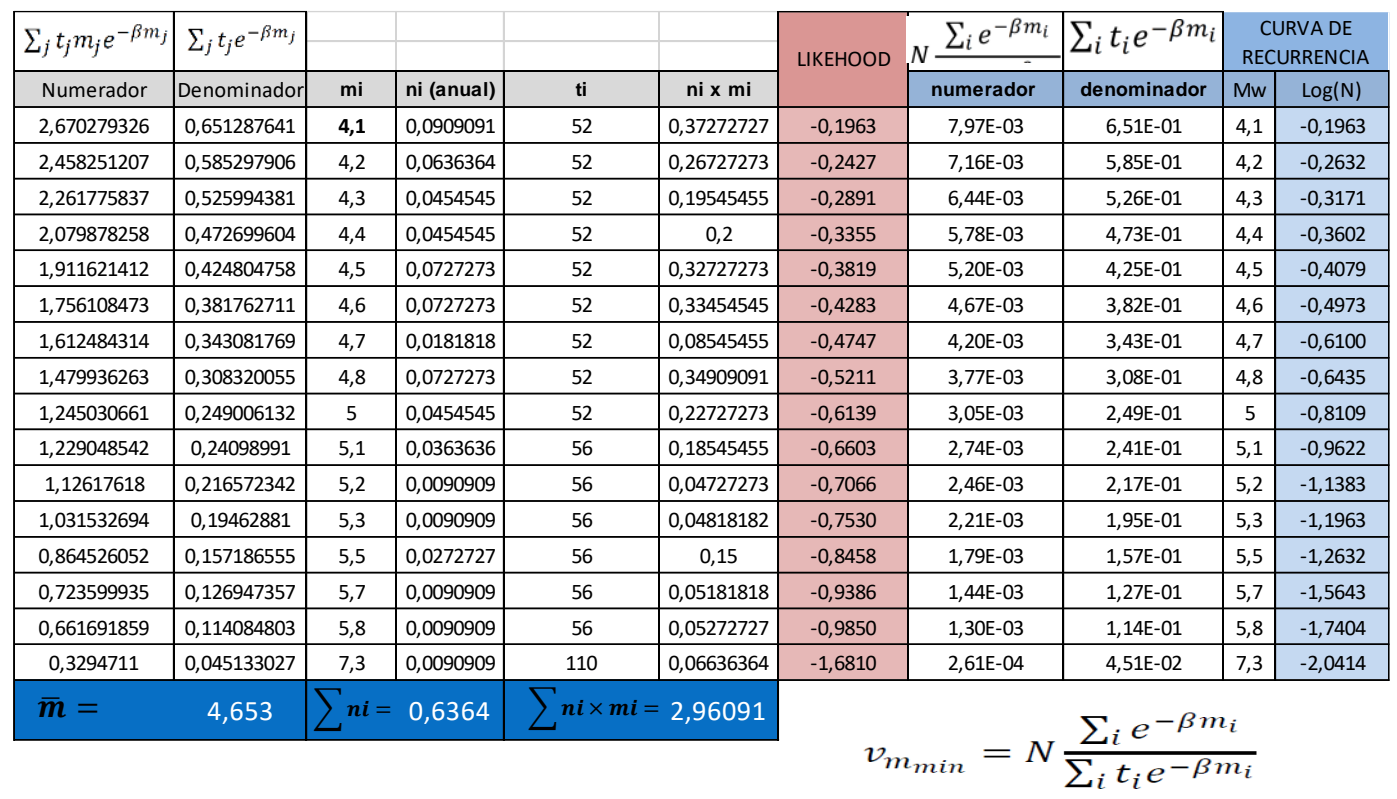

$$
\frac{\sum_{j} t_{j} m_{j} e^{-\beta m_{j}}}{\sum_{j} t_{j} e^{-\beta m_{j}}}=\bar{m}
$$

\begin{tabular}{|c|c|}
\hline Beta & 1,068 \\
\hline Tasa & 1,32 \\
\hline $\mathrm{a}$ & 1,7 \\
\hline $\mathrm{b}$ & 0,46 \\
\hline
\end{tabular}

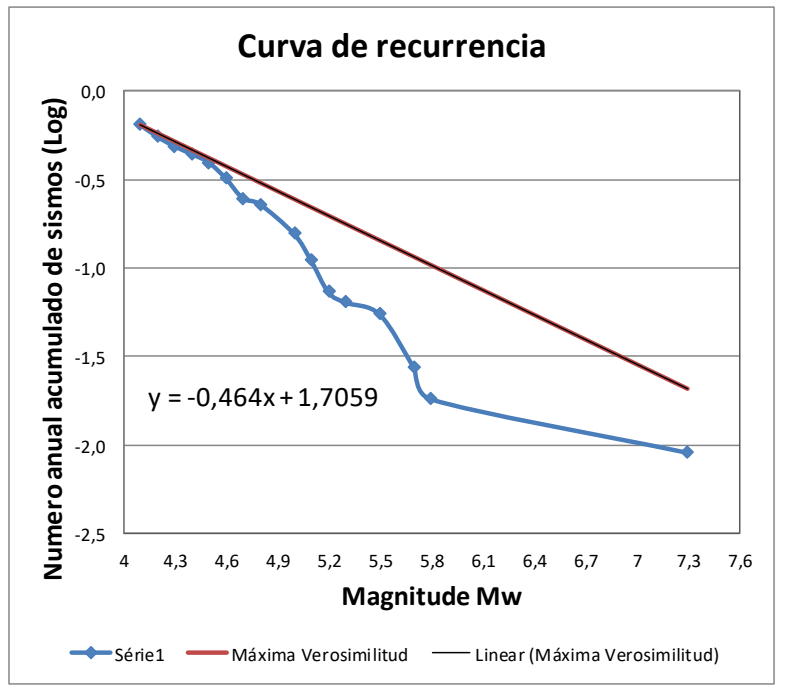


Parâmetros de sismicidade F-23

\begin{tabular}{|c|c|c|c|c|c|c|c|c|c|c|}
\hline \multirow{2}{*}{\begin{tabular}{|c|}
$\sum_{j} t_{j} m_{j} e^{-\beta m_{j}}$ \\
Numerador
\end{tabular}} & \multirow{2}{*}{\begin{tabular}{|c|}
$\sum_{j} t_{j} e^{-\beta m_{j}}$ \\
Denominador \\
\end{tabular}} & \multirow[b]{2}{*}{$\mathrm{mi}$} & \multirow[b]{2}{*}{ ni (anual) } & \multirow[b]{2}{*}{ ti } & \multirow[b]{2}{*}{ ni $\times \mathrm{mi}$} & \multirow[t]{2}{*}{ LIKEHOOD } & \multirow{2}{*}{$N \frac{\sum_{i} e^{-\beta m_{i}}}{\text { numerador }}$} & \multirow{2}{*}{\begin{tabular}{|c|}
$\sum_{i} t_{i} e^{-\beta m_{i}}$ \\
denominador
\end{tabular}} & \multicolumn{2}{|c|}{$\begin{array}{c}\text { CURVA DE } \\
\text { RECURRENCIA }\end{array}$} \\
\hline & & & & & & & & & $\mathrm{Mw}$ & $\log (\mathrm{N})$ \\
\hline 1,043025399 & 0,231783422 & 4,5 & 0,16071429 & 52 & 0,72321429 & $-0,1800$ & $2,95 \mathrm{E}-03$ & $2,32 E-01$ & 4,5 & $-0,1800$ \\
\hline 0,945360634 & 0,205513181 & 4,6 & 0,10714286 & 52 & 0,49285714 & $-0,2322$ & $2,61 \mathrm{E}-03$ & $2,06 \mathrm{E}-01$ & 4,6 & $-0,3010$ \\
\hline 0,856435876 & 0,182220399 & 4,7 & 0,01785714 & 52 & 0,08392857 & $-0,2845$ & $2,32 \mathrm{E}-03$ & $1,82 \mathrm{E}-01$ & 4,7 & $-0,4058$ \\
\hline 0,775524537 & 0,161567612 & 4,8 & 0,16071429 & 52 & 0,77142857 & $-0,3367$ & $2,05 E-03$ & $1,62 \mathrm{E}-01$ & 4,8 & $-0,4260$ \\
\hline 0,701952455 & 0,143255603 & 4,9 & 0 & 52 & 0 & $-0,3890$ & $1,82 \mathrm{E}-03$ & $1,43 \mathrm{E}-01$ & 4,9 & $-0,6690$ \\
\hline 0,63509535 & 0,12701907 & 5 & 0,05357143 & 52 & 0,26785714 & $-0,4412$ & $1,61 \mathrm{E}-03$ & $1,27 \mathrm{E}-01$ & 5 & $-0,6690$ \\
\hline 0,618558957 & 0,12128607 & 5,1 & 0,03571429 & 56 & 0,18214286 & $-0,4934$ & $1,43 \mathrm{E}-03$ & $1,21 \mathrm{E}-01$ & 5,1 & $-0,7939$ \\
\hline 0,559205687 & 0,107539555 & 5,2 & 0,01785714 & 56 & 0,09285714 & $-0,5457$ & $1,27 E-03$ & $1,08 \mathrm{E}-01$ & 5,2 & $-0,9031$ \\
\hline 0,505360644 & 0,095351065 & 5,3 & 0,03571429 & 56 & \begin{tabular}{|l|l|}
0,18928571 \\
\end{tabular} & $-0,5979$ & $1,12 \mathrm{E}-03$ & $9,54 \mathrm{E}-02$ & 5,3 & $-0,9700$ \\
\hline 0,456537671 & 0,084544013 & 5,4 & 0 & 56 & 0 & $-0,6502$ & 9,97E-04 & $8,45 E-02$ & 5,4 & $-1,1461$ \\
\hline 0,412290056 & 0,074961828 & 5,5 & 0,03571429 & 56 & 0,19642857 & $-0,7024$ & $8,84 \mathrm{E}-04$ & $7,50 \mathrm{E}-02$ & 5,5 & $-1,1461$ \\
\hline 0,372207834 & 0,066465685 & 5,6 & 0 & 56 & 0 & $-0,7547$ & $7,84 \mathrm{E}-04$ & $6,65 \mathrm{E}-02$ & 5,6 & 0,3010 \\
\hline 0,335915195 & 0,05893249 & 5,7 & 0 & 56 & 0 & $-0,8069$ & $6,95 E-04$ & $5,89 E-02$ & 5,7 & 0,3010 \\
\hline 0,303068011 & 0,052253105 & 5,8 & 0 & 56 & 0 & $-0,8591$ & $6,17 E-04$ & $5,23 \mathrm{E}-02$ & 5,8 & 0,3010 \\
\hline 0,27335148 & 0,046330759 & 5,9 & 0 & 56 & 0 & $-0,9114$ & $5,47 E-04$ & $4,63 E-02$ & 5,9 & 0,3010 \\
\hline 0,246477897 & 0,041079649 & 6 & 0 & 56 & 0 & $-0,9636$ & $4,85 E-04$ & $4,11 E-02$ & 6 & 0,3010 \\
\hline 0,245990049 & 0,040326237 & 6,1 & 0 & 62 & 0 & $-1,0159$ & $4,30 \mathrm{E}-04$ & $4,03 E-02$ & 6,1 & 0,3010 \\
\hline 0,221685202 & 0,035755678 & 6,2 & 0 & 62 & 0 & $-1,0681$ & $3,81 E-04$ & $3,58 \mathrm{E}-02$ & 6,2 & 0,3010 \\
\hline 0,199729804 & 0,031703144 & 6,3 & 0 & 62 & 0 & $-1,1204$ & $3,38 E-04$ & $3,17 E-02$ & 6,3 & 0,3010 \\
\hline 0,1799035 & 0,028109922 & 6,4 & 0 & 62 & 0 & $-1,1726$ & $3,00 E-04$ & $2,81 \mathrm{E}-02$ & 6,4 & 0,3010 \\
\hline 0,162005704 & 0,024923955 & 6,5 & 0 & 62 & 0 & $-1,2248$ & $2,66 \mathrm{E}-04$ & $2,49 \mathrm{E}-02$ & 6,5 & 0,3010 \\
\hline 0,145853951 & 0,022099083 & 6,6 & 0 & 62 & 0 & $-1,2771$ & $2,36 \mathrm{E}-04$ & $2,21 \mathrm{E}-02$ & 6,6 & 0,3010 \\
\hline 0,13128236 & 0,019594382 & 6,7 & 0 & 62 & 0 & $-1,3293$ & $2,09 E-04$ & $1,96 \mathrm{E}-02$ & 6,7 & 0,3010 \\
\hline 0,118140226 & 0,017373563 & 6,8 & 0 & 62 & 0 & $-1,3816$ & $1,85 \mathrm{E}-04$ & $1,74 \mathrm{E}-02$ & 6,8 & 0,3010 \\
\hline 0,106290705 & 0,01540445 & 6,9 & 0 & 62 & 0 & $-1,4338$ & $1,64 \mathrm{E}-04$ & $1,54 \mathrm{E}-02$ & 6,9 & 0,3010 \\
\hline 0,09560961 & 0,013658516 & 7 & 0 & 62 & 0 & $-1,4861$ & $1,46 E-04$ & $1,37 \mathrm{E}-02$ & 7 & 0,3010 \\
\hline 0,152552794 & 0,021486309 & 7,1 & 0,01785714 & 110 & 0,12678571 & $-1,5383$ & $1,29 \mathrm{E}-04$ & $2,15 E-02$ & 7,1 & 0,3010 \\
\hline 0,137167627 & 0,019051059 & 7,2 & 0,01785714 & 110 & 0,12857143 & $-1,5905$ & $1,14 \mathrm{E}-04$ & $1,91 \mathrm{E}-02$ & 7,2 & 0,0000 \\
\hline $\bar{m}=$ & 4,927 & \multicolumn{2}{|r|}{0,66071} & \multicolumn{2}{|c|}{$\sum n i \times m i=3,25536$} & \multicolumn{5}{|c|}{$\sum_{i} e^{-\beta m_{i}}$} \\
\hline
\end{tabular}

$$
\frac{\sum_{j} t_{j} m_{j} e^{-\beta m_{j}}}{\sum_{j} t_{j} e^{-\beta m_{j}}}=\bar{m}
$$

\begin{tabular}{|c|c|}
\hline Beta & 1,384 \\
\hline Tasa & 0,675 \\
\hline $\mathrm{a}$ & 2,17 \\
\hline $\mathrm{b}$ & 0,52 \\
\hline
\end{tabular}

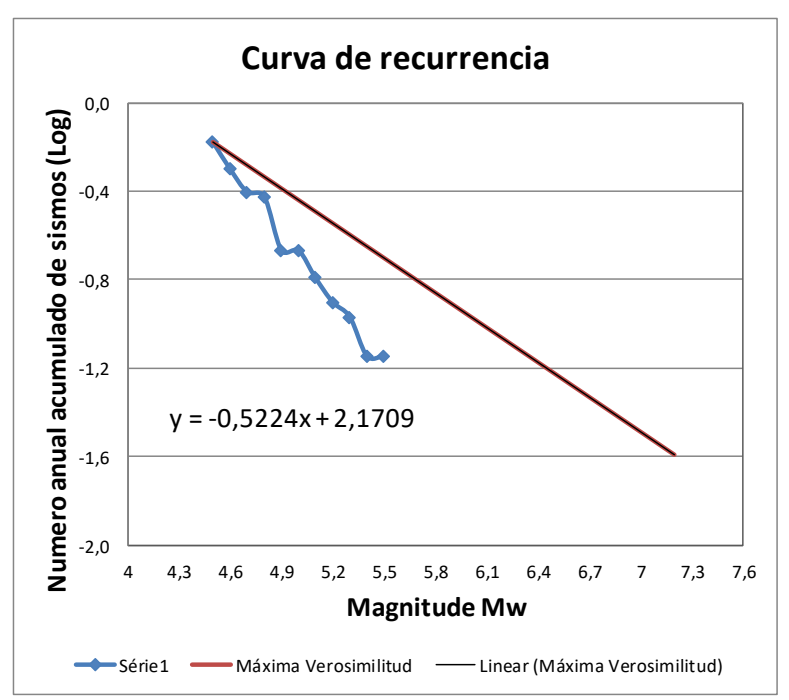


Parâmetros de sismicidade F-22

\begin{tabular}{|c|c|c|c|c|c|c|c|c|c|c|}
\hline \multirow{2}{*}{$\begin{array}{c}\sum_{j} t_{j} m_{j} e^{-\beta m_{j}} \\
\text { Numerador }\end{array}$} & \multirow{2}{*}{\begin{tabular}{|l|}
$\sum_{j} t_{j} e^{-\beta m_{j}}$ \\
Denominador \\
\end{tabular}} & \multirow[b]{2}{*}{$\mathrm{mi}$} & \multirow[b]{2}{*}{ ni (anual) } & \multirow[b]{2}{*}{ ti } & \multirow[b]{2}{*}{ ni $x \mathrm{mi}$} & \multirow[t]{2}{*}{ LIKEHOOD } & \multirow{2}{*}{$N \frac{\sum_{i} e^{-\beta m_{i}}}{\text { numerador }}$} & \multirow{2}{*}{\begin{tabular}{|l}
$\sum_{i} t_{i} e^{-\beta m_{i}}$ \\
denominador
\end{tabular}} & \multicolumn{2}{|c|}{$\begin{array}{c}\text { CURVA DE } \\
\text { RECURRENCIA }\end{array}$} \\
\hline & & & & & & & & & $\mathrm{Mw}$ & $\log (N)$ \\
\hline 0,129104748 & 0,028689944 & 4,5 & 0,19090909 & 52 & 0,85909091 & 0,1433 & 7,67E-04 & $2,87 \mathrm{E}-02$ & 4,5 & 0,1433 \\
\hline 0,111707274 & 0,02428419 & 4,6 & 0,15454545 & 52 & 0,71090909 & 0,0709 & $6,50 \mathrm{E}-04$ & $2,43 \mathrm{E}-02$ & 4,6 & 0,0792 \\
\hline 0,096608513 & 0,020555003 & 4,7 & 0,04545455 & 52 & 0,21363636 & $-0,0015$ & 5,50E-04 & $2,06 \mathrm{E}-02$ & 4,7 & 0,0193 \\
\hline 0,083512733 & 0,017398486 & 4,8 & 0,38181818 & 52 & 1,83272727 & $-0,0739$ & 4,65E-04 & $1,74 \mathrm{E}-02$ & 4,8 & 0,0000 \\
\hline 0,062326007 & 0,012465201 & 5 & 0,14545455 & 52 & 0,72727273 & $-0,2187$ & $3,33 \mathrm{E}-04$ & $1,25 \mathrm{E}-02$ & 5 & $-0,2089$ \\
\hline 0,057949284 & 0,011362605 & 5,1 & 0,10909091 & 56 & 0,55636364 & $-0,2911$ & $2,82 \mathrm{E}-04$ & $1,14 \mathrm{E}-02$ & 5,1 & $-0,3254$ \\
\hline 0,050012108 & 0,009617713 & 5,2 & 0,09090909 & 56 & 0,47272727 & $-0,3635$ & $2,39 \mathrm{E}-04$ & 9,62E-03 & 5,2 & $-0,4393$ \\
\hline 0,043146106 & 0,008140775 & 5,3 & 0,03636364 & 56 & 0,19272727 & $-0,4359$ & $2,02 \mathrm{E}-04$ & $8,14 \mathrm{E}-03$ & 5,3 & $-0,5643$ \\
\hline 0,037209464 & 0,006890642 & 5,4 & 0,06363636 & 56 & 0,34363636 & $-0,5084$ & 1,71E-04 & $6,89 \mathrm{E}-03$ & 5,4 & $-0,6264$ \\
\hline 0,032078663 & 0,005832484 & 5,5 & 0,03636364 & 56 & 0,2 & $-0,5808$ & 1,45E-04 & $5,83 \mathrm{E}-03$ & 5,5 & $-0,7626$ \\
\hline 0,027646205 & 0,004936822 & 5,6 & 0,02727273 & 56 & 0,15272727 & $-0,6532$ & $1,23 \mathrm{E}-04$ & 4,94E-03 & 5,6 & $-0,8653$ \\
\hline 0,023818602 & 0,004178702 & 5,7 & 0,00909091 & 56 & 0,05181818 & $-0,7256$ & $1,04 \mathrm{E}-04$ & $4,18 \mathrm{E}-03$ & 5,7 & $-0,9622$ \\
\hline 0,020514613 & 0,003537002 & 5,8 & 0,03636364 & 56 & 0,21090909 & $-0,7980$ & $8,79 \mathrm{E}-05$ & $3,54 \mathrm{E}-03$ & 5,8 & $-1,0000$ \\
\hline 0,017663683 & 0,002993845 & 5,9 & 0,00909091 & 56 & 0,05363636 & $-0,8704$ & $7,44 \mathrm{E}-05$ & $2,99 \mathrm{E}-03$ & 5,9 & $-1,1963$ \\
\hline 0,01448607 & 0,002374766 & 6,1 & 0,00909091 & 62 & 0,05545455 & $-1,0152$ & 5,33E-05 & $2,37 \mathrm{E}-03$ & 6,1 & $-1,2632$ \\
\hline 0,007923367 & 0,00121898 & 6,5 & 0,00909091 & 62 & 0,05909091 & $-1,3048$ & $2,73 \mathrm{E}-05$ & $1,22 \mathrm{E}-03$ & 6,5 & $-1,3424$ \\
\hline 0,006809799 & 0,001031788 & 6,6 & 0,01818182 & 62 & 0,12 & $-1,3772$ & $2,31 \mathrm{E}-05$ & $1,03 E-03$ & 6,6 & $-1,4393$ \\
\hline 0,00585139 & 0,000873342 & 6,7 & 0,00909091 & 62 & 0,06090909 & $-1,4496$ & $1,96 \mathrm{E}-05$ & $8,73 \mathrm{E}-04$ & 6,7 & $-1,7404$ \\
\hline 0,005647019 & 0,000795355 & 7,1 & 0,00909091 & 110 & 0,06454545 & $-1,7393$ & $1,01 \mathrm{E}-05$ & $7,95 \mathrm{E}-04$ & 7,1 & $-2,0414$ \\
\hline$\overline{\boldsymbol{m}}=$ & 4,988 & $\sum n i=$ & 1,3909 & $\sum n$ & 6,93818 & & $=$ & $\sum_{i} e$ & & \\
\hline
\end{tabular}

$$
\frac{\sum_{j} t_{j} m_{j} e^{-\beta m_{j}}}{\sum_{j} t_{j} e^{-\beta m_{j}}}=\bar{m}
$$

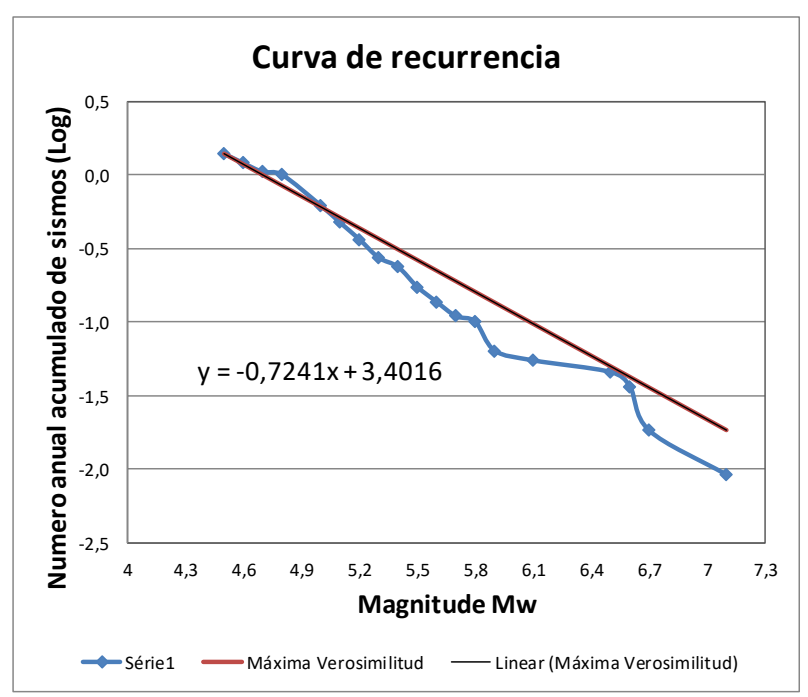

